Sous la direction de Katia Ghosn

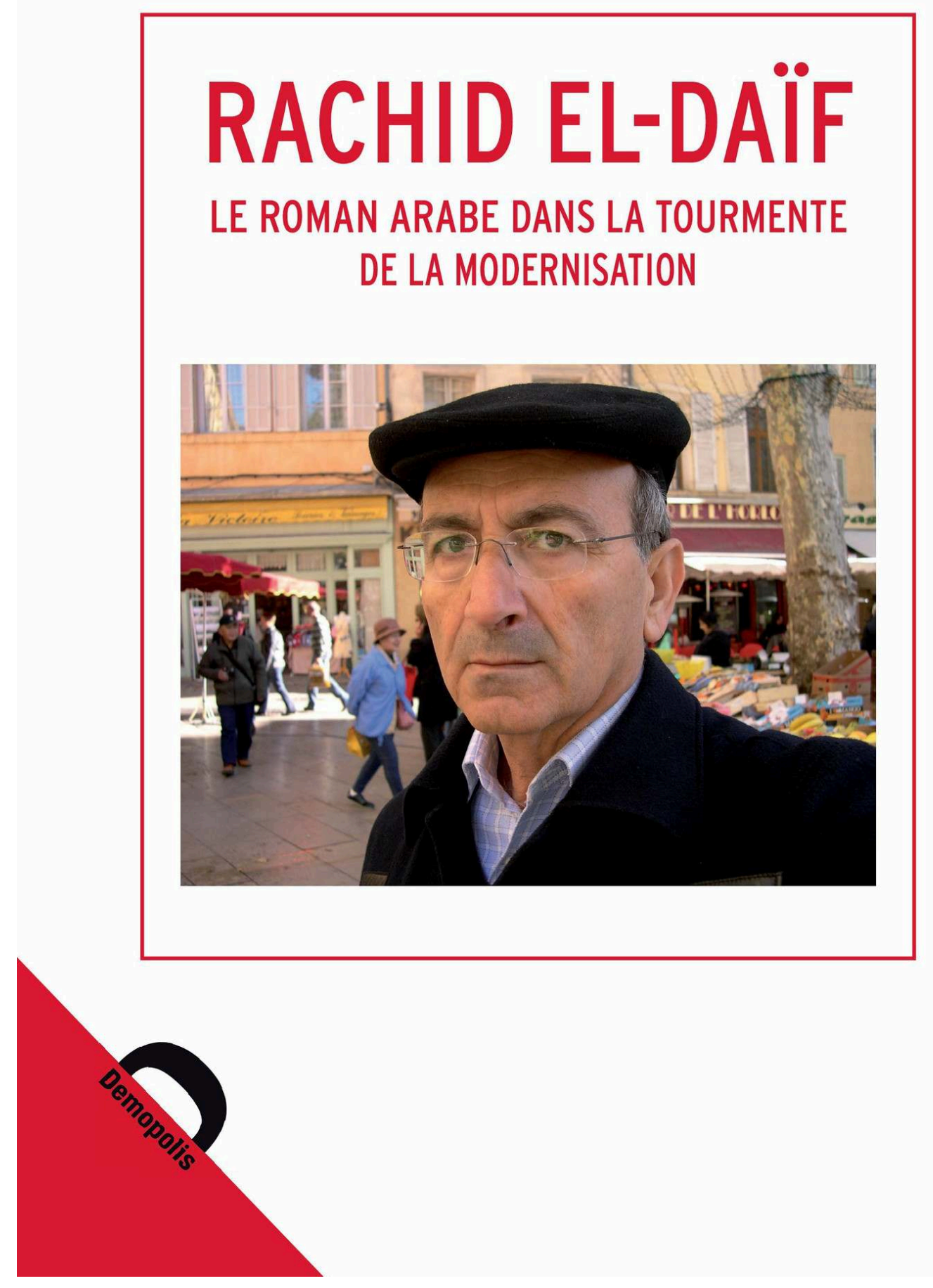




\section{Rachid El-Daïf}

Le roman arabe dans la tourmente de la modernisation

\section{Katia Ghosn (dir.)}

DOI : 10.4000/books.demopolis. 1678

Éditeur : Demopolis

Année d'édition : 2016

Date de mise en ligne : 1 octobre 2020

Collection : Quaero

ISBN électronique : 9782354571511

\section{oponatibito}

http://books.openedition.org

\section{Édition imprimée}

ISBN : 9782354570941

Nombre de pages : 186

\section{Référence électronique}

GHOSN, Katia (dir.). Rachid El-Daif : Le roman arabe dans la tourmente de la modernisation. Nouvelle édition [en ligne]. Paris : Demopolis, 2016 (généré le 10 décembre 2020). Disponible sur Internet : <http://books.openedition.org/demopolis/1678>. ISBN : 9782354571511 . DOI : https://doi.org/ 10.4000/books. demopolis.1678.

(C) Demopolis, 2016

Conditions d'utilisation:

http://www.openedition.org/6540 


\section{Sous la direction de \\ Katia Ghosn}

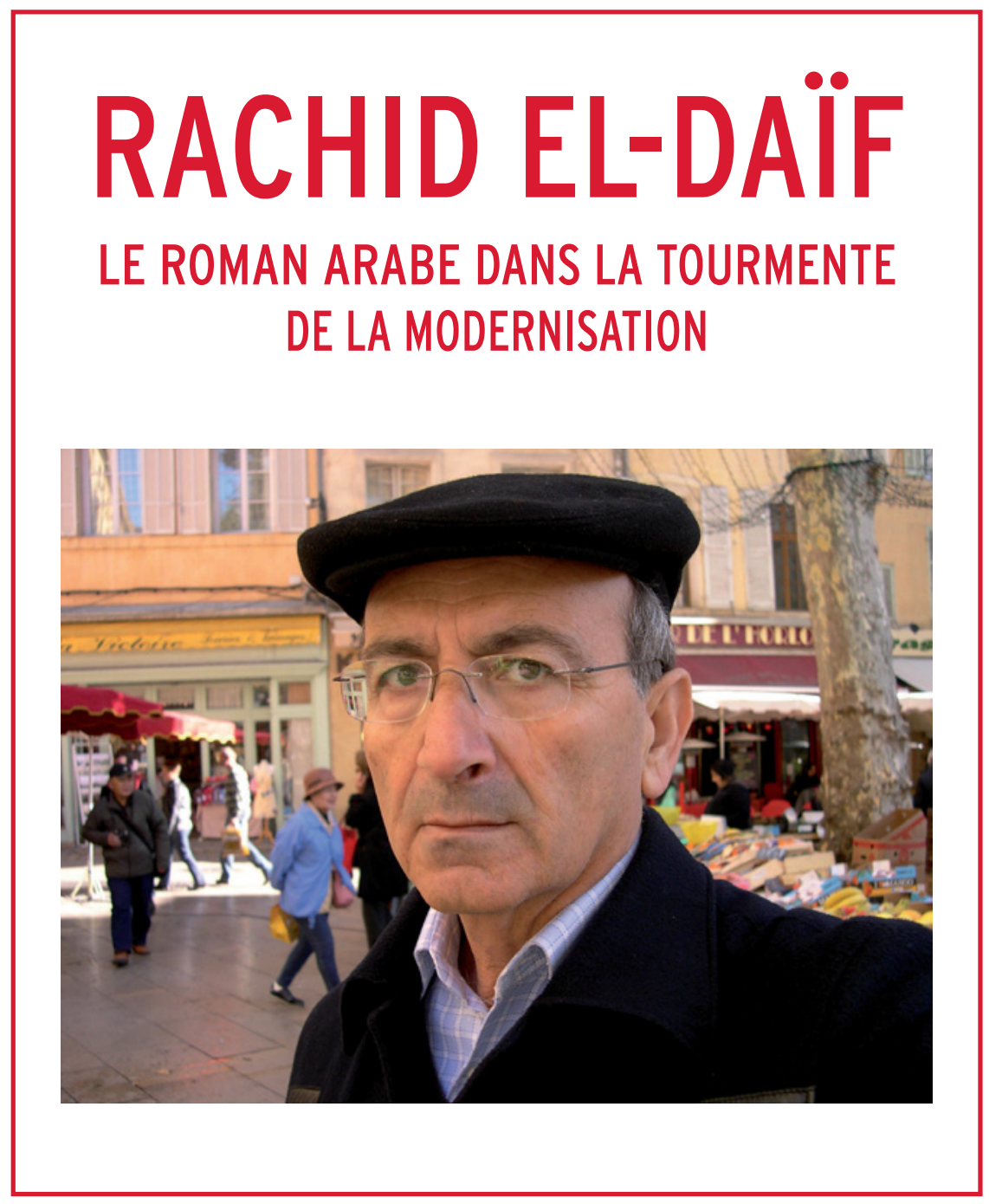




Rachid El-Daiif

Le roman arabe dans la tourmente de la modernisation 


\section{«Quaero 》}

\section{Collection dirigée par Jean-Christophe Tamisier}

Dernières parutions :

Emmanuel Ethis,

Le cinéma près de la vie. Prises de vue sociologique sur le spectateur du $\mathrm{XXI} I^{e}$ siècle.

Alexandre Fontaine, Aux heures suisses de l'école républicaine.

Prix Louis Cros 2015 de l'Académie des sciences morales et politiques

Christian Ghasarian,

Rapa. Île du bout du monde, île dans le monde.

Émilie Oléron Evans,

Nikolaus Pevsner, arpenteur des arts.

Pascale Rabault-Feuerhahn (dir.),

Théories intercontinentales. Voyages du comparatisme postcolonial.

Michèle-H. Salamagne et Patrick Thominet (dir.), Accompagner. Trente ans de soins palliatifs en France.

Alicia Fernández García et Mathieu Petithomme (dir.), Contester en Espagne - Crise démocratique et mouvements sociaux

Illustration de couverture:

Rachid El-Daif à Paris $D R$

(Les photographies réparties dans cet ouvrage appartiennent toutes à la collection privée de l'auteur)

(C) Éditions Demopolis, 2016

4 , rue Scipion

75005 Paris

www.demopolis.fr

ISBN : 978-2-35457-094-1 
Sous la direction de

Katia Ghosn

\section{Rachid El-Daïf}

\section{Le roman arabe dans la tourmente de la modernisation}

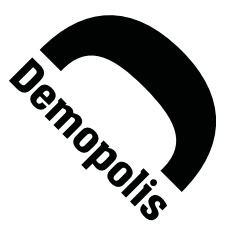



L'idée de cet ouvrage a germé suite à l'animation par Rachid El-Daïf, à Paris (à l'EHESS, à l'INALCO et à l'université Paris 8), du 6 au 20 décembre 2014, d'un cycle de conférences, tenues dans le cadre du séminaire " Orient-Littératures ", créé et dirigé par Gilles Ladkany, en collaboration avec Rania Samara et Marie-Thérèse Oliver Saidi. Il doit son existence et la richesse de son contenu à ce séminaire ainsi qu'à la copieuse contribution des auteurs, tous animés par un intérêt profond pour la littérature arabe et désireux de transmettre leur passion en faisant connaître un grand auteur et une œuvre originale. Ils rendent aussi chemin faisant un hommage à une plume exceptionnelle du monde arabe.

Sans l'intérêt des éditions Demopolis, la lecture critique de JeanChristophe Tamisier, directeur de la collection de recherche "Quaero " et le travail éditorial effectué avec Alexandra Delabie, l'ouvrage n'aurait pu voir le jour.

Ce livre a bénéficié des soutiens de la commission de la recherche de l'Université Paris VIII et du Centre de recherches Moyen-Orient Méditerranée (CERMOM) à l'Institut national des langues et civilisations orientales (INALCO).

Qu'ils en soient tous infiniment remerciés. 



\section{Translittération}

\begin{tabular}{|c|c|c|c|c|c|}
\hline$s$ & , & j & $\mathrm{z}$ & ق & $q$ \\
\hline ب & $\mathrm{b}$ & س & $\mathrm{s}$ & ك) & $\mathrm{k}$ \\
\hline ت & $\mathrm{t}$ & ش & sh & J & l \\
\hline ث & th & ص & ș & p & $\mathrm{m}$ \\
\hline ج & $\mathrm{j}$ & ض & $d \underline{d}$ & ن ن & $\mathrm{n}$ \\
\hline$\tau$ & $\mathrm{h}$ & $b$ & $\mathrm{t}$ & 0 & $\mathrm{~h}$ \\
\hline$\dot{\tau}$ & kh & ظ & $z$ & 9 & $\mathrm{w}$ \\
\hline 2 & $d$ & $\varepsilon$ & ' & ي & $\mathrm{y}$ \\
\hline j & $\mathrm{dh}$ & $\dot{\varepsilon}$ & gh & & \\
\hline J & $\mathrm{r}$ & ف & $\mathrm{f}$ & & \\
\hline
\end{tabular}

Voyelles longues

$\bar{a}$

$\overline{\mathrm{u}}$

$\overline{1}$

Diphtongues

و aw

أي ay

ال al- (même devant les antéro-palatales)

shadda par la double consonne.

Dans un souci d'homogénéisation, le nom de l'auteur, Rachid El-Daïf, est écrit tel qu'il figure dans la traduction française de ses romans, certains contributeurs - et lecteurs — n'ayant l'accès qu'aux œuvres traduites. Pour les articles en anglais, nous avons gardé la transcription retenue par les auteurs: "Rashid al-Daif ». Pour les noms des personnages, des lieux ou des ouvrages en arabe, nous avons suivi le système de translittération ci-dessus. Le narrateur - qui porte souvent le même prénom que celui de l'auteur — est transcrit par « Rashīd ». 



\section{Les auteurs}

Sobhi Boustani est professeur de littérature arabe moderne et directeur du Centre de recherches Moyen-Orient Méditerranée (CERMOM) à l'Institut national des langues et civilisations orientales (INALCO) à Paris. Depuis 2014, il est président du groupe EURAMAL (European Association for Modern Arabic Literature). Ses recherches s'orientent vers l'étude, dans la littérature arabe moderne, du style et de l'expression littéraire sous ses deux formes, poésie et prose. Ses publications les plus récentes: "La poésie romantique ", in Histoire de la littérature arabe moderne (1800-1945), tome I, Sindbad-Actes Sud, 2007; Poétique et politique: la poésie de Mahmoud Darwich, Bordeaux, Presses universitaires de Bordeaux, 2010; "Les Figures juives dans la littérature arabe moderne ", in Histoire des relations entre juifs et musulmans des origines à nos jours, Abdelwahab Meddeb et Benjamin Stora dir., Paris, Albin Michel, 2013; "Désirs sans limites, plaisirs assumés: Ismuhu al-gharām, un roman de 'Alawiyya Șubḥ ", in Alla rivisita degli studi orientali, nuova serie, volume LXXXVII, Sapienza, Universita di Roma, Pisa, Roma, 2014.

Vincent Colonna est sémiologue, écrivain et scénariste. Il a publié une dizaine de livres (nouvelles, romans et essais) sous son nom et des thrillers sous le pseudonyme de Barouk Salamé, dont Le Testament syriaque traduit dans plusieurs langues. il a soutenu en 1989 à l'École des hautes études en sciences sociales (EHESS) sous la direction de Gérard Genette la première thèse sur l'autofiction. Il dirige Protagoras, société qui propose du conseil éditorial et de l'expertise scénaristique. Dernier ouvrage publié: L’Art des séries télé, deux volumes, Paris, Payot, 2015.

Jean-Charles Depaule a enseigné à l'École d'architecture de Versailles (1969-1987) avant de poursuivre au CNRS (Le Caire, Aix-enProvence, Ivry-sur-Seine) ses recherches en anthropologie urbaine sur les espaces habités de l’Orient arabe. Également poète et traducteur, il est 
membre du comité de rédaction de la revue Gradhiva. Il a publié récemment Sur place, Marseille, cipM/Spectres familiers, 2011; Définition en cours, Coutras, Le bleu du ciel, 2013 et À travers le mur, avec J.-L. Arnaud, Marseille, Parenthèses, 2014.

Renaud Ego est poète, essayiste et critique littéraire. Son œuvre est ouverte au jeu des genres qui composent la littérature. Il fut l'un des fondateurs et des animateurs de la revue La Pensée de midi, éditée entre 2000 et 2010 par Actes Sud et l'introducteur en France du poète suédois Tomas Transförmer, lauréat du prix Nobel dont il a préfacé les œuvres complètes (Gallimard, 2004). Parmi la douzaine de livres qu'il a écrits, figurent des récits (Une Légende des yeux, Arles, Actes Sud, 2010.), des poèmes (la Réalité n'a rien à voir, Bègles, Le Castor astral, 2006) et des essais sur la littérature (L'Art comme San, art rupestre d'Afrique austral, Beaumont village, Adam Biro, 2000; L'Atelier de Jean Arp et Sophie Taeuber, coédition Fondation Arp et Les Cendres, Paris, 2012; L'Animal voyant, Paris, Errance, 2015).

Katia Ghosn est maître de conférences en littérature arabe contemporaine à l'université Paris VIII. Rédactrice à l'Orient littéraire, supplément culturel du quotidien libanais L'Orient-Le Jour. "Recherche identitaire et quête de territoire dans Learning English de Rašhīd al-Ḍa'if ", ARABICA, 62, novembre 2015; " Islam, politique et genre dans le roman libanais contemporain ", in Inspiriertes Schreiben? Islamisches in der zeitgenössischen arabischen, türkischen und persischen Literatur (sous la direction de Peter Dove, Hartmut Fähndrich et Wolfgang Müller), Bâle, Schwabe, décembre 2015.

Yves Gonzales-Quijano est chercheur au sein du Groupe de recherches et d'études sur la Méditerranée et le Moyen-Orient (GREMMO). Il a traduit de l'arabe une quinzaine d'œuvres littéraires contemporaines, principalement chez Actes Sud et Sindbad où il a été directeur de collection entre 1990 et 2000. Ses recherches actuelles portent sur la production culturelle dans les sociétés arabes d'aujourd'hui, en relation avec les modes d'expression politique. Depuis l'automne 2006, il publie chaque semaine sur ces questions un " carnet de recherche en ligne ", Culture et politique arabes (http://cpa. hypotheses.org).

As'ad E. Khairallah est professeur à l'Université américaine de Beyrouth (AUB). Après une licence en philosophie, il obtient un doctorat en littérature arabe, persane et en littérature comparée à Princeton. 
Il a enseigné à Freiburg, Princeton, Basel et Berkeley. Spécialiste de littérature arabe moderne, des relations culturelles Est Ouest, de littérature comparée et mondiale, il est également rédacteur en chef de la revue bilingue arabe-anglais, al-Abhath de la faculté des Arts et des Sciences (de l'Université américaine de Beyrouth). Il est l'auteur de Love, Madness, and Poetry: An Interpretation of the Majnun Legend, Wiesbaden, Franz Steiner Ferlag, 1980. Il a codirigé un ouvrage de référence en quatre volumes: Literature: A World History pour le Stockholm Collegium of World Literature dont il est membre du comité exécutif, paru chez Wiley-Blackwell, 2015.

Xavier Luffin est professeur à l'Université libre de Bruxelles (ULB) où il enseigne la langue et la littérature arabes. Il est l'auteur de nombreuses traductions de romans, de nouvelles, de poèmes, de récits de voyage et de théâtre de l'arabe (mais aussi du turc et de l'anglais) vers le français. Il a traduit Le Musicien et le Calife de Bagdad de Rachid El-Daï. Il est aussi l'auteur de plusieurs études sur la littérature arabe contemporaine, notamment Les Fils d'Antara. Représentations de l'Afrique et des Africains dans la littérature arabe contemporaine, Bruxelles, Safran, 2012; Religion et littérature arabe contemporaine. Quelques regards critiques, Bruxelles, Académie royale de Belgique, 2012; Printemps arabe et littérature. De la réalité à la fiction, de la fiction à la réalité, Bruxelles, Académie royale de Belgique, 2013.

Fatemeh Parchekani est maître de conférences à l'université Kharazmi de Téhéran où elle enseigne la littérature arabe moderne et comparée, ainsi que la traduction entre les trois langues, persane, arabe et turque. Ses recherches portent sur le mouvement théâtral entre Bilād al-Shām, l'Iran et la Turquie et sur le roman arabe moderne. Ses publications: Modernisme et théâtre en Orient: La Turquie ottomane, Bilād al-Shām et l'Iran, Beyrouth, 2015; Étude historique sur le théâtre iranien, Beyrouth, 2008; Le cinéma en Iran: histoire et défis, Beyrouth, 2009; Les universités iraniennes et les centres de recherche, Beyrouth, 2011.

Ken Seigneurie est professeur et directeur du programme Littérature-Monde à l'université Simon Fraser en Colombie-Britannique (Canada). Il est spécialiste des relations entre la culture littéraire et la pensée humaniste, avec un intérêt particulier pour la littérature arabe moderne. Parmi ses publications: Crisis and Memory: The Representation of Space in Modern Levantine Narrative, Ed. Ken Seigneurie, Wiesbaden, Reichert Verlag, 2003. Standing by the Ruins: Elegiac Humanism in 
Wartime and Postwar Lebanon, New York, Fordham University Press, 2011; " The Institution and the practice of Comparative Literature in Lebanon ", Comparative Literature Studies, 51.3, 2014. Seigneurie est également rédacteur en chef du Companion to World Literature, un ouvrage de référence en cinq volumes sur la littérature-monde publié par Wiley-Blackwell, 2017; traduction en anglais de 'Awdat al-almānī ila rushdihi (de Rachid El-Daif) in What Makes a Man? Sex Talk in Beirut and Berlin, Texas, University of Texas Press, 2015.

Heidi Toelle est professeure émérite de littérature arabe moderne au sein du département d'arabe de l'université Sorbonne Nouvelle et directrice de la revue d'études arabes et islamiques Arabica. Dernières publications: direction en collaboration avec Boutros Hallaq de l'Histoire de la littérature arabe moderne, 1800-1945, tome I, Arles, Actes SudSindbad, 2007; tome II, Arles, Actes Sud- Sindbad 2013; Les Suspendues (Al-Mu'allaqât) traduction et présentation, Paris, Flammarion, 2009; Avec $\mathrm{K}$. Zakharia, A la découverte de la littérature arabe $d u \mathrm{VI}^{e}$ siècle à nos jours, Paris, Flammarion, 2003, Poche 2005-2014. 


\section{Avant-propos}

Rachid El-Daïf est une figure majeure de la littérature arabe. Il est né en 1945 à Zgharta, bourgade du nord du Liban. Après avoir suivi des études de lettres arabes à l'École normale supérieure de l’Université libanaise, il s'installe à Paris en 1971 afin de poursuivre ses études et de fuir les feux de la guerre civile libanaise (1975-1990). Il obtient, en 1974, un doctorat en lettres modernes (à Paris 3) sous la direction d'André Miquel et, en 1978, un DEA de linguistique (à Paris 4). Durant ce séjour en France, il est influencé par la révolte étudiante de mai 1968, toujours présente dans les esprits. Il s'imprègne également de structuralisme et s'initie $\mathrm{au}$ "nouveau roman ", mouvements qui tiennent le dessus du pavé à l'époque. Très vite il se trouve engagé — tels les premiers missionnaires égyptiens arrivés en France au début du XIX ${ }^{\mathrm{e}}$ siècle, qui furent les promoteurs de la nahḍa (renaissance culturelle et littéraire arabe) - dans un dialogue avec la culture française qui se répercutera sur son œuvre. De retour au Liban, il enseigne la littérature arabe dans différents établissements: à l'Université libanaise, à l'Université libano-américaine (LAU) et à l'Université américaine de Beyrouth (AUB) où il dispense toujours, à ce jour, un cours de creative writing ("écriture créative ").

En 1972, il adhère au Parti communiste libanais et milite pour la cause palestinienne. Ce choix le contraint, pendant la guerre, à se réfugier à Beyrouth Ouest ${ }^{1}$. Le 11 juillet 1983, lors d'un bombardement de Beyrouth, il est grièvement blessé par des éclats d'obus. Échappé de justesse à la mort, il se retrouve paralysé de l'épaule droite et du cou. Une greffe des nerfs, opérée en France, lui permet de retrouver un peu de mobilité. Son roman 'Azīzī al-sayyid Kawabata ${ }^{2}$ (Cher Monsieur

1. Pendant la guerre civile, la capitale libanaise était divisée en deux parties séparées par une ligne de démarcation, Beyrouth-Est contrôlée par les milices chrétiennes et Beyrouth-Ouest, à majorité musulmane, bastion des forces palestiniennes et du Mouvement national qui réunit les arabistes.

2. Rachīd al-Ḍa'īf,'Azīzī al-sayyid Kawabata, Beyrouth, Mukhtārāt, 1995. Nouvelle édition, Riāḍ al-Rayyis, 2001. Traduit en français par Yves-Gonzales- Quijano sous le titre Cher monsieur Kawabata, Arles, Sindbad-Actes Sud, 1998. 
Kawabata) revient sur cet événement traumatique ainsi que sur les désillusions politiques de la gauche libanaise qui, à partir des années 1980, assiste impuissante à la perte d'influence des projets révolutionnaires et progressistes au profit d'un islamisme montant.

Son œuvre se distingue par une démarche singulière et témoigne d'un véritable renouveau esthétique. Après des débuts poétiques, il s'est consacré exclusivement à l'écriture romanesque. Ses romans, intimistes, relèvent pour la plupart de l'autofiction et ont pour narrateur «Rashīd", un personnage dont l'identité diffractée et multiple est marquée aussi bien par la violence de la guerre civile et les échecs des politiques du monde arabe que par les dynamiques propres à la mondialisation. Ses romans cherchent à illustrer un malaise multiforme. Le personnage principal est le plus souvent emblématique de l'époque contemporaine, en perte de repères et d'ancrages. Cependant, l'intimisme et l'obsession du détail ne doivent pas occulter le rapport fondamental au politique. Au sein de la crise identitaire des différents narrateurs - mêmes et autres tout à la fois - les dimensions de l'interne et de l'externe sont inextricables.

Outre les œuvres autofictionnelles, Rachid El-Daïd a publié des romans historiques: Țablit al-bahrr ("Paver la mer") et Ma'bad yanjạ. fi Baghdād (Le Musicien et le calife de Bagdad). Plusieurs de ses romans ont fait l'objet d'une adaptation théâtrale, aussi bien au Liban qu'en Europe. Qu'elle aille au diable, Meryl Streep!, réalisée par Mohamed Kacimi et présentée au théâtre du Rond-Point à Paris, fut une expérience des plus réussies.

Outre le français et l'anglais, certains de ses romans ont été traduits en espagnol, italien, allemand, suédois, polonais, danois et japonais. Prochainement, il sera possible de le lire en vietnamien.

Son style, attrayant, d'un abord facile, se tient au ras du langage le plus ordinaire et le plus courant. Il est toutefois le résultat d'un travail laborieux et relève de l'esthétique de "la simplicité inimitable ", ce que la rhétorique de la langue arabe appelle al-sahl al-mumtani'. Il se distingue par la sobriété, la concision et la proscription de toute forme de redondance. Son discours se donne à dessein d'être " correct » et non pas « beau », comme il l'explique lui-même.

Le présent ouvrage, collectif, aspire à combler un manque. Traduite - cinq romans publiés chez Actes Sud - et largement lue, l'œuvre de Rachid El-Daïd n'est pas suffisamment étudiée. Le choix 
des contributeurs, chercheurs, traducteurs de ses romans, critiques, fins lecteurs, issus de champs disciplinaires divers, permet d'offrir un aperçu panoramique de la richesse et de la diversité de l'œuvre et de dégager pleinement les fondements esthétiques sur lesquels elle se construit. L'ensemble s'adresse aux étudiants, mais aussi à tous les amateurs de littérature arabe, qui apprécient particulièrement El-Daïf. Ce livre permettra également au lecteur, qu'il munit des outils conceptuels appropriés, d'accéder à une vision, plus large, de l'état de la littérature arabe contemporaine, qui est présentement le chantier d'un profond mouvement de renouveau. 


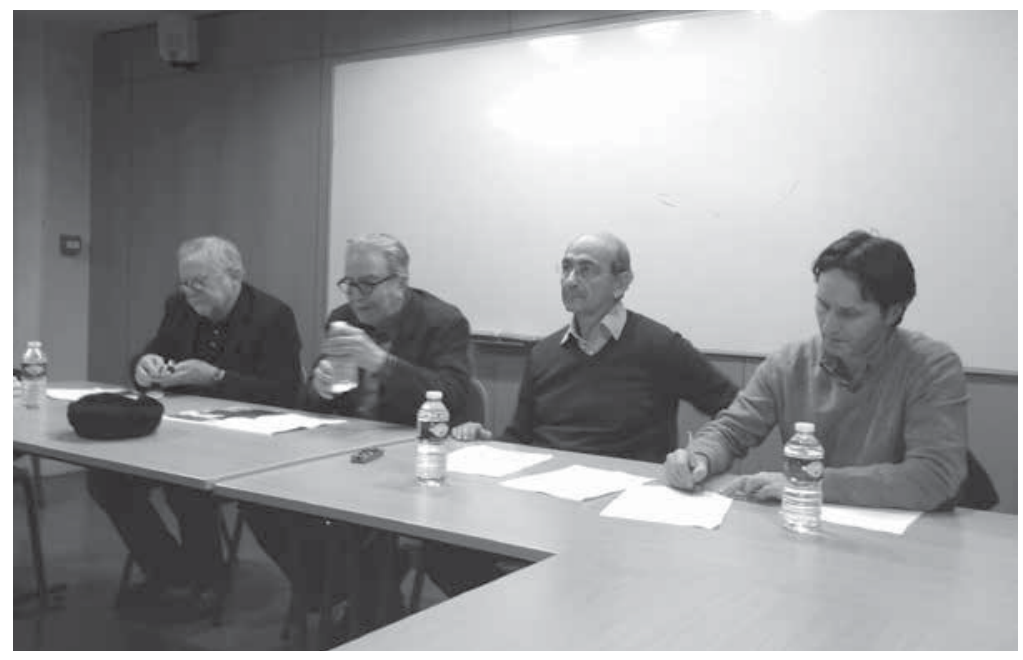

EHESS, 18-12-2014. De gauche à droite: Jean-Charles Depaule, Farouk Mardam Bey, Rachid El-Daïf, Renaud Ego

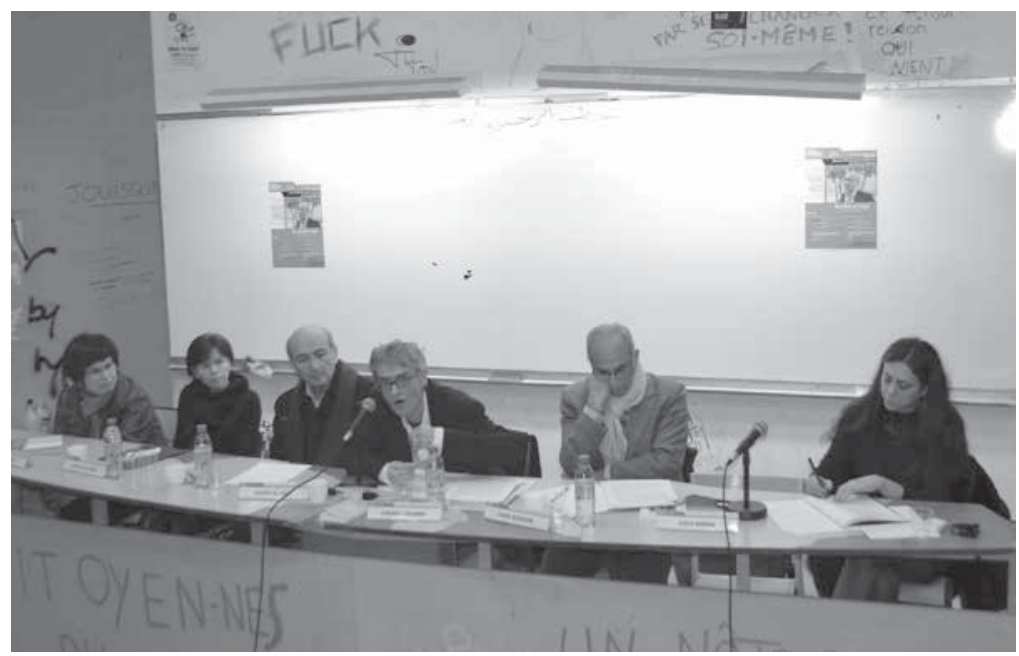

Paris 8, 11-12-2014. De gauche à droite: Salam Diab, Annick Allaigre, Rachid El-Daï, Vincent Colonna, Sobhi Boustani, Katia Ghosn. 


\title{
Introduction
}

\section{Le roman de Rachid El-Daïf à l'ère de la globalisation}

\author{
Katia Ghosn
}

L'œuvre de Rachid El-Daïf est communément désignée comme appartenant au "roman de la guerre civile", à laquelle elle fait largement écho. Or, il est à notre sens vain d'essayer de circonscrire une littérature spécifiquement libanaise. Certes, la guerre civile avec son lot de déchirements entre les communautés religieuses et de massacres sanglants a profondément marqué l'esprit des romanciers libanais contemporains. En brisant les repères identitaires, en désintégrant les structures d'un État né arbitrairement des accords conclus entre les pays vainqueurs de la Première Guerre mondiale, la guerre civile a dissipé à jamais l'illusion d'une exception libanaise, celle d'un pays oasis qui ne serait rien moins que "la Suisse du MoyenOrient ». Cet effondrement a donné naissance à une " littérature de la guerre $^{1}$ » (adab al-harb). Cependant, le Liban n’a jamais cessé de faire partie du continuum géographique, historique, culturel, politique, économique du monde arabe, du Machreq en particulier avec lequel il partage depuis les indépendances nationales bien des malheurs. La guerre civile elle-même fut aussi la conséquence de bien des conflits régionaux et oppositions d'intérêts internationaux. Elle eut dès le départ partie liée avec le problème palestinien, la nationalisation du canal de Suez, la guerre des Six Jours, et plus récemment avec le bras de fer entre le premier pays pétrolier sunnite de la région, l'Arabie saoudite, et l'Iran, instigateur de la révolution chiite de 1979, pour ne mentionner que ces quelques épisodes clés. Rassembler un

1. Cf. Abdū Wāzin, Riwāyat al-ḥarb al-lubnāniyya ("Le Roman de la guerre libanaise »), Dubaï, Dār al-Șadā, 2009. Voir également, Ilyās Khūrī, « Al-riwāya, al-riwā'ì wa-l-harb, wa kayfa tașīr al-ḥikāyāt riwāya » (" Le roman, le narrateur et la guerre ou comment les histoires deviennent fiction »), in Al-Ṭarīq, n 1, janvier-février 2001. 
certain nombre d'œuvres littéraires sous l'étiquette "roman de la guerre " ne doit donc pas pour autant impliquer la croyance idyllique en une entité libanaise organique (al-kiyān al-lubnān̄i). Depuis les années 1980, la critique en théorie littéraire reconnaît l'émergence d'un "nouveau " roman arabe, né à la fin des années 1960 et plus précisément après 1967, année de la défaite cuisante des Arabes face à Israël. Ce nouveau mouvement est en rupture avec l'existentialisme des années 1950 et 1960 et la littérature de l'engagement. Il rompt également avec le romantisme et avec le courant réaliste dont Najīb Maḥfūz (Naguib Mahfouz) est le principal représentant. Ainsi que le dit Walid Hamarneh, « les années 1960 ont vu le développement d'une nouvelle phase expérimentale de la fiction arabe, manifeste dans les œuvres aussi bien de la jeune génération que de la moins jeune $»^{2}$. [The 1960s witnessed the proliferation of a new experimentation phase in Arabic fiction that was manifest in the works of both the younger and older generation of writers].

Fabio Caiani observe avec justesse dans son ouvrage Contemporary arab fiction, innovation from Rama to Yalo ${ }^{3}$ que l'année 1967 apparaît par une sorte de " convention " apte à simplifier une approche historique et littéraire complexe qui n'occulte pas l'impact d'autres événements tout aussi déstabilisateurs que la guerre civile libanaise.

Parler d'une littérature « après 60 »- au sein de laquelle le roman libanais est largement représenté - a le mérite de proposer une dénomination plus large et de mettre l'accent sur l'interconnexion de la littérature libanaise contemporaine avec le contexte environnant, comme avec le monde globalisé.

D'ailleurs, l'œuvre de Rachid El-Daïf témoigne du tiraillement entre la culture "nationale", enracinée dans des traditions et des

2. Walid Hamarneh, "Some Narrators and Narrative Modes in the Contemporary Arabic Novel ", in The Arabic Novel Since 1950: Critical Essays, Interviews, and Bibliography, Cambridge, Dar Mahjar Publishing and Distribution, 1994, p. 210. La traduction est de nous.

3. Fabio Caiani, Contemporary Arab Fiction. Innovation from Rama to Yalo, London and New York, Routledge, 2007. "We can see 1967, the year of the naksa, as a turning point in literary orientation throughout the Arab world, when the prevalent mode of realistic writings starts to seam inadequate to portray a rapidly changing reality and a general identity crisis. Like all such generalizations, this one must betaken as no more than a convention to simplify presentation of a complex historical reality. [...] Other historical events also played an important role in destabilizing the writer's worldview and self-perception: It is impossible to ignore the impact (especially on Lebanese authors) of the long Lebanese Civil War and the gradual destruction of Beirut, once a vibrant cultural center for the whole Arab world, and of the many Gulf wars which destabilized Iraq ». (p. 9) 
valeurs " orientales " et une culture "occidentale " et mondialisée. Dans Learning English ${ }^{4}$ ("Apprendre l'anglais") dont rien que le titre traduit le désir d'apprendre la langue dominante, le narrateur, du nom récurrent de Rashīd, observe: «le Liban, aujourd'hui, est devenu comme une seule ville; le monde entier est devenu comme une seule ville $^{5}$. " La langue française qu'il avait apprise à l'école et qui lui avait ouvert les portes de l'université française à une époque où la révolte étudiante de mai 1968 incarnait les valeurs modernes, n'est plus celle du monde d'aujourd'hui:

Ma seule lacune, " culturellement parlant ", c'est l'anglais. C'est un problème qui ne m'est apparu comme tel que récemment, il y a de cela quelques années seulement. Avant, pour mes amis comme pour moimême, l'anglais ne nous était absolument pas nécessaire pour vivre notre modernité, notre révolutionnarisme, notre lutte à tous les niveaux, politique, social, revendicatif, etc. Le français suffisait et nous étions contents ainsi. Dans une certaine mesure, c'était même l'anglais qui pouvait empêcher ceux qui le pratiquaient de progresser. L'anglais — ou plutôt l'américain — c'était la langue de l'ennemi, la langue de l'exploitation, de la domination, de l'arrogance, de la superficialité intellectuelle, du pragmatisme... C'était la langue de l'argent et du commerce, pas celle des paradoxes subtils, ni celle de l'avenir, ou de l'égalité et de la justice sociale, non plus que celle de la théorie émancipatrice et de la véritable conscience. Le français incarnait toutes ces valeurs, il nous donnait plus de confiance en nous-mêmes pour assumer notre histoire, notre politique, les différentes manières de prendre en main notre destin pour orienter le cours de l'histoire comme nous l'avions décidé6.

L'apprentissage de l'anglais est donc, pour lui, une façon de poursuivre l'émancipation envers les formes de dépendance dans lesquelles ses frontières nationales, politiques et linguistiques le maintiennent. Pour avoir quelque chance de survivre dans un monde internationalisé, le passage à l'anglais s'impose. La confrontation des cultures, Rachid El-Daïf l'aborde également dans son autre roman $O k$, ma'a al-salāma ${ }^{7}$ ("Ok, au revoir "): pour séduire et garder sa maîtresse anglaise d'origine

4. Rachid El-Daïf, Learning English, Dār al-nahār, Beyrouth, 1998. Nous n'utiliserons pas la translittération (Lïrning Inglish) et garderons "Learning English ", le titre de la traduction française du roman. Pour la traduction, nous reprenons celle de Yves Gonzales-Quijano, Learning English, Arles, Actes Sud, 2002. Le numéro de la page renvoie au texte arabe.

5. Ibid., p. 21.

6. Ibid., p. 16-17.

7. Rachid El-Daïf, Ok, ma‘a al-salāma, Beyrouth, Riad al-Rayyis, 2008. 
libanaise, de vingt ans sa cadette, qui travaille dans une entreprise internationale et est passionnée de films américains, il lui fallait à tout prix apprendre l'anglais. De même, le rapport ambigu à la mondialisation tourmente le narrateur de Tișțifil Meryl Streep (Qu'elle aille au diable, Meryl Streep!). Les premières lignes du roman le décrivent assis avec son épouse devant la télévision - de marque Sony - en train d'écouter Georges W. Bush annonçant «la naissance du nouvel ordre mondial $^{8}$ ». La diffusion de certains programmes sans sous-titrage énerve Rashshūd (diminutif de Rashīd en arabe): "supposent-ils que tous ceux qui regardent ces programmes connaissent l'anglais? La mondialisation signifie-t-elle que nous faisons déjà partie du territoire américain $^{9}[\ldots]$ ? "

Le déclin des valeurs de la modernité portées par la France depuis les Lumières, l'emprise d'une nouvelle culture venue d'Amérique ainsi que l'informatisation à grande échelle des sociétés alimenteront son rêve d'un territoire global où le métissage culturel, choisi et partagé, favoriserait la dissolution des violences et la naissance d'une internationalité réconciliée.

Mon rêve, mon obsession, c'est de pouvoir rencontrer toutes sortes de gens avec qui j'entrerai en contact, faire la connaissance de personnes que je ne connais que de nom, que j'estime, dont j'apprécie les idées et avec lesquelles j'ai l'impression de partager un même espace, un même temps, un même "territoire ", les mêmes valeurs. J'ai toujours pensé — et je continue à le faire - qu'il nous faut parler, ensemble, de ce lieu où nous nous trouvons (ce qu'on appelle dans le langage contemporain le territoire national, le sol de la patrie...), aborder tous les problèmes liés à cela, surtout après l'introduction d'internet et ses développements prometteurs. J'ai toujours eu la certitude — et je continue à l'avoir — que nous sommes nombreux à partager le même territoire, et que ce qui nous réunit est plus important que ce que l'on peut trouver entre deux voisins, deux personnes appartenant à la même communauté, à la même nation, à la même confession, à la même religion, simplement parce que les circonstances ont voulu qu'il en soit ainsi. Donc, j'apprends l'anglais parce que c'est aujourd'hui le moyen qui permet le mieux d'atteindre ce résultat, et non pas nécessairement parce que j'aime cette langue, ou parce que je considère qu'elle a plus de mérites qu'une autre. Et pas davantage parce que je détesterais les autres, ou que je leur accorderais moins de valeur. Mais, aujourd'hui, c'est l'anglais, et pourquoi ne pas l'utiliser

8. Rachid El-Daïf, Tișțifil Meryl Streep, Beyrouth, Riyāḍ al-Rayyis, 200, p. 9.

9. Ibid., p. 57. 
comme instrument d'unification, de rapprochement, de connaissance et même de confrontation entre les peuples, sans chauvinisme national, culturel ou autre? Tout simplement ${ }^{10}$.

Dans cet espace mondial, l'internet est un outil incontournable que Rashīd apprend rapidement à maîtriser, tout comme il a appris, pour être un homme contemporain - ce qu'il désire par-dessus tout - à accompagner les nouveaux progrès technologiques et les évolutions des idées:

Je ne peux pas supporter de ne pas être de mon temps. J'ai toujours été ainsi, contemporain: pour la vague arabiste progressiste et modernisatrice, pour la nouvelle poésie et ses innovations formelles, pour le marxisme... Parfaitement à l'aise en français, j'ai été structuraliste et j'appartiens maintenant à ce que l'on appelle la "postmodernité ». Je me suis acheté un ordinateur très sophistiqué, j’ai un abonnement à Internet, et bien entendu une adresse électronique ${ }^{11}$.

Cependant, l'Amérique fantasmée représente-t-elle vraiment ce territoire ouvert où les individus partagent les mêmes valeurs et la même langue et communiquent sans contrainte? Michael Hardt et Antonio Negri ont montré dans leur livre Empire ${ }^{12}$ que sous des apparences d'harmonisation et d'homogénéisation, l'Empire cache des structures d'exploitation et des rapports de domination. Auparavant, Erich Auerbach avait mis en garde contre le processus d'homogénéisation et de concentration induit par la domination croissante de l'anglais: "Si l'humanité parvient à survivre aux bouleversements qu'entraîne un processus de concentration si brutal, si impétueux et si mal préparé dans les consciences, il faudra s'habituer à l'idée que, sur cette terre organisée de façon homogène, seule une unique culture littéraire, voire, dans des délais relativement courts, seuls quelques rares langues littéraires, bientôt une seule, peut-être, resteront en vie $^{13}$."

Dans Learning English et dans OK ma'a al-salāma, Rashīd est comme Rachid l'auteur - un professeur d'université. La bataille de l'anglais ainsi que la recherche d'une extraterritorialité traduisent un

10. Learning English, op. cit., p. 132-133. Le terme " territoire " est écrit en français dans le texte. Sur ce sujet, cf. Katia Ghosn, « Recherche identitaire et quête de territoire dans Learning English de Rašīd al-Ḍa'ïf ", Arabica 62, Brill, Leiden, 2015, p.688-711.

11. Ibid., p. 17.

12. Michael Hardt et Antonio Negri, Empire, Paris, Exils, 2000.

13. Erich Auerbach, « Philologie de la littérature mondiale » (texte de 1952), in Où est la littérature mondiale?, Saint-Denis, PUV, 2005, pp. 25-37, ici p. 26. 
processus d'émancipation de l'espace culturel national, vécu comme périphérique, visant à entrer dans un espace littérairement dominant et à se constituer ainsi une légitimité littéraire. Comme l'explique Pascale Casanova dans son ouvrage La République mondiale des Lettres: "Le processus de décolonisation ouvre la dernière grande étape de l'élargissement de l'univers littéraire et marque l'arrivée dans la concurrence internationale de protagonistes exclus jusque-là de l'idée même de littérature ${ }^{14}$. " Richard Jacquemond observe que la littérature arabe occupe une place marginale dans l'espace international parce qu'elle n'est pas assez traduite: "Pour exister dans cet espace, aujourd'hui, si l'on n'écrit pas en français ou en anglais, il faut être traduit dans une de ces deux langues [...] C'est parce que Mahfouz commence à être traduit en français et en anglais qu'il devient nobélisable ${ }^{15}$. » Contestant l'opinion de Casanova selon laquelle Paris continuerait à être le centre dominant de l'espace littéraire mondial, Jacquemond considère qu'" aujourd'hui, ce centre s'est déplacé vers Londres et New York ${ }^{16}$ ». Vouloir être contemporain implique, dès lors, l'entrée dans la concurrence littéraire internationale et le rapprochement avec des écrivains éloignés de l'espace géographique national. Ainsi, par exemple, Rashīd s'adresse à l'écrivain japonais Yanasuri Kawabata dans 'Azīzī al-sayyid Kawabata ${ }^{17}$ (Cher Monsieur Kawabata). Et Rashshūd, dans Tiștifil Meryl Streep, désapprouve le comportement de l'actrice Meryl Streep qui, dans le film Kramer contre Kramer, abandonne mari et enfant; il refuse qu'une telle attitude soit érigée en modèle à suivre par la femme libanaise.

Le difficile dialogue des cultures est abordé à travers des questions de genre. En plus d'être révélatrice des rapports de pouvoir et des tensions d'ordre éthique qui régissent les liens homme-femme, la guerre des sexes ("le lit») reproduit une confrontation non encore réglée entre l'Orient et l'Occident, entre les traditions et la modernité, comme le dit El-Daïf en commentant son propre roman Tiștifil Meryl Streep:

Je ne me lasserai pas de répéter que le lit est le lieu où se confrontent, souvent violemment, l'Occident moderne et l'Orient traditionnel. Par

14. Pascale Casanova, La République mondiale des Lettres, Paris, Seuil, 1999, p. 140.

15. Cf. Richard Jacquemond, "L'internationalisation de la littérature arabe moderne, du prix Nobel de Naguib Mahfuz (1988) à L'Immeuble Yacoubian (2006) ", intervention prononcée à l'université Paris 8 lors d'une journée d'étude sur la traduction et la mondialisation, le 7 décembre 2007. Consulté en ligne sur www2.univ-paris8.fr.

Najīb Maḥfūẓ a reçu le prix Nobel de littérature en 1988.

16. Jacquemond, op. cit.

17. Rachid El-Daïf, 'Azīzī al-sayyid Kawabata, Beyrouth, Mukhtārāt, 1995. 
" lit » j'entends les mœurs et les valeurs morales. Les effets du choc de la modernité provoqué par la conquête d'Égypte par Napoléon Bonaparte continuent toujours de se propager et de s'approfondir dans le monde arabe. Ces effets ont fait qu'une dialectique de fascination et de répulsion se soit installée chez les Arabes envers l'Occident ${ }^{18}$.

La relation crispée avec l'altérité de l'Autre achoppera sur un sujet autrement plus épineux, celui de l'homosexualité, abordé dans 'Awdat al-almāñ̄ ilā rushdihi ${ }^{19}$ ("Le retour de l'Allemand à la raison"). Issu d'une société arabe qui exalte la virilité (fuhūla/dhukūra) et condamne le rapport amoureux entre des personnes du même sexe, le considérant comme un acte avilissant, contre nature et passible de prison, Rachid tente de comprendre l'homosexualité de son collègue allemand Joachim Helfer, sans vraiment y parvenir. Pour l'hétérosexuel arabe qu'il est, la différence devient une épreuve impénétrable. Toutefois, l'irruption de l'altérité provoque une confrontation non seulement avec l'Autre, mais aussi et surtout avec soi-même. Rachid observe, en une sorte d'aveu impuissant, les répercussions subies, sur le plan individuel, d'un héritage ancestral transmué en déterminisme social:

Malgré ma précaution, à tout moment, de la nécessité de pendre du recul vis-à-vis des comportements, des représentations et des idéologies de la société à laquelle j'appartiens, et bien que je sois de ceux qui s'exercent constamment à réexaminer leurs convictions personnelles et celles transmises par les groupes sociaux, beaucoup d'idées héritées de mon milieu s'immiscent en moi et agissent à mon insu sans l'intervention de ma conscience ${ }^{20}$.

Différences et divergences semblent se dresser contre toute éventuelle poursuite de dialogue entre les deux hommes et par conséquent entre les deux cultures. La réponse de Helfer est un affrontement,

18. Rachid El-Daïf, « Le lit: un lieu de confrontation », intervention prononcée lors des $2^{\text {es }}$ Assises internationales du roman, in Les Actes des Assises, Lyon, 2008.

19. 'Awdat al-almānī ilā rushdihi, Beyrouth, Riāọ al-Rayyis, 2006. Ce livre a suscité une polémique aussi bien autour du sujet lui-même que par rapport au genre littéraire duquel il relève. Ken Seigneurie considère que cet ouvrage est une biographie fictionnelle ("novelized biographie »). Il écrit: "The narrator Rashid, [who] must be distiguished from the author Rashid al-Daif if one is to avoid an impoverishing reduction of the text's social relevance. " Cf. également Ken Seigneurie, Chiasmus on Masculinity in Rashid al-Daif's How the German came to his senses, papier presenté à la Modern Language Association Annual Convention, Philadelphia, décembre 2006. Yves Gonzalez-Quijano rejoint l'avis de Seigneurie. Voir son article «Un choc dans la bataille: le clash des programmes culturels ", Culture et politique arabes, 12 novembre 2006, republié ici.

20. Ibid., p. 12. La traduction est de nous. 
une provocation en duel. Son livre ${ }^{21}$ s'intitule: Die Verschwulung der Welt. Rede gegen Rede, Beirut-Berlin ( L'Homosexualisation du monde. Discours contre discours, Beyrouth-Berlin ") et répond, point par point, aux allégations de Rachid. La réponse de l'auteur libanais, quand bien même elle succombe au conservatisme et à un dualisme réducteur, ne se soustrait pas à une profonde remise en question: "Suis-je vraiment traditionaliste à ce point-là ${ }^{22}$ ? ». Et, sous-jacente aux souhaits émis à l'adresse de son fils, se lit une autocritique: "Je voudrais, du plus profond de moi-même, que mon fils me ressemble mais en mille fois meilleur. Peut-être, aussi, je voudrais qu'il "nous" ressemble, à "nous" "les Libanais, arabes et orientaux, mais bien entendu sans aucune de nos tares archaïques ${ }^{23}$. » Rachid est lucide sur le fait qu'il n'est pas aisé de se défaire des habitus millénaires et espère que la nouvelle génération réussira là où lui a tourné en rond. Il croit à la perfectibilité humaine; le temps est envisagé comme une dynamique ayant la libération comme horizon.

Dans ses aveux, Rachid va au bout de l'entreprise à laquelle les autorités allemandes ont convié les auteurs, résumée dans le titre du programme: "le divan oriental-occidental ${ }^{24}$ ». Comme dans une sorte d'autopsychanalyse, il se livre à un dévoilement compliqué. Et comme dans tout dévoilement authentique, il s'agit de dire le minable, le malsain, le refoulé, le déplaisant, le scandaleux, condition sine qua non pour un dépassement possible. Loin de constituer une raison pour une rupture inéluctable du dialogue, les obstacles soulèvent le défi et repoussent les frontières interculturelles. Réajuster son champ de vision permettrait d'éviter les impasses des chocs mortifères de civilisation. C'est l'enjeu exprimé par ce constat: "Il faudrait beaucoup

21. Je me suis référée à la traduction arabe par Yūsuf Ḥijāzī, Khițāb muqābil khițāb, Bayrūt-Birlīn, Beyrouth, Manshūrāt al-Jamal, 2009. Version originale: Die Verschwulung der Welt. Rede gegen Rede, Beirut-Berlin, Frankfurt am Main, Suhrkamp Verlag, 2006. Pour la traduction en anglais des deux livres ('Awdat al-almānì ilā rushdihi et Die Verschwulung der Welt) par Ken Seigneurie et Gary Schmidt, voir What Makes a Man?, Center for Middle Eastern Studies, University of Texas, 2015.

22. 'Awdat al-almānī ilā rushdihi., op. cit., p. 82.

23. Ibid., p. 13.

24. «Le Divan occidental-oriental » est le programme d'échange culturel, sur trois ans, de 2002 à 2004, lancé par les autorités allemandes: deux auteurs (ils sont plusieurs à avoir tenté l'expérience) issus de pays et de cultures différents séjournent pendant un certain temps chacun dans le pays de l'autre pour y livrer ce vécu par la suite. Suite à la rencontre, à Berlin, pendant six semaines, de Rachid avec son homologue allemand Joachim Helfer et au séjour de ce dernier à Beyrouth pendant trois semaines, chacun d'eux a écrit un livre comme contribution au dialogue des cultures. $C f$. les ouvrages cités plus haut. 
d'échanges entre les deux sociétés, allemande et arabe, pour que suffisamment de sujets soient clarifiés ${ }^{25}$. Une réflexion qu'il réitère à la fin du livre en faisant ses adieux à Joachim: "Il faudrait que beaucoup de choses soient dites pour que tout soit clair entre les Allemands et les Arabes $^{26}$. " Cet énoncé n'est pas une simple constatation, il révèle comme dans le souhait émis à l'attention de son fils et par conséquent aux générations suivantes - la croyance en une temporalité, à terme, positive. La phrase se lirait alors: « un jour, lorsque beaucoup de choses auraient été dites, les rapports entre "eux" et "nous" deviendraient clairs et pacifiques. " Aujourd'hui n'est pas encore demain...

L'espace toujours ouvert à la parole, si difficile qu'elle soit, structure le projet littéraire de Rachid El-Daïf; l'expérience du « divan orientaloccidental " ne pourrait être comprise qu'en l'y intégrant. Ce à quoi il invite lui-même d'ailleurs: " Je ne sais pas en fait ce qui m'a tellement séduit [dans cette affaire], il se pourrait que je sois tout simplement face à un événement narratif, à une réalité littéraire qui m’intéresse au plus haut point par sa singularité propre à élargir l'horizon et à repousser les frontières, c'est d'ailleurs le sens de la littérature telle que je le conçois ${ }^{27}$."

Son entreprise littéraire se réfère aux sources de la culture arabe qui agissent encore souvent comme un destin, tout en se soumettant à une dynamique de réévaluation des normes qui régissent ces dernières. Ce faisant, il réinvente des choix esthétiques, linguistiques, formels qui définissent sa position dans cet espace, une position autonome, lucide, se déployant hors des limites nationales, dans l'univers littéraire mondial, sans pour autant y perdre ses marques. Rachid El-Daïf réussit ainsi à transformer la question anxiogène des frontières culturelles à l'ère de la globalisation en une expérience esthétique singulière à forte charge critique. 



\section{1 \\ Quatre motifs de l'aliénation dans l'œuvre romanesque de Rachid El-Daïf}

Renaud Ego

Je voudrais vous proposer une lecture transversale des cinq premiers romans de Rachid El-Daïf traduits en français: Passage au Crépuscule, Cher Monsieur Kawabata, Learning English, Qu'elle aille au diable, Meryl Streep! et Fais-voir tes jambes Leïla! ${ }^{1}$. Je laisserai de côté Le Musicien et le calife de Bagdad qui, au contraire des précédents, est un roman historique, situé au $\mathrm{IX}^{\mathrm{e}}$ siècle de notre ère; il s'en distingue également par sa narration distancée, à la troisième personne du singulier, quand les romans que je m’apprête à évoquer sont tous écrits à la première personne. Ce choix de donner la parole à un sujet masculin adulte leur confère une certaine unité narrative et renforce le lecteur dans son intuition que, de l'un à l'autre de ces livres, un fil est suivi: à travers la voix de ces hommes, traversés par les tensions que font naître en eux un désir d'émancipation et leur fidélité à leurs cadres d'appartenance, qu'ils soient familiaux, religieux ou culturels, Rachid El-Daïf interroge les mutations d'une société encore traditionnelle aux prises avec cette " modernité ", venue d'Occident, qui la bouleverse.

Cette série de romans a aussi pour fond l'histoire libanaise récente, et certains aspects autobiographiques renforcent leur cohérence. L'auteur a intimement vécu ce qu’on appelle d'un euphémisme "les déchirures" libanaises. Né en 1945 dans une famille de chrétiens maronites du nord du Liban, il est à la fin des années 1960 un jeune militant communiste qui s'engage aux côtés des partisans de la cause palestinienne, jusqu'au moment où la polarisation confessionnelle

1. Je reprendrai, en le développant, le propos d’un article, "Le Tour du propriétaire ", publié dans le $\mathrm{n}^{\circ} 14$ de La Pensée de Midi, 2005. 
de la guerre, comme sa prise de conscience des limites de l'analyse marxiste, rend douloureuse en lui la coexistence conflictuelle de ces diverses identités. Ainsi, la somme des traits psychologiques, des sentiments, des expériences plus ou moins partagés par les narrateurs de ses livres leur confère, outre l'unité d'une voix singulière, la vraisemblance d'un portrait collectif. Pour autant, elle ne définit en aucun cas un quelconque idéal type sociologique. Rachid El-Daïf est trop conscient de ses propres contradictions pour croire en la validité de ce genre de modèle. C'est d'ailleurs pour cette raison qu'il pense en romancier et se coule dans une grande diversité de personnages, certains lui ressemblant, d'autres non, certains exposant sa pensée et son expérience, d'autres s'en éloignant tout à fait. Dans ce portrait, toutefois, un thème se dégage qui me servira de fil conducteur, c'est celui de l'aliénation. Je l'entendrai ici selon ses deux acceptions. Au sens large de ce terme, tout d'abord, l'aliénation est le fait de devenir étranger à soi-même, à sa propre histoire ou à sa propre culture. Dans son acception psychique plus restreinte, ensuite, l'aliénation est le fait de " perdre la tête " et de basculer dans la folie. Tel sera le thème que j'exposerai ici, en le suivant à travers quatre motifs: l'occupation, la filiation, la confession et la possession.

\section{L'occupation}

Le premier des motifs de l'aliénation, tel que l'expose Passage au crépuscule, est celui de l'occupation, dans ses formes spatiale, physique et psychologique. De retour chez lui après avoir été blessé et amputé d'un bras, le narrateur découvre que son appartement est squatté, comme nombre d'appartements de Beyrouth le furent pendant la guerre. Il lui faut cohabiter avec une femme enceinte, dont le mari a été tué, et son jeune garçon, en respectant une séparation stricte des espaces sur laquelle veille un étrange gardien d'immeuble, à la fois protecteur, menaçant et particulièrement intrusif. L'appartement, qui doit être partagé tout en étant divisé, est le microcosme symbolique d'un pays où chacun vit dans une promiscuité, désormais teintée de méfiance, avec ceux dont il ne partage pas la confession. Cette occupation spatiale semble une parabole de la perte de souveraineté politique du Liban, manifeste après l'invasion israélienne de 1982 ou la tutelle syrienne, latente ou effective depuis 1990, mais elle est plus encore l'image d'un pays où l'espace commun de la citoyenneté s'est effacé derrière le cloisonnement des appartenances communautaires. 
L'amputation donne à ce thème de l'occupation une dimension physique douloureuse. Au-delà de son aspect autobiographique, cette blessure exprime la façon dont la guerre s'inscrit dans le corps individuel de chacun et dans le corps collectif d'un pays. Tous deux sont démembrés et privés d'une composante essentielle à leur construction, à savoir une citoyenneté qui, semblable à un bras tendu, et désormais manquant, au-dessus des identités religieuses, les réunirait en les dépassant.

Mais l'occupation prend une dimension qui est, plus encore, psychologique. Elle est manifeste dans la paranoïa du narrateur et dans le caractère si souvent hallucinatoire de son récit qui lui fait revivre, sous des formes cauchemardesques toujours différentes, l'épisode de sa propre blessure. La réalité historique et sa transmutation sur le plan du cauchemar ne cessent de se fondre l'une en l'autre, si bien que le lecteur ne sait plus toujours dans quel plan de la vie ou du fantasme il évolue. Comme Rachid El-Daïf l'écrira dans Cher Monsieur Kawabata, «j'ai acquis la certitude, tandis que la guerre faisait rage, que seul le délire pouvait rendre cette réalité rebelle à toute autre expression ».

\section{La filiation}

Le second motif de l'aliénation est celui de la filiation, qui constitue pour chacun un déterminisme familial majeur. Elle est, au sens marxiste de ce terme, une aliénation quand elle est une entrave à la libre construction d'un sujet, soit qu'il ne puisse se dégager des attentes ou des espoirs dont il est investi par son milieu d'origine, soit qu'on le ramène à cette seule identité, en dépit de ses efforts pour y échapper. Quiconque n'est plus le libre dépositaire de la culture dont il hérite, mais son légataire obligatoire, perd sa souveraineté individuelle. Il n'a alors d'autre choix que de perpétuer cette identité originelle ou d'y être assigné, en paraissant, aux yeux des autres, en être le simple représentant.

Cher Monsieur Kawabata est le plus autobiographique des romans de Rachid El-Daïf. Son narrateur y raconte une enfance dans une famille de paysans maronites du nord du Liban, puis son éloignement quand il s'engage dans le parti communiste pro-palestinien, lui qui avait vocation à créer des « individus responsables, libres de toute attache avec leur famille, leur région d'origine, leur confession ou leur communauté ». Toutefois, son épopée politique s'avère être un leurre, il comprend avoir été le jouet de forces historiques qui le dépassaient et l'ont floué, mais plus encore d’une idéologie inadaptée à la réalité libanaise: « Rien que 
des mots, sans rapport avec ce qui se passait, des formules dont on se délectait et qui parlaient à travers nous qui n'en étions que les montures dont ils se servaient pour nous conduire là où ils le voulaient ${ }^{2}$. " Dès lors, sa biographie est moins la trajectoire d'une construction de soi dans un processus de transformation et d'épanouissement individuel qu'une accumulation de personnes mal ajustées: entre celui qu'il était par son milieu, celui qu'il a rêvé de devenir, et l'homme qu'il est effectivement devenu. Sa propre intégrité psychologique s’en trouve affectée. D’ailleurs, le livre s'ouvre sur le moment où il croit rencontrer son propre double dans la rue et où son équilibre mental vacille: « je veux dire mon unité, la cohésion des parties dont je suis formé, leur adhésion à ce vague quelque chose qui les lie ensemble. "Son récit prendra dès lors la forme d'une confession ou d'une cure dont il espérera retirer un apaisement, dans laquelle il s'adressera à un interlocuteur absent, romancier Japonais, Yasunari Kawabata.

Le narrateur de Learning English est, quant à lui, un universitaire qui n'a plus que de lointaines relations avec les membres de sa famille. "En réalité, c'était comme si leur existence me concernait, mais comme une chose du passé ", dit-il. " J'avais l'impression d'être devenu quelqu'un d'autre ». C'est ainsi qu'il apprend, à la lecture d'un bref article de journal, l'assassinat de son père dont personne ne l'a prévenu. Passé le choc de ce décès, cet événement brutal le replonge dans l'histoire qu'il a fuie, avec ses conflits familiaux et ses vendettas archaïques. Mais les circonstances dans lesquelles il l'apprend lui renvoient aussi l'image de l'étranger qu'il est devenu aux yeux des siens. Il est alors tiraillé entre le respect des codes d'honneur en vigueur dans son propre milieu d'origine, qui voudraient qu'il venge dans le sang la mort de son père, et sa fidélité aux normes éthiques qu'il s'est choisies et qui lui interdisent de se venger de la sorte. Or, s’il échappe à un tel dilemme, ce n'est pas en raison d'un choix personnel, mais en raison des soupçons qui pèsent sur sa propre bâtardise. Son propre clan le laisse à l'écart parce qu'il pourrait être le fruit d'une liaison adultérine et non le fils légitime de son père. Ici, la bâtardise n'est pas simplement un possible fait de naissance, c'est avant tout la parabole d'une identité vécue sous le signe de sa dualité conflictuelle, celle d'un intellectuel épris de culture universelle et de modernité technologique mais qui fut avant cela un enfant issu d'un milieu paysan, chrétien et traditionaliste.

2. Conférence de Rachid El-Daïf devant le bureau des Nations unies, Genève, 10 septembre 2001. 


\section{La confession}

Rien n'atteste mieux cette tension que le rapport entretenu par les personnages de ces romans à leur langue: dans ce qu'elle confesse ou trahit de leur identité, à travers leurs patronymes, et dans ce qui fait de leur récit la tentative assez vaine de trouver un soulagement dans l'exposé d'une parole qui confesse son intimité. Loin de dégager les individus des déterminismes culturels propres à leur héritage familial et confessionnel, la langue les perpétue et les redouble. Derrière ce motif, c'est toute la question d'un libre usage de la parole qui est posée.

Dans Passage au crépuscule, le narrateur explique que "quand on me demande mon nom, je leur dis un patronyme qui n'indiquait rien sur ma communauté, ni sur mes convictions politiques, ni sur ma région d'origine". Celui de Cher Monsieur Kawabata ajoute: "Chez nous, les Arabes - et je ne pense pas que nous soyons les seuls - un nom peut sauver ou causer à la perte [...] Chez nous: un endroit, c'est pour que les noms se ressemblent, en d'autres termes, une définition pédante de la guerre. " Quant à celui de Learning English, il souhaiterait avoir " un nom qui [fasse] de moi quelqu'un de différent, un étranger, dans un pays qui n'aime rien tant que ce qui est comme tout le monde". Il voudrait "avoir d'autres parents que les miens, une autre religion, une autre langue, un autre pays [...] je voudrais être un clone, comme Dolly, la brebis! ». " Un numéro, cela m'irait très bien ", dit-il encore.

Naturellement, c'est la raison pour laquelle il apprend l'anglais, adopte les comportements et les modes de consommation qui le relient au mainstream de la culture internationale. Avec l'anglais, dit-il, « mon rêve, mon obsession, c'est de pouvoir rencontrer toutes sortes de gens avec qui j'entrerai en contact, faire la connaissance de gens que je ne connais que de nom, que j'estime, dont j'apprécie les idées et avec lesquelles j'ai l'impression de partager un même espace, un même temps, un même territoire, les mêmes valeurs". Dans Cher Monsieur Kawabata, le narrateur, rêvait lui aussi « de parler toutes les langues, pour écouter l'humanité tout entière ». Il cherche dans le romancier japonais à qui il s'adresse, un auditeur qui ait "l'innocence de l'étranger ", "l'absence de préjugé de l'étranger ", comme s'il ne pouvait trouver un tel interlocuteur à l'intérieur de sa propre langue. Toutefois, en s'adressant à un mort, il dit bien qu'il n'est pas de témoin possible et dès lors, il est condamné à rester enfermé dans le soliloque de sa propre confession, sans personne pour l'écouter ou la comprendre. 
Dans ce rapport au nom et à la langue, Rachid El-Daïf met en scène plusieurs figures d'un même trouble identitaire. D’abord, la figure utopique de l'homme nouveau, débarrassé de toute attache familiale ou confessionnelle, tel que le portait l'idéal révolutionnaire. Ensuite, la figure défensive de l'être anonyme, tenant secrètes ses origines, voire de l'homme sans généalogie, semblable à la brebis Dolly. Enfin, celle rêvée d'un être si profondément acculturé, si bien fondu dans la culture globale et parlant si bien le " globish ", qu'il serait véritablement un autre. Il y a là une tension critique entre le désir d'accéder au statut de " personne " et le risque de n'être plus personne, tout juste un clone ou un numéro, vierge de toute histoire et de tout ancrage local. Telle est la dialectique de l'anonymat auquel aspire, tout en souhaitant y échapper, l'individualisme contemporain.

\section{La possession}

Le dernier des motifs de l'aliénation est la possession, qui désigne ici la relation patriarcale, machiste et même marchande à la femme, et qui induit sa possession maritale et sexuelle. Je l'entends aussi dans la dimension pathologique, comme lorsqu'on dit de quelqu'un " qu'il est possédé ", dimension que recouvrent l'obsession de la virginité féminine et la fascination inverse pour la femme libérée et sexuellement avertie.

Entre la maman et la putain, Rachid El-Daïf explore les attentes contradictoires dont le corps féminin est investi et la schizophrénie qui en découle dans le monde arabe - mais pas seulement, nous n'en sommes pas exempts non plus en Europe! En tout cas, je dis bien " arabe " et non pas " musulman ", car cette obsession de la virginité des femmes est un des éléments de l'archaïsme des vendettas qui minaient les familles chrétiennes décrites dans Cher Monsieur Kawabata et Learning English. La possession devient néanmoins le motif central de Qu'elle aille au diable, Meryl Streep! et Fais voir tes jambes, Leïla!. Elle y est traitée sur un mode ironique, voire burlesque, où le grotesque et le ridicule le disputent au pathétique et au tragique.

Dans Qu'elle aille au diable, Meryl Streep!, un narrateur du nom de Rachid s'inquiète de la vertu de sa jeune épouse et la soumet à des pratiques inquisitoriales quand il soupçonne qu'elle n'était pas vierge, comme il l'espérait, lors de son mariage. Dès lors il investit son corps et se livre sur elle à une investigation physique libidineuse d'une obscénité absolue, n’hésitant pas à la droguer afin de pouvoir l'inspecter en toute impunité et même à jouir d'elle en profitant de sa torpeur. La 
possession croise ici le motif de l'occupation, et d'ailleurs le corps de l'épouse n'est rien d'autre, pour son mari, qu'un appartement ou un objet. Elle est " mon vêtement, mon lit, ma demeure, ma volupté ", ditil, et il ajoute qu'à travers elle " [mon] espoir était d'avoir une maison, à moi tout seul, où je rentrais quand je voulais, d'où je sortais quand je voulais ». Cela ne l'empêche pas de souhaiter qu'elle soit également délurée, pour qu'elle comble ses propres appétits sexuels, et comme elle se montre, somme toute, assez sensuelle, il commence à soupçonner sa vertu. Comment peut-elle connaître ou désirer certaines pratiques sexuelles si elle ne les a pas expérimentées avant, avec d'autres? L'inquiétude puis le poison de la jalousie le gagnent.

Symétriquement, le narrateur de Fais voir tes jambes, Leïla! est très heureux d'avoir une petite amie dégourdie. Elle satisfait ses désirs intimes et l'emplit d'aise en exaltant le sentiment de sa propre virilité. Mais comme tout cela a lieu hors des liens du mariage, pas question qu'elle devienne son épouse, elle en est indigne! Cette inégalité de droits entre les hommes et les femmes, rien ne l'atteste mieux que le motif récurrent de ces hommes qui, après avoir couché avec des femmes, les abandonnent, non sans sarcasme ni mépris: eux-mêmes les ont privées par avance des qualités attendues d'une épouse, à savoir une dignité qui se confond à leurs yeux avec la virginité qu'ils viennent de leur ravir. Mais la responsabilité de cette situation incombe aux femmes, trop amoureuses ou trop naïves, quand les hommes se sentent libres d'agir comme ils le souhaitent, y compris comme des salauds!

Ainsi le narrateur de Qu'elle aille au diable, Meryl Streep! tente de violer une jeune couturière sans en ressentir le moindre remords. De même, celui de Fais voir tes jambes, Leïla! ravit la virginité de la femme avec qui son père, veuf, souhaite se remarier, dans le but de faire échouer ce mariage: il redoute que les biens dont il se sent l'héritier légitime soient aliénés au profit de cette nouvelle épouse ou de sa descendance. Il n'hésite pas à demander à sa petite amie de prodiguer des services sexuels à son père, afin de l'éloigner de son projet de mariage, et il se comporte vis-à-vis d'elle en véritable maquereau. Pour autant, aucun des deux ne perçoit l'abjection de ses actes, aucun ne ressent la contradiction qui mine son comportement. S'ils violent, maquereautent ou prennent la virginité des femmes, ils ne font que satisfaire les prérogatives qui, à leurs yeux, sont légitimes eu égard à leur sexe et à l'idée qu'ils se font d'eux-mêmes. Mais en agissant ainsi, ils deviennent à leur tour obsédés par la "pureté " qu'ils réclament de celles dont leurs propres conduites leur font soupçonner la vertu. 


\begin{abstract}
$* * *$
Les quatre motifs de l'aliénation que j'ai brièvement exposés mettent toujours en scène une crise des territoires de l'appartenance, qu'il s'agisse du corps, de la langue, de la famille restreinte ou étendue, de la communauté confessionnelle, voire du pays et de son histoire. Toujours, le conflit se noue entre soi et l'autre, l'espace intime et l'espace public, la tradition locale et la culture globale, l'individu et le groupe. Et toujours il cherche à se résoudre dans la quête d'un lieu préservé et pur, gage d'une intégrité préservée. Il n’en est pas de plus fantasmatique que le corps de l'épouse vierge, qui devient ainsi la parabole d'une utopie, un territoire étranger à l'histoire, incarné en une personne que l'on est seul à habiter. Mais il n’en est pas de plus réel que le corps politique d'une démocratie qui porterait haut l'idéal de son propre cosmopolitisme et où chacun serait respecté dans la singularité de son histoire individuelle et de son origine, comme le Liban a rêvé, un temps, d'en être le modèle.
\end{abstract}

Rien ne structure mieux ces contradictions que la langue, et aucune langue ne possède à l'égal de l'arabe ce statut séparé, qui lui vient de son origine coranique et donc sacrée. Le "sacré » désigne à l'origine un territoire séparé et inviolable. Ainsi s'explique la révérence du narrateur de Cher Monsieur Kawabata à l'égard de la langue arabe, dont il vante les ornements et les tournures à son interlocuteur absent et étranger. Mais Rachid El-Daïf souligne là, avec ironie, les occultations et les censures d'une langue qui, par certains aspects, refuse d'affronter la réalité profane. D’où le souhait de la jeune épouse de Qu'elle aille au diable, Meryl Streep! de connaître les mots anglais ou français qui évoquent le sexe, comme si elle ne pouvait avoir qu'une langue étrangère à son corps pour en dire le désir ou le plaisir, ou comme si elle devait préserver la langue arabe des souillures que porteraient avec eux les mots du sexe. D’où aussi, et de façon inverse, le désir exprimé par une femme occidentale éprise d'un jeune homme libanais de disposer des mots qui lui permettront de lui dire, en arabe, "remplis-moi ", afin qu'aucune barrière ne vienne s'interposer entre son corps et sa langue.

Si la figure de l'aliénation est celle d'un désordre et d'une souffrance, elle trouve sans doute son lieu d'élection dans cette disjonction de la langue et du corps, du vécu et du dit. Voudrait-on être anonyme (et ainsi avoir droit au secret) que notre nom nous trahirait. Voudraiton préserver son intimité qu'il nous faudrait néanmoins la dévoiler, 
comme l'épouse de Qu'elle aille au diable, tout au long d'un interrogatoire obsessionnel. Voudrait-on parler que certains mots nous seraient refusés dans notre langue, voire que toute possibilité d'entente dans notre langue serait désormais bannie, comme le manifeste le narrateur de Cher Monsieur Kawabata. Tout cela signale, en creux, la puissance qui est dévolue au langage et la portée critique de la littérature. Car elle seule restitue une parole, en l'incarnant en un corps, au plus près de la vérité singulière d'une existence vécue. Rien de plus. Ni de plus nécessaire.

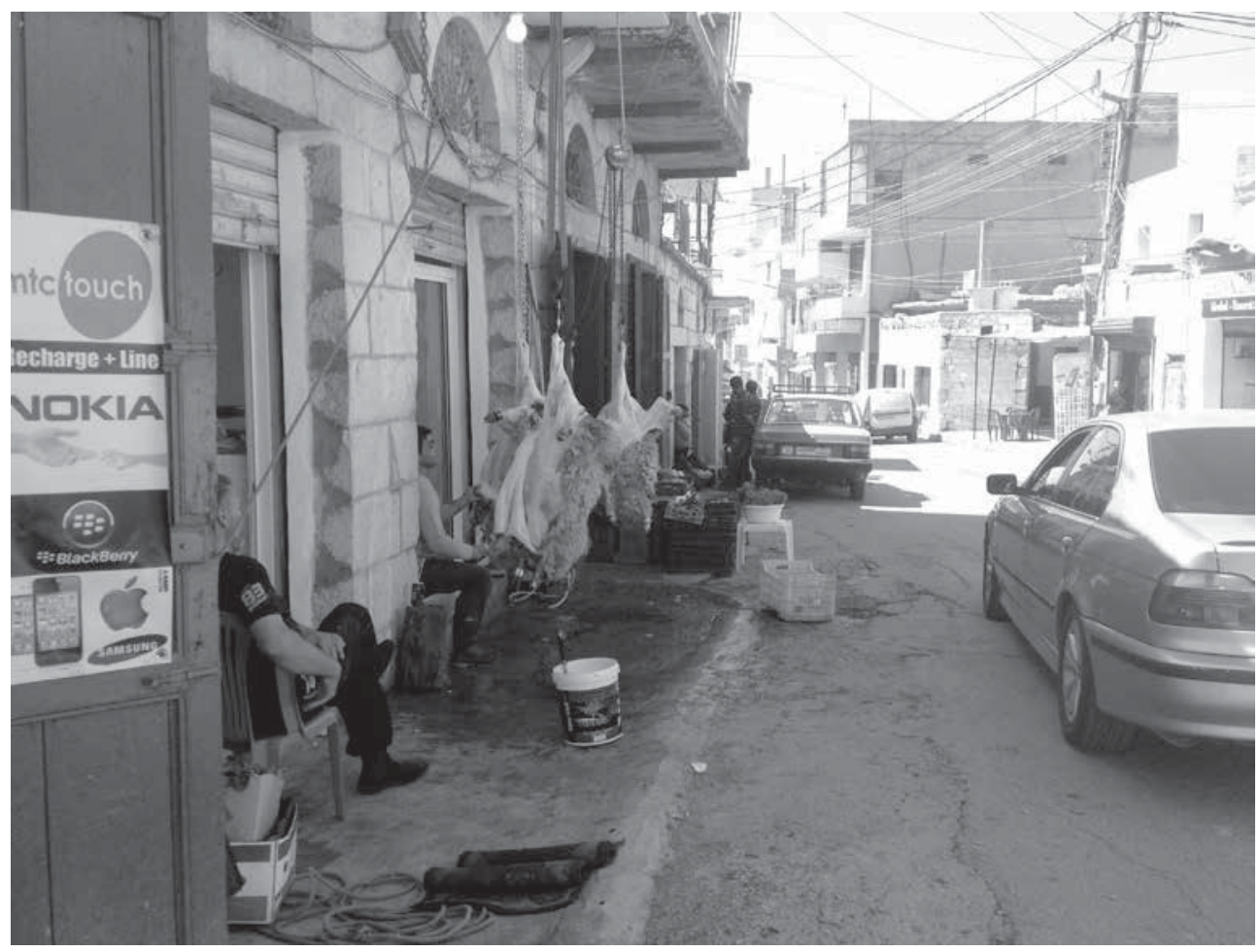

Rue commerciale à Ehden, ville natale de Rachid El-Daïf au nord du Liban 
Rachid El-Daïf - Le roman arabe dans la tourmente de la modernisation

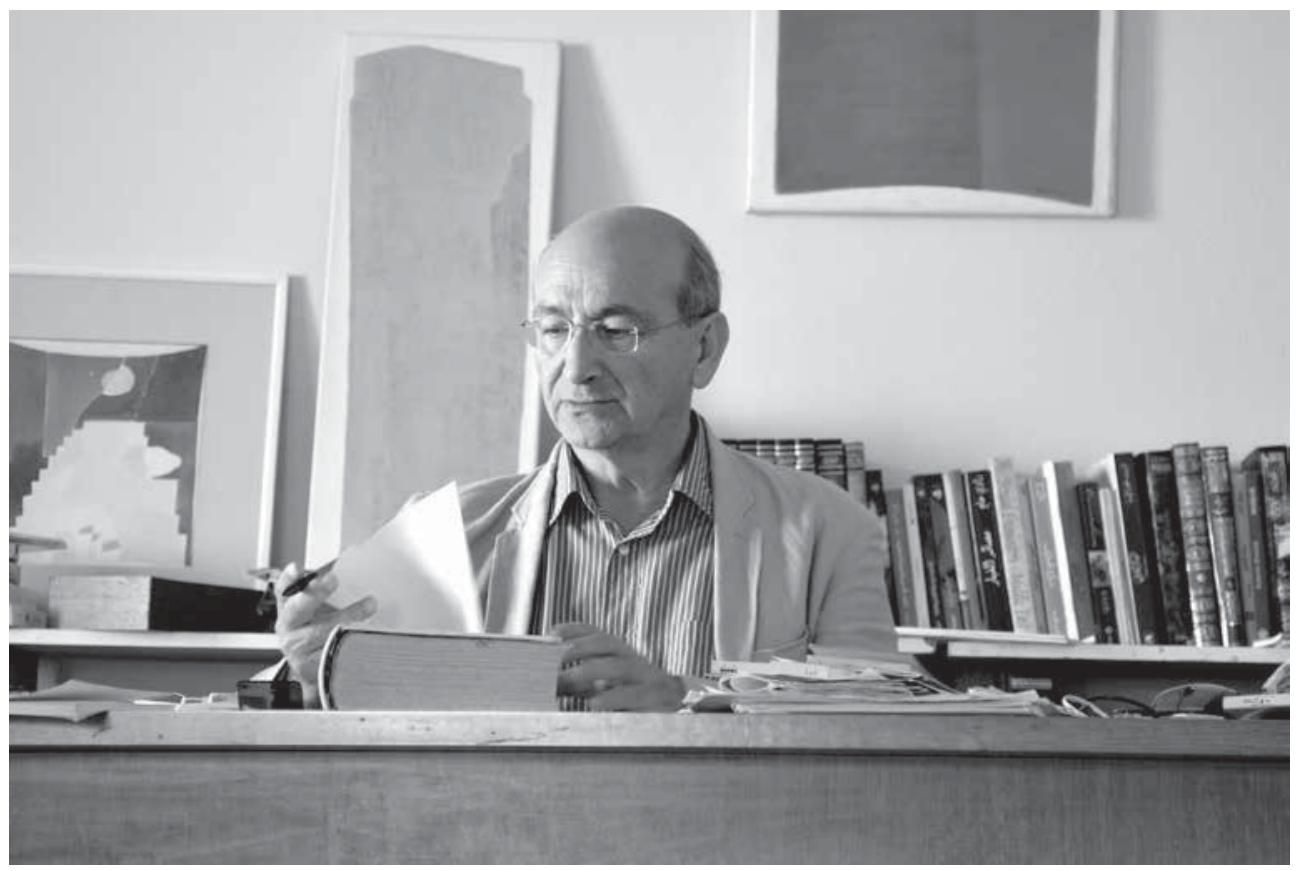

Dans son bureau à Ehden 


\title{
2 \\ Le Phénix fabule L'autofiction chez Rachid El-Daïf

\author{
Vincent Colonna
}

\author{
Car tu fleuriras comme un phénix ${ }^{1}$ \\ (Ps. 90, v. 13)
}

Quel symbole plus expressif que le Phénix, pour désigner la figure de l'auteur dans sa création? Comme l'oiseau du Soleil, son plumage promet mille irisations et échappe toujours à la perception; comme lui, il meurt avec chaque œuvre, pour renaître dans une autre composition, et l'immortalité règle son existence; comme le Phénix enfin, malgré son invisibilité, des choses essentielles lui sont attribuées, un savoir ultime du monde et des êtres. Dans Madame Bovary, dont le sous-titre est Mœurs de province, où se trouve Gustave Flaubert? Quels sont les signes de sa présence dans le roman? Comme Dieu, il est partout et nulle part.

De cette présence-absence du scripteur, de l'esquive permanente de la représentation auctoriale, le philosophe Jacques Derrida a tiré une riche et féconde suite de métaphores: la différance, le supplément, la dissémination. Plus loin dans le temps, la critique littéraire née de Roland Barthes et de Maurice Blanchot avait varié à l'infini sur cette évanescence de l'écrivain, au point d'en faire un topos de la modernité, le destin supposé de toute véritable littérature.

Vous doutez que les paradoxes de l'écriture puissent s'associer à cet oiseau fabuleux qui séjournait tantôt en Arabie, tantôt en Égypte, tantôt

1. Pour ce verset mis en exergue (13 du psaume 90 ou 91, tout dépend des éditions), j'adopte l'interprétation de Tertullien. Les traductions modernes ont tendance à lire: $t u$ fleuriras comme un palmier. Voici l'explication de Paul-Augustin Deproost: "Là où les versions latines du psaume 91 imposeront finalement la traduction "palma" désignant ainsi le palmier, homonyme grec de l'oiseau fabuleux, Tertullien lit encore un texte qui latinise le phoînix de la Septante, et qui lui permet d'authentifier le symbole mythique dans une citation biblique pour appuyer sa foi dans la résurrection ». in " Les métamorphoses du phénix dans le christianisme ancien ", Folia Electronica Classica (Louvain-la-Neuve) $-\mathrm{N}^{\circ} 8$-juillet-décembre 2004. 
en Phénicie (le Liban actuel)? Écoutez la fin du Poème du Phénix attribué à Lactance, qui date du $\mathrm{IV}^{\circ}$ siècle de l'ère chrétienne. Ne dirait-on pas qu'elle exprime la condition de l'écrivain, fils de ses œuvres?

Afin de pouvoir naître, il aspire à mourir

Il est son propre fils, son héritier, son père.

Il est tout à la fois nourricier et nourri;

Il est lui et non lui, le même et non le même,

Conquérant par la mort une vie éternelle.

\section{Fabulation de soi}

Il est pourtant une constellation de traditions, où loin de se cacher, le Phénix trottine sur la scène textuelle, devient un personnage de l'histoire, interpelle le lecteur. On pense au procédé de la représentation in figura, technique fameuse durant la Renaissance, par laquelle le peintre apparaissait dans le tableau: le Caravage qui avait l'habitude de prêter son visage à ses sujets. On songe à une manière de théâtre dans le théâtre: L'Impromptu de Versailles, dans lequel Molière fait répéter sa troupe. On évoque les travestissements par lesquels l'écrivain emprunte un masque, au travers duquel sa communauté l'identifie sans ambiguïté: la tradition de l'élégie érotique romaine ou, à partir du $\mathrm{XVIII}^{\mathrm{e}}$ siècle, du roman personnel.

Le topos de la mort de l'auteur n'est donc qu'une utopie littéraire, liée au paradigme structuraliste et plus avant, à une fascination quasi-religieuse pour l'écriture qui envahit les belles-lettres occidentales à partir des années 1890 et dont Mallarmé reste la plus formidable incarnation. Parallèlement, mais souterrainement, un autre courant artistique frémissait, une autre utopie attendait patiemment son heure. Il fallut la décrue structuraliste pour qu'elle s'épanouisse, et qu'on prenne conscience qu'elle puisait ses racines dans le passé de l'histoire littéraire mondiale. Au lieu de vanter la disparition de l'auteur, cette autre utopie en prônait la fictionalisation

Cette fabulation de soi se retrouve à toutes les époques; elle n’a rien à voir avec l'idée occidentale d'un sujet psychologique, n'est pas le fruit de la tradition intime ni de la psychanalyse. La plus haute antiquité en dévoile des exemples. Des érudits assurent que certains scribes égyptiens codaient leur nom propre dans leur écriture, afin de survivre au flux des générations. Une figure de rhétorique dénommée en grec ancien ethopoeia désignait cette usurpation d'identité: le dieu Hermès visitant en rêve Agamemnon, sous l'apparence de Nestor, dans l'Iliade; 
et, selon ma lecture personnelle, Platon s’abritant derrière Socrate, pour défendre ses idées sur la cité et les essences intelligibles.

Dans la littérature arabe, Avicenne, Ibn Arabi, Sohrawardi, al-Maarri, sont des Phénix que les lecteurs ont pu voir passer dans leurs écrits poétiques ou mystiques, sous leur propre nom ou sous un nom d'emprunt.

\section{Typologie}

Depuis trois décennies, le mot " autofiction " signifie cette constellation textuelle, dans laquelle l'écrivain s'enrôle dans sa fable, adopte les atours d'un personnage fictif, selon les modes les plus disparates. Pour permettre de cheminer dans ce fouillis pour ainsi dire galactique (le corpus comprend plusieurs centaines de textes, peut-être des milliers), j'ai proposé ailleurs un instrument de navigation, une sorte de boussole ${ }^{2}$ : une typologie permettant de trouver sa route dans cet espace dont l'exploration commence à peine. Cette typologie n'a pas la prétention de modéliser toutes les fabulations auctoriales ${ }^{3}$ possibles, avec les stratégies qui les inspirent; sa finalité est de fournir des points cardinaux.

Quatre directions créatives peuvent ainsi être décrites:

- l'autofiction biographique, dotée d'un registre vraisemblable, qui rassemble la tératologie autobiographique et le roman personnel; Colette, Genet ou Khaïr-Eddine en sont des exemples;

- l'autofiction chamanique, qui comprend tous les textes imaginaires, fantastiques ou mystiques, qui figurent leurs auteurs comme héros; Avicenne ou Dante l'illustrent;

- l'autofiction intrusive où l'auteur n'apparaît que sous la forme d'un narrateur extérieur à l'histoire (hétérodiégétique dans le jargon technique); voyez Fielding, Stendhal ou Coetzee;

- l'autofiction spéculaire, qui montre l'écrivain exclusivement dans un coin de sa toile, comme Hitchcock, silhouette traversant ses films; ainsi chez Rabelais ou Cendrars dans Bourlinguer.

2. Sur l'universalité de l'autofiction, je me permets de citer mon mémoire de thèse: L'Autofiction, Essai sur la fictionalisation de soi en littérature, in http://tel.archivesouvertes.fr/docs/00/04/70/04/PDF/tel-00006609.pdf et sur ma page Academia. edu. Pour la typologie de l'autofiction, voyez mon Autofictions \& autres mythomanies littéraires (Auch, Tristram, 2004, pp.67-147.

3. Cette théorie des forces actoriales est appliquée à l'autofiction dans un article publiée en italien, par la revue Algama (Rome, $n^{\circ} 29$, avril, 2015): Autofinzioni, affabulazioni $e$ istinti [Autofiction, Affabulation et instincts]. Une version française existe sur ma page Academia. edu. 
C'est dire que cette gerbe de pratiques n'est pas un " genre » simple, mais un ensemble complexe, soit un archigenre, soit une prénotion qu'il faudra éclater en différentes catégories; l'avenir tranchera. Car si dans cette deuxième décennie du XXI ${ }^{\mathrm{e}}$ siècle l'autofiction est à la mode; si dans les suppléments littéraires européens, il n'est guère de semaine sans que ce mot-valise ou un substitut soit utilisé pour classer tel roman personnel, ou situer une autobiographie qui revendique le "mentir vrai » (comme Goethe au début de Poésie et vérité), cette propension ne concerne pas tous les types de fabulations de soi. L'engouement porte sur la direction biographique de l'autofiction, les autres formes étant soit refoulées, soit négligées, soit méconnues.

\section{Voix}

L’originalité de Rachid El-Daïf commence ici. Bien que son éditeur français l'ait rangé sans précision dans la catégorie " autofiction ", son œuvre n'appartient pas au type le plus visible, le plus commenté. À son contact, le poéticien doit repenser ses outils. Car il est clair que son projet s'est construit dans la plus grande solitude, qu'il ne doit rien au courant littéraire qui émerge dans l'Europe des années 1990.

Avant d'envisager cette excentricité, citons le prière d'insérer qui accorde le label autofictif à Cher Monsieur Kawabata 4 (1995; tr. fr. 1998); car la manière dont les livres sont présentés au public n'est pas anecdotique, elle oriente leur lecture et leurs effets; elle canalise leur réception, détermine leur influence. Si l'éditeur (Rousseau lui-même) n'avait pas clamé urbi et orbi que La Nouvelle Héloïse était l'histoire à peine déguisée de l'auteur, le roman autobiographique ou personnel n'aurait peut-être pas existé; car jamais le XVIII ${ }^{\mathrm{e}}$ siècle n'avait connu un livre traduit en autant de langues, acheté par autant de gens.

Voici ce qu'annonce le quatrième de couverture de la première fiction de soi pleinement assumée de l'écrivain libanais:

Dans cette correspondance prétexte avec le prix Nobel japonais, initiateur d'une recherche inquiète entre tradition et modernité, Rachid ElDaïf explore brillamment les voies de l'autofiction, éclairant son écriture, volontiers tragique, de pages qui pourraient être comiques, n’étaient leur ironie grinçante.

Sans doute, ce n'était pas son premier roman, ni sa première excursion dans la littérature personnelle. Comme poète, El-Daïf avait

4. Cher Monsieur Kawabata est traduit par Yves Gonzales-Quijano, chez Actes Sud ,1998. 
forcément expérimenté le " Je lyrique "; cette première personne du singulier mêlant l'intime et la multitude, que permet seul le poème. Devenu narrateur, il n'oublia pas cet usage retors du "Je " poétique: Passage au crépuscule, publié près de dix ans avant Cher Monsieur Kawabata, possédait le caractère d'un roman autobiographique, et l'auteur conservait le sentiment d'avoir donné un avatar de lui-même, dans ce héros hanté par la mutilation:

Dans mon roman « Passage au crépuscule », le premier traduit en français, je décris mes peurs d'être assassiné ou mutilé par la guerre qui se déroulait à Beyrouth. Je décris mes cauchemars. Je décris ce qui m'est arrivé et ce qui est arrivé à des dizaines de milliers de Libanais et de résidents au Liban. Je décris ce qui m’est arrivé et ce qui peut m’arriver ${ }^{5}$.

Mais dans ce texte, l'écrivain tâtonnait encore, cherchait un style d'énonciation personnel. Si la prose avait déjà atteint sa maturité, si le sujet touchait un motif récurrent de son œuvre (la guerre du Liban), la narration restait marquée par les procédés avant-gardistes des années 1980; l'influence du " Nouveau Nouveau roman » était patente. L'écrivain hésitait encore à livrer son prénom en pâture à la publicité; il n'y avait pas de « Rachid » dans ce texte, seulement un héros-narrateur anonyme. J'ignore si l'écrivain libanais était alors un fervent partisan de Tel Quel et du groupe d'écrivains français gravitant autour de cette école (ou d'un cercle équivalent dans le monde arabe), mais nombre de techniques d'écritures y ramènent: l'impersonnalité du personnage principal, la décontextualisation, la répétition de séquences d'action, l'effort herméneutique exigé du lecteur.

\section{Japoneries}

C'est dans la confession fabulée de 1995, placée sous les auspices du grand écrivain nippon, que Rachid El-Daïf trouva sa voix la plus singulière. Pour la première fois, le narrateur se prénomme " Rachid » et le public découvre ce ton guilleret, mixte de prosaïsme et de dévoilement roués, qui va empiler, de roman en roman, des paroles de plus en plus scandaleuses. À partir de Cher Monsieur Kawabata, la bienséance est déchirée à belles dents, les limites de l'impudeur reculent avec chaque publication.

Sans jamais quitter le domaine du vraisemblable, « Rachid » se livre à une confession interminable sur ses parents, sa famille élargie ou

5. Le commentaire de Rachid El-Daïf sur Passage au crépuscule vient d'un entretien personnel avec l'auteur, réalisé en décembre 2014. 
lui-même; une confession qui trahit les convenances de l'ethos arabe contemporain, le respect de l'intimité des parents, le silence sur son épouse et sa sexualité. "Rachid " ne commet pas des actions rares ou particulièrement mémorables, il ne sort pas du registre des vies ordinaires. Mais les méfaits qu'il avoue, les pensées débridées qu'il reconnaît, relèvent soit de l'indicible, soit de cette sphère privée cantonnée aux amis masculins. Toutes les actions ou pensées de "Rachid " sont inavouables dans la sphère publique: abandonner l'honneur du nom familial, coucher avec la promise de son père, peloter une couturière venue ajuster des rideaux, revendre une voiture défectueuse.

Oui, l'aventure de la fabulation de soi commence, chez El-Daïf, avec cette lettre-hommage à un écrivain qui a su se rendre universel sans jamais renier les particularités de son pays d'origine. Un programme, et une ambition, littéraires qui deviendront ceux de Learning English, Qu'elle aille au diable, Meryl Streep!, Fais voir tes jambes, Leïla! Tous ces romans s'engageront dans la route ouverte par ce coup de maître.

\section{Anti-roman}

L'agencement de la narration sera marqué par ce livre inaugural. Car aucun de ces textes ne sont des romans au sens canonique, ce sont plutôt de longs monologues d'un dénommé " Rachid "; tous présentent l'aspect discontinu et sinueux de la missive envoyée à Kawabata. Il y a dans chacun d'eux, une " oralité " qui les rend propices à la scène (Qu'elle aille au diable, Meryl Streep! a été réécrit pour le théâtre par Mohamed Kacimi; Rahim Lasri a adapté et mis en scène Fais voir tes jambes, Leïla!). Non pas qu'ils soient à proprement parler dramatiques; ils manquent tous d'une histoire chapeautant nettement l'ensemble, d'une intrigue principale qui " fait la pyramide ", comme dirait Flaubert. Ce sont des "apartés » de la société libanaise; pas des drames ni des tranches de vie.

Cette poétique explique que les autofictions de Rachid El-Daïf, comme les " anti-romans " de Nathalie Sarraute, ne soient pas à proprement parler lues par les foules; mais sont les œuvres d'un écrivain d'abord réservé aux lettrés, aux lecteurs raffinés en attendant que ces codes littéraires se banalisent. La multitude peut apprécier un monologue à condition que ce dernier renferme une structure " aspirante ", qui l'agrippe et l'oblige à suivre un rail narratif. Cette " aspiration ", seule une structure régulière l'autorise, un agencement avec exposition, unité d'action, conflit majeur, yoyo de la situation du héros, dénouement. Notez bien que cette aspiration ne tient pas à la nature du sujet, 
nul besoin d'événements extraordinaires pour obtenir cette captation, il faut seulement provoquer la curiosité ou la surprise, puis l'entretenir par des procédés éprouvés depuis Les Mille et une nuits. Or, si l'une de ces deux émotions existe bien au début des cinq autofictions de Rachid El-Daïf, elles ne sont pas entretenues de manière conventionnelle: en refusant l'unité d'action, en diluant l'intrigue principale dans des micro-histoires secondaires, en multipliant les conflits comme autant de méandres, l'écrivain prend le parti de la prose contre celui de la narration (je parle des traductions françaises, il se peut qu'en arabe cette prose si singulière, si scandaleuse, suffise à " aspirer " le lecteur).

Comme le Nil en crue, fleuve par excellence du Phénix, l'écriture déborde de toute part, se répand sur tellement de plans, que la curiosité du lecteur n'est plus métabolisée en inquiétude, cette émotion-mère du récit qu'on appelle aussi suspense. Le plaisir du texte, émotion subtile et rare, prend sa place:

J'attire d'avance votre attention, Monsieur Kawabata, sur le fait que je peux donner l'impression de passer d'un sujet à l'autre, mais je suis certain que vous comprendrez vite pourquoi, et même que ce style ne sera pas sans vous faire forte impression ${ }^{6}$.

$\mathrm{Ou}$ alors, quand le régime narratif semble plus régulier, l'écrivain offre un dénouement incertain, escamoté, ce qui produit un effet disruptif très en amont de la clausule. Quand un nœud dramatique est véritablement installé, le texte demeure indifférent à son dénouement, à la résolution de l'enjeu. Dans Fais voir tes jambes, Leïla!, sans doute la plus narrative de ses autofictions, le problème du mariage du père de " Rachid » constitue l'enjeu principal. Mais il reste suspendu au terme du roman et les lignes secondaires sont également inabouties: la vente de la "Subaru ", voiture qui occupe tant de place dans l'existence du héros, la suite de la liaison de " Rachid " et de Leïla, le résultat de son union physique avec la laideronne $\mathrm{Z}$.

\section{Critique sociale}

Bien sûr, le caractère dérangeant de ces textes est également en cause; leur puissance comique n'est pas à la portée de tous, seulement des esprits libres; pour les esprits routiniers, ces romans risquent de paraitre plus attristants que divertissants. Rarement on aura autant parlé de sperme en littérature; rien n'est épargné sur les détails de la

6. Cher Moniseur Kawabata, ibid., p. 18. 
vie sexuelle d'un homme, à tous les âges de son existence; une séance de masturbation de " Rachid » adolescent, devant une amie de sa mère, dont il ignore si elle est endormie ou exhibe délibérément ses fesses; sa peur de souiller ses draps ou son pantalon; comment il "vole " son plaisir à son épouse endormie, etc.

Mais au-delà de ces aspects que les convenances répugnent à supporter, ces romans évoquent des opinions et des attitudes que l'on préférerait garder sous le boisseau, qui ne grandit pas l'homme arabe ordinaire, qui exhibe son machisme et son conformisme délétères. Tout en semblant adopter son point de vue, "Rachid " expose la plus féroce dénonciation des conservatismes et des égoïsmes du monde arabe contemporain, vu à travers un prisme masculin. Quand le héros explique benoîtement, dans Fais voir tes jambes, Leïla!, qu'il ne compte pas épouser Leïla parce qu'elle est trop libérée sexuellement, alors qu'il est pour elle « son prince » et qu'il n'a jamais été aussi heureux avec une femme, tout est dit.

Bien des turpitudes et des défaillances de cette civilisation s'éclairent d'un jour neuf. Cette critique est d'autant plus ravageuse que Rachid El-Daïf ne fait aucune différence entre les confessions: les musulmans ne sont pas plus stigmatisés que les chrétiens maronites, tous sont mis dans le même sac; la religion de son héros et de ses autres personnages restant le plus souvent dans le vague. Cette ellipse sur la religion des personnages se retrouve chez beaucoup d'écrivains libanais, comme s'ils se l'imposaient par devoir, pour refuser l'organisation confessionnelle de leur pays. Mais dans le cas d'El-Daïf, ce silence donne plus de poids à sa critique sociale, elle signifie que les comportements en cause s'enracinent dans une civilisation, et non dans une religion, comme le clament trop souvent les médias occidentaux.

\section{Langue}

Le néophyte qui croirait, pour autant, que ces cinq romans sont ésotériques, écrits dans une prose affectée, inutilement compliquée, tomberait dans l'erreur. Le choix d'une langue « orale ", qui évite les tours sophistiqués de la langue littéraire écrite, qui contourne la solennité inhérente au verbe oratoire arabe, est la caractéristique la plus constante du style de Rachid El-Daïf dans ce cycle autofictif. Tous les arabophones sont unanimes à reconnaître qu'il y a dans son œuvre un talent unique pour exprimer le prosaïsme du parler quotidien libanais, un pur génie pour épurer la langue arabe de son decorum poétique ou rhétorique. Très rares sont en effet les écrivains arabes qui ne cèdent 
pas aux séductions rhétoriques qu'un immense patrimoine littéraire, des odes pré-islamiques à Adonis, a sédimenté dans la langue du Coran. Le grand stylisticien Léo Spitzer évoquait un « effet de sourdine de la langue classique " française: l'effet inverse, un éclat et un ton ronflant qui touche au sublime, habite la langue arabe classique. Le francophone doit se rappeler le style de Bossuet ou certaines pages de Chateaubriand pour approcher cette grandeur.

Cette solennité a construit le prestige de cette langue, mais les religieux et les politiques en usent et en abusent. Au dire des connaisseurs, l'influence politique du leader Hassan Nasrallah, qui dépasse largement la communauté chiite libanaise, tient pour beaucoup dans cet usage grandiloquent du verbe arabe. En le refusant, en le déjouant, Rachid El-Daiff dénonce cette aliénation des mots, manipulation idéologique qui prétend remplacer la réalité par le miroitement d'un imaginaire verbal. C'est à une entreprise de déprogrammation de la solennité de l'arabe que s'attaque Rachid El-Daïf, une entreprise plus politique qu'il n'y paraît, car elle pousse le lecteur arabophone à quitter les mirages d'une culture irréelle, pour revenir aux rêves et aux larmes réels de ses contemporains. Le Phénix renonce à son plumage extraordinaire pour se rapprocher du bestiaire commun, pour parler la langue de la multitude.

Naturellement, ce trait si remarquable, si innovant dans la littérature arabe, échappe en grande partie à la traduction. Mais un lecteur attentif peut en avoir le soupçon, car les réflexions sur les tournures de l'arabe, leur force et leur emprise sociale, ne manquent pas dans les romans de Rachid El-Daïf, en particulier dans Cher Monsieur Kawabata:

Rien, ce sont seulement les mots qui m’entraînent. Et combien en ont-ils entraîné comme moi? Des générations !

Ces mots qui nous faisaient croire - vous comprendrez plus tard la raison de ce pluriel — que nous tenions, grâce à eux, le monde entier entre nos mains.

Même si j'ai compris ensuite — remarquez que je retrouve le singulier — que nous étions plus adroits avec les mots qu'avec la réalité [...]

Nous chevauchions le verbe, persuadés de chevaucher l'Histoire.

\section{Excentricité}

Ce qui éloigne les fabulations de Rachid El-Daïf du type le plus souvent pratiqué en France, c'est que ses autofictions sont en tension entre le type biographique et le type chamanique. $\grave{A}$ ma connaissance, cette situation est assez exceptionnelle, les précédents ne sont pas légion. 
Expliquons. Les romans où un certain " Rachid " emprunte le rôle de personnage principal et de narrateur proposent un contrat " réaliste » au lecteur et respectent les normes du vraisemblable. Sans doute, certaines séquences échappent à cette description, par exemple quand « Rachid " découvre son double au début de Cher Monsieur Kawabata, mais ces moments sont rares. Le choix esthétique dominant relève du réalisme: les rues et les villes citées appartiennent bien au Liban, les faits liés à l'actualité (Israël bombardant Beyrouth, la visite de Jospin en Cisjordanie) sont ceux du monde contemporain, les marques de voiture n'ont rien d'imaginaire; tout comme l'évolution religieuse et sociologique du Liban que « Rachid " prend soin de relever.

Impossible, pourtant, de caser l'œuvre de Rachid El-Daïf dans le type biographique, d'y voir un romancier personnel à la manière de Henry Miller ou de Blaise Cendrars. Le "Rachid" mis en scène dans chaque autofiction n'a pas le même état civil; il ne renvoie pas au même individu historique, ni à la même entité symbolique (l'anthroponyme "Rachid»). L'histoire de sa parentèle se modifie d'un écrit à un autre: dans un récit, il est enfant unique, alors que dans un autre il possède une sœur; dans l'un son père meurt avant sa mère, alors que dans un autre c'est l'inverse, etc. Il existe autant de "Rachid » que de romans, "Rachid " est un multiple de lui-même. Cette transgression des lois biologiques fait obstacle à une lecture testimoniale de ces textes; impossible de les déchiffrer comme des documents historiques ou intimes. Chaque fabulation propose une version-monde contradictoire de l'homme « Rachid»

Cher monsieur Kawabata.

Dans la mesure où je suis, moi, Rachid en personne, l'auteur et le sujet de ce discours, permettez-moi de vous faire part d'une remarque - non pas à vous personnellement, car vous savez cela mieux que quiconque, mais à un possible lecteur de cette missive.

Moi, Rachid, qui m'adresse à monsieur Kawabata, je ne suis pas tout à fait Rachid - l'auteur. Ce que j'ai en commun avec celui-ci, c'est qu'il m’a créé [...].

Pourtant, il ne s'agit pas d'une soumission totale, mais au contraire partielle, ou encore relative. Et c'est précisément ce qui me permet de me distinguer clairement de lui.

À nouveau, les paradoxes de l'écriture surgissent, mais ce n'est plus sous la forme d'une différance, pour parler comme Derrida. Désormais le vertige vient d'un excès identitaire, d'une identité monstrueuse. Au 
lieu d'être invisible, le Phénix devient trop visible, des simulacres envahissent l'oiseau du Soleil.

Ce geste est extrêmement original. Car dans la pratique chamanique de l'autofiction, la démarche la plus commune est de se construire un double magnifié, une entité symbolique imaginaire mais unique, singulière. Ainsi l'écrivain polonais Witold Gombrowicz, qui prend bien soin, dans les trois tomes de son Journal, et dans chacun de ses incipits romanesques, de marquer la continuité de l'individu mis en scène. Au début de La Pornographie, on peut ainsi lire:

Je vous conterai une autre de mes aventures, et sans doute la plus fatale.

Rien de tel chez Rachid El-Daïf, il n’y a pas le projet de construire un " Rachid " légendaire, un double élevé au rang de figure mythique. Le « Rachid » représenté est une entité particulière, et non singulière, un nom commun à plusieurs êtres différents. Un philosophe analytique donnerait cher pour avoir la possibilité de décortiquer la situation ontologique de cette entité.

\section{Chamanisme}

Pourquoi le rapprocher du type chamanique d'autofiction? On sait que le chaman visite en rêve les esprits et les dieux, combat les démons pour ramener la santé et la prospérité à sa communauté. Cet individu se trouve donc en relation avec des forces ou des dimensions essentielles pour sa société 7 . Le caractère le plus marqué de l'autofiction chamanique, c'est cette proximité avec l'essentiel, le primordial. Or dans les romans qui nous intéressent, les motifs dominants d'El-Daïf sont des histoires de famille et de couple, vues sous l'angle de leur stabilité, de leur incapacité à se maintenir, à perpétuer la société dont ils sont le tuf primordial.

Les «Rachid" représentés, quoique différents, ne sont pas des intellectuels distants ou critiques des valeurs dominantes de la société libanaise et plus largement du monde arabe. Bien au contraire, ce sont tous des individus ordinaires, attachées aux idéaux et aux sentiments les plus répandus du Moyen-Orient: l'homme est le chef du foyer, la femme doit arriver vierge au mariage, l'Occident va à sa perte en niant la différence sexuelle et en reniant le mariage, etc. Comme ces valeurs, souvent convoquées par les différents "Rachid", ne sont

7. La théorie des forces inhérentes aux personnages est développée dans mon essai L'Art des séries télé, 2: l'adieu à la morale, Paris, Payot, 2015, 2 partie, chapitre 6. 
jamais associées à une religion précise, elles prennent d'autant plus de poids - même si parfois le lecteur affranchi, travaillé par une nouvelle forme de name dropping, aimerait en savoir davantage sur leur origine confessionnelle.

Tout se passe donc comme si l'écrivain Rachid El-Daïf se projetait dans un héros-narrateur nommé "Rachid", différent à chaque fois par son passé biographique, mais identique dans son profil sociologique, dans son ethos. Comme le chaman, El-Daïf s'aventure au cœur de la civilisation arabe, en expérimentant des situations familiales ou amoureuses qui ne sont pas les siennes dans l'existence sérieuse. Il se démultiplie dans l'homme arabe contemporain, en adoptant ses valeurs et son point de vue sur le monde, pour le pousser au bout de sa logique, souvent calamiteuse et hilarante. Ces voyages imaginaires ne sont pas sans risque; car en fabulant son existence, le Phénix dévoile l'intimité de ses parents, les déroutes de sa vie sexuelle et de ses rapports sociaux - toutes choses mal vues dans la culture arabe, construite sur l'honneur et la retenue. On peut penser qu'une des premières fonctions de cette démultiplication des " Rachid " est de protéger l'écrivain réel. En multipliant ses avatars, il paye de sa personne, met en jeu son nom propre, démontre qu'il passe au crible son univers en commençant par lui-même; mais aussi, il évite de devenir une cible, la tête de turc des traditionalistes et des conservateurs, car le " Rachid » figuré n'est jamais le même.

D'un point de vue philosophique, ce "Rachid " multiple est très satisfaisant car on sait bien qu'il existe en chacun de nous des personnalités multiples. Mais le but littéraire est autre, il apporte une bien plus grande liberté d'expression, d'exploration; alors qu'un " Rachid " unifié, immuable dans son état civil, enfermerait bien vite le héros dans un cadre trop étroit, danger auquel n’a pas échappé Henry Miller, dans sa série de romans personnels, malgré sa prose somptueuse. L'écrivain risque alors de créer une caricature, un poncif.

\section{Exploration}

Dans un autre essai, j'ai suggéré que l'autofiction chamanique permettait un voyage au sein des forces culturelles de sa propre civilisation. Restituer en détail cette théorie m’obligerait à un long détour, d'autant qu'elle est compliquée ici par la traduction. Disons pour abréger que l'attrait des personnages fictionnels, en littérature, comme au cinéma ou dans la série télé, leur pouvoir de nous affecter, l'attachement que 
l'on ressent pour eux, tient à leur association à des catégories culturelles, dont certaines sont universelles.

Un protagoniste " jeune " transporte avec lui l'attraction de la jeunesse, qui existe dans toutes les civilisations, quoique sous des visages différents. Nul besoin de décrire longuement ce personnage, l'adjectif " jeune " suffit à l'associer à cette catégorie, à générer un affect lié à la jeunesse: l'amour de sa beauté, l'exaltation venue de son énergie, la tendresse ou le rire devant sa naïveté, la peur de sa sauvagerie. Pensez au personnage de Leïla dans le roman d'El-Daïf; aux connotations qu'elle véhicule, simplement parce qu'il est écrit qu'elle avait vingt ans. Cette force de la jeunesse s'exerce dans tous les genres de récit; peu importe leur statut, populaire ou lettré.

Sous une forme logiciste, trop rigide et trop dichotomique, le parcours génératif de catégories sémantiques qu’Algirdas Julien Greimas distinguait au travail sous la narration, donne une idée de ce mécanisme. La limite de ce modèle greimasien est de ne pas prendre en charge la puissance d'ébranlement émotionnel de ces catégories. Une sémiotique des passions a été proposée pour remédier à cet inconvénient, mais elle reste encore peu opératoire. Pour cette raison, je préfère me situer dans un autre cadre de pensée, construit par Marcel Mauss et Emile Durkheim.

Comme dit à peu près Mauss, le plaisir narratif est le plaisir d'un moment passé en compagnie des dieux et des héros. Dans l'Iliade ou dans Gilgamesh, les dieux sont des personnages à part entière; dans la narration moderne, les dieux se dépersonnalisent, ils se confondent avec les forces impersonnelles de la culture. Les émotions générées par la fiction résultent de forces impersonnelles mises en conflit à travers les personnages: la jeunesse, l'argent, l'honneur, le conformisme social, le pouvoir masculin, la virginité, le bonheur, la famille, et bien d'autres.

La fabulation chamanique a ceci de remarquable, dans le vaste ensemble des genres fictionnels, qu'elle explicite ce mécanisme des forces attachées aux personnages; elle ne se contente pas de l'utiliser, elle l'affiche, elle l'exhibe. "L'auteur " devient une de ces forces, jetée à la rencontre d'autres forces; il se mélange aux puissances culturelles qui irriguent sa civilisation. C'est bien sûr une utopie, comme celle de "la mort de l'auteur", car un écart incompressible demeure entre des forces impersonnelles et générales d'une civilisation et la catégorie d'auteur, qui est plus une fonction ou un statut qu'une force. Il n'empêche que sous la couverture d'un personnage vicaire, l'écrivain 
affronte d'autres protagonistes dotés de forces; part à la rencontre de ces puissances qui nous poussent, nous les humains, à agir.

En se démultipliant en autant de " Rachid " fictifs, El-Daïf entame autant de périples dans la culture libanaise et arabe, plonge dans cette boîte noire des forces qui gouvernent le comportement de ses contemporains. L'autofiction chamanique est en ce sens une catabase, un voyage aux Enfers et au Paradis, un genre littéraire appartenant à la littérature gréco-romaine mais aussi à la littérature médiévale, qu’elle soit byzantine, latine ou arabe. Dans La Divine comédie, les deux genres se confondent puisque c'est le poète Dante qui accomplit ce voyage.

Le choix de Yasunari Kawabata comme Virgile par El-Daïf n'a eu rien d'accidentel. Cet écrivain lui donnait l'exemple d'un art romanesque figurant les traditions avec un mélange de suavité impassible et de subtilité cruelle. Il n’y avait rien de personnel dans la littérature romanesque de Kawabata, sa narration sagement composée lui était étrangère, comme son goût pour les héros hiératiques et la Nature ne se retrouvait pas dans l'œuvre de son " disciple » libanais. Mais son rapport si intime aux habitus nippons, l'amour immense qu'il portait à son peuple, cohabitait avec une férocité sans pitié à l'encontre des parties nécrosées de sa civilisation.

Dans Cher monsieur Kawabata, un seul livre du Nobel japonais est cité, Le Maître ou le tournoi de Go. Plus qu'aucune autre œuvre, ce récit d'une mémorable partie de go jouée en 1938 et narrée par un journaliste, représente la lutte perdue d'avance de la tradition et de la modernité, l'ouragan de la mondialisation. Et sans doute est-ce là un thème cher à Rachid El-Daïf que ce face-à-face avec l'Occident, dont l'individualisme, le féminisme et la domination planétaire à la fois fascinent et inquiètent les héros réunis sous le prénom " Rachid ».

Mais El-Daïf n'est pas un écrivain engagé, son œuvre n'a pas pour but de suggérer d'autres comportements, de présenter au lectorat arabe des figures positives. De ses périples chamaniques, il ramène des mots, des tournures de phrases, des situations, des réactions, des affects et les organise en tableaux offerts à la délectation. Que ces tableaux fassent réfléchir, donnent à penser, qui en douterait? Mais cette réflexion reste sous la responsabilité du lecteur ou du critique. Pour construire son nid, le Phénix choisit en Phénicie un arbre élevé, dit encore Lactance. 


\section{3 \\ 'Awdat al-almānī ilā rushdi-hi \\ Retour sur une fiction d'un mauvais genre \\ Yves Gonzalez-Quijano}

En 2006, il y a de cela bientôt dix ans, Rachid El-Daïf publiait Le Retour de l'Allemand à la raison, un texte évoquant les semaines qu'il avait passées en compagnie de Joachim Helfer, son "partenaire " dans le cadre d'un échange culturel intitulé le Divan occidental-oriental. Pour sa part, l'écrivain allemand allait "répondre " par un commentaire intercalé dans la traduction allemande du texte arabe. Les deux publications provoquèrent à l'époque des échanges, parfois acerbes, entre les deux protagonistes et plus largement au sein des milieux littéraires locaux et internationaux. Il est aujourd'hui plus facile de revenir sereinement sur cette question, surtout après la publication, au début de l'année 2015, de What makes a man? Sex talks in Beirut and Berlin ${ }^{1}$, un ouvrage qui en reprend de nombreux aspects. Pourtant, le seul fait de s'interroger sur la manière dont on doit évoquer ce qui s'est passé alors prouve, s'il en était besoin, que tout cela n'appartient pas encore totalement au passé. Des questions restent ouvertes, en attente de réponses capables d'emporter la conviction.

À l'époque, choisissant à dessein une formulation aussi vague que possible, j'avais parlé de "bataille " (mawqa'a), en reprenant un mot utilisé, avec un peu d'humour ou en tout cas de distance, par une partie de la presse littéraire arabophone ${ }^{2}$. "Polémique » ou " affaire » semblent trop forts, d'autant plus que les deux parties - surtout la libanaise à mon sens — avaient manifestement voulu juguler l'incident.

1. Rashid Al-Daif \& Joachim Helfer, What Makes a Man? Sex Talk in Beirut and Berlin, translated by Ken Seigneurie and Gary Schmidt, Center of Middle Eastern Studies, The University of Texas at Austin, 2015.

2. Voir ci-dessous: Yves Gonzalez-Quijano, « Un choc dans la bataille: le clash des programmes culturels », Culture et politique arabes, 12 novembre 2006. 
" Incident », précisément, est un terme qui évoque immédiatement une dimension diplomatique, voire politique, assez étrangère à ce qui s'est effectivement déroulé, même si le différend - autre mot possible aurait pu assez facilement mal tourner. Le terme exact pour évoquer ce qui s'est passé échappe, d'autant plus qu'il est difficile de réduire ces " événements » à un domaine précis: il ne s'agit pas exactement d'une querelle littéraire, mais c'est bien de littérature dont il est question; des problématiques sociales et politiques y sont associées — la mémoire des massacres de la Seconde Guerre mondiale, l'affirmation homosexuelle pour ne citer que les plus évidentes - mais leur interprétation exige d'être rapportée à différents contextes, du plus restreint, celui des politiques culturelles, au plus large, les rapports entre "l'Orient» et «l'Occident".

Après toutes ces années, que reste-t-il de cette " histoire »? Parmi tous les commentaires possibles, il me semble que cette dernière pose de manière très riche la question de la définition générique d'un texte. Une question qui renvoie, plus largement, à un aspect en définitive assez rarement évoqué dans les études littéraires, celui des paramètres sociopolitiques à l'œuvre dans la taxonomie critique. Comme on le verra par la suite, le désaccord sur les lectures possibles du livre de Rachid El-Daïf intitulé 'Awdat al-almânî ilâ rushdi-hi, publié en 2006 aux éditions Riyad El-Rayyes, de même que sur ses conséquences littéraires (le texte de Joachim Helfer) ou non - trouvent leur origine dans le statut qu'il convient de lui donner. De mon point de vue, cette difficulté à s'accorder sur la nature de ce texte est moins une question technique, conséquence d'une imprécision terminologique, que le résultat d'un " jeu " littéraire (au double sens du mot en français, qui renvoie à quelque chose de ludique mais aussi au mode de fonctionnement d'une mécanique), jeu littéraire qui renvoie lui-même aux bornes sociologiques de la représentation fictionnelle.

\section{Les nombreux noms d'une fiction}

Sans prétendre le moins du monde à l'exhaustivité, je m'efforcerai dans les lignes suivent d'évoquer quelques-unes des dénominations proposées pour le texte de Rachid El-Daïf en question. Même si des termes seront mentionnés dans leur langue d'origine, ce commentaire, donné en français, charrie avec lui les connotations associées à leur traduction. Sachant qu'il m'est impossible de procéder autrement, il n'en est pas moins nécessaire de tenter de m'en justifier, en considérant notamment que ce passage d'une langue à une autre illustre 
précisément ce dont il est question dans cet article, à savoir le(s) jeu(x) possible(s) entre des taxinomies dont la construction repose sur des héritages culturels.

En arabe, le court texte écrit par Rachid El-Daïf se présente d'une manière quelque peu ambiguë. En effet, l'édition originale n'offre aucune indication générique (couverture ou pages intérieures). En revanche, dans la liste des œuvres qui accompagne les publications suivantes (chez le même éditeur) le titre 'Awdat al-almānī il rushdihi est systématiquement suivi de la mention riwāya ("roman»). Néanmoins Ken Seigneurie, qui a lui-même traduit cet ouvrage en anglais, mentionne quelque part que l'auteur considère qu'il s'agit bien d'une "biographie romancée " (novelized biography ${ }^{3}$ ). Dans le contexte des études littéraires francophones cependant, cette dernière expression est aujourd'hui presque désuète. Pour parler des "vies d'auteur " - ce qui, clairement, est bien le cas avec cet ouvrage dont le sujet principal est l'écrivain allemand - on lui préfère désormais la notion de "fiction biographique ». Comme l'écrivent Robert Dion et Francis Fortier, la fiction biographique se présente moins comme une reconstitution fidèle que comme une entreprise d'interprétation qui explore toutes les ressources de la narration et de la description. À travers ces pratiques biographiques, le biographe peut dès lors s'inscrire comme écrivain ou comme romancier, en revendiquant « la suprématie de l'écriture sur le matériau référentiel ${ }^{4} »$.

Pour l'anglais, les textes réunis dans le volume qui a récemment proposé la traduction des « essais » de Rachid El-Daïf et Joachim Helfer, accompagnés de plusieurs études et commentaires critiques, mettent en évidence un phénomène intéressant: en dépit de la parfaite connaissance du sujet qu'ont les différents auteurs (ou peut-être à cause de cela précisément), on remarque une profusion d'expressions. Si la « note de l'éditeur " (publisher's note) évoque un "récit/témoignage romancé " (novelized account), Andreas Krass, auteur d'un des commentaires, propose quant à lui deux expressions totalement différentes: celles de "reportage semi-fictif» (semi fictitious reportage, p. 244) et celle

3. Ken Seigneurie, "Chiasmus on Masculinity in Rashid al-Daif's How the German Came to His senses ", Paper presented at the Modern Language Association Annual Convention: Philadelphia, December 2006. URL: http://www.navidkermani.de/media/ raw/Rezensionen Diwan Engl.pdf.

4. Citation donnée par Damien Fortin in « Les « fictions biographiques » contemporaines, un nouveau ssacre de l'écrivain'? ", Acta fabula, vol. 12, n 4, Essais critiques, avril 2011, URL: http://www.fabula.org/revue/document6259.php. 
de « reportage de la taille d'un livre " (book-lenght reportage $e^{5}$, p. 245). Pourtant, l'éclairage le plus séduisant est dû au traducteur du texte allemand qui se fixe sur le terme générique donné par Joachim Helfer à sa " réponse ". En allemand, celle-ci est en effet accompagnée du sous-titre protokol, un terme qui n'est pas repris dans la traduction anglaise mais qui est en revanche commenté de manière fort instructive par Gary Schmidt dans les réflexions qu'il propose, toujours dans cet ouvrage ${ }^{6}$.

\section{Les conséquences d'un " protocole de lecture "}

Avec le mot protokol, doté d'un sens très particulier dans l'histoire littéraire allemande, Joachim Helfer met en place ce que l'on appellera en français, en utilisant une expression assez proche mais qui doit être entendue très différemment, un "protocole de lecture ", en d'autres termes la programmation, au sein du texte, des significations et des valeurs que celui-ci doit révéler au moment de son usage par le lecteur. Dans la tradition germanique, un protokol était presque genre littéraire à part entière, une variante du récit documentaire objectif, souvent à visée sociale car il est associé au monde du travail ${ }^{7}$, particulièrement en vogue vers le milieu du siècle dernier dans l'ancienne République démocratique allemande.

Nulle place pour la fiction avec ce type de protokol, ce qui d'ailleurs est assez conforme aux demandes formulées dans le cadre du programme " Divan occidental-oriental », qui suggérait aux acteurs d'écrire une sorte de rapport sur les échanges réalisés à cette occasion. Toujours est-il qu'en plaçant son texte sous cette définition générique, Joachim Helfer légitimait sa propre démarche, laquelle consistait à reprendre le déroulé du texte de Rachid El-Daïf en y ajoutant ses propres commentaires, avec un sous-titre - " parole contre parole " - en forme de jeu de mots aux significations complexes, fort bien exploitées, là encore, dans le texte de Gary Schmidt ${ }^{8}$.

5. Gary Schmidt, "Writing, Reading and Talking Sex: Negociating the Rules of an Intercultural Language Game ", in Rashid Al-Daif \& Joachim Helfer, What Makes a Man? Sex Talk in Beirut and Berlin, op. cit., p. 245 et 246. Le terme anglais de reportage, homonyme du français, ne doit pas être confondu avec l'allemand reportagen, " rapport ".

6. Gary Schmidt, "Writing, Reading and Talking Sex: Negociating the Rules..., art. cit., p. 228 et sq.

7. Gary Schmidt, «Writing, Reading and Talking Sex: Negociating the Rules..., art. cit., . 235. 8. Rede gegen Rede en allemand, au sens de "contre-discours" si les deux derniers mots sont attachés, ou encore discours $v s$ discours, comme une sorte de match libanoallemand, tel que l'auteur a choisi de l'écrire. 
Accusé de refuser le dialogue à travers ce procédé, l'écrivain allemand s'en est défendu avec vigueur, en écrivant par exemple en réponse à mes propres critiques qu'il ne s'agissait pas, de sa part, d'un refus de la parole de son alter ego libanais, mais, bien au contraire, " du sens même de la dialectique ${ }^{9}$ ". Quand bien même on accepterait de le suivre sur ce point, cela n'enlève rien au fait que sa démarche avait pour conséquence de nier en totalité le projet fictionnel créé par Rachid El-Daïf. Dès lors que Joachim Helfer installait son propre système textuel sous le sceau du protokol, et sans qu'il soit possible, à aucun moment, de noter la moindre distance ou ironie par rapport à ce choix, il mettait en place un protocole de lecture qui ôtait au texte commenté, à savoir 'Awdat al-almānī ilā rushdi-hi, toute réalité fictionnelle. Il fallait d'ailleurs que la proposition de Rachid El-Daïf soit réduite à un document quasi ethnographique pour que son propre commentaire, en allemand, n'apparaisse pas immédiatement comme un geste parfaitement odieux, aucun auteur ne pouvant prétendre intervenir de la sorte dans un texte littéraire créé par un autre.

\section{Le « non " à la fiction}

Si l'on accepte ce qui vient d'être suggéré à propos de la nature générique des deux textes, il devient loisible d'affirmer que l'essentiel de qui s'est joué entre les deux écrivains relève d'une perception différente de la nature du texte qui les lie l'un à l'autre. Au travers du dispositif adopté dans sa réponse écrite, Joachim Helfer opposait un " non " sans appel à la tentative de Rachid El-Daïf de jouer son propre jeu littéraire, depuis toujours marqué (et plus encore depuis qu'il se consacre à la forme romanesque) par la dimension autofictionnelle. Plutôt que de répondre à une commande en produisant un récit de circonstance, l'auteur libanais avait en effet choisi - par sincérité de mon point de vue - de l'intégrer totalement à son œuvre, selon sa propre manière littéraire caractérisée par un jeu incessant et souvent ironique entre le "véritable » auteur et son double narratif. Le titre lui-même, avec cet écho du prénom Rachid que l'on retrouve dans le substantif rush (raison) portait la trace de ce rapport complexe et sans nul doute quelque peu pervers (au sens figuré du terme bien entendu!) entre différents registres de la voix narrative, tantôt sincère, tantôt déloyale, tantôt immédiate, tantôt réfléchie - ou encore " raisonnable " pour

9. Yves Gonzalez-Quijano, « Un choc dans la bataille: le clash des programmes culturels ", art. cit. 
reprendre un qualificatif en lien avec le titre de ce texte. Peut-être parce qu'elle ne lui était pas assez familière, Joachim Helfer n'a pas perçu l'ironie (totalement dénuée de la moindre cruauté selon ma perception personnelle) dont fait preuve le narrateur du Retour de l'Allemand à la raison. Fermé au jeu fictionnel, enfermé peut-être aussi dans le ressenti d'une relation personnelle, qui se trouvait par ailleurs configurée par le dispositif mis en place dans ce programme d'échanges, son propre texte, de par son protokol, renvoie systématiquement à la "vraie personne " de l'auteur libanais, en coupant court à toute échappée vers ce qu'il est convenu d'appeler la « fiction biographique ».

Pourquoi une telle attitude de la part d'un auteur tel que Joachim Helfer, dont la sensibilité littéraire ne saurait être mise en cause? À l'image de nombreux autres commentaires suscités par les échanges entre les deux écrivains, les études proposées dans la traduction anglaise de leurs deux textes laissent entendre que le caractère sensible de la question homosexuelle explique, à défaut de les justifier, la vivacité et l'acidité de la réponse allemande, inévitablement vécue par la partie libanaise comme une sorte de "mise en pièces" de son travail d'écriture. En d'autres termes, ce serait la question du genre, au sens donné aujourd'hui à ce terme par les sciences sociales, qui expliquerait cette difficulté à entendre l'Autre, faute d'accepter de se glisser dans son dispositif narratif.

Sans la récuser totalement, cette explication, des années après les faits, continue à ne pas me satisfaire. Plutôt qu'un malentendu essentiellement provoqué par une perception différente des différences non biologiques entre les genres, je persiste à penser que ses véritables raisons tiennent en réalité bien davantage à la question générique, en tant qu'elle détermine la nature du texte et sa lecture. Faute d'une réelle complicité herméneutique entre les deux acteurs, la production de Rachid El-Daïf a pu paraître aux yeux de Joachim Helfer, littéralement parlant peut-être mais surtout au sens figuré de l'expression, "d'un mauvais genre »: comme quelque chose qui "n'était pas à faire " du point de vue textuel, le jeu générique choisi par l'auteur libanais n’ayant pas été partagé par son « compagnon » au sein de ce programme littéraire.

Sans accorder plus d'importance qu'il ne convient à ce qui s'est passé entre les deux écrivains, leur échec à se comprendre rappelle une vérité toute simple: entre Ouest et Est, quoi qu'on en veuille et quelles que soient les bonnes intentions, les échanges se font "en un certain sens ». En effet, il n'est pas encore venu le jour où l'on aura, 
en vis-à-vis du Divan occidental-oriental goethien, un nom arabe, un programme grâce auquel un ministère, libanais ou même arabe, offrira à des auteurs, allemands ou même européens, l'occasion de découvrir et d'échanger avec leurs homologues arabophones. Dans le cadre de cette circulation qui n'est égale qu'en apparence, il est inévitable que se produisent des ruptures de courant, des courts-circuits en somme.

Les lecteurs francophones, d'ailleurs, en sont quelque part les victimes à leur tour, puisqu'il y a fort à craindre que ce texte de Rachid El-Daïf reste longtemps encore sans traduction française. En effet, les règles de cet échange, telles que posées par le Divan occidental-oriental, voudraient que son éventuelle traduction soit accompagnée du texte de Joachim Helfer. Outre le fait qu'un éditeur français éventuellement intéressé par ce projet ne souhaitera pas forcément l'associer au texte écrit pas son homologue allemand, le fait que ce dernier ait choisi de le reprendre, en le commentant, rend une telle éventualité encore plus aléatoire puisque cela reviendrait à dupliquer le texte de Rachid El-Daïf, dans une double traduction, à la fois directement depuis l'arabe et depuis sa traduction en allemand sur laquelle s'appuie l'essai de Joachim Helfer. Il est vrai que c'est le parti qui a été pris dans l'édition anglaise, au risque de réduire ce texte à une sorte de document quasi ethnographique sur la perception des questions sexuelles par deux écrivains de culture différente. C'est d'ailleurs ce qu'énonce le titre retenu pour cette édition, duquel a disparu (y compris dans le paratexte) toute indication de son genre littéraire: What makes a man. Sex talks in Beirut and Berlin...

\section{ANNEXES}

1. Le texte du billet publié sur cette question dans mon carnet de recherches en ligne, Culture et politique arabes.

2. Ma propre traduction des pages finales (90-92) du Retour de l'Allemand à la raison.

\section{Un choc dans la bataille: le clash des programmes culturels}

12 novembre 2006

Pour en parler, la presse littéraire arabe, à l'instar du romancier égyptien Gamal Ghitany, utilise un mot un peu rare: mawqa’a (موقعة): quelque chose comme «le choc dans la bataille». Rien de plus qu'une anecdote pourtant, sans nul doute douloureuse pour ses protagonistes. Mais révélatrice, aussi, de la difficulté à mener un " dialogue à travers les cultures ». 
Tel était bien pourtant l'intention du programme culturel lancé par les autorités allemandes sous un titre inspiré du célèbre texte de Goethe, Le Divan occidental-oriental. Dans le contexte immédiat de l'après 11 septembre, le projet consistait à provoquer des échanges entre écrivains allemands et arabes: trois semaines dans le monde arabe pour les Occidentaux, auprès d'un de leurs « collègues ", égyptien ou libanais par exemple, six semaines à Berlin pour les Orientaux.

Le romancier libanais Rachid El-Daiff a été associé à un partenaire allemand, Joachim Helfer, pour cette expérience de " divan ». Y compris dans un sens psychanalytique, que Goethe n'avait certes pas imaginé, puisque ce jeune auteur vit, ouvertement, une homosexualité dont sa littérature se fait largement l'écho. (Je précise d'entrée que, faute de connaître l'allemand, les informations que je donne ne sont que celles que l'on peut lire dans la presse arabophone ou francophone.)

Comme il l'écrit dans le texte qu'il a tiré de cette rencontre - ce qui était un des buts du projet - les six semaines passées en compagnie de Joachim Helfer ont été l'occasion pour R. D. (il se nomme souvent ainsi dans ses propres textes) de partager le quotidien d'un homosexuel déclaré. Une réalité déconcertante comme il s'en explique, comme il le confesse même, pour un homme élevé dans une société qui n’aime rien tant que " fêter et célébrer la virilité ».

Ce bref récit (quatre-vingt-dix pages qu'on espère voir rapidement traduites en français), R. D. l'a appelé Le Retour de l'Allemand à la raison (عودة الالماني إلى رشده), titre qui mérite quelques éclaircissements. Il résume en quelque sorte l'anecdote du livre, l'invité occidental cédant, à Beyrouth, aux charmes d'une certaine Ingrid (allemande, donc...), à qui il fait un enfant. Mais il exprime également, par cette manière de présenter les choses, la façon dont R. D. se réjouit, compte tenu de ses propres codes d'Oriental (avec son propre « alphabet » comme il l'écrit), de la " conversion ", même passagère, vécue par son alter ego allemand en terre libanaise.

Le titre choisi par R. D. fait également référence à un autre texte, bien connu en français mais à travers une traduction qui ne peut pas laisser percer l'allusion. La Prairie parfumée où s'ébattent les plaisirs, le célèbre " manuel d'érotologie islamique " (sic!) a pour titre originel en arabe « Le retour de l'homme âgé à sa jeunesse " (رجوع الشيخ إلى صباه (ر) Même si on ne lit pas l'arabe, la parenté des deux titres se devine. Faire allusion à ce texte, c'est bien entendu, chez l'oriental R. D., assumer (mais discrètement et non sans auto-ironie) sa virilité arabe triomphante après la déstabilisante découverte d'une homosexualité assumée. 
(On peut même risquer une interprétation supplémentaire: le mot, peu fréquent là encore, qu'a utilisé R. D. pour désigner la " raison », ou plus précisément la " conduite raisonnable ", al-rushd, n'est certainement pas par hasard un écho sonore de propre prénom. À mon sens, il ne faut pas y lire une sorte de forfanterie, une manière d'affirmer la certitude de ses choix, y compris sexuels, en posant l'adéquation rush / Rashid mais plutôt un aveu par R. D. des fragilités de son être intime, avant de se proclamer, trop facilement rasséréné, faussement rassuré, confirmé dans sa propre " bonne conduite " par le comportement, enfin " viril » de cet étranger si étrange.)

En janvier 2006, R. D. a publié son texte, en arabe, non sans avoir sollicité et obtenu l'accord préalable, pour livrer des choses aussi personnelles, de Joachim Helfer. Celui-ci a publié le sien, tout récemment, en allemand (il est sorti à l'occasion de la foire du livre de Francfort). Mais sans demander à R. D. son accord, ou plutôt, si l'on en croit les récits, sans respecter les termes de l'accord convenu.

Apparemment blessé par ce que R. D. avait écrit sur lui, Helfer a en effet choisi de répondre à son livre en en commentant la traduction allemande. Mais il l'a découpé en fragments qu'il a arrangés à sa façon, et il l'a accompagnée de très longs commentaires, particulièrement blessants. À ses yeux, R. D., à travers son texte, ne fait qu'illustrer l'incapacité (probablement congénitale) des machos arabes à accepter l'homosexualité. Mais le pire coup qu'il assène à R. D., c'est de l'accuser, ouvertement, de n'être qu'un antisémite, accusation qui, comme on ne le sait que trop, ne peut qu'assurer à celui qui la profère la complaisance du public occidental, et allemand en particulier...

Alors que Rachid El-Daïf avait livré un texte courageux, retraçant le récit intime d'une véritable interrogation sur l'étrangeté de l'Autre tout en reconnaissant ses propres limites à sortir de son alphabet culturel et moral, Joachim Helfer préfère se vautrer dans les pires clichés à propos des « Arabes".

Rachid El-Daïf terminait son texte, par ces mots:

Je me suis dit en moi-même, en leur disant adieu, qu'il faudrait que beaucoup de choses soient dites pour que tout soit clair entre les Arabes et les Allemands. Beaucoup de choses, portées par un réel et irrépressible désir.

Joachim Helfer donne à son commentaire un titre qui ne saurait dire plus clairement le refus de la parole de l'Autre:

L'homosexualisation du monde.

Parole contre parole.

Beyrouth - Berlin. 
Faut-il vraiment s'étonner de voir tourner court, et même " tourner vinaigre ", un " dialogue à travers les cultures » qui n'est fondé que sur de bonnes intentions et qui fait à ce point l'impasse d'une réflexion sur les données politiques des échanges, fussent-ils culturels?

(26/11/2006) M. Joachim Helfer me demande d'apporter les précisions suivantes, qui contredisent ce qui a été écrit dans la presse arabe: « Le texte de Rachid (El-Daïf) est publié dans son ordre original, et sans aucune modification. Je ne l'ai jamais accusé d'être un antisémite, ni d'être un macho, et n'ai pas fait la moindre allusion à aucune théorie de nature congénitale. Tout ce que j'ai fait, c'est de commenter son texte et de citer ce qu'il a pu dire, ou faire. Le sous-titre " Parole contre parole » ne signifie nullement un refus de son discours, mais, tout au contraire, le sens même de la dialectique »

\section{Rachid El-Daïf, Le retour de l'Allemand à la raison, p. 90-92.}

La première fois que je l'ai rencontré à Francfort, Ingrid, son amie, était avec lui.

Je lui ai demandé des nouvelles de N., resté à Berlin. Il m’a dit qu'il allait bien et qu'il me passait le bonjour. Je l'ai interrogé à propos de son ami, le jeune homme qu'il voyait. Il m’a répondu qu'il y avait du nouveau, mais que c'était sans importance et qu'il n’y avait pas lieu d'en parler.

Le temps nous était compté à Francfort et nous n'avons pas pu parler à notre guise. Ingrid l'accompagnait la plupart du temps, ce qui naturellement limitait notre liberté de parole entre hommes "complices ", mais nous avons déjeuné une fois tous les deux dans un des restaurants de la foire du livre et nous avons longuement discuté de notre expérience avec ce programme, le Divan occidental-oriental, qui nous avait réunis. Durant la discussion, l'idée a surgi que je raconte son expérience au Liban, telle que je l'avais vécue, de mon point de vue, à savoir l'expérience de sa rencontre avec une femme (Ingrid), son désir de lui faire un enfant, ou d'avoir un enfant d'elle, ou encore les deux à la fois, après une vie strictement homosexuelle, pendant vingt ans. Nous nous sommes mis d'accord sur le fait qu'il écrirait à propos de cette même expérience, selon son propre regard.

Compte tenu de sa nature et de sa personnalité - et compte tenu des miennes également - il n'était pas étonnant que nous nous soyons mis d'accord sur ce sujet. Pourtant, ce fut une surprise pour moi. Je sentais une sorte de gêne dans la mesure où ce qui lui était arrivé était très personnel, très intime. Écrire sur ce que j'avais vu, le publier, 
pourrait me gêner, me déranger. Ce que j'avais vu n'était pas forcément ce qui s'était passé dans la réalité car je l'avais certainement lu avec l'« alphabet » que je maîtrisais, je l'avais vu avec mon propre regard, je l'avais entendu avec ma propre façon d'entendre. Mais j'ai surmonté ce sentiment et j'ai décidé de me conformer à ce que nous avions décidé quelles que soient les erreurs que je pourrais commettre.

Joachim n'a eu qu'une recommandation, celle de ne pas blesser les sentiments de son amie Ingrid, de ne pas violer son intimité, de ne pas lui faire de mal en faisant allusion à elle de manière trop transparente... autant que possible.

Lors de ma dernière rencontre avec lui avant de rentrer à Beyrouth, Ingrid était présente. Je voulais m'entretenir avec elle de cela, lui demander comment elle voyait elle cette relation, si elle en était satisfaite ou non... Bien d'autres questions encore qui tournaient dans ma tête mais qu'il m'était presque impossible de poser. Comment commencer? Par quoi? Avait-elle envie d'une telle discussion? Partageait-elle mon désir d'en parler, souhaitait-elle répondre à mes questions, à mes préoccupations?

Je voulais parler avec elle, l'entendre s'exprimer, pour savoir ce qu'elle pensait, ce qu'elle ressentait, comment elle envisageait sa vie présente, son avenir, comment elle vivait le fait d'être enceinte d'un homosexuel qui était lié depuis si longtemps à un autre homme et qui essayait d'entretenir une relation stable, capitale, avec un jeune homme, tout en partant à la chasse d'autres hommes - ou en se laissant chasser par eux - comme Sader? Acceptait-elle cela vraiment? Ou bien ne voulait-elle de lui rien d'autre qu'une goutte de sa semence?

En leur faisant mes adieux, je me disais qu'il faudrait que beaucoup de choses soient dites pour que tout soit clair entre les Allemands et les Arabes.

Beaucoup de choses, portées par un irrépressible désir.

\section{Appendice}

Nous étions en novembre 2005, et ce livre était en cours d'impression quand j'ai rencontré Thomas Hartmann, le directeur du programme, qui m'a appris qu'Ingrid avait eu une fille.

Je le savais car j'avais rencontré Joachim en août. J’avais été invité à participer aux activités du festival international de littérature de Berlin et il m’avait présenté au public avec des mots très gentils. Le jour de mon arrivée, il m'avait invité à diner au restaurant Einstein, près du Grand Hôtel Esplanade, juste à côté de l'ancien mur. Ingrid était avec 
lui. Elle était enceinte, au milieu de son neuvième mois. Ils m’avaient annoncé qu'ils avaient choisi pour leur fille un nom arabe (je ne leur avais pas demandé pourquoi, mais j'imagine que c'était son idée à elle, peut-être pour que ce nom garde la trace du début de la conception de celle qui le portait, un souvenir de ce hasard au Liban!)

Par la suite, Thomas Hartmann me dit que la fille portait le nom de famille de sa mère, pas celui de son père. Il me dit aussi que Joachim vivait toujours avec son compagnon mais qu'il partageait son temps entre eux deux (entre son compagnon et Ingrid, avec la petite bien entendu), dans une sorte de "ménage à trois" comme disent les Français.

Thomas me suggéra d'écrire cet appendice pour compléter les informations, en m'expliquant que Joachim n'y voyait pas d'objection. 


\title{
4 \\ De l'autodistanciation Oppression, dérision et autodérision
}

\author{
Sobhi Boustani et Fatemeh Parchekani
}

Malgré la publication d'un recueil poétique ${ }^{1}$, de deux recueils de réflexions à tendance poétique ${ }^{2}$ et d'un livre d'historiettes (Unsī yalhū $m a^{\prime} a$ Rit $\bar{a}^{3}$ ) regroupant quatorze textes ou contes - comme Rachid El-Daïf les appelle lui-même ${ }^{4}$ - dominés par l'imaginaire et le merveilleux, c'est aux romans que l'auteur doit essentiellement sa réputation.

La guerre libanaise déclenchée en 1975 marque profondément ses premiers romans. Leurs différents thèmes s'inspirent, directement ou indirectement, de ce conflit qui bouleversa toute la génération à laquelle appartient l'auteur. Ce dernier, progressiste, milite, une fois ses études terminées, en faveur d'un changement de la structure sociopolitique du Liban. Cependant, les héros de ses romans sont écrasés par la monstruosité des événements. Démunis et impuissants face au déchirement de la société, ils s'enferment dans une angoisse qui les torture physiquement et moralement.

Il s'agit ici de s'interroger sur les manifestations de cette angoisse, et d'analyser à travers les romans de l'auteur, particulièrement Nāhiyat al-barā'a ${ }^{5}$ (Du côté de l'innocence) et Tistifil Meryl Streep ${ }^{6}$ (Qu'elle aille au Diable, Meryl Streep!), le lien de ce dernier à la dérision. L’analyse

1. Rachid El-Daïf, Hīna ḥalla al-sayf 'alā al-șayf, Beyrouth, Dār al-Fārābī, 1979, traduit en français par J. E. Bencheikh sous le titre L'Eté au tranchant de l'épée, Paris, Le Sycomore, 1979.

2. Lā shay'a yafūqu al-wașf (Rien n'est indescriptible), Beyrouth, Manshūrāt Lubnān al-jadīd, 1980; Ayyu Thaljin yahbuțu bi-salām, (Quelle neige tombe en paix) Beyrouth, Mukhtārāt, 1993.

3. Unsī yalhū ma'a Ritta- kitāb al-bālighīn, Beyrouth, al-Mu'assasa al-jāmi‘iyya li-aldirāsāt wa-al-nashr, 1983.

4. Al-Adāb, nº 3/4 mars/avril 1999.

5. Rachid El-Daïf, Nāhiyat al-barā'a, Beyrouth, Al-Masār, 1997.

6. Tistifil Meryl Streep, Riad El-Rayyes Books, Beyrouth, 2001, traduit en français par Edgard Weber sous le titre Qu'elle aille au diable, Meryl Streep!, Arles, Actes Sud, 2004. 
se focalisera, également, sur la mise en texte des différentes formes d'expressions littéraires de l'angoisse.

\section{Oppression et évasion illusoire}

Signe d'une forte déception, al-aqrāṣ al-munawwima ( les somnifères et les calmants ») assurent au personnage le moyen de fuir la réalité de la guerre en la gommant de ses impressions. Un univers de fantasmes et d'illusions se substitue à l'univers "vrai » qui neutralise toutes les capacités du héros.

Le narrateur héros de Fusḥa mustahdafa bayna al-nu'ās wa-al-nawm ${ }^{7}$ s'inscrit parfaitement dans ce cadre. En effet, une atmosphère oppressante règne dans ce roman. Le narrateur, de confession chrétienne, est forcé de partager son appartement situé dans un secteur à majorité musulmane de la capitale avec une femme chiite, parente du gardien de l'immeuble. Mère d'un enfant et enceinte, elle vient de perdre son mari à la guerre. Les événements l'ont obligée à quitter son village. À cette situation imposée par la seule logique de la guerre s'ajoutent les restrictions en matière d'eau et d'électricité. Étant donné que tout contact avec cette belle et jeune femme pourrait avoir de lourdes conséquences, le narrateur ou bien reste reclus dans sa chambre, ou bien fuit vers les cafés du quartier à l'ambiance parfois hostile, voire dangereuse. De l'appartement, normalement espace d'intimité et de quiétude, sourd une tension intenable, jusqu'à l'irrespirable. L'angoisse, la peur de la mort et de la mutilation hantent continuellement le héros, pris dans un contexte qui ne cesse de se compliquer. Les scènes génératices de malaise se multiplient. Dans la chambre, "la chaleur s'intensifie, aucune brise, tout mon corps nage dans la sueur, je commence à sentir l'oppression, l'étouffement » (p. 76).

Cette sensation d'étouffement et d'oppression se répète (p. 101, 102, 120 et 124). Les scènes de la mutilation du bras droit et de la jambe par les différentes machines de guerre, sont également itératives: "le sang coulait abondamment, et mon bras est coupé au niveau de l'épaule » (p. 52, 54, 61, 64, 98). "La répétition, selon Genette, est en fait une construction de l'esprit, qui élimine de chaque occurrence tout ce qui lui appartient en propre pour n'en conserver que ce qu'elle partage avec toutes les autres de la même classe, et qui est une abstraction ${ }^{8}$. "

7. Fusḥa mustahdafa bayna al-nu'ās wa-al-nawm, Beyrouth, Mukhtārāt, 1986, trad. par Luc Barbulesco sous le titre Passage au crépuscule, Actes Sud, Arles, 1992.

8. Gérard Genette, Figure III, Paris, Seuil, 1972, p. 145. 
L'itératif dans la narration exprime parfaitement l'univers réduit et oppressif dans lequel évolue le narrateur. Le roman s'achève sur cette phrase qui résume bien son impuissance:

Je me dirigeai vers l'endroit où se trouvent les somnifères, j'en pris une double dose et me jetai sur le lit en attendant que ces pilules fassent leur effet. (p. 125)

Dans Ahl al-zill ${ }^{9}$, roman de 76 pages, le narrateur, toujours sous le poids de la guerre, décide de se faire construire une maison au village, dans la montagne libanaise malgré la nette préférence pour la ville qu'il exprime à plusieurs reprises: « je n'aime pas habiter à la campagne, j'aime étouffer en ville. J'aime respirer l'air que respirent des millions de gens" (p. 20). La construction de la maison n'est en effet qu'un fil conducteur liant les divers sujets évoqués tout au long du roman. La maison est un rêve, un espoir de refuge quand la vie à Beyrouth devient impossible. Aucun effort n'est ménagé pour construire cette maison, qui apparaît dans les circonstances du moment comme l'unique moyen du salut. Parallèlement à ce rêve qui commence à se concrétiser, une troublante angoisse s'insinue chez le narrateur héros; le lecteur est amené à constater que cet espoir de salut n'était qu'illusion. Les vipères ( $a f^{\prime} \bar{a}$ pl. $\left.a f \bar{a} \mathfrak{c}\right)$, avec 108 occurrences du mot dans ce court texte, et les scorpions ('aqrab pl. 'qärib), avec 42 occurrences, symbolisent fortement cette oppression. Plus on avance dans la réalisation du rêve, plus l'angoisse gagne. Croyant mettre son fils à l'abri des vipères et des scorpions, le narrateur se retrouve habité d'une façon obsessionnelle par l'image de ces animaux. Entre fantasmes, illusions et description réelle, les scènes s'enchaînent et se succèdent, : "vingt scorpions autour de la maison et sur ses murs, cinq dans la chambre de l'enfant " (p. 29); «l'enfant dort dans son lit et sur le mur, à quelques centimètres de sa tête, il y a un scorpion " (p. 29); « l'enfant dort, et une vipère allongée sur le lit juste à côté de lui » (p. 48); " la vipère dressée sur sa queue menaçant l'enfant qui dort dans son lit et moi [le père] n'ai pas accès à mon fusil de chasse pour la tuer » (p. 58). Force est de constater l'impuissance du père (le narrateur). À la fin du roman, un déluge emportera toute la construction. Cette chute, au propre comme au figuré, signera l'inefficacité de toutes les solutions envisagées pour sortir de l'angoisse.

9. Rachid El-Daïf, Ahl al-zill, Beyrouth, Mukhtārāt, 1987, traduit en français par Edgard Weber sous le titre L'Insolence du serpent ou les créatures de l'ombre, Toulouse, AMAM, 1997. 
Contrairement à ce qui se passe pour les deux romans précédents, le héros de taqaniyyāt al-bu's ${ }^{10}$ ( "Les techniques de la misère ») n’est pas le narrateur, mais Hāshim, un professeur de lycée. La même atmosphère d'angoisse et d'oppression y règne. Les calmants apparaissent dès la première page: " le verre est rempli d'eau, et à côté de lui une boîte de calmants » (p. 5). Ils accompagnent le parcours du héros jusqu’à la dernière page: « il prit un calmant qui le fit dormir » (p. 141). Toute l'activité de cet enseignant, représentant l'intellectuel dans la société, se limite dans les conditions de vie imposées par la guerre à assurer l'eau, l'électricité et le téléphone. Il dit à plusieurs reprises qu'il a sept millions d'idées dans la tête, mais il n'arrive pas à les exprimer. Les préoccupations du quotidien se substituent totalement à tout travail ou effort intellectuel. Avec beaucoup de subtilité, l'écrivain fait percevoir le malheur d'une société où les services élémentaires deviennent une obsession et où le bonheur se réduit à les assurer. Henri Morier souligne que l'autodérision relève de l'ironie dans trois cas. L'un d'eux est le suivant: « Dans une sorte d'amer apitoiement sur soi-même; par révolte et prenant conscience de l'excès de son infortune, l'être félicite le destin, loue la Providence ou la cause de son malheur ${ }^{11}$. " En effet, les rares situations provoquant la gaîté du héros et sa satisfaction sont liées dans le roman à la jouissance de ces services publics élémentaire: "Il avait tout rempli quand l'eau s'est coupée. Il avait fait aussi la vaisselle. Il sourit. La baignoire est pleine d'eau, les trois gallons aussi et des dizaines de bouteilles. La cuvette est propre, qu'est-ce qu'on demande de plus? » (p. 111). Et le narrateur de poursuivre quelques pages plus loin: "Le visage de Hāshim devint rayonnant quand il entendit la tonalité du téléphone revenir, il passa le combiné à Marie, sa fiancée, en lui disant: " la tonalité est revenue! ". Elle prit le combiné, l'approcha de son oreille et elle sourit » (p. 126). Cet événement anodin narré avec solennité imposante était suffisant pour rendre le couple de bonne humeur et pour les inciter à se donner à leur amour (p. 127). "Le rire intérieur », selon l'expression de Morier, que provoquent les raisons de cette gaîté est le signe d'une ironie et d'une autodérision ${ }^{12}$. L'auteur transforme les scènes quotidiennes naturelles et normales en scènes étranges et merveilleuses et « le personnage réel en personnage étrange et comique ${ }^{13}$ ».

10. Rachid El-Daïf, Taqaniyyāt al-bu's, Beyrouth, Mukhtārāt, 1979.

11. Henri Morier, Dictionnaire de poétique et de rhétorique, Paris, PUF, 1975, p. 566.

12. Ibid., p. 556.

13. Rafîf Riḍā Ṣ̄ḍāwī, Al-naẓra al-riwā'iyya ilā al-ḥarb al-lubnāniyya 1975-1995, Beyrouth, Dār al-Fārābī, 2003, p. 145. 


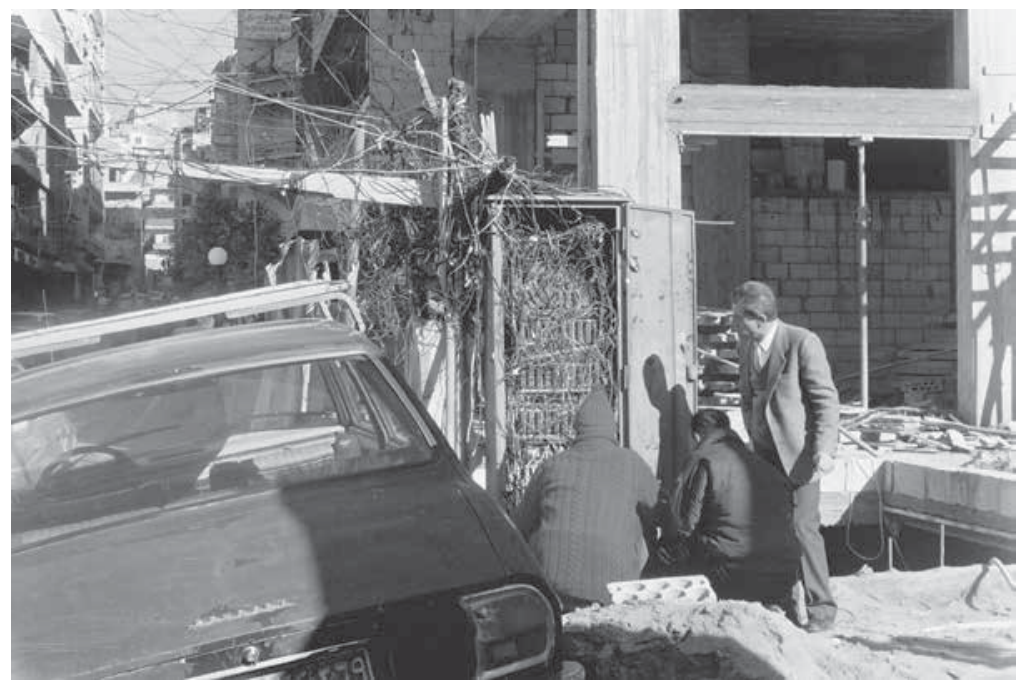

Beyrouth-Corniche al-mazra'a. fin des années 1980. Installations illégales de fils électriques et des câbles suspendus en l'air, nombreux et visibles partout.

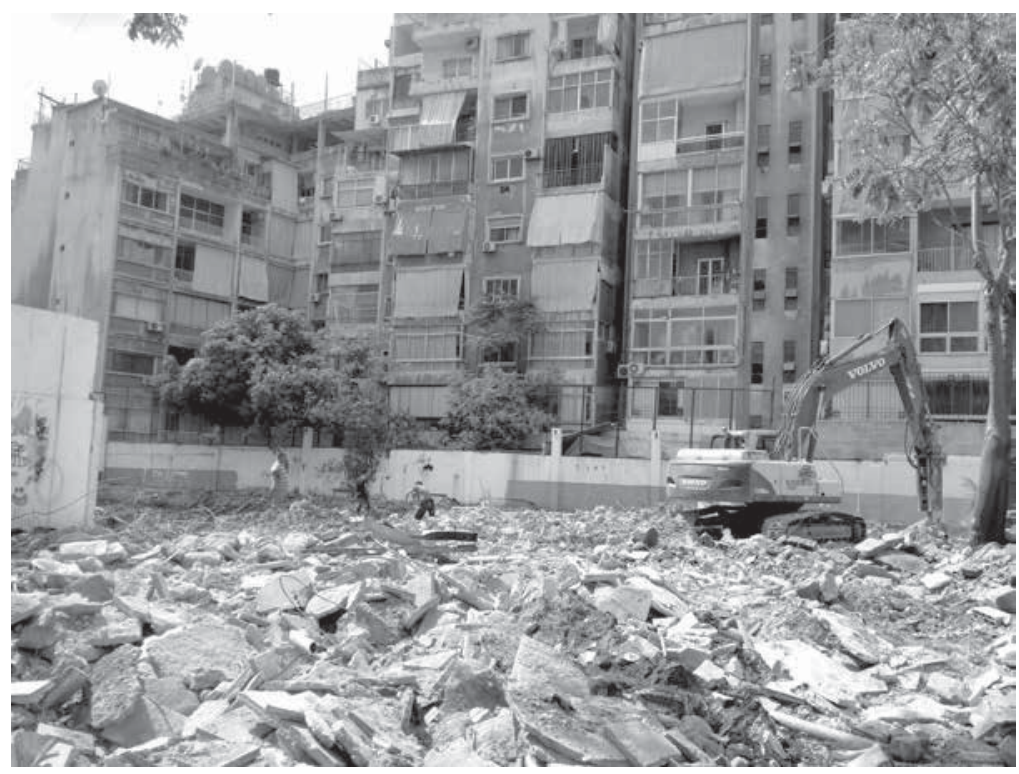

Chantier en cours à Beyrouth- Verdun. Construction d'une tour à la place de la prestigieuse école al-Rawḍa, cofondée en 1961 par le libano-palestinien Qaysar Haddad et par Marwān Jarrār. 


\section{Nāḥiyat al-barā'a: oppression et naïveté dérisoire}

\section{Instances et ordre narratifs}

Dès l'incipit, et à partir des sept premières lignes, le lecteur se rend compte qu'il s'agit d'un narrateur homodiégétique: le " Je " du narrateur est le héros ou plutôt l'antihéros du récit. On est également informé que le temps de la narration est postérieur au temps de l'histoire. L'écart temporel entre le passé relaté et le présent de la narration n'est pas clairement déterminé, mais on peut déduire que la narration est postérieure à la guerre libanaise. « Confier au narrateur le soin de raconter son histoire, dit Michel Raimond, entraîne une conséquence capitale: il en sait plus au moment où il raconte qu'il n'en savait au moment où il vivait tel ou tel épisode de sa vie $\mathrm{e}^{14}$. » Le narrateur bénéficie du recul que lui procurent les années pour donner des interprétations à l'épisode qu'il a vécu confusément et pour jeter un regard plus serein sur les événements. Ce qui explique en partie l'emploi abondant de phrases explicatives, mises souvent entre parenthèses dans le texte: « aurais-je dû vraiment me lever?" (p. 7); " aujourd'hui seulement je me rends compte que c'était une erreur de..." (p. 8); "je ne savais pas à ce moment que... » (p. 13); " je peux le dire franchement maintenant... » (p. 14).

Le narrateur/destinateur s'adresse à un destinataire dont l'identité complète reste indéterminée; néanmoins, l'incipit dévoile son sexe, c'est un homme: aqūlu laka ("je te dis " pour s'adresser à une personne au masculin en arabe). Quant à la perspective narrative ("Qui parle? Et qui voit? ", selon Genette ${ }^{15}$ ), le roman porte le point de vue du narrateur, parce que c'est lui qui voit et qu'il est le seul témoin: il y a donc focalisation interne; toutes les dispositions narratologiques sont prises pour favoriser cette focalisation axée sur l'aventure du narrateur.

Sur le plan de la morphologie du roman, le narrateur brise l'ordre narratif classique, le "schéma quinaire " qui va d'un état initial vers un état final en passant par l'intrigue. La fiction commence ici par l'intrigue où « la tension dramatique " est à son paroxysme dès la première phrase $^{16}$ : «qui a déchiré la photo?» (man mazzaqa al-șūra?). Une " ambiance étrange, chargée de tension surprend le lecteur ${ }^{17}$ ». À cette

14. Michel Raimond, Le Roman, Paris, 1989, p. 118.

15. Genette, op. cit., p. 203.

16. Voir Jean-Pierre Aubrit, Le Conte et la nouvelle, Paris, Armand Colin, 1997, pp. 140141.

17. Voir ‘Așim al-Jundī, revue al-Shāhid, n 152, avril, 1998, p. 102. 
inversion dans le schéma quinaire correspond une anachronie dans l'ordre des actions. La fiction commence par la scène de l'interrogatoire, alors que celle-ci devrait arriver après celle où le narrateur est introduit brutalement dans «le bureau» (p. 10). L'analyse de " ces anachronies narratives ou formes de discordance entre l'ordre de l'histoire et celui du récit » met en évidence l'importance du choix effectué par l'auteur ${ }^{18}$. En effet, ce dernier met en exergue la tension dramatique qui crée, dès les premières lignes, un problème insoluble ( $\left.m a^{\prime} z a q\right)$ : on pose la question au narrateur mais on ne le laisse pas répondre, on ne le laisse même pas communiquer son nom et son âge, ce qui provoque chez lui un sentiment "d'étouffement " (ikhtināq). La clausule ne répond pas non plus à la question posée à la première ligne. On ne sait pas qui a déchiré la photo, la situation devient plus compliquée, et «l'impasse " (al-ma'zaq) reste entière à la fin du roman où la même question est réitérée mais avec plus de violence verbale: «Enculé, fils de chien [yā manyūk, yā ibn al-kalb], qui a déchiré la photo? » (p. 143). La fin, comme dans la nouvelle, laisse le roman ouvert à toutes les interprétations et donne au lecteur la liberté de continuer la phrase: kāna 'alayya an ( "j'aurais dû », p. 158). Cette structure montre clairement que le narrateur est sous pression du début jusqu'à la fin du roman.

\section{Temps et espace}

Dans un roman, le romancier orchestre le temps de l'action, « il contracte la durée, comme le souligne Michel Raimond, et s'offre le privilège de raconter une vie en trois cents pages, mais à l'inverse, il peut raconter en cent pages un dîner de trois heures ${ }^{19}$ ". Ce qui a poussé quelques critiques «à considérer le roman comme étant, avant tout, un art temporel au même titre que la musique ${ }^{20}$ ". Le temps de l'action dans Nāhiyat al-barā'a est inférieur à vingt-quatre heures. La narration commence par un repérage temporel précis qui s'estompe et devient confus au fur et à mesure qu'on avance dans la fiction. On lit par exemple: «Une demi-heure est passée » (p. 16); "Une heure donc est passée » (p. 18); "Ça a fait deux heures que je résiste à ma pressante envie de fumer " (p. 20); "L'heure a bien avancé... plus de trois heures sont passées » (p. 25); «Que reste-t-il de la journée? Presque la moitié est déjà passée "... (p. 51) Cette évolution, de la précision vers la confusion, s'inscrit dans le projet narratif de l'auteur visant à explorer

18. Genette, op. cit., p. 79.

19. M. Raimond, op. cit., p. 145.

20. R. Bourneuf et R. Ouellet, L'Univers du Roman, Paris, PUF, 1981, p. 128. 
la profondeur psychologique du personnage principal. En effet, ce dernier, qui réussit au début de son arrestation à maîtriser le rapprochement entre comportement et temps, sera rapidement désorienté et totalement déboussolé. Les aiguilles de sa montre ne sont plus fiables (p. 25) et il est, par conséquent, incapable de distinguer l'éclairage par l'électricité de la lumière du jour (p.65). Quant au rythme de la narration, l'auteur use des possibilités techniques qui lui sont offertes pour créer, comme en poésie, plus une ambiance qu'une signification. À l'exception de quelques pauses descriptives indispensables dans une narration, l'écriture tend clairement vers " la scène ", comme s'il s'agissait d'une caméra filmant le héros, enfermé dans une surface ne dépassant pas quelques mètres carrés. Quatre-vingt-six pages sont consacrées à raconter les événements qui se déroulent en moins de douze heures. Le narrateur raconte en cinq pages et demie la première demi-heure, en deux pages et demie la deuxième moitié et puis en deux pages l'heure suivante. Une fois qu'il perd la maîtrise du temps réel, le temps de la narration se ralentit pour épouser parfaitement celui de l'action. Le fait de fumer une cigarette est décrit en six pages (p. 34-40). Le temps mis à lire les six pages est équivalent au temps mis pour fumer une cigarette. Le rythme de la narration exprime hautement l'angoisse du narrateur et l'oppression physique et psychologique qu'il subit, et suggère une ambiance d'étouffement justifiant parfaitement, comme nous allons voir, son comportement. L'attente le ronge.

Les événements se déroulent dans deux espaces: le bureau (almaktab) p. 10, lieu des événements de la première partie du roman (de la page 5 à la page 92) et la maison du narrateur: 'indamā iqtādūnī ilā baytī, "quand ils m'ont conduit chez moi " (de la page 92 jusqu'à la fin du roman). Le premier espace, par sa surface réduite et sa situation, probablement au sous-sol, a servi de cadre pour construire la psychologie du personnage. L'atmosphère de l'endroit où il est enfermé est al-jaw al-d̄äghit, " oppressif » (p. 19) et " la chambre, apparemment sans fenêtre, est fermée " (p. 20). Le passage de la description d'un objet de cet espace à un autre s'effectue d'une manière brutale. De même, pour le passage de la description au récit ou vice versa, comme: « Mon regard s'est tourné naturellement vers ma main... » (p. 14). Dans la découverte de son nouvel environnement, le narrateur cite les meubles: fauteuils en cuir; disposition des fauteuils par rapport à la fenêtre ou ce qui lui en a semblé être une; la bibliothèque où sont archivés les dossiers; un appareil téléphonique, un bureau; une moquette sur laquelle est posé un tapis (p. 17); un rideau blanc « comme la neige » qu'il n’ose 
pas toucher (p. 31). Cela étant, et malgré cette description plutôt détaillée, le narrateur insiste à plusieurs reprises sur l'obscurité qui règne dans ce bureau: "J'ai essayé, dans cette obscurité profonde, de ramasser les mégots de mes cigarettes "; " Le téléphone sonna, et l'obscurité était totale » (p. 54). Cette ambiguïté nous laisse supposer que la nuit est tombée alors que le héros est toujours enfermé dans le bureau. Est-ce qu'une fois dedans on a bandé ses yeux? Cette ambiguïté installée par l'auteur contribue également à mettre en évidence l'angoisse du narrateur et son étouffement: «Où suis-je? Quelle est la nature de l'endroit où on m’a enfermé? Est-il au-dessus de la terre ou bien en sous-sol? Et à quelle profondeur? Chacune de ces questions est susceptible de ravager une montagne, que dirait-on quand elles sont réunies? » (p. 32).

Le second espace, le domicile du narrateur, achève de camper le personnage. Sous la pression imposée par les enquêteurs, le narrateur mentionne, sans la décrire, la cuisine et la chambre à coucher et ne cite comme objets que couteau (p. 115) et lit (p. 117). Tous les deux sont exploités dans le texte pour révéler le paroxysme de l'oppression que subit le narrateur:

Est-ce chez lui qu'ils l'amenaient [sa femme] Quand ils la tiraient par les cheveux?...

- au lit!?

Le président lui demanda s’il souhaite prendre son café au lit. Que fait-il là-bas au lit? Quel genre de pression constitue tout cela?

\section{Personnages et dérision}

Étant donné que le temps de l'histoire est limité à moins de vingtquatre heures, le nombre de personnages reste très restreint. La fiction repose sur un personnage principal qui est le narrateur, et cela sur les deux plans: "distribution et autonomie ${ }^{21}$ ». Quantitativement, il est présent, à presque toutes les pages, du début jusqu'à la fin, et il est le seul, comparé aux autres personnages, à avoir son autonomie. "Le personnage s'incarne et se construit très concrètement dans des unités linguistiques qui le désignent et qui sont les désignateurs ${ }^{22}$." Étant donné que toute l'histoire est construite par et sur le narrateur, la part de paroles laissée aux autres protagonistes est extrêmement limitée. Cependant, il faut souligner que le narrateur ne prend pas lui-

21. Cf. Philippe Hamon, «Statut sémiotique du personnage », in Poétique du récit, Paris, Editions du Seuil, 1977, p. 155.

22. Yves Reuter, Introduction à l'analyse du roman, Paris, Dunod, 1996, p. 93. 
même l'initiative de s'identifier ni de se présenter, laissant ainsi toute instruction concernant son identité venir de la part des agresseurs/ enquêteurs. Il reste d'ailleurs anonyme dans le texte, et la seule allusion à un nom serait dans le discours du narrateur adressé à lui-même pour se donner un peu d'énergie et pour se remonter le moral: Hayyā ayyuhā al-Rashīd (« tiens bon al-Rashīd », p. 67), un jeu stylistique autofictionnel récurrent dans les œuvres de Rachid El-Daï ${ }^{23}$. À la page 8, puis aux pages 78 et 80 , il déclare qu'on ne lui a pas demandé ni son nom, ni son âge, ni son métier et ni de quelle ville ou village il est originaire, bref, rien sur son état civil, ce qui l'étonne. D'autant plus qu'au Liban on peut dévoiler, à travers le nom, plusieurs éléments identitaires de la personne: « le nom dans notre pays est la moitié du chemin pour ne pas dire la totalité » (p. 79).

Dépouillé de son identité antérieure, il en acquiert une autre. Une identité définie par ses tortionnaires et ses agresseurs. Le narrateur, avec eux, commence une nouvelle naissance, connaît de nouveaux parents et prend des noms nouveaux: "Mais maintenant j'ai un nom chez eux, ils m'ont donné un nom, ils sont mes parents ", dit-il (p. 79). Les noms qui lui sont attribués sont hautement éloquents: al-manyū. ("L'encu. », p. 78), nom, écrit sans écorchement à la page 143: al-manyūk ("l'enculé »); d'autres sont de la même veine: baghl (" mulet », p. 98), hayawān ("bête", p. 108), ibn al-Kalb ("fils de chien", p. 143). Ces désignateurs/qualificatifs, outre qu'ils tournent en dérision le narrateur, portent profondément atteinte à sa singularité et suppriment l'un des éléments fondateurs de l'identité. Ils dévoilent un premier aspect de son image dans le roman. Cette image sera complétée soit par le discours du narrateur sur lui-même, soit par son comportement. Ce dernier serait, comme dit à juste titre Roland Bourneuf, « une réponse donnée à l'image projetée par autrui »:

J'ai tenu, dès le premier instant qu'ils m'ont fait entrer dans le bureau, $\grave{a}$ rester moi-même, c'est-à-dire de rester pondéré, serein, calme, cohérent, d'agir à la lumière de la raison, même plus, J'ai tenu dès le premier instant, non à paraître naturel mais à être vraiment naturel.

À être vraiment naturel!

Les deux qualités que je dois avoir sont le naturel et le rationnel. (p. 10)

23. Maitre dans l'art de l'autofiction, l'auteur, en donnant son vrai nom ou un nom proche du sien à son personnage, fait croire au lecteur qu'il s'agit d'une autobiographie, et cela dans plusieurs romans: Rashīd dans 'Azīzī al-sayyid Kawabata (Cher Monsieur Kawabata) et Rashshūd dans Tiștifil Meryl streep (Qu'elle aille au diable, Meryl Streep!). 
Tout ce qui peut neutraliser ces qualités est à écarter, comme l'épouvante, al-hala; par exemple: « Elle est rejetée et condamnée parce qu'elle neutralise le rôle du cerveau et paralyse la pensée scientifique et objective " (p. 28). Ces qualités, sur lesquelles insiste le narrateur sont redondantes dans le texte. Quant à son comportement, il s’inscrit dans le même cadre de la maîtrise de soi. Il dit:

Je me suis entraîné petit à petit, durant cette période, à maîtriser mes mouvements, de sorte que chacun d'eux soit le résultat d'une décision bien réfléchie, bien étudiée, bien préparée dans tous ses détails et dans toutes ses étapes. (p. 26)

Les événements évoluent, surtout dans la première partie, sous forme d'épisodes qui se succèdent selon un schéma répétitif mettant en exergue le comportement du narrateur. Les actions de ce dernier dans le « bureau " pendant les heures d'attente, décrites comme des aventures, rappellent à bien des égards les cycles de violence qui ont rythmé la guerre libanaise. À peine une accalmie ou un semblant de solution se profilent-ils à l'horizon que les hostilités reprennent, annonçant un nouveau cycle de violence. Espoir et désespoir alternent continuellement. Les aventures du narrateur dans le lieu de son enfermement ont la même structure interne. Dépossédé de son identité, soumis à une pression humiliante, le héros décrit son comportement qui reflète subtilement l'état de dérision dans lequel il se trouve. Dès les premières pages, il dévoile sa personnalité:

Oui, j'avoue que quand ils sont entrés [dans le bureau] j'étais surpris!

Oui! Je l'avoue.

J'étais surpris pourtant je m’y attendais, et me voilà commettre la première faute. La première dans une série de plusieurs autres. À peine sont-ils entrés que je me suis levé — je n'aurais pas dû le faire —, j'ai commis par cela la deuxième faute. (Aurais-je dû vraiment ne pas me lever !?). Et puis, quand ils se sont assis, je suis resté debout — oui debout — et les fautes se multiplient. (p. 7)

Les aventures du narrateur dans le bureau, une fois que les agresseurs sont sortis, sont de la même veine. La pièce où il est détenu plonge dans une obscurité totale: "Subitement la lumière s'éteint, et une obscurité absolue régnait dans la chambre » (p. 34). Dans l'obscurité, et pour se détendre, il prit une cigarette et l'alluma. Ce qui fut une source de détente, il y a quelques instants, devient lui-même source de tension. "Les instants de tranquillité ne durent pas « dit-il, et un nouveau problème surgit: « Où dois-je jeter la cendre de la cigarette? » Il mit la main 
sous la cendre pour éviter qu'elle tombe sur le tapis, mais le problème resta entier: "il faut que je trouve un cendrier, ou que je cherche une autre solution "Si le revers de son pantalon, dans lequel il jeta la cendre, l'aida à traverser cette épreuve, ce n'est pas pour autant qu'il retrouva sa quiétude: "Je me suis assis sur le fauteuil me reposer suite à cette épreuve unique, et, subitement, je vis le brasier de la cigarette, jamrat al-sijāra: "Où et comment l'écraser pour l'éteindre? "Ce nouveau problème fut résolu en laissant la cigarette s'éteindre lentement sur le verre du bureau. " (pp. 34-40). C'est à ce moment que le narrateur se rend compte que la peur le met dans cet état de déstabilisation, et il avoue clairement: «Et puis, je me suis rendu compte qu'il n'était pas permis d'être idiot à ce point » (p. 40).

Cependant, le cycle des "aventures " n'est pas terminé. Une fois qu'il a trouvé des solutions pour se débarrasser de la cendre et du brasier, une forte envie lui vient de fumer une autre cigarette, ce qu'il fait. Il prend une autre cigarette sans toutefois prévoir qu'une nouvelle épreuve surgira:

Une fois reposé, [...] je pris le paquet de cigarette, tirai une cigarette et l'allumai, et je commençai à la fumer tranquillement, avec joie et grand plaisir. À ce moment de bonheur je sentis, non l'envie d'uriner, mais que si je vais aux toilettes, à ce moment précis, j'urinerai. (p. 41)

À travers ces aventures ou ces " épreuves ", comme il tient lui-même à les appeler, qui s'enchaînent tout au long du roman, l'image du héros prend de plus en plus forme. Cette image n'est autre que le croisement de l'oppression sous ses différentes formes et de la dérision. En effet, elle se cristallise dans le texte sous plusieurs formes:

1. L'assujettissement et la contrainte al-qahr. Dès le début de la fiction, émerge l'image d'un personnage séquestré, réprimé, mis d'emblée dans une situation oppressante. Les règles élémentaires d'un dialogue ne sont pas partagées entre le narrateur et les quatre agresseurs qualifiés "d'hommes au vrai sens du terme, malgré leur jeune âge " (p. 5). Ces règles ne sont pas les mêmes quand il s'agit d'un échange entre eux ou quand il s'agit d'un semblant échange avec le narrateur. Ce qui suscite d'ailleurs son étonnement: « Ce qui m'a beaucoup étonné, dit-il, c'est que personne n'interrompt personne quand ils parlent " (p. 9). En revanche, les paroles du narrateur, voire ses réponses, sont systématiquement interrompues, parfois avant même qu'il ait pu prononcer un seul mot. Les passages témoignant de cette 
répression se succèdent et finissent par la déstabilisation du narrateur. L’enquête pour savoir " qui a déchiré la photo " ne laisse pas de place aux réponses:

Quand je m’apprêtais à répondre, il m’a tout de suite interrompu.

- Je t’avais demandé: qui a déchiré la photo?

Il a répété plusieurs fois la question, sans que je puisse prononcer une seule lettre... Qu'est-ce que cela veut dire! Quel sens a le fait de me poser des questions sans me laisser répondre. (p. 6)

Même répression incompréhensible par le narrateur à deux reprises trois pages plus loin:

- Tu ouvres la bouche quand on te le demande. Par cette expression j'étais arrêté à chaque fois que je m’apprêtais à parler (p. 9).

Cette situation contribue à l'étouffement, al-ikhtināq, du narrateur: "Quelque chose me tient à la gorge et s'enroule autour de mon cou ", affirme-t-il. L'espace réduit, l'emplacement et l'absence totale de la lumière seront le cadre idéal pour développer le sentiment d'étouffement et créer une atmosphère oppressante, al-Jaw al-ḍaghiț, soulignée régulièrement par le narrateur.

L'univers étouffant dans lequel évolue le narrateur modifie les codes et perturbe les normes. En effet, les événements vécus par le narrateur ne sont plus soumis quant à leur évaluation aux critères communément admis et naturellement reconnus. Des vocables comme Khața" ( faute »), ma'ziq ("impasse»), warța ("situation embarrassante)», mushkila (" problème »), mușība (" catastrophe »), tajriba (" épreuve ») et la liste peut s'allonger, sont vidés de leurs contenus sémantiques conventionnels et usuels. Ils sont réinvestis pour exprimer des émotions imposées par les contraintes et par l'espace étroit dans lequel vit le héros. L’autodérision apparaît dans l'inadéquation et la disproportion entre, d'un côté, le discours théorique, argumentatif et parfois philosophique du narrateur et, d'un autre côté, la banalité de l'événement. Elle apparaît également dans le jeu entre les dispositions qu'il prend avec prudence, ambition et retenue, d'une part, et les conséquences insignifiantes de l'incident, d'autre part. Comparons, par exemple, la préparation psychologique qui précède un "problème ", celui de la cendre de sa cigarette:

La mission dont je me suis chargé était difficile, voire impossible, mais ici, dans cette chambre, j'ai réalisé pour la première fois de ma vie que rien n'est possible sans la réalisation de l'impossible. Seulement en réalisant l'impossible, tout peut continuer comme avant, c'est-à-dire je 
serai sauvé. C'est pourquoi, et tout simplement, il faut que je trouve un cendrier ou que je trouve une solution au problème dû à la cendre de la cigarette et à son mégot. Voilà le problème, al-mushkila, que je dois résoudre à cet instant même... (p. 47)

L'autocensure pratiquée par le narrateur réduit fortement sa liberté et fait de lui son propre tortionnaire. Le fait de trouver rapidement le paquet de cigarettes dans le noir appelle un discours de grandiloquence: " Le moral de l'homme [ma'nawiyyāt] a effectivement un effet primordial sur sa réussite ou sur son échec » (p. 41). Tous ces incidents insignifiants sont des grands problèmes alors que le vrai problème n'en est pas un: " Je serai obligé, dit-il, de passer toute la nuit enfermé ici, ce n'est pas grave, ce n'est pas une catastrophe, la vraie catastrophe c'est de perdre patience » (p. 51).

Pousser la rationalité à l'extrême, c'est tomber dans l'autodérision. Le narrateur va même jusqu'à justifier l'action des agresseurs et à considérer la torture comme un droit: «Si cet homme m’a giflé ou m’a donné un coup de pied, il aura exercé un droit qui lui est parvenu de ses supérieurs " (p. 13). Cet excès de rationalité mène naturellement à la résignation, à la docilité et à l'écrasement total du narrateur. Il sera privé de sa dignité et de son amour-propre et sera tourné en dérision. Le narrateur déclare, sur un ton dissimulant à peine l'ironie, qu'il est passé maître dans l'art de la résignation et qu'il maîtrise parfaitement l'art d'inventer de nouvelles formules d'excuse (p. 49). À la maison, il s'efforce aussi à attirer sa femme dans son camp et à la persuader d'adopter, comme lui, la politique de la docilité et de la complaisance ${ }^{24}$.

Pourquoi adopte-t-il une telle attitude? Dans l'objectif d'alléger ses souffrances, le narrateur crée dans la fiction toutes les raisons qui peuvent justifier la torture et l'humiliation. Il justifie la tyrannie, uniquement pour pouvoir la supporter. Dans une interview à Mulhaq al-Nahār, Rachid El-Daïf déclare ${ }^{25}$ : "Souvent l'innocent s'oblige à tout supporter, même si c'est au-dessus de sa capacité, pour trouver une excuse au tyran, parce que la tyrannie est insupportable si on ne lui trouve pas des excuses [li'anna zulma al-ẓālimi lā yuhtamal bi-lā 'udhr]. ”

2. Un narrateur vaincu, battu et défait (mahzūm). La défaite du héros est intimement liée à la défaite de la société. Le narrateur n'est qu'un membre de la société qui subit la dictature des milices et des

24. Voir aussi Naoum Abi-Rached, "Violence et innocence », in Mélanges, Toulouse, AMAM, 1998, p. 343.

25. Samedi 28 juin 1997. 
fractions armées. Dans ce contexte, et vu l'inversion des codes relationnels habituels, l'individu s'inspire dans son comportement de nouvelles règles imposées par la partie qui tient la force, ce qui va nous permettre de compléter la reconstitution d'une image illustrant la dérision et l'autodérision du héros.

La torture (al-ta'dhīb) et l'humiliation (al-idhlāl) du narrateur sont les conséquences de cette défaite. Elles touchent le physique et le moral. La torture physique apparait à plusieurs endroits dans la fiction. Même dans ses douleurs, le narrateur ne manque pas de se tourner en dérision. En effet, et malgré son extrême prudence et son calme prétendu, la sonnerie inattendue du téléphone sur le bureau conduit à un drame, il dit: "C'est sûrement en "fuyant" [hāriban] spontanément et rapidement le téléphone qui a subitement sonné que j'ai cogné la table au milieu de la chambre, une table en fer sur laquelle est posée une planche en verre, je suis tombé et la planche s'est cassée » (p. 56). Et, quelques pages plus loin, il décrit la situation dans laquelle il se trouve: "J'étais toujours étendu sur les morceaux de verre, saignant, les jambes dans l'air, les bras blessés et paralysés, comme si je subis une séance de torture avec des méthodes primaires » (p. 60).

La description de la torture exercée sur lui par ses agresseurs est de la même veine. L'humour s'unit à la souffrance pour créer une image de dérision. Abandonné, momentanément, une fois qu'il est plongé dans une souffrance physique inouie, il aurait souhaité se débarrasser de ses membres ou du moins les diminuer, on lit:

Pourquoi je m'allonge sur le lit? Pour me reposer, pour me reposer!

Et puis, une fois que j'ai réussi à soulever la première jambe, j'ai essayé de soulever la deuxième je n'ai pas réussi. Heureusement que l'être humain n'en a que deux. Il ne sera pas obligé d'en soulever plus s’il veut se reposer... Imagine un homme avec plusieurs bourses attachées toutes à un courant électrique. Je pense que deux jambes suffisent, même une seule bourse. C'est-à-dire le "strict minimum" ${ }^{28}$ pour être un homme. (p. 153)

La torture morale, imaginée dans la première partie du roman devient réelle et effective dans la deuxième. En effet, l'imagination d'une scène de viol subie par le narrateur au bureau et présentée comme étant de vagues idées noires, des illusions, des fantasmes ou des hallucinations (halwasa) devient une réalité à la maison. Ce qui rend cette scène plus dramatique et plus humiliante, c'est qu'elle s'est déroulée devant son fils. L'image du père idéalisé par son fils sera doublement entachée.

26. Cette expression est en français dans le texte. 
Premièrement, les enquêteurs empêchent l'enfant de venir accueillir son père comme il faisait habituellement, quand celui-ci rentrait à la maison:

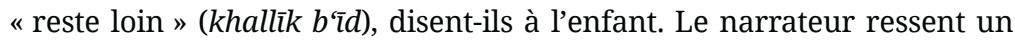
sentiment d'humiliation qu'il n'avait jamais ressenti auparavant, car, rien n'est aussi dur que l'humiliation d'un père devant son fils; il dit: "Les moments les plus horribles sont ceux où le père est humilié devant son fils» (p. 93). Deuxièmement, le narrateur est aussi violé devant son fils et probablement devant sa femme bien qu'il affirme le contraire. La scène est subtilement suggérée à travers la vision innocente de l'enfant:

Oui, oui, j'ai eu le courage et demandé à mon fils plus tard, bien plus tard, ce qui s'est passé pendant que j'ai perdu conscience, il m’a répondu:

Tonton a fait pipi ['ammu 'imil pipi]. (p. 96)

Cette situation humiliante est complétée par le viol de sa femme aussi (p. 97).

\section{Tișțifil Meryl Streep: obsession et ridicule}

"Les écritures à la première personne proposent toujours, peu ou prou, un contrat de véridiction grâce auquel le lecteur peut croire vrai ce que l'énonciateur s'efforce de lui présenter comme tel ", dit Sébastien Hubier $^{27}$. L'écriture de Rachid El-Daïf s'inscrit dans ce cadre, et abolit les frontières entre genres référentiels et genres fictionnels. Sous sa plume, ces genres s'empruntent les thématiques et les enjeux et finissent par dérouter le lecteur. Cette technique caractérise profondément la poétique de ses romans et particulièrement la poétique narrative de Tistifil Meryl Streep (Qu'elle aille au Diable, Meryl Streep!).

\section{L'illusion d'une autobiographie}

Dans ce roman, le narrateur homodiégétique s'appelle Rashshūd, manière familière d'appeler Rachid au Liban. Ce nom qui est également le nom de l'auteur est dévoilé dès les premières pages (p. 8). Cependant, le ton intime par lequel le narrateur introduit la fiction se heurte, également dès les premières pages, à un anachronisme qui fait glisser habilement l'histoire du réel vers le fictif. En effet, les repères chronologiques et le cadre temporel dans lequel le narrateur situe l'action désorientent complètement le lecteur. Le texte évoque un phénomène naturel et situe le temps de l'histoire par rapport à cet événement, il s’agit de

27. Sébastien Hubier, Littératures intimes, Les expressions du moi, de l'autobiographie à l'autofiction, Paris, Armand Colin, 2003, p. 18. 
l'éclipse totale du soleil en 1999: " Je me sentis frustré lorsqu'il y eut l'éclipse, l'an passé2 ${ }^{28}$ (p. 13). Les événements se déroulent donc en 2000. Mais le narrateur, et avant de donner cette précision, raconte qu'il regardait à la télévision, chez ses beaux-parents, le président américain Georges Bush, et c'est de Bush père qu'il s'agit, car il dit: " Il est à remarquer que Bill Clinton, le président qui lui succéda, souffrait lui aussi de graves problèmes de voix " (p. 11). Or, Bush a quitté le pouvoir en 1992 et la guerre du Golfe à laquelle il fait allusion s'est déroulée en 1991. En même temps qu'il invite, presque explicitement, son lecteur à faire le rapprochement entre le narrateur, exprimé par le "Je ", et Rachid l'auteur, il accentue l'anachronisme référentiel, manière de mettre en garde le lecteur contre cet éventuel rapprochement ${ }^{29}$.

L'objectif de d'auteur n'est pas de tracer une histoire cohérente chronologiquement: il exploite l'histoire pour dévoiler les caractères et la personnalité de son héros. En effet, dès le début du texte, l'auteur s'appuie sur la rhétorique du contraste et de la disproportion. Une technique narrative permettant au lecteur de pénétrer dans l'univers intime du héros. On évoque des questions universelles et des problèmes majeurs pour mettre en évidence l'univers clos et dérisoire du héros. Aux deux événements évoqués, à savoir la naissance d'un nouvel ordre mondial et la guerre d'Irak, s'opposent les problèmes, terre à terre, qui occupent le narrateur: le refus de sa femme de venir avec lui dans leur appartement, et puis le lit dans lequel ils dormaient, lui et sa femme, chez sa belle-mère, celui-ci "grinçait chaque fois qu'ils faisaient un bruit inhabituel » (p. 9).

\section{L’intimité du héros: le « Je » du narrateur est sujet et objet}

Rashshūd est le prototype d'un modèle conformiste qui frôle la naïveté, l'obsession et le ridicule. Il découvre, à 35 ans, un autre univers autour de lui et vit le choc entre son éducation, ses valeurs, ses convictions et son immobilisme, d'un côté, et le changement de la société dans laquelle il vit, de l'autre. Il découvre surtout le changement de la femme. Cette société est perçue à travers l'évolution survenue dans les

\footnotetext{
28. Toutes les citations se réfèrent à la traduction d'Edgard Weber. Les numéros des pages cités correspondent à la version arabe.

29. L'anachronisme apparaît également dans le parcours de sa femme. Le temps de l'histoire devrait correspondre au temps de la narration 2010-2011. Or, la même année, sa femme avait 9 ans (déflorée dans la voiture en allant visiter le sud du Liban après sa libération qui a eu lieu en 2000) (p. 107), puis la même année elle a 16 ans (p. 110) et 23 ans « 7 ans plus tard... » (p. 11).
} 
domaines de la communication et de l'information, d'où le rôle important et symbolique de la télévision dans le roman (p. 13).

La technique adoptée dans la narration s'appuie profondément sur cette situation, en ce sens que le héros se dévoile dans le roman à travers une série de réactions. Rarement il prend l'initiative: il dévoile ses pensées et justifie ses comportements par réaction au comportement des autres. Nous sommes donc devant un héros passif, fragile et vulnérable dont le désir se limite à trouver une explication, sans réussir souvent, à ce qui se passe autour de lui. Contrairement à un héros positif, dépositaire d'une mission dans la société dans laquelle il vit, le héros de Tistifil Meryl Streep se replie sur lui-même et s'offre comme le modèle type de l'intimiste. Il est le "sujet ", et en même temps il est " objet » dans le sens que Greimas donne à ce terme dans son schéma actantiel. Sa réaction face à la femme française qui ose exprimer ses désirs sexuels s'inscrit dans ce cadre. Cette dernière, pour satisfaire ses désirs, prend pour amant un garçon moins âgé qu'elle et d'un niveau social très modeste: transporteur des valises à l'aéroport, et elle avoue être prête à être son esclave. Cette relation qui déroge aux codes sociaux et traditionnels tels qu'il les conçoit, le trouble profondément. L'expression de sa réaction révèle sa naïveté, il dit:

Cette fille me fit exploser la cervelle. Elle me mit dans tous mes états. J'éjaculai plusieurs fois, simplement à l'entendre parler! Ça ne m’était jamais arrivé! Je ne croyais même pas qu'une telle chose pouvait arriver, sans y mettre la main! Non, ça ne m'était jamais arrivé auparavant. Ça ne se reproduisit plus jamais non plus ensuite. (p. 20)

Sa réaction face au comportement de Meryl Streep qui quitte son mari et son enfant dans le film Kramer contre Kramer n'est pas moins dérisoire. Entre jalousie et convictions stupides, il mélange réalité et fiction et, naïvement, se porte garant des bonnes mœurs:

Je souhaite qu'elle n'aille pas chez son amant. Je souhaite à vrai dire, et en tout état de cause, qu'elle revienne à la maison, auprès de son fils, dans sa famille. Certes, son mari n'est pas de son niveau [...] Elle a accepté le mariage, elle l'a épousé et elle a eu un enfant de lui, par-dessus tout. Maintenant elle ne peut pas laisser son enfant à son mari, de cette manière... Je dis cela, bien qu'au plus profond de moi je souhaite qu'elle ne revienne pas auprès de lui. (p. 69)

La conception qu'a le héros du mariage, de son mariage particulièrement, contribue aussi à dévoiler sa personnalité. Il n’y voit que 
la relation sexuelle. C'est pourquoi la virginité de la femme en est une condition incontournable:

Le corps de la femme, l'époux doit le recevoir parfait, intact. C'est un cadeau précieux qui lui laissera une impression positive pour toute sa vie et consolidera les liens entre eux en tant que mari et femme. (p. 139)

Dans ce cadre, le narrateur étale, fièrement, sa conception des règles « naturelles » qui régissent le mariage:

Depuis fort longtemps, ma décision était prise. À vrai dire, ce n'était pas une décision, mais quelque chose de naturel, comme la nature est naturelle. Ma décision était donc la suivante: je n'épouserais qu'une fille sage, je veux dire ordinaire, c'est-à-dire sans histoire faite de multiples incartades. (p. 138)

Dans son univers clos, le narrateur rejette les habitudes occidentales, qui, à travers les chaînes satellitaires, envahissent le monde oriental et déstabilisent ses convictions.

\section{Le héros et sa femme}

Force est de constater que la relation entre le narrateur et son épouse, depuis leur première rencontre au café Al-Rawḍa à Beyrouth jusqu'au divorce, révèle magistralement le ridicule du narrateur et le dérisoire de son comportement. La rencontre au café Al-Rawḍa met en exergue l'image d'un héros totalement dépassé par l'évolution de la société et plus précisément par l'émancipation de la femme. L'inadéquation entre sa mentalité figée et ses prétentions qui se veulent libérales et progressistes le met dans une situation hautement dérisoire. En effet, la simple commande d'une bière par celle qui va devenir sa femme, ravage profondément son univers. On lit:

Nous étions à peine assis et nous n'avions pas encore échangé trois mots du style: ce café te plaît-il ou qu'aimes-tu boire? Lorsque le serveur vint vers nous. Et avant qu'il ne prenne notre commande, avant même qu'il ne soit tout à fait arrivé à notre table, elle lui lança:

"Une bière! "

Elle me surprit!

Franchement, j'étais désemparé, ne sachant plus quelle attitude adopter, ni où regarder ni quoi dire. Elle était sûre d'elle, pleine de confiance... (p. 90)

Tout en considérant que la femme a commis " une faute " en commandant une bière, il n'hésite pas à déclarer ses prétentions, sans se 
rendre compte de son aveuglement et de son enfermement dans « une coquille » :

J'aime beaucoup aider la femme à sortir de la coquille dans laquelle les coutumes l'ont enfermée. Mais, en même temps, j'aime que la femme conserve un minimum de retenue. Si au moins elle me l'avait demandé, je lui aurais donné la permission, de tout cœur. Mais qu'elle fasse ce qui lui passe par la tête et que j'apparaisse comme un fantoche, ça, je ne peux pas l'accepter. (p. 91) 30

Malgré cette "faute », le narrateur, considérant qu’ils n’étaient qu'au début du chemin et " tout, grâce à Dieu, pouvait encore s’améliorer et changer ", l'épouse. Une fois devenue sa femme, le narrateur entame une nouvelle démarche. Il observait scrupuleusement son comportement, ses gestes et ses expressions dans un seul objectif: savoir si elle avait eu des expériences sexuelles avant le mariage. Tout le dynamisme du héros sera exploité dans cette seule direction: fouiller dans le passé de sa femme parce qu'il considère que ce passé, comme le sien d'ailleurs, appartient aux deux. Le roman décrit un narrateur dans la tourmente, obsédé continuellement par le passé intime de son épouse, oscillant régulièrement entre quiétude et doute. Une autre source de dérision dans le roman réside dans l'inadéquation, souvent caricaturale, entre l'insignifiance des actions d'un côté, les réactions fortes et les interprétations stupides et ridicules du narrateur de l'autre. En effet, le fait que sa femme va tout de suite dans la salle de bains après leurs ébats le rend heureux, il dit:

Elle se levait pour aller dans la salle de bains, aussitôt que nous avions fini nos ébats. Et souvent, c'était immédiatement lorsque j'avais fini, moi. J'aimais cela de sa part. Je l'aime toujours, parce que c'est la preuve qu'elle n'est pas excessivement experte en la matière. C'est la preuve aussi de sa candeur [...] C'est d'une certaine manière la preuve aussi de son honnêteté morale, la preuve de sa pureté d'âme et de son peu d'expérience. (p. 25-26)

Sur un geste anodin de son épouse, il construit, poussé par ses obsessions, un univers idyllique chargé des qualités les plus éloquentes: " candeur, honnêteté morale, pureté d’âme... ".

30. Cette même prétention, suscitant le rire, se répète à plusieurs reprises dans le texte, il dit par exemple: « J'ai le droit que certaines choses chez ma femme n'appartiennent qu'à moi. Je n'aime pas que quelqu'un d'autre les partage, ni avec le toucher, ni avec la vue, ni avec le nez. Je ne suis pas vieux jeu mais j'aime qu'une femme au moins dans ma vie soit à moi tout seul. Qu'y a-t-il d'étonnant à cela ? » (p. 115) 
Les repères extérieurs qui balisent l'évolution de la fiction sont presque absents dans Tistifil Meryl Streep, c'est pourquoi, les interprétations du héros et les fluctuations de ses émois rythment le développement de l'histoire. Le non-dit serait donc la porte ouverte à l'imagination. Une autre action, aussi insignifiante que la précédente, inverse la donne et réveille tous les soupçons. Dans l'immeuble de ses beauxparents, l'ascenseur tombe souvent en panne, le narrateur raconte:

Un jour elle [sa femme] resta bloquée dans l'ascenseur. Il y avait avec elle un étudiant français. Je lui fis remarquer qu'elle devait avoir très peur: "Tu devais crever de peur! ». Elle répondit: " Non, au contraire. » Je lui demandai alors: "Ça veut dire quoi au contraire? ». (p. 26)

Il aurait suffi donc d'un mot, bi-l-'aks ("au contraire") pour que le narrateur casse l'image positive qu'il avait construite de sa femme suite à son comportement précédent. L'évolution du narrateur dans le roman, ses sentiments, son humeur et son regard sur sa femme sont tributaires d'une expression ou d'une comparaison. En raison de sa fragilité psychologique, une courte scène le fait passer, en quelques secondes, d'un extrême à un autre. Lors d'une promenade, avant leur mariage, au bord de la mer, sur la corniche al-Manara à Beyrouth, le couple contemple le coucher du soleil. Ému, le narrateur lui dit: «Regarde comme ce paysage est beau! On dirait que le disque solaire est une boule de feu qui plonge dans la mer " (p. 47). Face à cette comparaison, digne des poètes romantiques, la femme, qui va devenir son épouse, éclata de rire, et le narrateur de dire:

Et sans que je ne lui demande rien, elle raconta qu'elle avait entendu quelqu'un comparer le disque solaire à la tête de son pénis dressé! Il avait dit: "Tiens, le soleil est comme la tête de ma bi... "Auprès de qui a-t-elle bien pu entendre une telle phrase? Quelle espèce de gens fréquente-t-elle? (p. 47)

Suite à son désarroi, elle le prit par la main en lui disant: "Je suis heureuse, mon cher époux, que tu aies ce niveau d'éducation. Je t’aime! " (p. 48). Le fait de l'appeler "mon époux " avant même leur mariage lui a fait plaisir et l'a conduit à changer d'avis à son égard. Il estime qu'elle avait honte, qu'elle avait regretté ses paroles et que c'était un signe stimulant indiquant qu'elle évoluait dans le bon sens.

Cependant, la bonne impression qu'a laissée en lui cette déclaration n’a pas duré longtemps. Cette comparaison osée donne libre cours à son imagination. Les interprétations et les suppositions se multiplient: 
La vérité est peut-être que c'est elle qui voyait la ressemblance entre le disque du soleil qui disparaissait derrière la mer et la tête du membre viril tout rouge à force de bander et de s'exciter? Mais d'où tenait-elle cela? L'individu qui établit une comparaison entre les choses doit nécessairement connaître ces choses ou en avoir l'expérience. (p. 49)

Cette comparaison évoque une autre, non moins audacieuse, dans la mémoire du narrateur:

Un jour, mon épouse me dit que les films pornographiques étaient comme de l'engrais chimique qui favorisait la croissance du fruit, augmentait son volume au plus haut point, mais lui faisait perdre son goût et sa saveur! D'où tenait-elle cela? (p. 49)

Tous ses souvenirs ressassés ne font que confirmer son immobilisme et sa situation dérisoire. Sa réaction démesurée par rapport à la télévision va parfaitement dans ce sens. Il rend cet appareil responsable de tout changement qui le dépasse et qu'il trouve intenable, et le diabolise:

Je souhaitais pouvoir recouvrir cet appareil devant moi, je veux dire la télévision, avec quelque chose d'épais, de l'acier, afin que rien ne puisse sortir... Mon Dieu! C'est ça la bombe atomique dont on parle. Peut-elle exploser? (p. 49)

Nous ne souhaitons pas clore cette partie sans nous arrêter sur la réaction du narrateur quand son épouse lui avoue qu'elle a été déflorée par le doigt de son cousin et qu'elle a subi une opération pour rétablir sa " virginité " perdue. Rachid El-Daïf consacre une trentaine de pages à nous présenter un narrateur en situation de complet ridicule, amenant sa femme d'un gynécologue à un autre afin de savoir si elle a été vraiment déflorée, comme elle le prétend, par un doigt, le doigt de son cousin en l'occurrence, ou suite à une relation sexuelle, et depuis combien de temps la défloration a eu lieu. Le héros qui avait pour ambition de changer le monde dans le roman 'Azīzì al-sayyid Kawabata (Cher Monsieur Kawabata ${ }^{31}$ ) du même auteur, n'a qu'une seule ambition dans Tistifil Meryl Streep, c'est de connaître " la vérité " sur la défloration de son épouse. La scène où il pose les questions à la gynécologue installe pleinement le narrateur dans la dérision totale:

Alors je lui demandai si elle peut évaluer grosso modo la date de l'entrée... Je poursuivis: « Pouvez-vous définir le moyen avec lequel l'affaire a été effectuée? »... J'insistai: « Est-ce un objet dur par exemple ou les

31. 'Azīzī al-sayyid Kawabata, Beyrouth, Dār Mukhtārāt, 1995. Traduit par Yves GonzalezQuijano sous le titre Cher Monsieur Kawabata, Arles, Sindbad - Actes Sud, 1998. 
doigts d'une main ou autre chose? "... Je n'hésitai pas alors à lui dire:

"Pouvez-vous définir la grosseur de la chose qui a été utilisée, je veux dire son calibre?» (p. 117)

Le mal à l'aise visible sur le visage du médecin et ses réponses mesurées ne découragent pas le narrateur: «Mais je ne fis pas marche arrière; je lui fis comprendre que j'étais venu pour savoir, pour connaître toute la vérité et non pas pour autre chose » (p. 117). Ses questions continuent à ce rythme, ce qui donne une idée claire de l'univers dans lequel il s'est enfermé.

\section{$* * *$}

Il va sans dire que l'évolution de l'écriture, dans les romans étudiés, reflète les deux périodes de l'histoire moderne de la société libanaise: la guerre et l'après-guerre. Et dans les deux cas, l'auteur campe, à travers une écriture intime et une rhétorique de simplicité, un narrateur/ anti-héros noyé dans les broutilles de sa vie quotidienne. $A$ travers cette écriture intime, mélangeant savamment le romanesque et l'autofiction, l'auteur montre que le problème, dans la société arabe, gît dans l'individu, et particulièrement chez l'homme. Plus on creuse dans son intimité profonde, plus on se rend compte de la fragilité de son idéologie moderniste et de sa pensée progressiste.

Cela étant, les œuvres de Rachid El-Daïf présentent une nouvelle approche de l'engagement social. À travers l'humour, l'ironie et la dérision, l'auteur réussit à interpeller son lecteur et l'invite, subtilement, à s'interroger sur de multiples questions qui dressent les obstacles devant le développement de la société arabe et devant son entrée réelle dans la modernité. Le style caricatural et grotesque avec lequel sont décrites les valeurs morales et les convictions traditionnelles prônées par le narrateur suscite, sans détours, l'effet inverse et suggère au lecteur de comprendre le contraire de ce qui est dit. L'effet stylistique de la dérision et de l'autodérision fait basculer le sens d'un côté à un autre, de son champ sémantique conventionnel à un champ opposé. À travers cette mise en texte, l'auteur adresse un message consistant à rejeter les convictions du narrateur, non à les conserver. 



\section{5 \\ À propos de Hirrat Sīkīrīdā La religion au service du meilleur et du pire \\ Heidi Toelle}

Hirrat Sīkīrīdā, le dernier roman de Rachid El-Daïf ${ }^{1}$, se déroule pendant la guerre civile libanaise; il se focalise sur deux personnages féminins qui habitent, l'un et l'autre, dans la banlieue sud de Beyrouth Ouest, à la population majoritairement chiite. Les deux femmes se trouvent confrontées sinon au même problème, du moins à des problèmes analogues, à savoir des grossesses extraconjugales. La première, Adība, doit faire face à la grossesse de Sīkīî̀nā, sa bonne éthiopienne et chrétienne, âgée de trente-cinq ans; la seconde à celle de sa fille, Amal, âgée de dix-huit ans et paralysée des deux jambes depuis sa naissance.

Les deux femmes vont adopter la même attitude tolérante à l'égard des "fautives" et aller de la sorte à contre-courant de leurs environnements respectifs et de la société en général, pour qui une grossesse extraconjugale demeure une faute inexcusable, entachant définitivement l'honneur de la mère, de l'enfant et de l'ensemble de la famille. Mais parallèlement, et en raison même de la condamnation dont une telle grossesse fait l'objet de la part de la société, les deux femmes vont se voir contraintes d'agir de manière à ce que ces grossesses passent pour tout ce qu'il y a de plus conforme aux traditions. Pour ce faire, elles vont trouver de l'aide auprès d'un cheik chiite qui acceptera, dans les deux cas, de procéder à un "mariage temporaire ", la fameuse mut ${ }^{\prime}{ }^{2}$ : dans le cas de la bonne éthiopienne, avec un faux père; dans le cas de Amal, avec le vrai père qui n'est autre que le fils de Sīkīrīdā, Riḍwān; ce dernier, alors âgé d'un peu plus de quinze ans, a été kidnappé par des milices chrétiennes à Beyrouth Est, où il était parti apprendre un

1. Rashīd al-Ḍa‘îif, Hirrat Sīkīrīdā, Beyrouth, Dār al-Sāqī, 2014.

2. Sur cette pratique voir plus loin p. 8. 
métier: on ignore au moment de ce mariage temporaire s'il est vivant ou mort. Enfin, à travers cette prise d'otage et au gré des tractations financières auxquelles elle donne lieu, l'espoir de faire libérer Riḍwān restant vain, une opposition se dessine entre, d'une part, une religion et une foi qui se caractérisent par la tolérance et la générosité et, de l'autre, une religion instrumentalisée par des chrétiens ou musulmans, pour s'enrichir, voire s'entre-tuer.

Pour expliquer ce paradoxe où la religion et la vraie foi se montrent plus tolérantes que la société censée les pratiquer, il ne sera peut-être pas inutile de procéder à l'analyse des deux personnages féminins principaux, Adība et Umm Amal', ainsi qu'à celle de Sīkīrīdā, de son fils Riḍwān et d'Amal: le lecteur découvre leurs vies respectives à travers des analepses dispersées tout le long de la première moitié du roman pour ce qui concerne Adība et de son entourage, tout le long de la seconde moitié pour Umm Amal et les siens, le roman commençant alors que Riḍān a déjà treize ans.

Il conviendra, enfin, de dire un mot de cette tradition de la mut' $a$ et de mettre en relief l'opposition entre deux conceptions opposées de la religion avant de tenter de comprendre le titre du roman.

\section{Adība et Umm Amal:}

\section{quand les croyants se montrent tolérants}

Différences. Adība est née en $1909^{4}$ dans une famille pauvre. Enfant, elle a rarement goûté à la viande. Elle n'a pas été scolarisée, tant et si bien qu'elle ne sait ni lire ni écrire. Dès l'âge de dix ans, elle travaille comme bonne dans une famille où le mari de sa maîtresse ne cesse de la tripoter sous de fallacieux prétextes. Cette expérience identique à celle d'autres filles, dont elle a eu vent, sera l'une des raisons de son indulgence à l'égard de Sīkīrīdā. À quatorze ans, son père la marie à son associé, un commerçant qui, a cinquante ans, est veuf et vit au Gabon. Adība ne restera dans ce pays que huit mois, puis reviendra à Beyrouth pour accoucher de son premier enfant et rester sur place. Malgré la différence d'âge, Adība et son mari, qui ne vient la voir qu'une fois par an, finissent par bien s'entendre. Elle aura de lui neuf enfants dont trois

3. Ce " nom " signifie "la mère de Amal ». Une telle dénomination - la mère (Umm), suivie du nom de l'aîné(e) de ses enfants - est, certes, courante dans la société arabe pour toutes les mères. Nous verrons, cependant, que le fait que ce personnage n'a ni nom de famille, ni prénom est à mettre en relation avec son parcours et son attitude à l'égard de sa fille.

4. Cf. Hirrat Sīkīrīdā, op. cit., p. 73. 
mourront en bas âge. Les trois filles et les trois garçons restants ainsi que les parents d'Adība émigreront tous au Gabon et contribueront de la sorte à l'amélioration considérable de sa situation, tant et si bien qu'elle finit par être financièrement assez à l'aise. Lorsque son fils cadet s’apprête, à son tour, à émigrer, elle est déjà assez âgée et, de surcroît, cardiaque. Aussi, la famille lui impose-t-elle de prendre une première bonne dont elle se voit contrainte de se séparer trois mois plus tard en raison d'une note de téléphone faramineuse. C'est alors que son mari ainsi que ses enfants l'obligent à recruter Sīkīīiā qui se révélera être une bonne exemplaire: les deux femmes deviennent pour ainsi dire amies et Adība ne cesse de remercier Dieu de lui avoir donné une telle servante. Aussi fera-t-elle tout pour protéger et garder Sīkīrīdā, après en avoir constaté la grossesse, et élèvera-t-elle Riḍwān, le fils de celle-ci, comme si c'était le sien.

Tout autre est le parcours d’Umm Amal. Son âge n’est pas indiqué, mais elle doit avoir environ quarante ans de moins qu'Adība. Issue d'une famille émigrée au Michigan dont elle a hérité un bout de terre près de Beyrouth ainsi qu'une somme d'argent conséquente, elle est diplômée en pharmacologie de l'université des jésuites et propriétaire de la pharmacie dans laquelle elle travaille. Contrairement à Adība, elle n’a pas fait l'objet d'un mariage arrangé. Le sien aura été la conséquence d'une sorte de coup de foudre réciproque. Les époux s'entendent à merveille jusqu'au moment où Umm Amal accouche d'une fille qui a les deux jambes paralysées: le père ne supporte pas de voir sa fille dans cet état, n'est visiblement plus amoureux de sa femme et ne la désire plus. Il décide donc, peu de temps après la naissance d'Amal, d'émigrer en Côte d'Ivoire, sous prétexte que, du fait de la guerre, il doute de l'avenir économique du Liban et donc du sien; ce alors même que ses affaires sont florissantes. Il revient, au début, deux fois par an pour la 'ìd al-fițr (fête de la rupture du jeûne) et la 'ìd al-aḍhạ (fête du sacrifice), puis ses visites s'espacent, si bien qu'il ne revient plus à Beyrouth que tous les deux ans, raccourcit systématiquement ses séjours, tant il supporte mal de voir la paralysie de sa fille, d'autant plus douloureusement même qu'au fur et à mesure qu'elle grandit, elle devient de plus en plus belle. Il a des maîtresses en Afrique et à Beyrouth, chose que sa femme n'ignore pas, mais elle ne veut pas demander le divorce, car non seulement elle comprend la tristesse que son mari éprouve en voyant sa fille paralysée, mais elle sait de surcroît que Amal adore et admire son père. Quant à elle, elle a décidé de ne vivre que pour sa fille avec laquelle elle s’entend à merveille - raison pour laquelle le texte la désigne exclusivement 
comme la " mère de Amal ». Lorsque cette dernière entre en terminale, Umm Amal embauche Riḍwān pour amener sa fille, le matin, dans sa chaise roulante au lycée et la ramener, l'après-midi, à la maison.

Les deux femmes, tout en habitant le même quartier, ne sont donc ni de la même génération, ni de la même classe sociale, ni du même niveau d'instruction. Les types de mariage qu'elles ont vécus sont aux antipodes et si l'une a six enfants, l'autre se voit contrainte, en raison de la paralysie de son unique fille et de l'attitude de son mari, de ne plus songer à faire d'autres enfants. Mais comme nous allons le voir, malgré ces différences, les deux femmes ont bon nombre de traits en commun.

Convergences. L'une et l'autre sont chiites et profondément croyantes, même si elles ne pratiquent pas leur religion de la même manière. Umm Amal ne porte pas le voile, ne jeûne qu'un seul jour au mois de ramadan et ne prie que quand elle en ressent le besoin. Cependant, elle le fait alors de tout son être et se retrouve de ce fait dans un état proche de l'extase mystique. Quant à Adība, elle porte le voile, fait tous les jours ses cinq prières, jeûne au mois de ramadan, même quand elle est en voyage ou malade, a fait le pèlerinage et visité maints lieux saints, s'abstient de chanter par respect pour l'imām Husayn ${ }^{5}$ et s'attache à se comporter en toutes circonstances conformément à la loi religieuse. En cas de doute, elle consulte régulièrement le cheik Qāsim. Ainsi procède-t-elle lorsque Riḍwān s'apprête à atteindre ses quinze ans, l'âge légal de la majorité: selon la norme, Adība devrait dès lors se voiler devant lui, parce qu'il n'est pas de la famille, un geste qui ne manquerait pas de chagriner le jeune homme qui l'appelle " māmā " (maman), car à ses yeux elle assume le rôle du père absent. Le cheik acceptera, sur insistance d'Adība et à l'insu de l'ensemble des autres

5. L’imām Ḥusayn est le deuxième fils de Fāțima, fille du prophète, et de 'Alī b. Abī Ṭâlib, quatrième calife, cousin et gendre du prophète. L'élection de ce dernier après l'assassinat du troisième calife, 'Uthmān, est contestée par plusieurs partis dont Mu‘āwiya, alors gouverneur de la Syrie et futur fondateur de la dynastie omayyade. Les batailles qui s'annoncent entre les deux partis sont à l'origine des deux schismes de l'islam, du chiisme et du kharijisme. En effet, lors de la bataille de Șiffin (657), 'Alī se voit contraint par Mu‘āwiya et certains de ses partisans d'accepter un arbitrage, alors que d'autres - les futurs Kharijites - sont contre et préconisent la poursuite de la guerre contre Mu'āwiya. Les divers partis continueront à s'opposer et à se combattre jusqu'au moment où 'Alī, alors âgé de 62 ou 63 ans, est assassiné devant la porte de la mosquée de Kūfa. Sa tombe à Najaf en Iraq est encore de nos jours un lieu de pèlerinage. Quant à son fils al-Husayn (626-680), appelé par certains Kufiens chiites à une insurrection contre le successeur de Mu'āwiya, Yazīd, il est tué lors de la bataille de Kerbalā' et considéré par les chiites comme un martyr. Pour plus d'informations, cf. Encyclopédie de l'islam, Leyde, Brill, et Paris, G.-P. Maisonneuve et Larose, 1990, entrées " 'Alī b. Abī Țâlib » et « Ḥusayn b. Alī b. Abì Țālib ». 
personnes concernées, de procéder à un mariage temporaire entre Riḍwān et l'une des petites filles d'Adība, de façon que le jeune homme devienne légalement un membre de la famille et permette ainsi à Adība de se présenter dévoilée devant lui.

Un autre trait rapproche les deux femmes: c'est leur disposition à mentir pour protéger ceux qu'elles aiment. C'est ainsi qu'Adība décide spontanément de cacher le fait que Riḍwān a, sans le vouloir, tué un ouvrier. En effet, un jour, le jeune homme ouvre la fenêtre de la salle de bains de l'appartement de Adība. La fenêtre dont les gonds sont rouillés lui échappe des mains et tombe dans la cour. Inquiet, il en informe Adība qui le rassure et l'envoie à l'école. Mais dès que le jeune homme est parti, elle se précipite dans la cour et constate que la fenêtre est tombée sur la tête d'un ouvrier et l'a tué. Considérant, non sans raison, que Riḍwān est innocent et que c'est plutôt elle la coupable, puisqu'elle avait oublié d'informer Riḍwān du mauvais état des gonds, elle s'empresse de cacher la fenêtre et prévient les voisins qu'un mort ou un blessé grave gît dans la cour. On appelle la police qui se contente de constater la mort de l'ouvrier et de prévenir la famille de celui-ci sans procéder - au grand soulagement d'Adība - à une quelconque enquête, tant les rixes et les morts qui s'ensuivent en cette période de guerre civile sont nombreux. Cependant la mauvaise conscience ne cessera de tourmenter la vieille femme. Aussi finit-elle, pour se disculper et faire amende honorable, par remettre à Umm Amal un testament dans lequel elle lègue à la famille de l'ouvrier défunt son appartement.

Quant à Umm Amal, elle cachera un problème moins grave mais néanmoins susceptible de porter préjudice à sa fille. Celle-ci vient de passer ses examens finaux pour obtenir le baccalauréat. Quelques jours plus tard, ses camarades de classe et amies viennent la voir pour la féliciter. En effet, son nom figure sur la liste des bacheliers affichée au ministère. Ravie, Umm Amal décide aussitôt de préparer en l'honneur de sa fille et dans les jours qui viennent une grande fête à laquelle elle compte inviter parents et amis. Elle prévient également son époux qui, lui aussi ravi, annonce qu'il viendra pour assister à la fête. Il faut croire - le texte ne le précise pas - qu'Amal a un pressentiment, car elle ne réussit pas à dormir cette nuit-là. Le matin, elle réclame avec insistance à sa mère de l'amener au ministère, car elle veut s'assurer que son nom figure bien sur la liste des bacheliers. La mère, quelque peu étonnée de cette réclamation, finit par céder. Or, il s'avère que la liste de la veille était erronée, comme l'indiquent les excuses du ministère précédant la nouvelle liste sur laquelle le nom d'Amal ne figure plus. La mère et 
la fille en restent saisies. Après un moment de réflexion, elles décident pourtant d'un commun accord de maintenir la fête et de cacher l'échec de Amal à tout le monde, car celle-ci s'engage à préparer d'arrache-pied les examens de rattrapage d'automne et à réussir à tout prix.

À cette volonté de protéger les êtres aimés, s'ajoute l'esprit de tolérance dont Adība et Umm Amal font preuve à toute occasion. Contrairement à bon nombre de maîtresses de maison libanaises, affirme le texte, Adība n'oblige pas Sīkīrīdā à se convertir à l'islam, ni à se voiler. La bonne a le droit d'aller le dimanche à l'église, et sa maîtresse finit par lui faire des cadeaux à Noël et à Pâques. Ajoutons que Sīkīrīdā, de son côté, ne voit aucun inconvénient à ce qu'Adība fasse de Riḍ̂ān un bon musulman. Par ailleurs, l'honnêteté, la propreté et la disponibilité de sa bonne font qu'Adība ne la surveille guère, ni ne l'empêche de sortir, ni ne la questionne, quand elle tarde à rentrer. C'est ainsi qu'elle ignore totalement que Sīkīrīdā couche avec divers hommes du quartier et est très étonnée, lorsqu'elle ne peut plus nier que sa bonne est enceinte. Elle s'oppose alors habilement à sa sœur et à son entourage qui veulent renvoyer Sīkīrīdā à Addis-Abeba par le prochain avion. Elle met en avant la mise en danger de la vie du bébé qui en résulterait - argument que le médecin consulté confirmera -, menace qu'on ne saurait faire peser sur un être innocent et nullement responsable des frasques de sa mère. Pour se rassurer, Adība ne manque pas de consulter le cheik Qāsim, qui finit par trouver dans ses livres (p. 28) une tradition qui rapporte que l'imām 'Alī ${ }^{6}$ aurait refusé de faire lapider ${ }^{7}$ une jeune femme qui avait fauté avec l'argument que le bébé dont elle était peut-être enceinte était innocent. Par la suite, elle fera tout pour sauver l'honneur de Sīkīīìā et du fils qu'elle porte. L'homme avec lequel celle-ci affirme avoir couché au moment où elle était tombée enceinte niera ces rapports et refusera, par conséquent, tout engagement. Adība se met donc en quête de quelqu'un susceptible d'accepter, contre espèces sonnantes et trébuchantes, d'accepter un mariage temporaire avec sa bonne. Elle finit par trouver de l'aide auprès d'un certain Abū Ibrāhīm, un chauffeur de taxi dont la voiture est en très mauvais état et qui accepte contre une somme lui permettant d'acheter une Volkswagen d'occasion. Le contrat sera validé, en présence de Adība, par le cheik Qāsim.

6. À propos de l'imām 'Alī, voir ci-dessus la note 4.

7. En cas d'adultère et de fornication, le Coran prescrit cent coups de fouets aux deux coupables à condition qu'il y ait eu quatre témoins. Cf. la sourate al-Nūr, versets 2-4. C'est 'Umar, le deuxième calife, qui semble être à l'origine de la lapidation en cas de fornication. Voir plus loin, p. 7-8. 
Quant à Umm Amal, elle se montre, elle aussi, très tolérante à l'égard de sa fille et de Riḍwān. Elle accepte que celui-ci amène Amal au bord de mer, voire les laisse seuls à la maison. Lorsque sa fille se fait déflorer et explique à sa mère les traces de sang dans la salle de bains par le fait que ses règles sont en avance, celle-ci se doute, certes, qu'il se passe quelque chose entre les deux jeunes gens, mais ne change pas d'attitude à leur égard. Enfin, quand Amal lui avoue qu'elle est enceinte, elle ne se met nullement en colère et laisse sa fille libre de choisir entre avorter ou garder l'enfant, tout en espérant que Amal choisira de conserver le bébé. Et c'est effectivement ce qui se passera. Umm Amal est ravie et envisage même de prendre Riḍwān comme gendre, et ce malgré la différence de classe sociale et d'instruction entre celui-ci et Amal. Elle aura, en revanche, un long différend avec son mari qui, une fois mis au courant, exige que sa fille avorte et menace de leur couper les vivres, ce que son épouse ne redoute guère, étant donné sa situation matérielle relativement confortable. Le père reviendra du reste sur cette décision, mais coupera tout autre lien avec son épouse et sa fille. Parallèlement, Umm Amal fera tout pour que les relations sexuelles entre sa fille et Riḍ̂an puissent continuer, tout en veillant à ce que celles-ci puissent avoir lieu à la maison plutôt qu'à la plage où les deux jeunes gens risquent un jour de se faire surprendre. Enfin, elle invite sa fille à informer Riḍwān de sa grossesse, bien qu'elle ait fini par comprendre que Amal ne le veut pas comme époux. Car le problème est de savoir s'il acceptera de prendre ses responsabilités et de faire ainsi en sorte que le bébé ait un père légal. Or, Riḍwān, une fois informé, ne fait aucun commentaire et disparaît, car, comme nous allons le voir, il en aime une autre. Il part avec son meilleur ami et un patron à Beyrouth Est pour y apprendre le métier de peintre en bâtiment, dans l'idée de pouvoir demander sa bien-aimée en mariage. Mal lui en prend. Les trois hommes sont pris en otage et les négociations pour libérer Riḍwān échouent, tant et si bien qu'on pense qu'il a finalement été tué. Umm Amal se met alors en quête d'un homme qui accepterait contre une rémunération importante de conclure avec Amal un mariage temporaire. Elle réussit à en convaincre le même chauffeur de taxi qui avait conclu le mariage temporaire avec Sīkīrīdā, mais celui-ci est assassiné - nous verrons pourquoi. Elle entre alors en contact avec Adība qui, persuadée que Riḍ̂ān est encore vivant, accepte que soit conclu par l'intermédiaire du cheik Qāsim un mariage temporaire entre lui et Amal.

La tolérance dont font preuve les deux femmes à l'égard des " coupables » est d'autant plus étonnante et louable qu'elles savent que ni la 
grossesse de Sīkīrīdā pour ce qui est d'Adība, ni celle d'Amal pour ce qui est d’Umm Amal, n'est le résultat d'une histoire d'amour irrépressible, mais celui de relations purement sexuelles.

\section{La valorisation des plaisirs de la chair}

Sīkīrīdā aime les hommes. En Éthiopie, elle était mariée, mais ne s'entendait pas avec son mari qui la battait, raison pour laquelle elle décide de quitter son pays dans l'espoir de se constituer un pécule qui lui permettrait de revenir et de refaire sa vie comme elle l'entend. Elle va d'abord au Yémen où elle devient la bonne d'une famille musulmane très rigoriste qui la surveille de près. Impossible dans ces conditions de satisfaire ses désirs sexuels. Ayant entendu dire que les Libanais sont un peu plus tolérants, elle décide de quitter le Yémen et de venir à Beyrouth où elle est engagée par Adība. La relation de confiance qui s'instaure entre les deux femmes lui laissera, nous avons vu, une grande liberté. Assouvir ses désirs sexuels paraît à Sīkīrīdā tout ce qu'il y a de plus normal. Elle est réputée avoir couché avec une vingtaine d'hommes, ce qui vaudra à son fils, au grand dam d'Adība, d'être encore parfois appelé par ses copains et camarades de classe Ibn al-‘ishrīn ( le fils des vingt pères »). Le premier rapport sexuel de Sīkīrīdā a lieu avec le patron d'une entreprise qui approvisionne l'appartement d'Adība en eau potable, l'eau du robinet étant en ces temps de guerre civile souvent coupée et de toute façon impropre à la consommation. Elle couche ensuite à plusieurs reprises avec le fils de l'épicier et quelques autres. Elle ignore, par conséquent, qui est le vrai père de son fils et ne s’en préoccupe point.

Quant à la relation entre Amal et Riḍwān, elle est, elle aussi, purement sexuelle. Du reste, Riḍwān n'accepte le travail proposé par Umm Amal que parce qu'il lui permet de voir le plus souvent possible Ilfat, une camarade de classe de Amal dont il est amoureux, qui l'aime en retour et qu'il compte bien demander en mariage dès qu'il aura appris un vrai métier. Aussi est-ce Amal qui est à l'origine de leur premier baiser et de leur premier rapport sexuel. La jouissance qu'elle en éprouve est telle qu'elle ne pourra plus s'en passer, au point qu'elle incite Riḍwān, de plus en plus souvent, à l'amener à la plage plutôt qu'à l'école - d'où son échec au baccalauréat. Ils font l'amour face à la mer, cachés derrière une tente qui fait fonction de café. Cette réaction de la jeune fille paralytique au plaisir sexuel n'est guère étonnante, car c'est la première fois de sa vie qu'elle perçoit son corps non plus comme un insupportable handicap, mais comme une source de jouissance. Enfin, 
c'est elle qui préside à l'initiation sexuelle de Riḍwān qui n’a aucune expérience en la matière, sinon les films pornographiques qu'il lui arrive d'aller voir en cachette avec ses amis au centre de Beyrouth, à al-Ḥamrā, projections pendant lesquelles ils se masturbent joyeusement. C'est Amal qui lui apprend que les filles ont toutes des règles, c'est elle qui l'oblige à faire l'acquisition de préservatifs, c'est elle encore qui, choquée que les programmes scolaires ne comportent aucune information sur la sexualité, lit maint livre pour apprendre comment faire en sorte que son partenaire ait un maximum de plaisir.

Quant à Riḍ̂ān, le texte reste muet sur ce qu'il éprouve à l'égard d'Amal. Tout au plus apprend-on qu'il a honte le jour où il se voit contraint d'acheter des préservatifs, démarche qu'il retarde d'ailleurs à plusieurs reprises au grand dam de Amal. Il craint par-dessus tout qu'Ilfat n'apprenne sa liaison avec celle-ci. Taiseux, il ne s'exprime ni sur ses sensations, ni sur ses sentiments, et nous avons vu qu'une fois informé de la grossesse d'Amal, il ne dit mot et disparaît.

Notons, enfin, que, comme dans le cas d'Adība et d'Umm Amal, il existe, malgré leurs ressemblances, une différence entre Sīkīrīdā et Amal. La première cède, en général, à des hommes qui la tripotent ou la draguent et a de ce fait plusieurs amants; la seconde, elle, prend les devants, et c'est Riḍwān, son seul amant, qui cède à ses désirs à elle. Cette différence nous semble là encore liée au fait que les deux femmes ne sont pas issues de la même classe sociale et n'ont pas le même niveau d'instruction, l'une est une bonne analphabète, l'autre est la fille d'une pharmacienne et s'apprête à passer le baccalauréat.

\section{Le mariage temporaire ou la mut'a}

Nous avons vu qu'Adība et Umm Amal, pour tolérantes qu'elles soient face aux grossesses extraconjugales de leur bonne et de leur fille, n'en sont pas moins conscientes que de telles grossesses ne sont point acceptées par la société dans laquelle elles vivent. Il est dès lors urgent de faire accroire qu'elles n'ont rien d'infamant, d'où le recours, dans les deux cas, au mariage temporaire appelé mut'a, terme qui signifie littéralement « jouissance ». Il ne sera donc pas inutile de dire quelques mots sur cette pratique.

Celle-ci remonte probablement à l'époque préislamique et a perduré à l'époque du prophète. En effet, le verset 24 de la sourate médinoise al-Nisā' ("Les femmes") du Coran affirme, après l'énumération des femmes avec lesquelles le mariage est interdit: "En dehors de celles qui ont été énumérées, il vous est licite de rechercher [des épouses], en 
usant de vos biens, en homme concluant un mariage en honnêteté, non en fornicateurs. Celles des femmes dont vous avez tiré jouissance ( $f a m \bar{a}$ istamta'tum bihi minhunna), donnez-leur leur salaire (ujūr) comme imposition (farịda). Nul grief à vous faire à l'égard de ce sur quoi vous avez pris consentement mutuel, après [versement de] l'imposition $\left(\right.$ farị $\left.d a^{8}\right)$. " Une autre version a été supprimée: « [...] celles des femmes que vous avez prises par mariage temporaire jusqu'à un terme fixé ${ }^{9}$ (famā istamta'tum bihi minhunna ilā ajal musammā) [...] ».

Ce verset a donné lieu à des interprétations divergentes, les uns considérant qu'il n'a trait qu'au mariage habituel (nikāḥ), les autres au mariage temporaire. Mais il semble bien que la mut'a ait été autorisée par le prophète pour certains motifs et pour une courte durée. Elle était surtout autorisée pour trois jours lors d'une expédition ou pour une courte durée, lorsqu'un homme se trouvait dans une localité étrangère de manière à ce que la femme puisse prendre soin de lui. Cependant, le prophète aurait interdit la mut'a le jour de la célèbre bataille de Khaybar (628), ou encore pendant le pèlerinage d'adieu. Quant au deuxième calife, 'Umar (634-644), il a interdit la mut'a vers la fin de son règne en menaçant les contrevenants de lapidation. Cela n'a pas empêché que des jurisconsultes émettaient encore dans la seconde moitié du VII ${ }^{\mathrm{e}}$ siècle des fetwas en faveur de la mut'a. C'est au VIII ${ }^{\mathrm{e}}$ siècle que les opposants à la mut'a prennent le dessus. Celle-ci ne sera plus autorisée que par les chiites, car pour eux 'Umar n'était pas une autorité en droit de l'interdire. Cela n'a pas empêché les sunnites de faire des concessions. Shāfi'ī, entre autres, autorise un mariage conclu avec l'intention tacite d'en limiter la durée, à condition que cela ne soit pas expressément stipulé dans le contrat. À l'inverse, les chiites exigent que tout contrat de mariage temporaire fasse état d'une durée - un ou plusieurs jours, plusieurs mois ou années - et d'une rémunération, douaire (mahr) ou salaire (ajr, pl. ujür), faute de quoi il n'est pas valable. La femme ne doit pas encore être mariée, et doit être honorable et chiite. La mut'a prend fin à l'expiration de la période convenue ${ }^{10}$. On

8. Nous avons repris avec de légères modifications la traduction de Régis Blachère. Cf. Le Coran, Traduction selon un essai de reclassement des sourates, op. cit., p. 931-932.

9. La seconde version qui fait nettement allusion au mariage temporaire se trouvait dans les corpus de Ubayy b. Ka'b et d'Ibn Mas'ūd ainsi que dans le Coran d'Ibn 'Abbās. Le passage ilā ajal musammā ("jusqu'à un terme fixé ") a été supprimé, soit vers la fin de l'apostolat de Muhammad, soit plus tard, peut-être sous le califat de 'Umar. Cf. Régis Blachère, Le Coran. Traduction selon un essai de reclassement des sourates, Paris, Maisonneuve et $\mathrm{C}^{\mathrm{ie}}$., 1951, p. 931.

10. Pour plus de précisions cf. Encyclopédie de l'Islam, op. cit., entrée " mut‘a ». 
peut voir dans ce type de mariage une manière de protéger et la femme et l'éventuel enfant, car, à l'époque ancienne, il n'existait aucun moyen de se protéger: ni préservatif, ni moins encore de pilule contraceptive!

À l'époque moderne, en revanche, la mut'a équivaut à une sorte de prostitution légale. Elle fut même encore pratiquée à la Mecque, mais sans que la durée soit mentionnée dans le contrat. Tout se passait verbalement, et l'homme prononçait au moment de la conclusion du contrat la formule du țalāq, à savoir de la répudiation. À partir $\mathrm{du} \mathrm{xx}^{\mathrm{e}}$ siècle, cependant, la mut'a s'est faite plus rare, même si de tels mariages étaient encore conclus à Dayr ez-Zor (Syrie) par les bédouins ${ }^{11}$.

\section{Quand les croyants se montrent intolérants et cèdent à l'appât du gain}

Nous avons vu plus haut qu'Abū Ibrāhīm, le chauffeur de taxi, accepte à deux reprises de conclure un mariage temporaire contre espèces sonnantes et trébuchantes, la première fois avec Sīkīīinā, une seconde fois avec Amal, mais qu'il se fait assassiner avant la conclusion de ce dernier contrat. En effet, du fait de la guerre civile qui ravage le Liban depuis quinze ans, sa situation s'est aggravée. Son travail de chauffeur de taxi ne lui permet plus de vivre convenablement. Dès lors, il s'est mis au service d'une petite bande qui sévit à Beyrouth Ouest où elle prend des chrétiens en otage dans le but de les échanger contre des musulmans pris eux en otage à Beyrouth Est par des chrétiens, contre un minimum de trente mille dollars. Abū Ibrāhīm, qui se vante de ne jamais avoir participé directement à une prise d'otage, sert d'intermédiaire à la bande en question pour négocier avec la partie adverse l'échange des otages et le prix auquel elle accepte de les rendre. Cette fonction lui rapporte un peu d'argent. Lorsqu'il lui revient qu'une personne proche d'Adība a été capturée à Beyrouth Est, il propose son aide à cette dernière. C'est alors qu'il apprend que, parmi les trois otages musulmans, figure Riḍwān, le garçon dont il est le faux père et qu'il connaît de vue. Il n'en est alors que plus disposé à aider à sa libération, mais il se rend compte qu'Adība est beaucoup moins riche qu'il ne le pensait. Elle lui précise qu'elle ne pourra guère payer plus de dix mille dollars, une somme dont ses partenaires ne se contenteront jamais. Il décide alors de tenter d'agir seul afin d'empocher, à son profit, la somme en question et, de manière à ce que ses acolytes ne se doutent de rien, il incite Adība à engager elle-même les négociations avec la

11. Ibid. 
partie adverse. Elle y consent, malgré le danger que cela représente, car il est hors de question pour elle d'enlever son voile, même à Beyrouth Est. Or, ce voile la fera repérer comme musulmane et est susceptible de conduire à sa prise d'otage. Néanmoins, les pourparlers avec le chef de chantier pour lequel Riḍwān, son ami et leur patron avaient travaillé commencent par aller bon train. Entre-temps, Abū Ibrāhīm songe d'abord à s'en prendre, seul, à un chrétien, mais se rend vite compte qu'il n'en a pas les moyens. Mais sachant où ses acolytes logent les chrétiens pris en otage, il décide de leur en soustraire un et de s'enfuir avec lui pour l'échanger contre Ridiwān. Mal lui en prend. En effet, le membre de la bande préposé à la surveillance des otages le surprend, et Abū Ibrāhīm lui échappe de justesse, ce qui l'oblige à se cacher. Du coup, les négociations pour libérer Riḍwān se mettent à piétiner, puis se trouvent définitivement interrompues, sans qu'on sache exactement pourquoi. Peu de temps après, on retrouve Abū Ibrāhīm baignant dans son sang dans son appartement, ses acolytes ayant décidé de se venger pour ce qu'ils considèrent comme une trahison. Il survit, cependant, après avoir été soigné à l'hôpital, mais ne peut plus marcher qu'avec des béquilles. C'est alors qu'Umm Amal qui cherche activement un homme susceptible d'accepter un mariage temporaire avec sa fille apprend cette tentative d'assassinat dont tout le quartier, à l'exception de Adība, ignore les raisons. Elle décide d'aller voir Abū Ibrāhīm à l'hôpital, lui apporte ce dont il a besoin, le cajole, enfin, après lui avoir fait jurer de garder le secret, elle lui demande d'accepter de conclure une mut'a avec sa fille. Elle lui promet de lui acheter une boutique et de pourvoir en outre pendant trois mois à l'achat des marchandises qu'il compte y vendre. Il va sans dire qu'Abū Ibrāhīm accepte immédiatement, tout en demandant à Umm Amal de bien vouloir lui installer dans son appartement une porte en fer munie d'un judas pour qu'il puisse se prémunir contre de nouvelles tentatives d'assassinat de la part de ses acolytes. Les travaux n'ont pas encore commencé quand on le retrouve, cette fois-ci, mort, tué au moyen d'une arme munie d'un silencieux.

On le voit, derrière les actions de la bande dont Abū Ibrāhīm fait partie se profilent à la fois l'inimitié entre chrétiens et musulmans qui était l'une des caractéristiques de la guerre civile libanaise et une inextinguible soif de gain. La bande - Abū Ibrāhīm compris - a beau prétendre qu'elle fait le bien, en sauvant la vie de certains musulmans, elle n'accepte de sauver que ceux d'entre eux qui sont riches et n'a cure des pauvres qui ne peuvent payer les sommes faramineuses qu'ils exigent. Cette attitude est non seulement en opposition complète avec l'attitude 
tolérante dont Adība et Umm Amal font preuve en toutes circonstances, mais elle se trouve également en totale opposition avec la générosité des deux femmes qui, elles, n'emploient leur argent que pour rendre service, l'une à une pauvre bonne chrétienne, l'autre à une pauvre fille paralysée des jambes.

Le roman se lit ainsi comme une critique implicite, mais acerbe du comportement des Libanais, chrétiens et musulmans, pendant la guerre civile et en même temps comme une tentative de suggérer que la religion et la foi pourraient servir à autre chose qu'à s'entre-tuer et à s'extorquer réciproquement de l'argent. Et ce n'est sans doute pas un hasard si ce sont deux femmes, à la fois différentes et semblables, ainsi qu'un cheik chiite qui sont mis en scène pour illustrer l'attitude de tolérance et de générosité qui est implicitement valorisée par le narrateur. Et comme celui-ci est un narrateur omniscient, c'est en même temps l'opinion de l'auteur lui-même qui se profile derrière cette position, ce qui nous amène à dire un dernier mot sur le titre du roman choisi par ce dernier.

\section{Le sens du titre du roman}

On ne peut s'empêcher de se poser des questions sur le sens du titre du roman: Hirrat Sīkīrīdā ("La chatte de Sīkīīidā »). Certes, à un moment donné, Sīkīrīdā amène un chaton qu'elle a trouvé dans la rue dans l'appartement d'Adība. Celle-ci lui donne tout d'abord l'ordre de remettre le chaton dehors, et Sīkīrīdā s'exécute, tout en déposant le chat à un endroit qui lui permette de retrouver l'appartement. Et, effectivement, le chaton revient plusieurs fois, tant et si bien qu'Adība finit par céder et accepte de le garder. Elle finit même par l'adorer, par le caresser et le mettre en lieu sûr en cas de bombardement. Ce petit intermède qui ne joue aucun rôle dans le déroulement des événements et qu'on peut interpréter à la limite comme l'un des signes de la bonne relation entre Adība et sa bonne est-il, à lui tout seul, à l'origine du titre choisi par l'auteur? On peut en douter, si l'on tente d'aller plus loin dans l'analyse.

En effet, en dialectal libanais, le mot qittta, un synonyme de hirra, est parfois employé avec le sens de vagin, tout comme le mot « chatte » en français, langue que l'auteur du roman ainsi que beaucoup de Libanais maîtrisent, par ailleurs, parfaitement, tant et si bien qu'on peut se demander, s'il ne s'agit pas en libanais dialectal d'une simple traduction de mot français. Mais il y a plus. En effet, la langue arabe possède deux laryngales « $h$ ». Un « $h$ » proche de l'« $h$ » aspiré allemand qu'on 
trouve dans le terme hirra du titre du roman et un « ḥ » défini comme " un souffle sourd émis dans la position de la voix chuchotée ${ }^{12}$ » - d'où le point sous ce type ce " $\mathrm{h}$ " en cas de transcription pour le distinguer du premier. Or, en arabe classique les termes hirr ou hirra désignent précisément le vagin ${ }^{13}$. On ne peut donc s'empêcher de penser que le titre Hirrat Sīkīìidā renvoie implicitement et pudiquement - en remplaçant le «h » par un " h » - au vagin de la bonne éthiopienne, car ce sont bien les aventures sexuelles de celle-ci qui sont à l'origine de l'ensemble des événements du roman.

12. Cf. R. Blachère, Grammaire de l'arabe classique, Paris, Maisonneuve \& Larose, 1952, p. 26.

13. Cf. A. de Biberstein Kazimirski, Dictionnaire arabe-français, Dār Al-Burāq, Beyrouth, tome I, p. 400. Je remercie Jean-Charles Coulon de m’avoir rappelé ce terme et cette signification, en me citant un vers d'une des Khamriyyāt (poèmes chantant le vin) du célèbre poète Abū Nuwwās (747 ou 747 - 813 ou 815). Cf. Dīwān Abū Nuwwās, Beyrouth, Dār al-Kitāb al-‘arabī, s.d., p. 6. 


\title{
6
}

\section{Le Musicien et le Calife de Bagdad Traduire les niveaux de langue d'un roman historique arabe}

\author{
Xavier Luffin
}

Le Musicien et le Calife de Bagdad ${ }^{1}$ constitue le premier roman historique de Rachid El-Daïf, dont les romans précédents se déroulaient tous à l'époque contemporaine. Nous choisissons ici le terme "roman historique " parce que l'intrigue du livre se déroule effectivement à une époque reculée, en l'occurrence à l'époque abbasside, au moment de la rivalité entre les deux fils de Hārūn al-Rashīd, al-Amīn et al-Ma'mūn, au début du $\mathrm{IX}^{\mathrm{e}}$ siècle de notre ère.

Le défi majeur qui s'est présenté à nous lors de la traduction de ce roman fut de tenter de rendre les niveaux de langue utilisés par l'auteur, présents principalement de deux manières: dans les dizaines de poèmes de l'époque abbasside et même d'époques antérieures cités dans le roman, ainsi qu'à travers les nombreux termes anciens utilisés dans la narration elle-même et souvent glosés par l'auteur à l'intérieur du texte, entre parenthèses.

Notre objectif principal était que le lecteur francophone ressente, d'une part, le même écart entre la langue de la narration et celle des poèmes - singularisée à la fois pas un registre lexical plus élevé, la métrique et la rime - et, d'autre part, le même aspect désuet de certains termes anciens introduits dans la narration.

\section{Littérature arabe contemporaine et niveaux de langues}

D’une manière ou d'une autre, chaque langue présente plusieurs niveaux; cependant l'arabe offre une réelle situation de diglossie, avec

1. Rachid El-Daïf, Le Musicien et le Calife de Bagdad, Arles, Actes Sud, 2010, trad. Par Xavier Luffin. Ma'bad yanjah fì Baghdād, Beyrouth, Riyāḍ al-Rayyis, 2005. 
un écart très marqué entre, d'une part, l'arabe classique - al-fuṣhā et, d'autre part, l'arabe dialectal - al-āmmiyya ou encore al-dārija tant au niveau de la phonologie et de la morphosyntaxe que du lexique.

Théoriquement, l'usage de ces deux niveaux de langue est clairement défini et délimité, l'arabe classique (et sa version moderne, l'arabe standard) étant destiné au discours oral formel (discours religieux, politique, intellectuel, registre écrit, etc.) et à l'écrit, et l'arabe dialectal au discours informel, essentiellement oral. Mais dans la pratique, la limite est souvent moins évidente, et pas seulement à l'époque contemporaine: il existe une poésie dialectale écrite, de même que des textes en moyen arabe, un registre particulier mêlant les codes de l'arabe classique et du dialectal ${ }^{2}$.

Traditionnellement, les auteurs littéraires ne recourent qu'à l'arabe classique, puisqu'il s'agit par excellence de la langue de l'écrit. L'œuvre de Najīb Maḥuuz, par exemple, n'est rédigée qu'en arabe classique, intégrant parfois tel ou tel terme dialectal mais ne présentant aucune phrase ou structure qui ne soit classique. Toutefois, très tôt, certains auteurs ont fait le choix de recourir à l'arabe dialectal. Généralement, celui-ci est utilisé dans les dialogues tandis que la narration reste en arabe standard, même si quelques auteurs, certes beaucoup moins nombreux, ont même décidé de n'écrire qu'en arabe dialectal, y compris pour la narration - pensons notamment à Laban al-'uṣfür de Muḥammad Yūsuf al-QQa'īid ${ }^{3}$.

L'usage de l'arabe dialectal dans la littérature arabe contemporaine, parfaitement justifié d'un point de vue littéraire, est certainement l'un des défis majeurs du traducteur francophone, dont la langue n'est pas aussi dichotomique. En effet, si les linguistes n'hésitent pas à parler également de diglossie dans le cas du français, elle ne correspond pas du tout à la situation de l'arabe, où l'arabe dialectal et l'arabe classique sont clairement différenciés sur les plans tant phonologique que morphosyntaxique et lexical. Alors, comment rendre cette variation linguistique, qui est une composante essentielle de l'œuvre arabe, par ailleurs immédiatement identifiée par le lecteur du texte original? La situation devient encore plus compliquée lorsque l'auteur utilise, d'une part, l'arabe standard pour la narration, et, d'autre part, plusieurs dialectes pour les dialogues. Un cas d'école est le roman Inna-hā Lundun ya

2. Pour une définition récente du moyen arabe, voir Johannes Den Heijer, « Middle and Mixed Arabic. A New Trend in the Arabic Studies ", in Liesbeth Zack and Arie Schippers, Middle Arabic and Mixed Arabic: Diachrony and Synchrony, Leiden, Brill, 2012.

3. Muḥammad Yūsuf al-Qa'īd, Laban al-'uṣfūr, Le Caire, Dār al-Hilāl, 1994. 
' $a z \bar{\imath} z \bar{l}^{4}$ de l'écrivaine libanaise Ḥanān al-Shaykh, où interviennent des personnages parlant anglais, mais aussi arabe libanais, syrien, irakien, marocain et du Golfe. Cette large variété linguistique n'est tout simplement pas traduisible dans son ensemble en français.

\section{Le cas particulier du roman historique}

D'un point de vue linguistique et traductologique, le roman historique arabe présente encore un autre genre de difficultés que celles évoquées jusqu'ici. En effet, les auteurs utilisent généralement la langue comme l'un des marqueurs permettant au lecteur de situer le texte qu'il lit dans un temps reculé. On retrouve là une technique à laquelle les écrivains européens ont recours eux aussi. Pour prendre l'exemple particulier de la langue française, il suffit d'ouvrir les pages de l'un des volumes de l'œuvre désormais classique de Maurice Druon, Les Rois maudits, fresque historique en sept volumes se déroulant tout au long $\mathrm{du} \mathrm{XIV}^{\mathrm{e}}$ siècle. Dès les premières pages du premier volume, on se trouve confronté à des termes désuets - familiers seulement au lecteur averti, versé dans la culture médiévale - ou encore à des tournures de phrases certes parfaitement compréhensibles, mais désormais peu communes, comme celle-ci, mise dans la bouche de la reine Isabelle:

Que voilà donc de touchantes paroles, dit-elle, et qu'on croirait tout juste faites pour moi. Ah! Le temps n'est plus où les grands seigneurs comme ce duc Guillaume étaient aussi exercés à la poésie qu'à la guerre. Quand m'avez-vous dit qu'il vivait? Deux cent années? On jurerait de ce lai qu'il est écrit d'hier ${ }^{5}$.

Ou encore ces paroles de Robert d'Artois:

Petite affaire! dit Robert d'Artois en abattant sa patte sur l'épaule de Philippe, qui en chancela. Un plaisir pour moi. C'est le mouvement naturel de tout gentilhomme que de se porter au secours des gens qu'on attaque. Mais l'agrément est double lorsqu'il s'agit de seigneurs de connaissance, et je suis bien aise d'avoir conservé à mes cousins Valois et Poitiers leurs meilleurs écuyers. Mon seul regret est qu'il ait fait si sombre. Ah si la lune s'était plus tôt montrée, j'aurais aimé découdre quelques-uns de ces trousse gousset. Je n'ai point osé piquer vraiment, de crainte de vous trouer... Mais, dites-moi, damoiseaux, qu'aviez-vous à muser dans ce fangeux réduit ${ }^{6}$ ?

4. Ḥanān al-Shaykh, Inna-hā Lundun ya 'azīzī, Beyrouth, Dār al-ādāb, 2001.

5. Maurice Druon, Les Rois maudits. Le Roi de fer, Paris, Le livre de poche, 1970, p. 18.

6. Ibid., p. 111. 
Cependant, il ne s'agit pas non plus d'écrire comme on l'aurait fait il y a cinq ou dix siècles: dans le cas du français, cela rendrait le texte incompréhensible pour le lecteur contemporain. D'ailleurs, lorsque les personnages de Maurice Druon citent de la poésie médiévale, si elle paraît bien ancienne, en réalité, elle n'en est pas moins retraduite dans un français abordable. Ainsi, les vers qui figurent dans les premières pages du premier volume des Rois maudits, dus à Guillaume d'Aquitaine (1071-1127) « D'amour ne dois plus dire bien/Car je n'en n'ai ni peu ni rien/Car plus n'en ai qui ne convient ${ }^{7} \ldots$ » sont bien plus modernes malgré leur apparence que la langue originale du poète, aujourd'hui incompréhensibles: « D'Amor non dey dire mas be/Quar no n'ai ni petit ni re?/Quar ben leu plus no m'en cove ${ }^{8} . .$. »

Dans le cas de l'arabe, la situation est quelque peu différente: les normes grammaticales de l'arabe moderne restent extrêmement proches de celles de l'arabe classique de l'époque médiévale, et par ailleurs un corpus important de poèmes anciens est étudié encore aujourd'hui par les Arabes dans leur parcours scolaire. Un texte médiéval, qu'il soit historique ou littéraire, est donc aisément identifié comme ancien par le lecteur, mais aussi largement compréhensible pour un individu correctement scolarisé, qui n'a pas besoin d'une traduction semblable à l'exemple des vers de Guillaume d'Aquitaine adaptés par Druon. Plusieurs cas de figure apparaissent néanmoins. Le premier cas est celui de l'œuvre de Jirjī Zaydān, le pionnier du roman historique arabe qui a publié au début $d u x^{e}$ siècle de nombreux romans se référant à l'histoire médiévale arabo-musulmane (citons par exemple Al-Amīn wa-l-Ma'mūn $n^{9}$ et Shärl wa-'Abd al-Raḥman ${ }^{10}$ ), en s'inspirant vraisemblablement de modalités narratives occidentales, puisées notamment chez Walter Scott et Alexandre Dumas ${ }^{11}$. De manière générale, Zaydān utilisait une langue très classique, tant pour la narration que pour les dialogues, comme c'était l'usage à l'époque. La traduction de ses romans pose donc peu de problèmes, parce que l'arabe classique semble bien se prêter à un roman censé se passer à la période médiévale - nous avons vu que les auteurs français de romans historiques

7. Ibid., p. 17.

8. Alfred Jeanroy, Les Chansons de Guillaume IX Duc d'Aquitaine (1071-1127), Paris, Champion, 1927, p. 17.

9. Jirjī Zaydān, Al-Amīn wa-l-Ma’mūn, Le Caire, Dār al-Hilāl, 1900.

10. Jirjī Zaydān, Shārl wa-'Abd al-Raḥman, Le Caire, Dār al-Hilāl, 1904.

11. Kadhim Jihad Hassan, Le Roman arabe (1834-2004), Arles, Sindbad-Actes Sud, 2006, p. 31. 
se tournent eux aussi vers une langue plus soutenue, classicisante, pour donner à leur texte un aspect ancien - mais aussi parce que son usage est relativement uniforme, à la fois dans la trame et dans les dialogues.

Cependant, les auteurs arabes de romans historiques plus récents, influencés par une tradition romanesque nouvelle qui a maintenant plus d'un siècle, optent généralement pour une autre technique. Ils ont recours à une langue plus moderne que celle de Zaydān, mais néanmoins teintée de références intertextuelles, de termes désuets, voire de formules aujourd'hui inusitées. Si l'on prend l'exemple de Majnūn al-ḥukm de l'auteur marocain Bin Sālim Ḥimmīsh, un roman qui décrit l'étrange règne de Ḥākim Bi-amrillah, célèbre souverain fatimide des $\mathrm{XI}^{\mathrm{e}}-\mathrm{XII}^{\mathrm{e}}$ siècle, on retrouve clairement ces éléments. Concernant l'intertextualité, chaque chapitre commence en effet par un ou plusieurs extraits de textes historiques médiévaux ayant trait à la période concernée. Par exemple, le premier chapitre est précédé de plusieurs citations d'auteurs médiévaux, notamment Abū al-Faraj ibn al-Jawzī (mort en 1201) et Ahmad al-Maqrīzìi ${ }^{12}$ (mort en 1442), clairement identifiables par le lecteur arabe comme étant rédigés dans une langue médiévale. Ensuite, la narration elle-même imite la langue médiévale, comme l'illustre cette formulation archaïque des dates: yawm al-khamīs liarba'i layālin baqīna min shahri'l-awwal sanata khams wa-saba'īn wa thalāthami'a ${ }^{13}$... Cependant, tout cela se mêle à une langue plus contemporaine, avec notamment des néologismes - par exemple le terme nafsiyyū ${ }^{14}$, qui signifie " psychologues " - volontairement intégrés pour créer une langue hybride, à la fois archaïque et contemporaine.

Un second exemple intéressant est celui de la nouvelle intitulée Qalaq al-fāris, que l'on doit à Muhammad Gharnāț, également marocain. Il ne s'agit pas a priori d'un texte appartenant au genre historique, puisque la trame se déroule à l'époque contemporaine; cependant le personnage sort tout droit du passé: 'Antara, célèbre poète préislamique connu pour sa bravoure et devenu le héros d'une épopée chevaleresque, sort de sa tombe sans savoir que quatorze siècles ont passé. Il est donc confronté à toute une série de choses qui lui sont inconnues - les immeubles, les voitures, les cigarettes, les policiers en uniforme, etc. Parallèlement, la langue utilisée par 'Antara est évidemment complètement anachronique, notamment lorsqu'il s'exprime en

12. Bin Sālim Ḥimmīsh, Majnūn al-ḥukm, Le Caire, Al-Afāq, 1998, p. 10.

13. Ibid., p. 11.

14. Ibid., p. 12. 
vers poétiques, tandis que celle utilisée par les autres personnages, qui s'expriment parfois en arabe marocain contemporain, lui paraît bien étrange également. L'extrait suivant, un dialogue entre 'Antara et une jeune Marocaine qu'il pense être sa cousine bien-aimée, 'Abla, montre bien les malentendus entre les deux personnages, dus autant à l'incongruité de la situation qu'aux registres linguistiques:

- Je suis 'Antara ibn Shaddād. Au diable l'Histoire et l'obscurité de la tombe.

- Ah, tu joues donc le rôle de 'Antara, celui dont le Prophète a dit: « Le seul bédouin que j’aie jamais voulu voir de mes propres yeux, c'est 'Antara. ” Il secoua la tête avec fierté, avant de déclarer:

- Je suis Abū'l-Mughallis, celui qui combat dans l'obscurité.

À quoi elle répondit avec une amabilité feinte:

- [en arabe marocain]: Bien, enchanté, monsieur. Et maintenant, que voulez-vous exactement?

Il déclama alors ces vers:

«Fais donc mon éloge,

Je me montre bon lorsqu'on est juste envers moi. »

Elle ne prêta guère attention à ce vers ancien, et répondit:

- Tu es parfait pour ce rôle, mon gars. Mais où est donc la caméra ${ }^{15}$ ?

À l'évidence, l'auteur joue ici sur les différents niveaux de langues utilisés dans les dialogues - arabe standard, arabe marocain, arabe poétique préislamique - donnant bien du fil à retordre au traducteur potentiel.

\section{Le Musicien et le Calife de Bagdad}

Venons-en au roman de Rachid El-Daïf, Le Musicien et le Calife de Bagdad. Pour écrire ce livre, l'auteur s'est inspiré notamment de la lecture du célèbre Kitāb al-aghānī d'Abū'l-Faraj al-Isfahānī (897-967), "Le livre des chants", un imposant ouvrage contenant une somme de vers et d'anecdotes à propos de grands poètes et chanteurs, hommes et femmes, depuis l'époque préislamique jusqu'à celle de l'auteur. On y parle notamment de Ma'bad ibn Wahb - chanteur et compositeur prolifique, il est même le premier chanteur cité dans le livre, et l'auteur nous rapporte quelques anecdotes à propos de son parcours: c'était à l'origine un esclave vivant dans les environs de Médine, qui reproduisait le jour des mélodies qu'il percevait la nuit - mais aussi

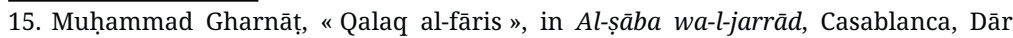
Qurțuba, 1988, p. 78. 
des nombreux autres poètes cités dans le livre: Majnūn Laylā, Nușayb, al-Farazdaq ${ }^{16}$, etc.

Le roman se concentre sur la vie de Ma'bad ibn Rabah que Rachid El-Daïf présente comme un jeune poète et chanteur originaire du Hedjaz, noir de peau et descendant d'esclaves; ce dernier, une fois persuadé de son talent, décide de se rendre à Bagdad pour y chercher fortune. Il arrive dans la capitale abbasside au moment de la rivalité entre les deux fils de Hārūn al-Rashīd, al-Amīn et al-Ma'mūn, au début du IX siècle de notre ère, et se voit malgré lui balloté entre les partisans des deux frères ennemis. Une note préliminair ${ }^{17}$ nous apprend d'emblée qu'il ne s'agit pas du Ma‘bad ibn Wahb cité dans le Kitāb al-aghānī, malgré les ressemblances biographiques évidentes - notons que Ma‘bad ibn Wahb est mort bien avant les événements décrits par Rachid El-Daïf. Et c'est là que le travail du romancier prend forme: même si l'on croit reconnaître à chaque page des événements et des personnages de l'histoire arabe médiévale, ceux-ci sont remaniés à la guise de l'auteur.

L'utilisation de la langue dans Le Musicien et le Calife de Bagdad rejoint en apparence celle que l'on a mise en évidence dans Majnūn al-ḥukm sur au moins deux points l'intertextualité et la recherche d'une langue narrative archaïsante, mais pas archaïque. En ce qui concerne l'intertextualité, elle est omniprésente, puisque le roman se passe dans le monde des poètes et des chanteurs de l'époque abbasside, et que les poèmes de ces derniers sont abondamment cités. En effet, plus de soixante-quinze extraits de poèmes, généralement assez courts — deux à quatre hémistiches en général - apparaissent dans le roman. Dans le texte original, les vers sont aisément reconnaissables, parce qu'ils sont écrits en caractères gras dans le texte original, mais surtout en raison de leur forme: ils se terminent généralement tous par la même rime, comme cela est l'usage en poésie arabe classique. Dans la version française, ces mêmes vers sont tout aussi reconnaissables visuellement, puisqu'ils sont notés en retrait et en italique. Mais surtout, nous avons tenté d'utiliser une langue plus relevée mais néanmoins tout à fait compréhensible pour les traduire, comme dans cet exemple:

Qui donc te prêtera un œil pour verser une larme, As-tu jamais vu quelqu'un emprunter des yeux pour pleurer ${ }^{18}$ ?

16. Cf. Hilary Kilpatrick, Making the Great Book of Songs, Londres, Routledge Curzon, 2010.

17. Rachid El-Daïf, Le Musicien et le Calife, op. cit., p. 9.

18. Ibid., p. 98. 


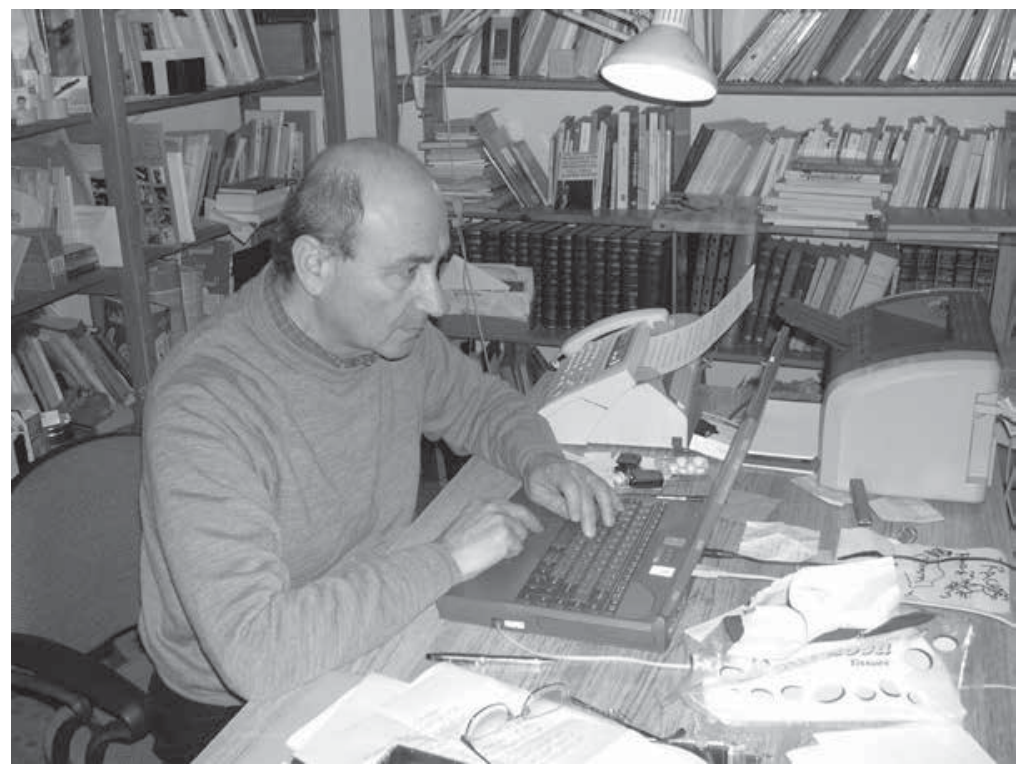

Dans son bureau à Beyrouth

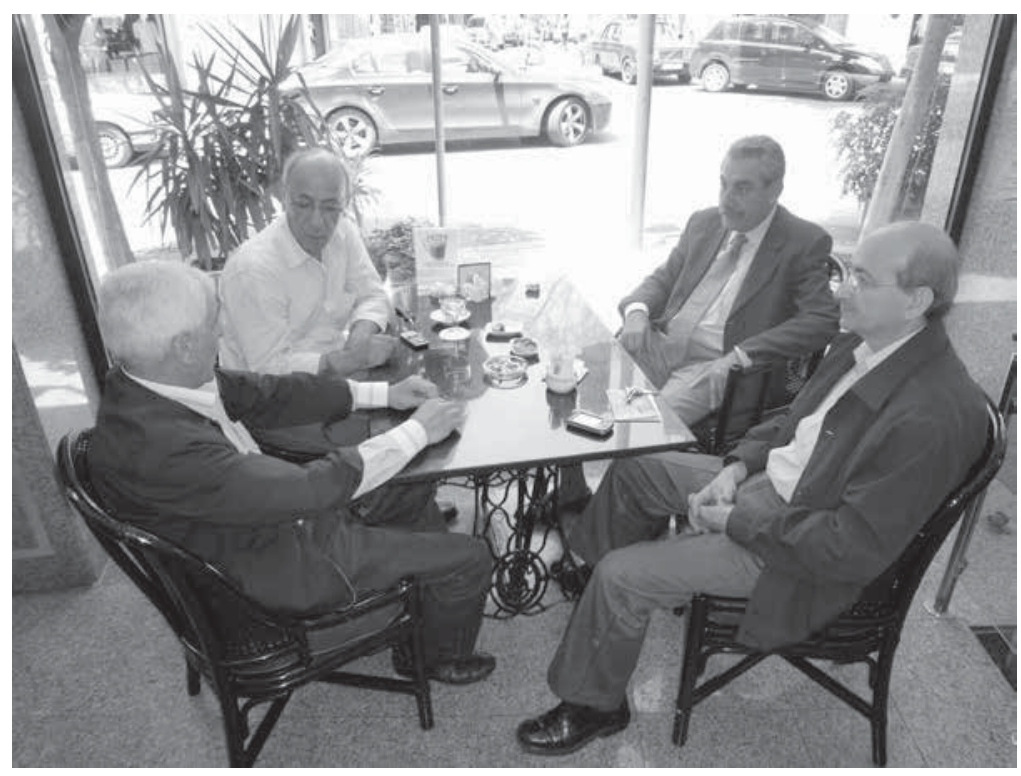

$\mathrm{Au}$ café avec un groupe d'amis 
En effet, le texte original reste parfaitement compréhensible aujourd'hui pour un arabophone, tant sur le plan du vocabulaire que de la grammaire:

Man dhā tu'îru-ka 'ayna-hu tabkī bi-hā

a-ra'ayta 'aynan li-l-bukā' tu'āru' .

Concernant l'aspect archaïque de la langue narrative, il transparaît aussi à travers l'usage de termes désuets, compréhensibles mais peu ou pas utilisés dans la langue moderne. Cependant, Rachid El-Daïf rend cela encore plus complexe, en proposant de manière récurrente une glose en arabe moderne proposée entre parenthèses juste après les termes concernés. Par exemple, fa-stakhlā-hā (ḍajja'a-hā) wa-ḥabilat

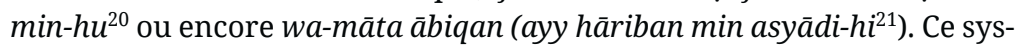
tème faisant partie du texte arabe de manière formelle, il fallait trouver une parade pour le conserver dans la langue d'arrivée. Nous avons donc décidé de rendre systématiquement les termes glosés par des termes désuets en français, puis de les faire suivre par un terme usuel entre parenthèses. Cela donne pour les deux exemples précités: « il se retira avec elle (c'est-à-dire qu'il lui fit l'amour ${ }^{22}$ ) » et " il est mort en marron (c'est-à-dire qu'il a fui ses maîtres ${ }^{23}$ ) ». Parfois, le terme arabe glosé est encore d'usage courant en arabe moderne, mais il a néanmoins acquis un autre sens. Nous avons alors décidé de garder ce terme en français et de le gloser, même s'il n'a pas connu la même évolution sémantique en français, comme dans le cas du mot șawt, glosé par ughniyya dans le texte original, que nous avons rendu par « cette voix (c'est-à-dire cette chanson) » en français. En effet, lorsque al-Isfahānī par exemple utilise le terme șawt, il se réfère à une chanson.

Souvent, le recours à l'ancien français a permis de rendre l'écart linguistique encore plus profond, lorsque cela était nécessaire. Ainsi, nous avons rendu ayfā' (al-yafa‘ huwa kull makān mushrif ${ }^{24}$ ) par " poix (c'est-à-dire colline surplombant la plaine ${ }^{25}$ ) ", ou encore al-minașșa (ayy firāsh-ha al-‘ālĭ $\left.\bar{\imath}^{26}\right)$ par « colte (c'est-à-dire le lit ${ }^{27}$ ) ».

19. Rashīd al-Ḍa'ịf, Ma'bad yanjah fì Baghdād, op. cit., p. 79.

20. Ibid., p. 18.

21. Ibid., 2005, p. 32.

22. Rachid El-Daïf, Le Musicien et le Calife, op. cit., p. 18.

23. Ibid., p. 40.

24. Ma'bad yanjah fi Baghdād, op. cit., p. 54 .

25. Le Musicien et le Calife, op. cit., p. 67.

26. Ma'bad yanjah fi Baghdād, op. cit., p. 74.

27. Le Musicien et le Calife, op. cit., p. 91. 
Parfois, ces gloses sont introduites dans les poèmes cités, ce qui doit aux yeux du lecteur rendre le poème encore plus châtié, puisqu'il nécessite une explication, comme dans ce vers:

wa-lan yuqaddima nafsan, qabla muddati-hā/jam'u l-yadayni, wa-lā alșamșāmatu al-dhakaru (jam'u l-yadayni: al-qabụu 'alā l-sayfi bi-l-yadayni al-ithnātayni. al-șamșāmatu: al-sayf. al-dhakaru: al-matīn ${ }^{28}$ )

Nous avons alors eu recours encore une fois à l'ancien français pour rendre le poème moins immédiatement compréhensible par le lecteur francophone:

Même un espadon aduré tenu fermement entre deux mains/ne s'emparera jamais d'une âme avant l'heure prévue », suivi d'une note en bas de page: «Espadon: épée. Aduré: solide ${ }^{29}$. (N. d. A.)

Bien sûr, le parallèle fait entre arabe médiéval et français médiéval est imparfait, pour au moins deux raisons. D'un point de vue historique d'abord, les deux langues ne correspondent pas exactement à la même époque, puisque l'histoire de Ma'bad se déroule au tournant $\mathrm{du} \mathrm{VIII}^{\mathrm{e}}$ siècle et $\mathrm{du} \mathrm{IX}^{\mathrm{e}}$ siècle de notre ère, alors que les dictionnaires d'ancien français sont basés sur un corpus de textes allant du $\mathrm{IX}^{\mathrm{e}} \mathrm{au}$ $\mathrm{XIII}^{\mathrm{e}}$ siècle. Mais surtout, l'évolution des deux langues est très différente: un texte arabe du VIII ${ }^{\mathrm{e}}$ siècle reste largement compréhensible aujourd'hui pour un lecteur cultivé; il arrive d'ailleurs fréquemment dans le monde arabe qu'un interlocuteur cite un vers ancien, parfois antérieur à ceux de l'époque concernée par le roman. Pareille situation est impensable dans le monde francophone, tant l'ancien français diffère de l'idiome contemporain - repensons aux vers de Guillaume d'Aquitaine adaptés par Maurice Druon. Néanmoins, l'effet offert au lecteur contemporain est assez comparable: il distingue clairement l'usage de niveaux de langues différents, associés à des périodes chronologiques différentes.

\section{$* * *$}

Dans Le Musicien et le Calife de Bagdad, Rachid El-Daïf utilise différents registres de la langue arabe: une langue moderne pour la narration, quoique truffée de termes archaïques, et une langue médiévale pour les nombreuses citations de vers poétiques. Cet usage rejoint celui du roman historique arabe en général, qui joue souvent

28. Ma'bad yanjah fi Baghdād, op. cit., p. 42.

29. Le Musicien et le Calife, op. cit., p. 53. 
sur l'intertextualité, d'autant plus abordable que l'arabe moderne a conservé les mêmes règles grammaticales que l'arabe médiéval, et que le lecteur contemporain a généralement une culture poétique qui intègre de nombreuses œuvres anciennes. Le rapport à la langue classique est donc très différent que celui que le lecteur francophone entretient avec l'ancien français, aujourd'hui largement incompréhensible. Là où l'auteur de romans historiques français « imite » la langue ancienne, l'auteur arabe peut se permettre d'intégrer des passages de textes médiévaux et des poèmes, nécessitant tout au plus quelques gloses pour des termes particuliers.

Afin de ne pas perdre cette situation linguistique particulière de l'arabe dans le texte français, nous avons opté en tant que traducteur pour deux techniques. La première, concernant les termes glosés par l'auteur lui-même, a été de recourir à un français châtié, voire à l'ancien français pour rechercher des termes désuets et généralement incompréhensibles, ensuite glosés entre parenthèses comme dans le texte original, une technique susceptible d'offrir au lecteur francophone un effet langagier similaire. La seconde a été de traduire les poèmes en un français soutenu, parfois classicisant, mais néanmoins toujours compréhensible pour le lecteur francophone. Cet usage offre le double avantage de se rapprocher, d'une part, de la variation linguistique du texte original arabe, et de donner, d'autre part, un style relativement proche de celui du roman historique français, où l'on trouve également de nombreux termes désuets qui donnent une impression d'ancienneté sans pour autant rendre le texte incompréhensible. 


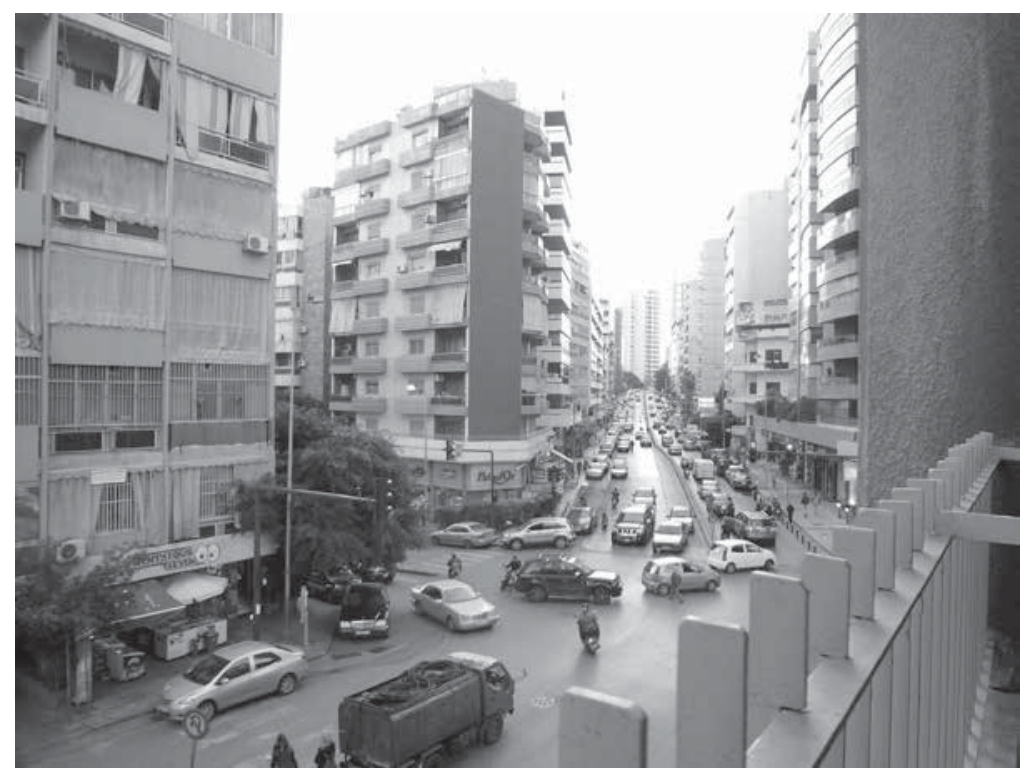

La rue visible du balcon de son appartement à Verdun

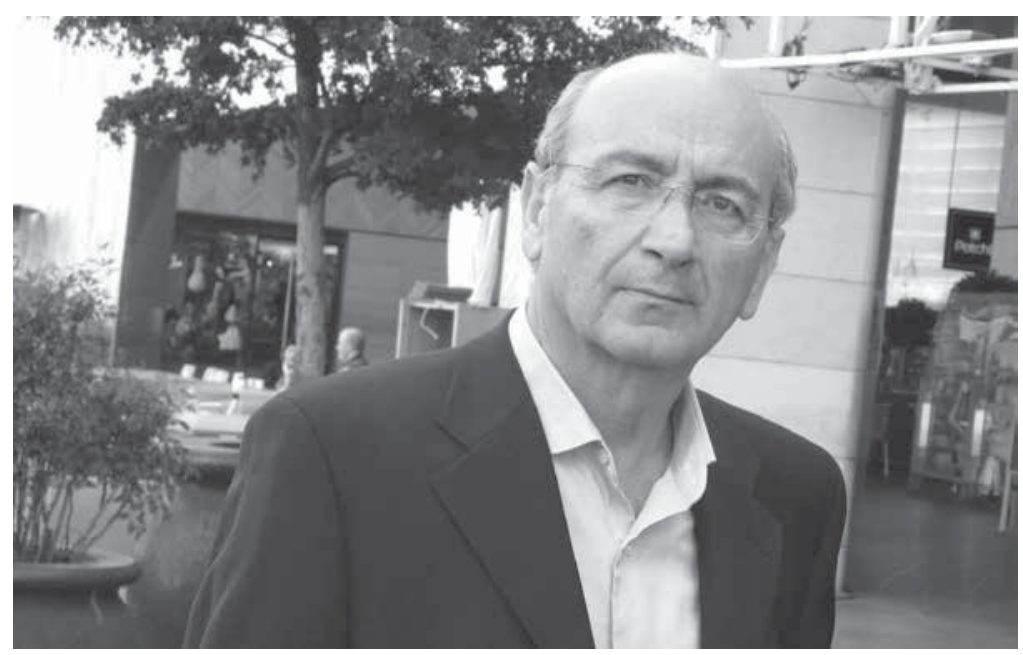

$\mathrm{Au}$ centre-ville de Beyrouth 


\section{7 \\ La nécessité du récit \\ Jean-Charles Depaule}

En général, c'est à Paris ou à Beyrouth, tantôt chez lui tantôt au café, le plus souvent, avant sa fermeture définitive, au Café de Paris, rue Hamra; parfois dans sa maison à Ehden, au-dessus des nuages. Je me rappelle aussi un moment passé ensemble à Bruxelles où une rencontre avait été organisée autour de lui au Théâtre flamand: nous avions visité le musée des Beaux-Arts. Et à Poitiers: nous parcourions les rues réservées aux piétons, il cherchait un baromètre-thermomètre électronique, nous sommes entrés dans Notre-Dame-la-Grande. Périodiquement Rachid me raconte des histoires, des aventures qui lui seraient arrivées ou qu'on lui aurait rapportées, et je suis sous le charme. Au cours d'une promenade, tandis que nous marchons côte à côte, il souligne la drôlerie ou le caractère dramatique d'un épisode de son récit par une pression de sa main sur mon bras - ce geste me rappelle mon père.

Un jour, je ne saurais dire au juste quand, j'ai cru reconnaître dans un de ses livres une des histoires qu'il m'avait contées naguère. Et depuis, de roman en roman, il m'est arrivé d'en identifier des fragments, recomposés par l'écriture. Une fois, aussi, une anecdote que je lui avais rapportée. Le lui ai-je dit? Maintenant il le saura, je tire une forme de satisfaction d'être mis de la sorte à contribution, ne serait-ce qu'en lui prêtant l'oreille voire en lui posant des questions ou en formulant à sa demande des commentaires, et de lui avoir procuré l'occasion de tester les éléments d'un texte à venir.

" Mais le temps ne revient jamais en arrière ${ }^{1}$. » Il me faut sans doute préciser que ma démarche ne prétend ni à l'interprétation ni à une analyse thématique. Elle s'attache surtout aux opérations que l'écrivain effectue, dans son travail dans et sur la langue, à son art de faire, art

1. Rachid El-Daï, Le Musicien et le Calife de Bagdad (trad. Xavier Luffin), Arles, Actes Sud, 2010 [2005].p. 174. 
poétique en acte, notion qui n'est pas si éloignée de ce qu'on appelait jadis la "manière " d'un auteur. Sans s'interdire des rapprochements avec des écrivains qui ne sont pas forcément familiers à Rachid, mais avec lesquels des affinités sont assez probantes pour autoriser des digressions intertextuelles.

Les procédés que j'ai dégagés doivent être compris comme des outils destinés à aider à l'intelligibilité du texte, en mettant en exergue des caractéristiques retenues pour leur pertinence présumée.

L'inattendu attendu. La nécessité du récit sous-tend l'œuvre de Rachid El-Daïf. Déjà, dans les poèmes apparemment peu narratifs de L'Été au tranchant de l'été, on décelait des embryons d'histoire où se manifestait, contenue, une pression narrative. Rachid, et on n'a pas de raison de ne pas le croire, affirme qu'il ne sait pas ce qu'il veut faire quand il entreprend l'écriture d'un texte ${ }^{3}$. Mais, s'il ignore ce qu'il veut écrire (et comment?), il sait, me semble-t-il, qu'il veut écrire. Et, si, comme il l'affirme avec netteté, il n'a pas l'intention de délivrer un message, s'il n'est pas animé par un vouloir dire (ceci ou cela), par le dessein d'illustrer une thèse ou d'échafauder une démonstration, lorsqu'il se met à la tâche son désir est de raconter.

Raconter, c'est, de fait (et d'abord?), assumer la "fatalité » que la structure linéaire de la langue impose: l'enchaînement même de la parole parlée et écrite est celui d'une succession de mots, de phrases et d'instants qui engage "naturellement " à une certaine narrativité. En écho, je citerai un commentaire de Claude Simon sur sa pratique de romancier. Après avoir souligné le caractère « très vague " de son projet initial, il note: " Puisqu'en définitive parler ou écrire, c'est toujours une question d'ordre [...] je ne sais par où commencer ${ }^{4}$. Dans cette fatalité réside sans doute pour une part le caractère énigmatique - un mystère aurait dit Jean Paulhan — de la force d'entraînement que le récit recèle pour le romancier et pour son lecteur.

En effet, le récit suscite immanquablement une attente, même si celui qui le lit ignore où le mène l'auteur, qui, d'ailleurs, n'a pas toujours su vers quoi il se dirigeait (Rachid explique: "Je me laisse aller, en

2. L'Été au tranchant de l'épée (trad. Jamal Eddine Bencheikh), Paris - Beyrouth, Le Sycomore - Dar Al-farabi, 1979.

3. Les propos rapportés sans référence dans cet essai ont été tenus soit au cours de conversations privées, soit dans le séminaire organisé le 9 décembre 2014 à l'INALCO par Sobhi Boustani ou lors de la journée d'étude coordonnée par Katia Ghosn le 11 décembre 2014 à l’Université Paris VIII.

4. Claude Simon, Quatre Conférences, Paris, Minuit, 2012, p. 92 et 66. 
écrivant, au mouvement des vagues à la surface de ma conscience. "). L'inattendu attendu, dirait Claude Simon ${ }^{5}$. Je pense à une situation limite de Qu'elle aille au diable, Meryl Streep!: le narrateur assiste à la télévision, en version originale et sans sous-titres, à une scène de rupture, interprétée par Dustin Hoffman et Meryl Streep. Lui qui ignore l'anglais, il se déclare néanmoins " envoûté sans y comprendre un traître $\operatorname{mot}^{6} »$. Cette scène pourrait être une métaphore du récit, entendu comme pur fonctionnement narratif, qu'il veuille ou non jouons sur l'ambiguïté de l'expression - dire quelque chose.

À propos de tautologie, j’ai relevé chez Clément Rosset une remarque qui s'applique à la chanson populaire; la proximité avec ce qui est évoqué ici est forte et troublante:

Il arrive bien que le texte de la chanson raconte une histoire, mais cette histoire est alors aussi muette que les «faits" rapportés dans le cas de figure le plus fréquent, car c'est une histoire sans enseignement ni morale et qui se donne seulement pour ce qu'elle est. La nature tautologique de ce genre de textes ne fait aucun doute: ce qu'on chante dans la chanson populaire revient toujours ou presque à mentionner que $\mathrm{A}$ est $\mathrm{A}$ ou que $B$ est $B$. Le chant populaire ressemble ainsi à une commémoration à vide: une commémoration de ce qui n’a aucun titre particulier à être mémorable ou mémorisép.

Un roman de Rachid comme une chanson populaire? Ne prétendant pas, lui non plus, dire, à sa façon, autre chose que ce qu'il dit.

La parataxe. C'est un procédé qui consiste à "juxtaposer des phrases sans expliciter par une particule de subordination ou de coordination le rapport de dépendance qui existe entre elles dans un énoncé, dans un discours, dans une argumentation ${ }^{8}$ ". Je l'illustrerai par les premières lignes, très connues, de L'Étranger:

Aujourd'hui, maman est morte. Ou peut-être hier, je ne sais pas. J'ai reçu un télégramme de l'asile: "Mère décédée. Enterrement demain. Sentiments distingués ». Cela ne veut rien dire. C'était peut-être hier.

5. Claude Simon, "L'inattendu attendu », in Mireille Calle-Grüber (dir.), Les Tryptiques de Claude Simon ou l'art du montage, Paris, Presses de la Sorbonne nouvelle, 2009, pp. 19-21.

6. Rachid El-Daïf, Qu'elle aille au diable, Meryl Streep! (trad. Edgard Weber), Arles Sud, 2004 [2001], p. 67, 68 et 69.

7. Clément Rosset, Le Démon de la tautologie suivi de Cinq petites pièces morales, Paris, Minuit, 1997, p. 50.

8. Jean Dubois (dir.), Dictionnaire de linguistique et des sciences du langage, Paris, Larousse, 1994. 
L'asile de vieillards est à Marengo, à quatre-vingts kilomètres d'Alger. Je prendrai l'autobus à deux heures et j'arriverai dans l'après-midi ${ }^{9}[. .$.$] .$

$\mathrm{Au}$ début de Passage au crépuscule, son premier roman, Rachid El-Daïf recourt à ce procédé minimal, donnant le ton - simplicité apparente et précision de l'écriture - de ce qui va suivre. L'action se passe pendant la guerre civile libanaise, le narrateur, qui a perdu un bras, est progressivement contraint à la réclusion, jusqu'à ne plus pouvoir sortir de sa chambre. Par exemple:

Je me suis rendu à la porte.

J'étais torse nu. Mon bras droit était coupé à la hauteur de l'épaule: je ne portais pas de chemise, ni rien.

Décidément, je me rendais à la porte.

J'y étais. Je l'ouvris de la main gauche. Je fis un pas au-dehors et je dis à voix haute:

Oui $^{10}$ ?

Dans ces exemples, le procédé n’est pas appliqué de façon stricte puisqu'il y a dans les deux cas un " et ». Et en général lorsque, dans la suite de Passage au crépuscule et dans le reste de son œuvre, il y recourt, Rachid El-Daïf n'est pas systématique, il tend à la parataxe. Spécialement dans L'Insolence du Serpent, quand il construit son récit par juxtaposition de propositions indépendantes, s’il n'élimine pas toute conjonction, il conserve des particules de coordination de préférence à celles qui indiquent la subordination. Dans le texte original arabe, on relève, au lieu de l'emploi de qabla an, b'ada an, ou 'inda $m \bar{a}$ (" avant que, après que, tandis que »), celui, récurrent, de wa (" et "; " et aussi »), ou de thumma (" ensuite »; " et puis »). Il arrive aussi qu'un paragraphe, un épisode commence par un thumma et se trouve rattaché en quelque sorte à une plus vaste narration potentielle, hors champ.

Même si, en introduisant un peu de liant, elle rend la juxtaposition moins sèche, moins nue, l'utilisation de telles particules n'atténue pas l'absence de hiérarchisation et de relation causale entre les moments, événements ou propos rapportés qu'une construction parataxique implique: le déroulement du récit se limite quasiment à une succession. En outre, la répétition de ces particules contribue, me semble-t-il, à l'impression d'une mise à plat, sans hausser le ton, et d'un certain prosaïsme.

9. Albert Camus, L'Étranger, Paris, Gallimard, 1942.

10. Passage au crépuscule (trad. Luc Barbulesco et Philippe Cardinal), Arles, Actes Sud, 1992 [1986], p. 8. 
Cette réitération peut poser au traducteur de l'arabe en français un délicat, et typique, problème: il lui faut choisir entre maintenir la répétition (et... et... et...) que, dans sa langue, le bon usage proscrit, ou bien, pour respecter celui-ci, introduire de la diversité en affaiblissant assurément l'effet produit par l'original, entre angoisse et dérision. Trop souvent, note Rachid, on ne traduit que "l'histoire " d'un roman, c'est-à-dire l'argument, l'intrigue à quoi le récit ne saurait être identifié, puisqu'il est indissociablement sens et forme, écriture. En outre il comporte généralement une dimension réflexive qui fait d'un auteur un écrivain, et non juste un " écrivant ", selon la distinction de Barthes que Rachid reprend à son compte. On en mesure d'autant mieux la difficulté de la tâche du traducteur qui, ainsi que le soulignait Walter Benjamin, ne se limite pas à la restitution $d u$ sens ${ }^{11}$.

La composition parataxique induit une indécision qui, selon le qualificatif utilisé par Farouk Mardam Bey, est éventuellement " rusée ". Fréquemment désinvolte aussi, et légère - et d'autant plus inquiétante, chez Rachid, qu'elle paraît légère. Des critiques ont souligné l'effet d'étrangeté, d'insolite, de distance produit ainsi par un regard qui semble ne pas aller au-delà de la surface des choses (Sartre, à propos de L'Étranger de Camus, parlait, avec une certaine condescendance, d'une vision du monde à travers une vitre). Par exemple, dans l'écriture de Fais voir tes jambes, Leïla! Josyane Savigneau percevait " une sorte de naïveté enjouée ${ }^{12}$ ". Dans L'insolence du serpent, parmi les habitants descendus en pyjama dans la rue, après un tremblement de terre, " certains portaient dans leurs bras leurs enfants, d'autres portaient sur eux un paquet de cigarettes ${ }^{13}$ ». À une lectrice regrettant que Rachid ne l'ait pas aidée davantage dans sa lecture, car il ne compose pas ses romans en chapitres (que dire alors de W. G. Sebald ou de Thomas Bernard, lorsqu'ils enchaînent leurs récits sans paragraphes, et a fortiori de Marie Ndiaye ou Mathias Enard écrivant un roman en une unique phrase qui se développe jusqu'au point final?), on pourrait répondre qu'il s'en remet, au moins pour une part, au lecteur, en lui laissant le soin de combler à son gré les interstices du récit. Et citer Allen Ginsberg, qui, à partir de la façon dont Cézanne juxtaposait les couleurs, avance "l'idée, peut-être excessivement raffinée, que [...]

11. Walter Benjamin, "La tâche du traducteur », in Mythe et violence (trad. de l'allemand par Maurice de Gandillac), Paris, Denoël, 1971 [1923], pp. 271-275.

12. "Au Liban, scènes de genre et théâtre d'ombres ", Le Monde, 3 novembre 2006.

13. Rachid El-Daïf, L'Insolence du serpent ou les créatures de l'ombre (trad. et prés. Edgard Weber), Toulouse, AMAM, 1997 (1987), p. 77. 
par la juxtaposition d'un mot à un autre, un trou entre deux mots - comme le trou spatial sur la toile - , il y aurait un trou entre les deux mots que l'esprit remplirait avec la sensation de l'existence ${ }^{14}$ ". Ou, encore, Emmanuel Hocquard:

Les propositions sont indépendantes entre elles. Des relations s'établissent. Alors les propositions s'enchaînent ou s'attirent ou se repoussent ou se font écho. Le récit procède de ces rencontres ${ }^{15}$.

L'inachevé. La conception d'une œuvre littéralement ouverte se profile. La fin des romans de Rachid - plus encore que leur incipit - sans chute, sans nœud ni dénouement, laisse en suspens le développement narratif. Des exemples: "Mais j'ai quand même fini par dire, après un temps de silence et en prenant une grande respiration, pour rassembler tout mon courage: Bien sûr! Bien sûr ${ }^{16}$ ". Ou bien: "Il écrivit aussi à la fille de son " oncle ", celle que son père lui avait interdit d'épouser, pour la convaincre de divorcer, mais elle refusa - il continua toutefois d'espérer un jour de recevoir une réponse favorable ${ }^{17}$. " Et, plus radicalement, la dernière phrase, inachevée, de $N a \overline{h i y}$ at al-barā' $a^{18}$, sur laquelle Sobhi Boustani a attiré notre attention: Kāna 'alayya an..., " Il me fallait... ". Un inachèvement qui pourrait répondre à un thumma ( " ensuite »; " et puis ») placé en ouverture d’un récit.

Difficile de ne pas penser aux catégorisations de Mikhaïl Bakhtine: à la différence de l'épopée dont le temps est "fermé, arrondi, parachevé $^{19}$ ", le roman, écrit-il, représente « un monde où le " premier mot « (celui du début idéal) fait défaut, où le « dernier « n’a pas encore été prononcé ». Il ajoute:

L'objet s'intègre dans le processus inachevé du monde en devenir, et il est frappé du sceau de l'imperfection. Si éloigné soit-il de nous dans le temps, il est relié, à notre présent incomplet par de continuelles mutations temporelles, relié à notre imperfection, à notre présent, et ce pré-

14. Paris Review, les Entretiens, Anthologie, Vol. 1 (trad. de l'anglais Anne Wicke), Paris, Christian Bourgois, 2010, p. 164.

15. Emmanuel Hocquard, Conditions de lumière, Paris, P.O.L., 2007, p. 181.

16. Rachid El-Daïf, Learning English (trad. Yves Gonzalez Quijano), Arles, Actes Sud, 2002 [1998].

17. Rachid El-Daï, Le Musicien et le Calife de Bagdad, op. cit.

18. Rachid El-Daïf, Nāhiyat al-barā’a (Du côté de l'innocence), Beyrouth, Dār al-Masār, 1997, non publié en français.

19. Mikhaïl Bakhtine, " Récit épique et roman ", in Esthétique et théorie du roman, Paris, Gallimard, 1991 [1975], p. 455. 
sent avance vers un avenir inaccompli. [...] Son sens et sa signification se renouvellent et grandissent à mesure que le contexte se développe ${ }^{20}$.

Aussi, lorsqu'il n'a pas la prétention de « dire » quelque chose, le récit parle-t-il immanquablement de la vie.

La rhétorique du simple. Salam Diab, qui est une spécialiste de son œuvre, voit en Rachid El-Daïf le " maître de la rhétorique du simple, du quotidien ", de ce qui n'a aucun titre à être mémorable (je reprends les mots de Clément Rosset), mais qui à l'occasion acquiert une présence insupportable. C'est le cas dans Techniques de la misère: dans une ville en guerre dont aucun service ne fonctionne plus, les tours d'électricité ou d'eau rythment l'existence des habitants. Sous la plume de l'auteur, modes d'emploi de la survie et recettes alternatives se succèdent: par exemple, comment alimenter le réservoir installé au-dessus de la salle de bains, à quel tuyau le raccorder et comment alimenter les autres robinets de l'appartement ${ }^{21}$... Une dizaine d'années plus tard, Rachid disait au journaliste Christophe Ayad - son propos prend un relief particulier en 2015: "Le prix du téléphone, l'état des trottoirs, c’est aussi important que changer la société et ça, nos intellectuels ne l'ont pas intégré. On reste obsédés par les grandes causes ${ }^{22}{ }^{2}$.

Les ressources de la balägha ("éloquence "). "Maître de la rhétorique du simple", cette formule s'applique non seulement à une réalité jugée d'habitude négligeable, mais à la recherche d'une simplicité qui fait l'efficacité d'un récit (Salam Diab parle également de « facilité impossible », le simple est difficile), à la manière dont Rachid traque tout procédé qu'il estime inutile: "Lorsque j'ai fini d'écrire un texte, explique-t-il, je le relis et je supprime un certain nombre de choses qui peuvent relever d'une certaine éloquence. "

Il joue aussi avec les types de construction, qu'il combine. D'un roman à l'autre et à l'intérieur d'un même livre, non seulement il opère des dosages, par exemple en introduisant plus ou moins de parataxe, en appliquant le procédé à des passages de différente longueur, mais il varie les figures et les temps, alterne discours direct ou indirect, récit rapporté, insère au besoin une narration seconde dans le déroulement principal et, périodiquement, des répétitions-variations...

\section{Ibid., p. 464.}

21. Rachid El-Daïf, Taqniyyāt al-bu’s, Beyrouth, Dār Mukhtārāt, 1989. Seuls des extraits ont été publiés en français: "Techniques de la misère " (trad. Leila Guermouche et Brigitte Marino), Méditerranéennes 5, 1993, pp. 96-101.

22. "Liban Gueule de bois ", Libération, jeudi 29 octobre 1998. 
Une vingtaine d'années après Passage au crépuscule, dans Le Musicien et le Calife de Bagdad (les aventures, au IX ${ }^{\mathrm{e}}$ siècle, de Ma'bad, talentueux poète et chanteur, parti chercher fortune dans la glorieuse capitale des califes abbassides), il propose une anthologie savante et amusée de figures et montages narratifs. Entre minimalisme et foisonnement, il combine à plaisir vitesses et échelles de temps, la " grande histoire ", riche en intrigues et en événements sanglants, et les péripéties dans lesquelles est pris le héros. Il les agrémente d'incrustations, comme les ornements dont use abondamment la littérature ancienne savante et populaire: digressions, vers, chantés notamment par Ma‘bad, et énoncés proverbiaux. À première vue, ils ne sont pas essentiels à la logique narrative, mais au fur et à mesure que le récit progresse, il s'avère que, même (et surtout?) quand ils paraissent gratuits, ils en sont partie prenante, en marquant des pauses, en suggérant de possibles rebondissements, ou en retardant le dénouement. Sans parler des réjouissantes paraphrases synonymiques qui viennent, avec un pédantisme bouffon, traduire de temps à autre des mots ou des usages forgés par Rachid, censés appartenir à une langue ancienne.

Il diversifie aussi les narrateurs: l'auteur, qui, nous rappelle-t-il en passant, en sait plus que son héros ( "Ma‘bad ne connaissait pas tous ces détail ${ }^{23}$ »), et ceux qui interviennent en cours de route, tels des narrateurs délégués, par exemple Khulayda: "Elle lui dit: - Ton père ne t’a-t-il jamais rapporté l'anecdote d'AAtā' Ibn Abū Rabāh, qui avait un jour vu Ibn Surayj vêtu d'un manteau aux couleurs chatoyantes, tenant dans la main une sauterelle dont l'une des pattes était attachée à un $\mathrm{fil}^{24}$ ? » Etc. Le héros, Ma‘bad, revient lui-même à deux reprises sur le déroulement des événements, en une sorte de sommaire narratif, qui rafraîchit au besoin la mémoire du lecteur. Par exemple:

Il lui apprit donc qui il était et pourquoi il était allé à Bagdad, comment il était parvenu à chanter lors d'une soirée d'Al-Amīn, ce qui lui était arrivé durant la guerre et comment il avait décidé de quitter Bagdad, après avoir vu la tête d'Al-Amīn plantée sur un pal, à la Porte de fer dans la capitale. Il lui parla aussi de son ami Abū Zakkār le Bagdadien, l'aveugle, qui pourrait peut-être intercéder en sa faveur auprès d'Al-Ma'mūn et de ses partisans ${ }^{25}$.

Dans le Musicien et le Calife, Rachid ne se frotte pas pour la première fois au "style ancien " dont il est un expert, pour tirer profit, comme

23. Le Musicien et le Calife, op. cit. p. 85.

24. Ibid. p. 47.

25. Ibid. p. 184. 
il dit, de "l'électricité transmise par lui ": par exemple, l'intrigue de Fais voir tes jambes, Leïla! était inspirée ${ }^{26}$ - certes, loin de son intense lyrisme - du chef-d'œuvre de l'amour courtois de Qays Ibn al-Mulawwah contant la mythique passion du « Fou de Leïla ». Mais il n'est sans doute pas indifférent que ce soit dans un roman historique qu'il joue de la sorte, explicitement, avec les ressources de la balāgha (« l'éloquence/la rhétorique ") ancienne, en puisant dans les classiques arabes du $\mathrm{x}^{\mathrm{e}}$ siècle, spécialement le monumental Livre des chansons, Kitāb al-aghāni, d'Isfahānī.

À la différence de ce dialogue avec la tradition qui mêle reprise, parodie et invention, la démarche consistant à retrancher du texte achevé les procédés et effets superflus pouvait signifier une certaine défiance, voire un rejet. Au lieu de les opposer, il est possible de voir dans ses choix narratifs les modalités d'une même exigence, qui s'est enrichie au fil des années: la recherche de l'inattendu attendu. Il s'agit donc moins pour l'écrivain de se placer sous l'autorité protectrice d'un héritage prestigieux, ou, à l'inverse, de le répudier, que d'en exploiter les ressources en mettant à l'épreuve leur efficacité, de prendre la mesure de leur distance et de leur proximité, en battant en brèche l'idée insistante d'une langue arabe hors du temps, achevée. Écrire dans une langue historique, affirme Rachid, c'est-à-dire dans une langue d'aujourd'hui.

Ce texte ne fait qu'esquisser quelques stratégies et tactiques narratives. Bien d'autres restent à découvrir. Il convient de lire et relire Rachid El-Daïf, qui construit de livre en livre, pour le plaisir renouvelé du lecteur et son édification, son œuvre romanesque et, à travers elle, une réflexion en acte sur l'art du récit.

26. Rachid El-Daïf, Fais voir tes jambes, Leïla! (trad. Yves Gonzalez Quijano), Arles, Actes Sud, 2006 [2002]. 



\section{8 \\ The Importance of Being Kawabata \\ The Narratee in Today's Literature of Commitment}

Ken Seigneurie

This is one of those rare essays, Dear M. Barthes, that will persuade you some minor critical category has been scandalously overlooked. I'm sure if you pay close attention, you will agree that it develops a valuable thesis about how stories inflect consciousness. You may even be surprised to see that concepts derived from particle physics like "inflect," "valence," and "oscillate" help us to recover a sense of human dignity.

The overlooked critical category is that of the "narratee" and the thesis is that this textually inscribed "you" can vector a sense of ethical commitment to a war-exhausted readership. Along the way, the essay will also make a case for a more fluid paradigm of literary communication. The intended result: a revalidation of literature's role in our personal lives and in civil society.

One need not have enjoyed the Woody Allen film Zelig or Erving Goffman's Presentation of Self in Everyday Life to know that in any storytelling situation, the narrative that gets told depends to a large extent on the narrator's assessment of the narratee. Why does Homer have Odysseus tell his story in such magnificent detail to Nausikaa's father? Is it the hero's homage to the narratee-host to obtain guest gifts? Or a sublimation of his desire for the daughter? Or maybe a purging of guilt felt for the acts he recounts? At any rate, one can argue that the narrator-narratee relation conditions the story and not only that but also the listener and even the story-teller himself since Odysseus is arguably a different man after telling his story - less impulsive, more circumspect.

A couple of obstacles, however, stand in the way of theorizing the narratee. For one, since narratees are often only indirectly depicted, the reader often must infer their characteristics. For another, since the narrator tailors the story largely to a perception of the narratee, the narratee 
often appears as a projected image. Then again, some narratees such as those of most heterodiegetic realist novels are almost indistinguishable from the reader. In each case, the difficulty is to theorize an unexpressed subject position that, nevertheless, conditions the story to some extent. Maybe this is why theorists often slip the narratee in as an addendum to their discussion of the narrator (see Chatman and Rimmon-Kenan ${ }^{1}$ ). Already in his ground-breaking early work, Prince traced the neglect of the narratee to the overwhelming presence and role of the narrator, taking it for granted that, "the narrator, on a superficial if not a profound level, is more responsible than his narratee for the shape and tone of the story as well as for its other characteristics" ("Introduction”, p. 8).

In an effort to attain a more profound understanding of the narratee's role in storytelling, it is helpful to remember that the narrator, the narratee and, for that matter, all the characters, are projected subjectivities. Overdetermined and riven by discourse as he or she may be, the author deploys a particular constellation of characteristics and perspectives in the narrator and assumes this subject position in order to, in turn, project the characteristics and perspectives of the narratee and characters. None of these entities fully separate from the author, but at the same time, they can exercise a quasi-autonomous function in the narrative. ${ }^{2}$ All this by way of saying that if projected subjectivities are usually invisible, it is because they are everywhere. The fact that the narratee is largely a second order projection of the author through the narrator does not make it any less effective in conditioning the narrative.

From the standpoint of reception, readers introject narrator, narratee and character subject positions. ${ }^{3}$ This essay assumes a capacity among

1. Seymour Chatman, Story and Discourse. New York, Cornell UP, 1978. Shlomith Rimmon-Kenan, Narrative Fiction: Contemporary Poetics, 1983. London, Routledge, 1992.

2. It is anything but unusual to read about how characters escape their author's control. In the novel under question, for example: I, the Rashid who am addressing $M r$. Kawabata, am not exactly Rashid the author. What links me to the author is the fact that he created me. I admit that I am largely subject to his control. However, this subjection is not total, but partial or relative. And because it is only partial or relative, I am quite different from him. (p. 9; ellipses original).

3. As an alternative to "narratee," Peter Rabinowitz, a principal theorist of the "rhetorical turn" in narratology, uses the term, "narrative audience," to describe "a role which the text forces the reader to take on" (p. 95). I trace the source of my problem with this otherwise enlightening work to the meaning of the word "role" which ranges from a "performer's part" that can be assumed or rejected at will to a "function or position" that is either realized or not, but once assumed cannot be simply willed away, only ceased. In this essay, I try to show that the distinction is crucial. This essay rejects the first meaning of role and embraces the second. The first notion of role privileges a temporary, "epidermal" grasp of the narrative, the second an interiorized, functional grasp. 
readers to interiorize the other (whether narrator, narratee, character or author) and therefore literally change their minds. It is not a given that readers take on or throw off roles; they can also realize the addressee within themselves. This efficacy of literary representation applies even, and especially, to a poststructuralist world of decentered, constantly becoming consciousness. In historical terms, Prince initially conceived of the narratee as a hypothetical existent outside the reader, preserving the reader's integrity. Rabinowitz brought the narratee within the reader, calling it a narrative audience, but stressed that it was a role that a part of the reader's mind assumes temporarily. The narratee presented here and, for that matter, the other represented subject positions as well, are realized in our minds as readers. ${ }^{4}$ Raskolnikov becomes a part of us, not merely a role that we put on and off. So, alas, does Beavis. The result is that literature recovers some of the weight and consequence that it has traditionally had since Plato: it is a game with stakes in identity.

The novel whose treatment of the narratee I find most useful for the purpose of showing the relations among narrator, narratee and reader emerged in 1995 from the rubble of the Lebanese Civil War (1975 1990). Rashid al-Daif's Dear Mr. Kawabata, first published in Arabic in Beirut, has since been translated into eight languages. ${ }^{5}$ Included among Arabic "experimental novels" by Stefan G. Meyer ${ }^{6}$, it certainly displays a post-modern penchant for theoretical self-awareness, but ultimately it ill fits this category derived from contemporary Western literature. Most obviously, if there's one thing Western postmodernists agree on, it is the bankruptcy of humanism ${ }^{7}$. Al-Daif's novel, however, retains a humanist priority on individual conscience provided it is defined relationally in society and dynamically as an ongoing process and not as a reified "central essence" ${ }^{8}$. This refusal to jettison the human, as I have written elsewhere, distinguishes much contemporary Arabic fiction from Western counterparts (“A Survival Aesthetic” and “Ongoing War”).

4. This is not to underestimate the sheer difficulty of actually overcoming self-projection in representing (from the author's perspective) or interiorizing (from the reader's perspective) another subjectivity.

5. Daif, Rashid al-. Dear Mr. Kawabata. Trans. Paul Starkey. Foreword by Margaret Drabble, London, Quartet, 1999. Trans. of 'Azizi al-sayid Kawabata, Beirut, Mukhtarat, 1995. All references in this article are to the English translation.

6. Stefan G. Meyer, The Experimental Arabic Novel: Postcolonial Literary Modernism in the Levant, Albany, State U of New York P, 2001.

7. Linda Hucheon, A Poetics of Postmodernism: History, Theory, Fiction. New York: Rout-ledge, 1988, p. 7.

8. Tony Davies, Humanism, London, Routledge, 1997, p. 24. 
Written in the wake of civil war, Dear Mr. Kawabata explores a society in shambles, one in which no ideology, institution or ethnic/ sectarian identity went unscathed by corruption and opportunism. It is part epistolary novel in that it takes the form of a long letter to the great Japanese novelist, Yasunari Kawabata (1899-1972), and it is also part autobiography in that the homodiegetic narrator, one Rashid al-Daif, shares many characteristics with the author, Rashid al-Daif: both were born and raised in a Maronite Catholic village, obtained doctorates in France, became professors of Arabic literature in Muslim West Beirut, were active members in the Lebanese Communist Party, and, finally, both suffered grave shrapnel wounds during the war. ${ }^{9}$ The narrator's effort to redeem and recover civil society, therefore, begins with the redemption and recovery of the self.

$\mathrm{He}$ is most interested in the interface between the self and the social in language use. His story begins in immediate postwar Beirut as he glimpses a former comrade-in-arms strolling smugly in the street, postwar opportunism writ large in the way he glides over craters in which others founder. Rashid is stunned by the transformation of the erstwhile Leftist militant and by the epiphany that the grand narrative they had once fought for is now a mess of empty signifiers. He becomes obsessed with the opportunist and is terrorized at the prospect of morphing into his former mentor trait for trait in a Baudelairean loss of identity. Jean Baudrillard has glossed this essentially modern phenomenon:

Quand les choses, les signes, les actions sont libérées de leur idée, de leur concept, de leur essence, de leur valeur, de leur référence, de leur origine et de leur fin, alors elles entrent dans une auto-reproduction à l'infini.

[When things, signs and actions are freed from their idea, their concept, their essence, their value, their reference, their origin and their end, they then enter into infinite selfreproduction. $]^{10}$

The narrator knows that the split between the world and language is foundational wisdom of not only opportunism but also of

\footnotetext{
9. Aghacy, Samira. "The Use of Autobiography in Rashid al-Daif's Dear Mr. Kawabata." Writing the Self: Autobiographical Writing in Modern Arabic Literature. Eds. Robin Ostle, Ed de Moor and Stefan Wild. London: Saqi 1998. 217 - 28. Samira Aghacy explores the network of autobiographical and intertextual references in this novel. Her analysis, revealing how the text blurs generic and formal boundaries for thematic purposes, dovetails with my own interest in showing how blurred diegetic levels achieve the rhetorical purpose of interpellating the reader as a subject of a civil society that does not yet exist. 10. Jean Baudrillard, La Transparence du Mal: Essai sur les phénomènes extrêmes. Paris: Galilée, 1990, p. 14. Translations of Baudrillard are mine.
} 
posthumanism, so his search for a way out of opportunism is also a search for a non-contingent sense of the human. Yet he also knows that the grail of human essence is a mug's game, so his quest will have nothing to do with distinguishing characteristics of one kind or another.

In the long letter to Kawabata that springs from this crisis, Rashid recounts his life history, unwittingly probing the points at which language and the world were sundered in his and his nation's life. He examines in memory the first fiery days of his youthful commitment to reason, how he stung the village theologian into spiritual breakdown, how he disdained his father's life-long commitment to clan and sectarian struggle, and how he glibly disabused his mother of her religious misconceptions - and her source of strength in a harsh life: "[T] here is no reward to be collected in heaven for the suffering you suffer today" (p. 81). The relentless demystification touches all the bases - or rather sweeps them away: religion, clan, and bourgeois political ideologies. The narrator grows from smart-aleck adolescent to Communist intellectual until, during the war, the Party itself falls into the gap between language and real-world events:

A lot of killing was being done by our allies on the basis of identity cards, many robberies were taking place, and Christian interests and homes were being pillaged and destroyed in the areas where our allies the Palestinians (and ourselves with them) had begun to assume control. When anyone objected, the response to them was the passage from Lenin where he said that the revolution was bound to be infiltrated by opportunists, but that these people could not change the overall course of events! (p. 142)

In the anomic aftermath of the war Rashid is helpless to counter his former friend's cynicism. The balance of the novel unfolds as a struggle to escape the logic that if all language-world links are ephemeral and contingent, then why not churn out "commitment signifiers" for the nonce?

I can understand that a man should distance himself from an event, so as to speak about it with some neutrality, but to mock convictions which we held, or rather, I held, from the bottom of the heart... "The bottom of the heart! Another unchanging expression! How is it that language writes itself through us? How is it that we are merely its vehicles?" (p. 136; ellipses and emphasis original). Precisely to the degree that Rashid becomes aware of the equivocality of language, he becomes aware of opportunism's seduction. 
His quest to demystify language and eradicate his own unwitting opportunism leads him to Kawabata. As a dupe of discourse in a corrupt society, the narrator has no purchase on language. Kawabata becomes his Archimedean point. Their relation is, on the one hand, exceptionally verisimilar. Just as the narrator, Rashid, shares numerous characteristics with his author, the narratee, Kawabata, is closely associated with the extradiegetic Nobel Prizewinning author of The Master of Go. At the same time, however, the novel seems to squander its hard-won reality effect by endowing the narrator with a perfect memory of all events from prior to his conception to presumably after his death. Nor does choosing a narratee who committed suicide in 1972 do much to soften the contradiction between maximum authenticity and maximum artifice. The resulting tension bears compare with Robyn Warhol's notion of "engaging" and "distancing" narrative modes. The engaging narrator's intimacy, "strives to close the gaps between the narratee, the addressee and the receiver" 11 to encourage a sense of shared humanity. Conversely, the distancing narrator sharpens these distinctions and conveys a sense of his authority and control. It is a crucial feature of Dear Mr. Kawabata that these terms are useful not only to characterize the narrator, but the narratee as well. Kawabata, the "you" inscribed in this text, participates in the thematic and rhetorical work by forming a third, silent subject position in addition to those of narrator and reader. ${ }^{12}$ Why fuss about this narrator-narratee-reader relation? Because the modulation of engaging and distancing functions first thematically in the recovery of language, and second rhetorically in the appeal to the reader to reembrace ethical commitment. No mean feat. The theoretical

11. Robyn R. Warhol, "Toward a Theory of the Engaging Narrator: Earnest Interventions in Gaskell, Stowe, and Eliot.” PMLA. 101. 5 (1986), (pp. 811 - 818), p. 811.

12. I avoid using here the term, "implied reader," the audience presupposed by the text. The term has ostensible value as a hypothetical entity corresponding to the cultural profile of the intended audience. Yet as such, the implied reader is otiose, not because it lacks a referent, but because, for the purposes of criticism, the reader is always hypothetical. In any communicative situation, even face-to-face conversation, the sender always presupposes a receiving subject that never fully corresponds to the actual receiver. As a cultural category, the implied reader (for example, in this novel, "the educated Lebanese citizen who lived through the war") is needlessly coercive. By invoking such an implied reader we are saying that the cultural codes deployed in the text bear an a priori privileged relation to those of this category of readers. This yields a prescriptive reading that subordinates actual dialogic reading practices to cultural cliché. I do not deny culture-specific codes but they can vary so widely in any given text that it is more accurate to refer specifically to the codes and referents as they occur - the Lebanese or western readers, male readers, middle-class readers, etc. - rather than to the implied reader who occupies, to boot, an entire diegetic level to himself. 
upshot is a complicating of the communicational paradigm to include multiple, simultaneous messages across diegetic levels.

In two articles and a book, Warhol explores how the narrator variously interpellates the narratee to aesthetic or rhetorical purpose. The narratees she studies are generally extradiegetic and associated with the reader and, therefore, the communicative situation resolves itself into a binary relation between narrator and reader-narratee. She is aware that binaries tend to congeal into essences and suggests that we look at engaging and distancing narrators as "both/and" rather than "either/or"13? The present essay follows this counsel but also takes a different approach by studying a text in which the narrator, narratee, and reader positions are exceptionally distinct, yielding a three-way narrative relation perhaps paradigmatic of similar but less prominently figured triangular narrative situations in other texts and traditions. A glance at how each corner of the triangle relates to the others in this novel is a necessary preamble to showing how triangulation serves the purpose of exploring the problem of language and commitment.

\section{Kawabata, the Narratee}

Both the narrator Rashid and the historical Kawabata suffer modernity to the point that death tempts Rashid and takes Kawabata. Yet despite these biographical similarities, Kawabata is primarily a projected, virtual presence. The narrator mentions little from the actual Kawabata's life, and since the extradiegetic Kawabata had few ties to Arab culture, the narrator is free to attribute qualities to him:

Dear Mr. Kawabata,

I always used to dream of being appointed king of some distant peoples. I would rule over them with justice, and dedicate myself to their service. I dreamed that I would be appointed as an arbitrator between warring factions, in some part of the world, to provide a model of fair play [...]. I loved the innocence of the stranger. Perhaps I still do. The stranger's lack of preconceptions to me meant neutrality. Perhaps it still does.

So here I am, Mr. Kawabata, appointing you as the king I dreamed of being myself, the arbitrator obeyed because of his sincerity. (p. 8)

One may be tempted to dismiss this narratee as a mere cipher-ideal, a replacement for the God that the narrator dispensed with as an

13. Robyn R. Warhol, “'Reader, Can You Imagine? No, You Cannot': The Narratee as Other in Harriet Jacobs's Text.” Narrative. 3. 1, 1995, (pp. 57 - 72), p. 69. 
adolescent, but this would be to ignore that Kawabata is also a trusted friend and colleague:

Mr. Kawabata,

There is no doubt in my mind that the more I press on with what I have to say, the more eager you are to listen, despite the fact that your own style in constructing a narrative is to hurry to reach a conclusion, like a piece of architecture striving towards a perfect form. But your mind is open, no doubt, to other temperaments. (p. 10)

With respect to the narrator, then, Kawabata is ontologically distant but emotionally engaging. His distance from the narrator ensures his authority; his emotional proximity fuels the narrator's desire to meet the great writer's standards: "You will doubtless detect in what I say a desire on my part to demonstrate the purity of my inner self and the sincerity of my commitment” (p. 104).

As for Kawabata and the reader, if, as James Phelan writes, "the fuller the characterization of the you [the narratee], the more aware readers will be of their differences from that you," ${ }^{14}$ then Kawabata clearly has little in common with the reader. Kawabata, the paragon, is maximally distanced. Moreover, the narrator's constant metanarrative comments to Kawabata maintain the reader in the position of observer as opposed to addressee. The canonical narratees in Balzac, George Eliot, Thackeray, Stowe, Conrad and Camus stand as a "relay" between the narrator and the reader, but not lofty Kawabata15. Whereas most discussions of the narratee - I'm thinking of Prince's, Warhol's and Phelan's - show how readers are invited to blur the boundaries between addressee and observer positions, Kawabata is a thoroughly distant narratee and the reader never has the privilege of sharing his addressee position.

\section{Rashid, the Narrator}

Warhol lists five ways in which narrators can be distinguished as engaging or distancing according to: 1) the form and 2) the frequency of address to the narratee, and the level of irony in referring to 3) the narratee, 4) the characters and 5) the act of narration itself. By

14. James Phelan, Narrative as Rhetoric: Technique, Audiences, Ethics, Ideology, Columbus, Ohio State UP, 1996, p. 351.

15. Prince, Gerald. "Introduction to the Study of the Narratee." Reader Response Criticism: From Formalism to Post-Structuralism, Ed. Jane P. Tompkins, Baltimore, Johns Hopkins UP, 1980, (pp. 7 - 25), p. 23. 

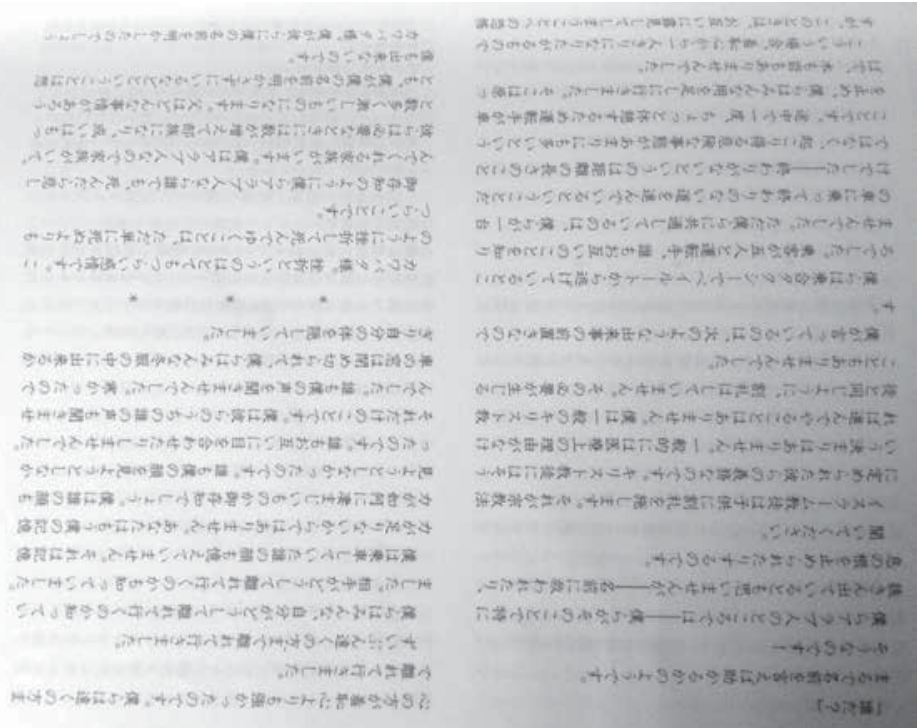

Extrait de 'Azīzī al-sayyid Kawabata, paru au Japon

this measure, the narrator of Dear Mr. Kawabata maintains a thoroughly engaged relation with his narratee, Kawabata. At the same time, however, and against almost all five criteria, the narrator, Rashid, also engages his reader. By naming and frequently addressing a specific narratee quite distinct from the reader, Rashid would seem maximally distant. Moreover, he refers to potential readers with some irony:

We Arabs find it natural to express our suffering, because we are peoples who have been oppressed and humiliated by time, which has appropriated everything we hold noble and sacred. Like other peoples, Greeks, Portuguese, Turks, etc., etc. (p. 10; emphasis original)

We recall, as well, that his doubt about his compatriots'capacity to judge him motivated him to chose Kawabata as his narratee in the first place (p. 8). The narrator also boasts an impossible, and hence distancing, memory: "I can define for you the precise color of each day that I have lived. What is more, I can also define the precise color of each night that has passed over my eyes for the past fifty years” (p. 16). The only criterion that is unambiguously engaging is the narrator's attitude toward the act of narration. He is always sincere - almost but never 
quite to the point of self-irony - and this engagement far outweighs the other four distancing characteristics. The intimacies he recounts - sexual infidelities in the family and a bout of childhood pinworms among them - emotionally engage the reader for their apparent frankness. His earnest, almost naïve exclamations encourage the reader to drop pride and pretence even if the comments are specifically addressed to Kawabata. Thus the reader feels included in a cultural "incrowd" when the narrator exclaims, "This is how they [the French] have breakfast!” (p. 32). Most important, the narrator struggles with the same problems that any postwar Lebanese reader faces - the simultaneous disgust with, and temptation of, opportunism, the guilt and sorrow for wartime destruction, the amibivalence toward the West. Rashid's refreshing candor also engages the reader when, like a latter-day Augustine, he talks himself into a new subject position:

I promise you straightaway that I will not let you hear weeping, that I will not complain, that I will not expose my suffering to you, and that I will not grumble about the bad situation fate has brought me to, as if I were a young prince reduced by the world to an outcast. (p. 11)

And we remain engaged as the topos of the Christian seeker fades into that of the modern prodigy whose warmth redeems his impertinence:

Now, Mr. Kawabata, I hope that you will forget everything else, and will pay attention only to what I am going to say, because I shall go straight to the heart of the matter - a matter that concerns you as much as it concerns me. (p. 11)

Thus readers are encouraged to share the narrator's subject position and, crucially, his reverence for Kawabata. In this way, the reader, wittingly or not, participates with the narrator in his quest to recover language from the grasp of opportunism. The engaging narrator, like Dante pilgrim leading the reader toward Beatrice, leads the reader toward Kawabata.

\section{We, the Reader}

The hypothetical intermediaries between the actual reader and the author such as the implied reader and the diegetic levels devoted to them, are intended to account for the mediated nature of text. Be that as it may, these intermediaries also function nefariously to anesthetize the reader by buffering the appeal from one person to another. Rabinowitz 
recognizes this when he stresses that the reading function he calls the "authorial audience" is sharply distinguished from the maximally anesthetized reading that used to be called "disinterested response"16. Yet at the same time Rabinowitz cannot bear to jettison an anesthetizing "distance" that allows the reader to maintain a morally incorrupt core while assuming a reader's "role." Thus his reader does not have to fully taste unpleasant subject positions. His "authorial audience" shields the actual reader:

The authorial audience has knowledge and beliefs that may well be extrapersonal - that is, not shared by the actual individual reader (I, for instance, do not personally share the racist perspective of the authorial audience of Ian Fleming's Live and Let Die). (p. 26; emphasis original)

Literature, like sex, can be made safe but also boring and irrelevant. If we do not at some level of our real selves introject, say, Fleming's racism, then we do not have to do the disturbing work of comparing the darker part of ourselves with that of the text. Instead, we can pretend we don't have a speck of racism in us and read the text for... what? Theoretical or escapist import? Messages from the author become cleansed and our piety remains intact.

Dear Mr. Kawabata's constitutive metalepses eliminate buffering intermediaries between author and reader and expose the diegetic level model as a theoretical apparatus for keeping us from actually reading. ${ }^{17}$ Poised between an engaging narrator and a distant narratee, the reader's investment exceeds what his status as "observer" implies. Even though the narrator never directly addresses the reader, his ethos engages the reader's affections. Kawabata may be the linguistic addressee but the reader is the addressee of a simultaneous ethical appeal. If we recall the diegetic level model: "The author addresses actual readers (receivers); the implied author the implied reader (addressee); and the narrator the narratee (enunciatee)," we see here the narrator "crashing the gates" to address the reader ${ }^{18}$. This triangular relation whereby the narrator addresses both Kawabata and the reader simultaneously in linguistic and ethical modes across diegetic levels

16. Peter Rabinowitz, Before Reading: Narrative Conventions and the Politics of Interpretation, Columbus, Ohio State UP, 1987, p. 25.

17. Metalepsis is the crossing of presumably separate diegetic levels. By taking metalepsis for granted, Dear Mr. Kawabata shows that the whole theoretical edifice of diegetic levels is as necessary as the seven levels of heaven.

18. James Phelen, op. cit., p. 139. 
contradicts the notion that discrete senders and receivers exist at welldefined diegetic levels. To this extent Dear Mr. Kawabata forces the reader to do what good readers ought: to interiorize, not role play, various subject positions and modes of communication simultaneously. Thus whereas the diegetic level model can entertain multiple addressees only by postulating separate compartments to contain them, the narrative paradigm assumed in Dear Mr. Kawabata consists of numerous, simultaneously realized subject positions within author and reader at one diegetic level. Given therefore that multiparous, metaleptic messages are a constitutive and not an occasional feature of narrative, the rationale for postulating various diegetic levels evaporates - unless it is to maintain an ideological commitment to singular, unified subjectivity.

\section{Language and Commitment}

The narrator's aim of rescuing language from opportunism, depends on the triangulation of narrator-narratee-reader. In this account of a struggle against the opportunist within, as opposed to the shadow struggle at separate diegetic levels, each point is in tension with the other two. Kawabata embodies lofty projected aspirations but if the narrator did not simultaneously keep one eye on the reader, his discourse would soon wax hermetic. Conversely, without Kawabata, the address to the reader would degenerate into didacticism - yet another harangue from a member of the discredited intellectual class. As for the reader, one tends to accept Kawabata as paragon, perhaps at first out of playful complicity with the charming narrator, and later in earnest as the stakes in language become clear. Eventually, we are confronted with our own opportunism just as the narrator is.

Thanks to triangulation with Kawabata and the reader, Rashid learns a few things about language and commitment that he did not learn by living through the events he recounts. Through Kawabata, the master artist of peerless rectitude, Rashid extends his youthful demystification of faith, clan and sect to the realm of language. At the same time the reader, who is never assumed to be a sympathizer with the narrator's political views, keeps a watchful eye on Rashid's capacity to make a fair account of events. Rashid first learns that language and its flower, doctrine, disarm moral discernment. At the beginning of the novel, he unabashedly revels in all manner of rhetorical excess:

Who else could walk along like this... when the war had scarcely yet shed its burdens? Notice this expression, Mr. Kawabata - "the war had 
shed its burdens”; you will see how many similar expressions of eternal beauty we have in Arabic. (p. 3; emphasis original)

Yet an inexplicable sensation of a mouthful of ants spoils his pleasure in language (p. 6). By the end of his narrative, it becomes clear that the ants are a compensatory agony following the orgy of language and he eventually quits indulging in rhetorical excess. Finally, he realizes: "I smell in this eloquence the scent of blood, Mr. Kawabata” (p. 150). Why didn't he smell it at the time of the events or during the intervening years? Only in narrating his story to Kawabata, his narratee of high literary and ethical standards, does Rashid come to take a moral measure of rhetorical excess. It is as if the new subject position he assumes in order to address his narratee ironizes on the old one. And as the narrator smells blood in eloquence, so does the engaged reader.

Rashid also learns that language often dupes those who ostensibly master it. Early in the novel, he recalls a magisterial command of language and the world:

We took words for our mounts, confident that we were riding history! [. . .] The world, with all its constituent parts, was simply words turned into things. As soon as the word changed, the thing would change: water, earth, air, individuals, groups - in short, all living and inanimate creatures. (pp. 5-6)

Thinking that they could use language to transform the world, Party intellectuals fail to reckon that its equivocality could turn against them. Thus Rashid's commitment to fight against "bourgeois elements" (Christians) may at first seem congruent with Party doctrine - and even perhaps highly principled since he was raised a Christian — but gradually the signifiers slide in front of one another. "Communist" and "Muslim" become superimposed and Rashid is encouraged to take a Muslim name. At which point he recapitulates his father's reactionary, sectarian struggle - but from the opposite side! (p. 126)

In telling the story of his involvement in the Party, Rashid gradually sees that language also transforms its users and admits: "We are not alone then in letting words run away with us wherever they will, or in running away with them wherever we will, while he, the poisonous being - history - just goes on” (p. 116). Thanks to the equivocality of language, a martyrdom motif in the novel seems increasingly like a running sick joke on oneself - the dearest investment in the ficklest of stocks, language. Kawabata is the touchstone; the narrator's desire to please Kawabata pushes him to exercise care in dealing with language. 
The reader - captivated by the engaging narrator - again follows Rashid toward Kawabata, acquiring an ever more sensitive grasp of language along the way.

Finally, Rashid learns that the danger of language lurks in its role as a social constituent of private consciousness. It constantly infuses the social non-self into the self. Early in the novel, the narrator assumes a stable, centered self as evidenced by his fondness for didactic asides:

I will draw your attention in advance, Mr. Kawabata, to the fact that I may appear to switch from one subject to another while I am speaking. But I am confident that you will quickly understand the underlying reason behind each switch. The style will actually be an object of admiration on your part. (p. 4)

These gentle directives, suffused with the narrator's good will, place him in the center of a universe of innocent, non-contingent meaning. They also convey a sense of unselfconscious vulnerability. By the end of the novel, the double-edged nature of language has compromised that center of consciousness. Rashid regards his own comments with irony and eschews didacticism to the point of questioning the origin of his own desires and beliefs:

I suffer twice when the victim becomes an executioner, but I am certain...

I am certain? (p. 160)

The question added in italics puts into doubt both the certainty and the "I." This inquiry into language and subjectivity eventually strips the narrator of identity and even of volition. Not only is self-expression impeded - a mouthful of ants and lips sewn tightly shut - even the slightest velleity is problematized: "It is just that if left to my own inclinations (to my own inclinations!) I would choose goat's yoghurt rather than any other sort of yoghurt" (160; emphasis original). Here, the narrator is hyperconscious that to be socially interpellated is to be a plaything of language. Unable to muster a noncontingent subject position from which to voice a simple desire, he seems compelled to accept his very being as a shadow game of signifiers, leading inevitably to opportunism. Since no language corresponds to the self or to the world "as they are," the opportunist reasons, why not use discourse expediently? Thus Rashid has come a long way in his narrative to reach a grasp of language that is still only roughly equivalent to that of his ex-friend.

The narrator's intellectual itinerary in this short novel has passed from a premodern belief system to a modern ideology of commitment to 
a post-structuralist suspicion of language and identity, yet still he cannot distinguish himself from the opportunist. He finally succeeds only as a result of the triangular relation with Kawabata and the reader. Their projected, virtual presence gives him points of reference which allow him to evaluate discourse. At one point, late in the novel, he declares:

It was true that what was happening in Lebanon was not a socialist revolution in the strict sense of the word. However, it was something close to that - a step of such enormous importance in the right direction that it could be regarded as a first step in the revolution. The part that our party, the Communist Party, was playing as the vanguard of the working class was shining proof of that. (p. 134)

Immediately upon uttering this apologia in a vocabulary and tone reminiscent of ideological dogmatism, Rashid is self-chastened by a part of his mind that has assimilated what it perceives to be Kawabata's judiciousness:

Mr. Kawabata, I am almost laughing at what I am telling you. It's almost as if I were saying it with a touch of superiority. It's as if the "blame" fell on them, them, the others, as if I alone were the victim and they were the executioners. (p. 134)

The "them" may be his erstwhile opponents - Christians and other non-Communists - who are now his readers and who must exonerate him from his war-time guilt if he, and they, are going to be worthy of Kawabata. Only after succeeding in the quest to assume his readers'and Kawabata's moral perspectives is he able to see the vanity of his victimhood. Thus Rashid finally forges an identity, paradoxically by renouncing autonomous centralized subjectivity and instead triangulating himself with the largely self-made beacons of Kawabata and his readers.

The final pages of the novel ratify Rashid's new identity. Fading in and out of consciousness under a pile of corpses, he imagines reconciliation with his erstwhile opponents, mother, father and village theologian. Having recognized himself in them as a fellow dupe of language, he is serene, understanding and even repentant in contrast to his youthful arrogance. At the same time, he also hears the ex-friend's voice exclaiming: "Well done! You have been wounded and escaped, so now you can boast about your rich experience of life!” (p. 165). This time, instead of feeling himself double into the opportunist, Rashid recalls a scene that had not previously registered in his memory: 
After I had passed him, Mr. Kawabata, on the Hamra Street pavement, I couldn't stop myself looking back. I saw the ripped turn-up of one of his trouser legs covering the heel of his shoe, being dragged along the dirt of the pavement. (p. 165)

This, the man who appeared to glide over shell craters in the sidewalk. As a result of adapting his narrative to Kawabata's high standards, Rashid has acquired something of Kawabata's acumen and can now see in his memory what had hitherto been invisible.

Through Kawabata, the narrator (and the reader) trump the exfriend's cynicism. Rashid's heightened awareness of language allows him to recover a sense of commitment consisting simply of the rigorous and critical use of language through triangulation with other subject positions. In displacing the discourse of opportunism, the narrative reinserts the human, conceived of relationally, at the center of consciousness. Nothing, of course, prevents this grasp of language from eventually becoming a reified dogma itself just as, in the past, family, clan and ideology had. Yet, whereas the previous demystifications depended on a binary opposition to the world, Rashid's critical sense at the end of the novel is methodological as he stands poised in a triangular relation with the world (mother, father, village theologian, his readers) and impeccable Kawabata.

We are thus in a position to respond to the last sentence of Warhol's essay on the political role of the narratee:

One task of the new narratology is to illuminate the ways those pairings [such as engaging and distancing narrators] oscillate within literary texts, to open up politically significant subtleties of rhetoric and see narrative discourse as a means of access to history ${ }^{19}$.

Oscillations, yes, but not pairings. Dear Mr. Kawabata shows how the triangulation of narrator, narratee and reader can intervene in historical crisis through a play of engaging and distancing to reposition subjectivity in a stable relation with the world.

Not that narrative triangulation in itself is such an unusual notion, but it is perhaps particularly well suited to times of crisis such as that through which much of the developing world is passing where the breakdown of modern institutions forces a rethink of binary paradigms. In J.-M. Coetzee's Waiting for the Barbarians ${ }^{20}$, the narrator's

19. Warhol, "Réader", op. cit., p. 69.

20. John Maxwell Coetzee, Waiting for the Barbarians. London: Penguin, 1982. 
insistent intradiegetic appeals to the torturer and the tortured woman function to create a subject position for himself outside those of executioner and victim. At the beginning he is aware of his merely contingent distinction from the torturer; by the end, having also experienced victimhood, he has managed to occupy a corner of a subjective triangle distinct from those of executioner and victim. Whether triangulation can be further generalized to other texts or literatures is a question for further research.

Triangulation in Dear Mr Kawabata distinguishes itself from Coetzee's novel by, among other things, its extradiegetic narratee, but both novels display constantly shifting valences of engaging and distancing, which function to maintain a tension among each corner of the triangle. This oscillation stands in stark contrast to canonical examples of triangulation such as in Dante's Divine Comedy and Augustine's Confessions where Beatrice and God, respectively, are resolutely distant. The simultaneously distant and engaging narratee, which is distinct from both classical precendents and the modern narratees studied by Warhol, may therefore be among the features of a contemporary narrative of commitment, one that seems to be groping toward a sense of the human that avoids both essentialism and proteanism by positing a dynamic subject who is nonetheless stabilized relationally.

Dear Mr. Barthes,

The relational and self-reflexive nature of writing and reading means that the whirling codes that you so magisterially envisioned in $\mathrm{S} / \mathrm{Z}$ are not disembodied. They connect us to other subjects and through them we can oscillate among subject positions, like the beautiful equilibrium of a benzene ring - separate but only by virtue of being connected! I get dizzy, Mr. Barthes, from atomic eloquence! 



\title{
9
}

\section{The Hidden Hypotext: Transtextual Strategies in Rashid al-Daif's}

\section{Forget about the Car (Insay as-sayyāra)}

\author{
As‘ad E. Khairallah
}

One of the problems raised by the theories of intertextuality is what one may call the problem of the hidden or lost hypotext. " "The question of what happens when specific inter-texts are culturally lost” has been aptly discussed by Graham Allen in his book, Intertextuality, ${ }^{2}$ where he mentions the basic difference between two major positions. The first is that of Michael Riffaterre, who thinks that, even when an intertext is not known or recognized, one has to suppose its existence. In other words, the unawareness of such an intertext does not change the fact that it does exist, waiting to be discovered some day. In the meantime,

all that is needed for communication is the postulation of the absent meaning. All that is needed for the text to function is the presupposition of the intertext. Certainly, presupposition itself cannot exist unless the reader is familiar with the structures organizing a representation of reality: but these are the very stuff of our linguistic competence. ${ }^{3}$

1. Instead of the general term "intertextuality", I am using the term "hypertextuality", per Genette's definition: "By hypertextuality I mean any relationship uniting a text B (which I shall call the hypertext) to an earlier text A (I shall, of course, call it the hypotext), upon which it is grafted in a manner that is not that of commentary." (Gérard Genette, Palimpsests: Literature in the Second Degree, translated by Channa Newman and Claude Doubinsky. Lincoln and London: University of Nebraska Press, 1997, p. 5). Good instances are Homer's Odyssey as hypotext for Joyce's Ulysses and, in Arabic, Jamāl al-Ghīțānī’s az-Zaynī Barakāt as hypertext 'grafted'on Ibn Iyās's chronicle, Badā'i' az-zuhūr fì waqā'i' ad-duhūr.

2. Allen Graham, Intertextuality, London and New York, Routledge, 2000. See particularly pages 111-126.

3. Michael Riffaterre, "Interpretation and Undecidability", in New Literary History, Vol. 12, No.2, Interpretation and Literary History, Winter, 1981, 227-242, here p. 239; also quoted in Allen, Intertextuality, pp. 125-26. 
On the opposite side, we have the position of Gérard Genette, who conceives of the hypotext as a prior text used in full consciousness by the author. In Genette's opinion, the reader may well understand the hypertext without being conscious of its hypotext, but the hypertext "always stands to gain by having its hypertextual status perceived" (Palimpsests, 398), that is, if the reader is made aware of the relation between hypertext and hypotext, for "the beauty of the hypertext always does consist in such a relation, which it legitimately whishes to be apparent.” (Ibid., 398)

If Riffaterre tends to focus on short poetic texts, Genette is more concerned with large narratives. In this respect, his position is of central relevance to the present paper, namely that "contrary to the case of intertextuality, as it has been so aptly described by Riffaterre, a simple understanding of the hypertext never necessitates resorting to the hypotext. Every hypertext... is invested with a meaning that is autonomous and thus in some manner sufficient. But sufficient does not mean exhaustive" (ibid., 397).

Discussing Genette's standpoint with respect to the "problem of the missing or forgotten hypotext," Allen remarks that "Sometimes even the scholarly community forgets important hypotexts, long buried in forgotten traditions. In such cases the hypertext becomes merely a text, a non-relational, non-transformational work." 4 Yet when the hypotext is not really missing, I think one has to take into consideration Genette's statement that hypertextuality is more or less mandatory more or less optional according to each hypertext. But the fact remains that it cannot be overlooked without voiding the hypertext of a significant dimension, and we have often seen that authors went to great trouble - at the very least by means of paratextual clues - to guard against such loss of meaning or of aesthetic value (Palimpsests, 398).

But what if an author, like Rashid al-Daif, does not give any paratextual clue to his readers?

This question will be the focus of the present article, namely to study the transtextual strategies of a leading Arab novelist, Rashid al-Daif, in his Insay as-sayyāra ${ }^{5}$ (Forget about the Car, 2002), and simultaneously to shed some light on the problem of the hidden and forgotten hypotext, as illustrated by this particular novel, in order to show the difference in reading when we become aware of the hypotext and its cultural field.

\footnotetext{
4. Allen Graham, Intertextuality, p. 111.

5. Rashīd aḍ-Ḍa'īf, Insay as-sayyāra, Beirut, Riyāḍ ar-Rayyis lil-kutub wan-nashr, 2002. I am writing al-Daif's name as he writes it in English.
} 
Rashid al-Daif's work is a frontal attack against the various aspects of the dominant discourse, be it religious, ideological, social, political, moral, or aesthetic. He deconstructs established codes and systems by resorting to transtextual strategies in an inverted or parodic manner. This is true of some of the poems in his La shay'a yafüqu l-wașf (Nothing is Beyond Description, 1980) ${ }^{6}$, as well as of his novel, Ahl az-zill (The Shadow Creatures, 1987), which tries to prove that life is just the contrary of the "Tranquility" that the inaugural intertext claims it to be. ${ }^{7}$ Some of his novels, however, are structured around and narrated in line with their intertext, such as al-Mustabidd (The Obstinate, 1983), ${ }^{8}$ with citations from Camus'novel, The Plague, or Tiștifil mīrīl strīb (Who Cares about Meryl Streep, 2001), with citations from and allusions to The Arabian Nights. ${ }^{9}$

In his novel, Insay as-sayyāra, the author does not overtly mention his major hypotextual source, namely al-Ișfahānī’s Kitāb al-Aghānī. ${ }^{10}$ Yet, this work has clearly inspired the novel, not only in some motifs, but also in style and, above all, in spirit, moral attitude, and basic narrative theme.

As far as I know, no critic has yet noticed the hypertextual connections of this novel, which is linked to its hypotext by some markers that do not seem to be all that present in the minds of modern Arab critics. Thus, the absence of a clear reference to al-Aghāni has not only robbed the readers of the greater pleasure of the text, but has also caused the critics to miss an important dimension of its message and a great part of the interrelations that are activated by the various markers linking the novel to al-Aghānī.

While focusing on al-Daif's transtextual strategies and the complexity of their ramifications throughout his novel, this paper will also attempt to shed light on the benefits and shortcomings of some intertextual devices when they depend too much on the capacity of the reader to decode the diverse indices that signal the presence of the hypotext.

6. Rashīd aḍ-Ḍa'īf, Lā shay’a yafūqu l-wașf, Beirut, Manshūrāt lubnān al-jadīd, 1980).

7. Rashīd aḍ-Ḍaīif, Ahl az-zill, Beirut, Mukhtārāt, 1987, p. 5. See the original text, "aț-Ṭuma'nīna” (Tranquility) in Mikhā’îl Nu'ayma, Hams al-jufūn, Beirut, Mu’assasat Nawfal, 1988, pp. 73-74.

8. Rashīd aḍ-Ḍa'îf, al-Mustabidd, $2^{\text {nd }}$ edition, Beirut, Riyāọ ar-Rayyis lil-kutub wannashr, 2001. On page 8, there is a citation in French, and on page 17, a citation in Arabic from Camus'novel, La peste.

9. Rashīd aḍ-Ḍa īf, Tișțifil Mīrīl Strīb, Beirut, Riyāọ ar-Rayyis lil-kutub wan-nashr, 2001, pp. 120-121.

10. Abūl-Faraj al-Iṣfahānī, Kitāb al-Aghānī, vol. 9, ed. 'Abdassattār Aḥmad Farrāj, Beirut, Dār ath-thaqāfa, [1957], $8^{\text {th }}$ printing, 1990, pp. 172-211. All subsequent references are to this edition. 
In the following, I shall, first, present a detailed summary of Forget about the Car, in order to give us a broad basis for comparison. Second, I shall take a look at its reception by some critics who, having either missed the intertextual marker or chosen not to give it enough importance, were not aware of the interconnections with the hypotext and the dialogical dimensions it activates. Finally, I shall attempt to analyze the novel in light of the interaction between two major transtextual elements, namely, the story of Qays Ibn Dharīh, from al-Aghānī, and the citation from Suhayl Idrīs's Memoirs ${ }^{11}$ concerning his father.

\section{The Story}

The narrator wakes up one morning suffering from amnesia after a car accident. He gradually recovers his memory and thus remembers that the accident happened with the Subaru he bought from his best friend, Rafĩq. At the time, he had been talking on the cell phone with his girlfriend, Laylā.

Thus, we are directly set at the heart of the story, which is going to unfold through the narrator's recollections. His Japanese car was designed for the United States and not for Europe or Lebanon, and therefore has no spare parts. Rafīq (the "companion and friend"), who often used to race with the car, had worn its brakes out. He then sold it to the narrator without telling him about this serious problem. So, the narrator finds himself using a car with worn-out brakes and always in danger of a major accident.

The narrator's car, a status symbol, but especially a symbol of modern life, becomes a booby trap ("mufakhkhakha", the term for cars packed with explosives) and incorporates the most common vehicle of terror and destruction during the Lebanese civil war; it is a constitutive element in the narrative structure. Since its defective brakes are practically beyond repair, the car becomes a key symbol for human relations, even between best friends -- relations that exhibit no restraint in seeking one's interests through cheating and hypocrisy. This is confirmed by the novel's frequent description of all human relations as hiding a "fakh", a trap, or being "mufakhkhakha".

While trying to remember what happened during the few months before the accident, the narrator is repeatedly astonished and shocked by the course of events and keeps exclaiming, "Oh God!” He then recalls

11. Suhayl Idrīs, Dhikrayāt al-adab wa-l-hubb (Memoirs of Literature and Love), Part one, Beirut, Dār al-ādāb, 2002. 
his father, who had always told him, "You only remember God when you are in trouble." But, he adds, "my father is a dissolute unbeliever" (p. 10).

Thus we are introduced to the second constitutive element of the narrative: the problematic father-son relationship, which is based on self-interest, rather than on paternal or filial ties, and which is characterized by the son's fundamental mistrust of the father's moral integrity. At the same time, the narrator's comments hint at an inversion of roles, since he sees himself as the one who knows his responsibilities, while his father "is still a child in need of someone to rear him and to take care of him" (p. 15). And as with the car, we soon discover that this fatherson relationship has its ramifications in the whole network of relations with the two other major characters of the novel: Laylā, the narrator's girl-friend, and Zāy, the father's future wife.

As the story unfolds, the car becomes a minor element in comparison with the new catastrophe that threatens the narrator: he discovers that his 65 year-old father plans to marry an extremely ugly 30 year-old woman, who can still bear children and whom he mentions only by her first name's initial, Zāy (Z). The hero, or rather antihero, is then launched on an obsessive race to stop this marriage, which could prove catastrophic for him, since his father has no income and he himself would have to sustain a whole new family. Having lost his job, he had been counting on selling his car for a decent price which he would add to his savings to start a new business, especially since his father had promised to help him get a financial loan by mortgaging their apartment. Now he discovers that the penniless father is about to sell their only apartment in order to enjoy a comfortable life with his future wife. Here again, the narrator perceives this potential marriage as a trap: "I will never allow him to marry: it is an entrapped marriage” (p. 24). By using the very term "mufakhkhakh" (entrapped) for the marriage as for the car, the narrator established a clear relation between the two.

The rest of the story is a labyrinthine series of abortive schemes to foil the father's plan to marry Zāy. The more the protagonist plots to get rid of his obsessive fears about his car and his father's marriage, the more entrapped he becomes. While all the other major characters -- his father, his sister, Laylā, Zāy, and Rafĩq -- seem to know what they want and to be light-hearted about what they do, he is the only one who finds everything strange and hard to understand. It is no surprise then that they see him as an odd character who spoils their fun with unwarranted worries, and that they pay little attention to such anxiety. 
The first big scheme is to pressure the father by torturing himself slowly by means of a sun-stroke. For this purpose he uses a combination of two old Arab methods reported in al-Aghānī, namely to expose his naked head to the heat of the summer sun (on June $21^{\text {st }}$, as he says, p. 21), adding to that another method of torture, namely, to rub his head with oil, so that the sun would burn him all the stronger. ${ }^{12}$ At first, the father feels guilty and tries for hours every day to stand next to his son and shelter his head from the scorching sun. After a few days, the father retaliates by rubbing his own head with oil and sitting on the balcony in front of his son. It is now the turn of the son to feel worried that the sun's heat might cause his father's death and leave him behind with an unbearable sense of guilt. He thus stands up and tries to shade his father's head, but his father makes a sign of refusal. When the narrator sits back in his place, his sister comes out with two buckets of water. She pours the first one on his head, so he jumps up and begins gasping for breath. And instead of pouring the second bucket on the father's head, "as any reasonable person would expect," his sister repeats the same act over the narrator's own head. The father stands up victoriously and leaves, and the narrator has to admit defeat and realize the difficulty of stopping his father from marrying Zāy. "My stratagem has failed, then. My attack was absorbed and repelled, and I am a laughing stock...” (p. 44).

The protagonist is then obliged to think of some other scheme. This time he works on two fronts. While discussing his father's problem with Laylā, a "devilish idea" (p. 51) dawns upon him: why not find him a young woman with whom he can sleep a couple of times a month? If his father can satisfy his long frustrated need for sex, he will forget about Zāy. He asks Laylā to find one of her acquaintances who would be ready to do the job, whether for free or for money. Laylā proposes one of her friends, who would certainly want some money, she says, and the narrator accepts the idea. But it turns out that her friend Sin (S) is not interested in having sex with the old man, but would be ready to sleep with the narrator. So he asks both girls to make love to each other first, then, once excited, he joins them in their love match.

Finding no one else to do the job, and noticing that Laylā is interested in buying the car, the narrator thinks of selling it to her for a low price, while asking her to do him the great favor of sleeping with his father

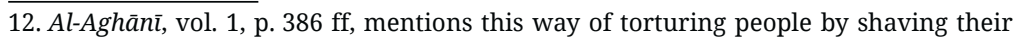
heads, rubbing them with oil, and exposing them to the sun. 
once every month or two. But the experience turns to the advantage of the father, who proves to be a lady's man, to whom Laylā feels quite attracted. The protagonist realizes that he has played with fire, for he discovers another Laylā than the one he thought he loved and regarded as a "pure" and true girlfriend.

His other front and last resort is to try to spoil his father's game by seducing his future wife, Zāy. She seems attracted to him and makes much effort to be appealing whenever he visits her. So he practically rapes her, without giving her the only satisfaction she has ever dreamt of, namely, to be, at least once, desired as a full human being. This we know from Laylā, who learns later that Zāy was keeping her virginity for her future husband, but was ready to offer it, as the greatest gift, to the one who would take her for her own person, if only once in her life (p. 141). Yet the narrator doesn't satisfy this single wish of hers. He insists on turning off all lights and deflowers her (i. e., his future stepmother) in an aggressive and dehumanizing way.

At the depth of her humiliation and the height of his triumph, she reminds him that he forgot to take any precautions and that she may very well become pregnant. She tells him that she has never been so happy in her life: she will be both married and a mother; this is beyond all her dreams (p. 133). "Never in my whole life," says the protagonist, "had I had such a sense of failure and despair as I had that night." Yet soon it occurs to him that "Laylā is the solution!....The car is the solution!” (p. 133). He is ready to let her have the car for the lowest price or even as a gift if only she would intervene in his favor.

But Laylā gives him the cold shoulder. She has become friends with both his father and his future wife (here we learn that she used to have "massage" sessions with his father behind closed doors in Zāy's apartment!). After many failed attempts to talk to her on the phone, he tries to induce her to call him by leaving his car in front of her house, announcing it for sale and adding his telephone number (p. 134). The people of that district are afraid that the car might be booby trapped. Rather than recognizing the car, Layla calls up the police, who give the protagonist much trouble during a whole night's investigation. Once he realizes that the narrator is harmless, the policeman asks him in astonishment: "Where do you think you're living!" (p. 135), reminding him of the dangerous situation, particularly in that district, the very tense atmosphere in the whole region after September 11, and the many booby-trapped cars that had exploded in Lebanon over the last thirty years (p. 135). When he later meets with Laylā and asks her why she called 
the police, she answers that she wanted to punish him for treating Zāy so rudely. At that point he feels lost and unable to comprehend the situation any longer (p. 137).

The only little hope that seems to remain is to convince Zāy to abort of the child. He threatens her to make a scandal, telling everybody that he is the father of the child, but his threats remain without effect. "What is in her womb is hers. This is what she used to repeat" (p. 149). She wants to keep the child, with or without a father. In the meantime, he visits a doctor and asks him to abort Zāy, claiming that she is his wife. But on his second visit, the doctor insults him, calling him a cheat and a crook. The narrator was even afraid that the doctor would accuse him of being an agent "trying to set a trap for him" (p. 149), but he later learns that his father had already told the doctor the whole story.

This also means that his father knows about Zāy's pregnancy and is still ready to marry her and keep the child. And here the protagonist goes into another one of his self-lamentations:

Instead of being an instrument of pressure against her, her pregnancy has become an instrument of pressure against me; not only in her hand, but also in his (sc. his father's) hand. O my God! O Lord of the universe! Why should all this injustice befall me! (p. 150)

The defeated hero's last attempt is to call Laylā, who tries to cool him down, still hoping that the pregnancy is not real. In his total despair, he drinks too much and loses all powers of concentration (p. 152). On his way home, he is busy talking to Laylā on his mobile phone, when he smashes his car against an electric post and breaks a leg. His 'friendly'neighbors take care of the rest, until he wakes up from the shock. He realizes later that his demolished car was very cheaply sold by one of his neighbors. After some days his 'friend'Rafiq gets in touch and tells him that he shouldn't worry, for the only thing that matters is one's health. In full disgust and resignation the protagonist bitterly answers: "You are right."

This is certainly no Sophoclean tragedy. The protagonist is far from possessing the nobility of the classical tragic hero, and the reader is often led to laugh at the ridiculous behavior of this anti-hero. The whole narrative is imbued with a distinct cynical tone demolishing all social and moral pretensions and exposing the permanent war within the war, nourished by the economic and material struggles for everyday survival. It is a disturbing novel that breaks many taboos and ends without catharsis. Throughout, and true to his own mode of writing, al-Daif 
is extremely provocative. He desecrates what modern Arab society still holds as sacred, including those ideals and norms that in everyday life many may trespass, but not without guilt feelings, nor without the need to confess and liberate their conscience or to free themselves from profound fears of some kind of divine revenge. For most traditionallyminded readers, the problem with al-Daif's narrative world is that it seems to be devoid of the notion of sin. This does not mean that no one of his characters has that notion or the remorse it generates. It means, rather, that the novel as a whole presents a general worldview that is amoral. This is no innocent point of view in such a moralistic society. It surely has an alienating effect and is very provocative for some people, especially for those who, down deep, would feel lost without sacred norms and divine commandments.

Al-Daif devaluates by attacking all three main taboos, ${ }^{13}$ the political, the religious, but mostly the sexual and its corollary, namely, the supposed sacredness of love, marriage, and family relations. He ridicules the old ideal of chastity as only a thin veil hiding sexual debauchery of all kinds. Laylā sleeps around as a "masseuse", but she is very careful not to arouse her parents'suspicions. So long as it is secret, "illicit" sex is practiced under all its aspects: homosexual, lesbian, ménage à trois, outside the family bonds (e.g., the married man with the pearl necklace, p. 57), between old and young (pp. 17, 57), foreigners and Lebanese (p. 17); sexual behavior seems to respect no taboos, so long as it is behind secret walls and especially when generously rewarded. The father, who also has homosexual tendencies, used to sleep with his wife from the back, and she enjoyed it (p. 77). It is probable, then, that Zāy attracts him with her large buttocks, as Laylā thinks (p. 77).

Part of the author's struggle is to be able to say these things without fear or prudence. "Tranquility," says al-Daif, "is to divulge, to divulge, to divulge, to divulge what you are, to divulge whatever you want, to be able to..."14 This is surely a clear contrast to the "Tranquility" of Mikhail Naimy, cited at the beginning of al-Daif's Ahl az-zill. It is as if the author was telling us: "If these things happen in real life, why should we be ashamed of narrating them?” In fact, people do talk about them, but to write them down breaks a taboo. It is similar to the printing of The

13. For a pioneering discussion of these taboos see: Bū 'Alī Yāsīn, Ath-Thālūth al-muharram: Dirāsāt fi d-dīn wal-jins waș-șira' aț-țabaqū, Beirut: Dār at-Ṭalī‘a, 1973.

14. Rachid El-Daïf, L'Eté au tranchant de l'épée, transl. and introd. by J.E. Bencheikh, Paris, Editions Le Sycomore, 1979, coupled with the original Arabic version, Rashīd aḍ-Ḍa'īf, Hīna hạalla s-sayf 'alā ṣ-șayf, Beirut: Dār al-Fārābī, 1979, p. 61. 
Thousand and One Nights. It was normal to tell its tales in male café houses, but it has always been a problem to publish them, since they could fall into the hands of women and children.

The Syrian novelist, Hayfā' Bīṭār, vehemently attacks al-Daif'for the openness of his descriptions and his naked language; she admits that his style is attractive, but that fact endows it with more power to corrupt the youth. Since Bītār believes that "the aim of art is the Good, the True, and the Beautiful," it is no surprise that she finds the novel extremely provocative, for it unmasks the emptiness of such ideals in modern Arab society. ${ }^{15}$ It is interesting that Bīṭār does not seem to recognize that fact. To conceal such complicated relations seems to be her choice for dealing with them. This is similar to censorship in some Arab countries: it blocks internet access to anything dealing with sex or coming from Israel. In this manner, the censors imagine, these factors will have no more effect, since they no longer exist! The curious thing, though, is that Bịțār admits that Arab youth are already heavily exposed to pornographic films through movies, TV, and the internet. That is why she blames al-Daif for contributing to that current instead of taking a stand against the immoral tide. In her blind fury against what she sees as the corruption of the youth, she is unable to see many important elements and nuances. In analyzing the story, she does not even mention the episode of the suicide attempt as the narrator's first means of stopping his father's marriage, let alone the link between this narrative and the context of its Abbasid hypotext. She pities the father, who is denied the right to have company in the loneliness of his old age. Such company, she thinks, must not necessarily be for sexual pleasure; otherwise, "where is the spirit!" she wonders. She forgets that this "poor father" is eager to sleep with a twenty-year old girl in the apartment of his future wife, and that to be sure of his sexual performance and of the girl's pleasure he takes Viagra pills (p. 106). In short, Bīṭār projects her own feelings and values on the novel, and thus cannot tolerate their deconstruction. She starts by admitting that she was not able to find any maghzā (meaning or moral) in the novel, except provocation. She ends her article with an open instigation against the author: "Is it possible that literature becomes a cheap pornographic film... I wonder where is the function of constructive [i. e., morally committed] criticism in front of novels that are illogical on top of being immoral!" Under the

15. See Hayfā’ Bīṭār, “'Indamā yataḥawwal al-adab ilā film porno”, Akhbār al-adab, Cairo, May 4, 2003. 
guise of exercising “constructive criticism," her words smack of a spirit of Inquisition.

\section{Other Critics}

Without being so provincially narrow-minded, other critics tend to declare their lack of understanding of the novel's structure and of all the fuss made about the car, as well as about the father's marriage. One extreme position is that of 'Aql al-'Awitt. He sees the whole narrative with its complications only as a pretext for what he considers pornographic episodes, and this reminds him of those TV films that use a narrative ploy in order to exhibit erotic scenes. ${ }^{16}$

Of course, when al-'Awìt fails to find a narrative aim behind the novel, ${ }^{17}$ all details become haphazard and whimsical to him, and this corroborates his thesis that they are there only as pretexts. He then, naturally, wonders: "Why the reader should accept this extent of pornographic relationships only because the hero cannot bear the problems resulting from his father's marriage!” At the same time al-'Awīt declares that he has no problem with pornography when it is part of a sound narrative structure.

Curiously enough, al-'Awīt considers the novel to be totally simple like the naïve Arab and French love stories of the 1950s and 60s, adding that these stories were very arresting. Above all he detects a great simplicity in the narrative as well as in the language, while admitting that

these are very genuine and very realistic stories that happen within hushed and discrete walls, but they are actually very true. The inner world of such walls may not be open or told. Rashid al-Daif's "achievement" is that he does this in a very plain style and with a very "insolent" coldness. But do the father's second marriage and the son's terror in the face of this eventuality deserve all these sexual stratagems which make up this novel? I don't know! (p. 10)

Al-'Awìt differs fundamentally from Bītār on at least two major points. He is not blinkered about the fact that these things take place everyday behind closed walls; and he does not impose on a good novelist the championing of "The Good, the True, and the Beautiful" as antidote to the reality that is secretly hidden behind these walls. In this sense it is interesting to read a critic who is open-minded and liberal yet unable

16. 'Aql al-'Awīṭ, "Insay as-sayyāra li-Rashīd aḍ-Ḍa‘îf: Burnugrafia l-ḥayāt as-sirrīyya riwāyatan”, Mulḥaq an-Nahār, Beirut, December 8, 2002, p. 10.

17. "Where is really this narrative's aim? I don’t know." Ibid. 
to see the point. Here, I should like to argue that the inability of a liberal critic like al-Awit to see the necessity for what he calls "all the sexual stratagems" is mainly due to his missing the link with the classical text and the basic inversion of moral and social mores that the author wants to substantiate through his hero's obsessive fixation on his father's plans.

I personally enjoyed reading this novel maybe twice as much as I would have had without being aware of the intricate way it integrates the multiple aspects of its hypotext, which I shall discuss later. That is why I fully understand that most critics missed its comic side and were not at all amused by the scenes of the father's and the son's sexual games. Bìțār is the best example of missing most points. Blind as she is to the pleasure side of the text, she cannot see any fun in the whole thing and is totally infuriated by the light treatment of what for her is a morally and socially serious subject. She is even unable to read the text with any alertness. In her idealistic view of Arab society, she simply refuses to see any possibility that such illicit behavior may exist. Where al-'Awīt sees perfect realism, she claims that al-Daif is trying to emulate Henry Miller and she wonders whether it is possible at all to find any resemblance between 'our'society and Miller's, where "sex has become a sheer absurd act that does not lead to any paradise, but to an increase in one's isolation and melancholy, after the chaos of absurd sexual relations."

In answer to both critics one may say that the use of al-Aghāni as his major hypotext serves the author's main strategy to contrast classical and modern Arabic discourses on sex. In the past, modern Arab prudishness was scorned. This goes for al-Ișfahānī as much as it goes for the great writer and theologian, al-Jāhiz (d. 869), who has a clear position on the moral question raised by the open discourse on sexual matters:

Words have been coined so that speakers use them; if they were supposed not to be uttered, then their existence would have no sense in the first place, and it would have been more resolute and more protective of the Arab language that these names and terms be eliminated from it.

He who says, "For every situation there is a speech" is totally right. ${ }^{18}$

Al-Jāhiz then tells a number of anecdotes in which the Prophet's companions use "obscene" words without any false prudence; and in one story a woman comes to the Prophet requesting permission to go back to her ex-husband because the new one, she says, "has a penis softer than the tip of my dress." The Prophet only smiles and then tells

18. al-Jāhịiz, "Mufākharāt al-jawārī wal-ghilmān”, in Rasā’il al-Jāḥiẓ, vol. 2, ed. ‘Abdassalām Hārūn, Cairo, Maktabat al-Khānjī, 1965, pp. 87-137, here p. 93. 
her that she cannot go back to her ex-husband before she and her new husband have tasted of each other's "honey". ${ }^{19}$ For al-Jāhiz the matter seems to be straightforward:

Some of those who show off asceticism and abstinence are disgusted and displeased when one mentions the vagina, the penis, and fucking. Most of those who are like that are men who have no part of chastity, honor, nobility or dignity, except this affectedness. ${ }^{20}$

Intertextuality is also a matter of style. Indeed, what seems to shock many critics is al-Daif adoption of al-Aghān $\vec{\imath}$ s matter-of-fact style and of the liberal attitude to sex in classical Arabic literature. In this regard, al-Isfahānī is not far from al-Jāhị in considering that if sexual organs, thoughts, and acts exist along with the terms that express them, why should one avoid talking about sexual matters in openly sexual terms? Even more disturbing, perhaps, is the novel's adoption of al-Aghān $\vec{\imath}$ s style of passing lightly over what may be seen as very serious matters, rarely depicting any real inner turmoil or presenting any dramatic, moral conflict.

In general, various positions have been taken by the main critics. Some were able to see the positive sides and deeper layers of the novel, putting their fingers on the symbolic nature of the seemingly simple narrative and on the basic critique it conducts against practically all aspects of modern Arab society, and especially the falsehood of postcivil-war Lebanese society. Others honestly mentioned their sheer pleasure at reading the text. Sulaymān 'Awda asserts that "Insay as-sayyāra is a text [made] for joy. It is a novel that one reads with love and pleasure, and this, in an Arabic perspective, is an achievement, in the midst of the huge quantity of texts of boredom presented to us yearly by the Arabic writing factory."21 'Awda's comment touches a central point in al-Daif's narrative art; he thinks that a novel can narrate anything and take any form so long as it is not boring. ${ }^{22}$

Among those who have noticed the double layers of the narrative and highlighted the success of the text in denouncing the contradiction and duplicity in Lebanese and Arab modern life, we find Șabrī Hāâz, who published a perceptive analysis that, besides illuminating many

19. Ibid., p. 93-94.

20. Ibid., p. 92.

21. Sulaymān 'Awda, "al-Mukhayyila al-hūlyūdiyya”, an-Nuqqād, No. 138, Beirut, January 16, 2002, p. 24.

22. Rashid al-Daif, Personal Interview (20 October 2004). 
interesting sides of the text, foregrounds the central symbolism of the car and its structural relevance, considering it a good token for all the cheating and double-crossing in the social, economic, and human relations that represent the "Lebanese material and moral devastation." 23

The most important insight Hāfiz offers, however, is the relationship he draws between Insay as-sayyāra and al-Daif's earlier novel, Who Cares about Meryl Streep! He sees in both an embodiment of the author's intention to show us "that the Arab male is an eternal adolescent and an eternal debauchee, who does not know sexual maturity, be he thirty-five years of age, like the son, or a sixty-five year old man, like the father." In another basic observation Ḥāfiz notes that "deep down, the Oriental hero does not have confidence in a woman who offers herself to him. Her generosity toward him makes him treat her as if she were a kind of a prostitute, no matter how much he is the cause of that prostitution.” At the same time Hâfiz highlights the author's insistence on presenting socially alienated males who are fixated on proving their false sexual potency at a time when different parts of their homeland are being raped by foreign invaders. ${ }^{24}$

Despite the perceptive remarks of many of these critics, I should like to investigate the possibility of a different reading based on an intertextual marker that establishes a link with classical Arabic culture, and thereby opens a whole new perspective on the text, making it a real dialogue between two epochs, if not two cultures, to the detriment of the 'modern'one, in which people have lost their soul and authenticity and have become entrapped in a mindless, heartless, and treacherous life, as the hero says (p. 106). This is similar to his car, in which he feels that he is riding a viper (p. 89), and similar to all the families he knows, no one of which is normal (p. 108).

Besides his many insights, Ḥāiz makes an important remark which, in my opinion, can be attributed to his ignorance of the classical hypotext of the novel. Thus, he says:

In reality, the novel passionately strips all its characters naked, to the point where we finally discover that we have to do with many uneven mirrors that convey various manifestations (tajalliyāt) of one and the same male character and one and the same female character. (p. 14)

23. Șabrī Ḥāfiz, "Insay as-sayyāra” wa-tajalliyāt al-kharāb al-māddī wal-ma‘nawī fī Lubnān”, al-'Arab, London, April 23, 2003, p. 14.

24. Ibid. See also Insay as-sayyāra, p. 93. 
This I should like to contest, and will attempt to show that these characters are not the same. For if they all behave according to the same patterns of falsehood and cheating, they still have different functions and play different roles, otherwise one would not be able to invert these roles, nor would one be able to contrast them with their classical counterparts as well as with the classical set of norms and values. For this purpose, I should like to sum up the basic hypotext taken from al-Aghāni, the $9^{\text {th }}$ century literary encyclopedia, namely the story of Qays Ibn Dharīḥ and his beloved Lubnā.

\section{The Story of Qays and Lubnā}

First, I should like to draw attention to the great importance of style in al-Aghānī, a style which al-Daif tries to adopt. At the beginning of the story, al-Ișfahānī gives us the key to his sources and explains his method of composing the story of Qays and Lubnā:

A group of our masters told me the story of Qays and Lubnā, his wife, in connected and disconnected stories and anecdotes, in prose and poetry. I composed them, so that his story would be consequent, except what occurred as a single report, which I mention alone... [Here the author mentions about 15 transmitters] I related all the concurrent reports in a connected way, and I attributed the variants to their different transmitters. They all said... ${ }^{25}$

And then al-Ișfahānī tells what one may summarize as follows:

Qays ibn Dharīḥ and Lubnā fell in love. Dharīḥ, Qays’s father, was a rich man and wanted Qays to marry one of his cousins. Neither was his mother ready to help. However, al-Ḥusayn ibn 'Alī ibn Abī Ṭālib, his milkbrother, intervened and helped the lovers to get married. They spent a period in perfect harmony. But then the mother became jealous, feeling that Lubnā was distracting Qays from taking care of her. It so happened that Qays fell very ill, and once healed, his mother found it a proper occasion to tell his father that she was afraid that Qays would die without leaving any children behind, for Lubnā seemed to be barren, and all his money would go to distant relatives. The best solution would be to make him marry another woman, so he might have children (p. 213).

Qays rejected the idea of marrying anyone but Lubnā. He would neither divorce her nor take any concubines. He then proposed that his father marry and get more children of his own. The father insisted on

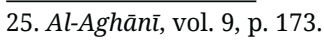


the divorce, swearing that he would never be under any roof so long as Qays did not divorce Lubnā. He went out and stood in the heat of the sun, and Qays came and held his own clothes above his father so as to provide him with shade, while he himself was scorched by the sun.

This went on for forty days, and then Qays agreed to divorce Lubnā. Others say that this report is false and that his parents remained years without talking to him, so he had to divorce her. In any case, the result was that he regretted his action very strongly and his longing for her drove him nearly mad. He would visit her or at least come close to her camp. But her parents reported Qays to the caliph, who gave them permission to kill him if he came near them again.

One of his parents'solutions was to find him a beautiful girl who would distract him from Lubnā. Others say that, while going through the market, he met another woman called Lubnā who greatly resembled his divorced wife (p. 229). She took a liking to him, and her brother, who had heard of Qays and had a great admiration for him, succeeded in convincing him to marry his sister. Yet, Qays's fidelity to his ex-wife prevented him from consummating this marriage. Still, when the first Lubnā learned that Qays had remarried, she was grieved and accepted an offer to remarry.

As for the end of the story, there is more than one version. One says that Qays and Lubnā remained separated and that he died before she did and then she died of grief (p. 251); another story relates that she died first, and Qays cried over her grave until he fell unconscious; he remained silent for three days and then died (p. 252). Yet another important variant says that a certain Abì 'Atīq was able to get her husband to divorce her, and then to allow the two lovers to marry again (pp. 252-253).

The moral of the story is clear: despite all suffering and imposed divorce, the lovers may make mistakes and fall in to various kinds of misunderstanding, but they basically remain true to the 'udhri ideals of truthfulness and chastity. In spite of their separate marriages, they die out of grief over each other.

\section{Al-Aghānī as Background}

Al-Aghānī is an encyclopedic compendium of stories, mainly of poets and singers, covering at least four centuries, from pre-Islamic times to al- Ișfahānī's second half of the $10^{\text {th }}$ century. Although it naturally reflects its author's perspective, it tries to report these stories with as much objectivity and detachment as possible. In her master work on 
this subject, Hilary Kilpatrick, ${ }^{26}$ not only considers it an "epic panorama of pre- and early-Islamic literature, history and culture” (p. 277), she discusses and confirms Ișfahānī's accuracy and induces examples to that effect, among which we find an example having to do with Qays ibn Dharīh. ${ }^{27}$ She discusses one case concerning the story of Qays and Lubnār (p. 118), and considers that al- Ișfahānī respects the "artistic truth" in judging that "a year" is "more appropriate that the mere forty days Khārlid ibn Kulthūm mentions" (IX, 183-84) in connection with the time span Qays was able to resist his father's insistence on him to divorce Lubna.

From an interview with al-Daif, ${ }^{28}$ I learnt that, for about three years, he was intensively absorbed in al-Aghānī, reading and taking notes in preparation for his later novel, Ma'bad Succeeds in Baghdad. ${ }^{29}$ Once we are aware of the ancient story, it would not be too far-fetched to claim that it provides the novel with a nuclear structure that the author travesties by inverting its motivation and the roles of the main protagonists. The second major operation the author does is to amplify the story from about 20 pages to about 200 and to transpose it in the modern Lebanese climate of violent breakdown of all traditional mores.

\section{Transtextuality and Inversions}

Once we are aware of the marker of the suicide by sun-stroke, we gradually realize that we are not dealing here with a simple peripheral allusion, and that the marker activates the whole hypotext, spreading its structure all through the novel. Simultaneously, the basic inversion operated on the marker's structure draws our attention to the same inversion the author applies to the very core of the story and its social and moral dimensions.

The core and meaning of the Qays and Lubnā story is that of chaste and truthful 'udhri love, whereas the core of love relations in Forget about the Car is untruthful libertinage and hidden fornication. The former relations are based on the open declaration of real, licit love that, through society's obstacles and constraints, ends in separation and

26. Hilary Kilpatrick, Making the Great Book of songs: Compilation and the author's craft in Abū l-Faraj al-Ișbahānī’s Kitāb al-aghānī, London and New York: Routledge, Curzon, 2003.

27. See "Accuracy and the criticism of Akhbār", in Kilpatrick, Making the Great Book of songs, pp. 111-119.

28. Rashid al-Daif, Personal Interview, Beirut, 15 October 2004.

29. Rashīd aḍ-Ḍa'îf, Ma'bad yanjah fĭ Baghdād, Beirut, Riyad ar-Rayyis lin-nashr, 2004. 
death, whereas the modern relations seem to flourish much more in illicit sexual practices and in hiding and cheating. The social and moral values of the hypotext reflect the stability of a traditional society, whereas those of the hypertext reflect the instability and treachery of civil war, going in line with the Arab adage "war is a deceitful maneuver" (al-harbu khid'a).

The aforementioned features of the new mores are emphasized through another transtextual element, namely a quotation from Suhayl Idrīs's Dhikrayāt al-adab wal-ḥubb (Memoirs of Literature and Love), where he remembers his adolescent years when his father used to bring home a young boy whom he used to take into the sitting room and lock the door. This intertext not only strengthens the contrast between the 'udhrī morality and its modern counterpart, it also helps elucidate some moral and psychological aspects of the narrator's father, since it is followed by an open discussion in which he disapproves of divulging such secrets about one's father as Suhayl Idrīs does. More importantly, the discussion insinuates that this divulgence upsets the father because he may have been the young boy to whom Idrīs's father made love. But while Suhayl Idrīs is disgusted by the duplicity in his father's behaviour (Idrīs, pp. 12-13), the narrator's father is outraged only by the divulgence. The act itself does not seem to concern him too much. For, as we have seen, he has no qualms about making love to a twenty-year old girl, Laylā, behind locked doors, nor about doing that at home, namely, in his future wife's apartment. In the course of the discussion, as elsewhere in the novel, we also learn that he is exceptionally interested in homosexuality, although he disapproves of homosexual marriages which he considers to be against nature and an expression of a death-wish in the societies that allow such marriages (pp. 32-33). Although the author frequently hints to the father's possible homosexuality, he wraps this point in intentional ambiguity (pp. 32-36).

In short, these two major transtextual operations serve to show the decadence and falsehood of the modern mores based on mutual bluffing, while safeguarding appearances to the detriment of authentic sentiments and values. In this modern game, no one is spared. Only the sister's character and minor role are presented under a somewhat neutral light. 


\section{The Structural Inversion and its Consequences}

The inversion of all values as a structural element takes place in some essential characters and relationships and, above all, in the relationship between father and son, where many terms are inverted:

The basic structural inversion is operated on the main element of the plot and on the roles of the two major protagonists. In the story of Qays and Lubnā, Qays's father insists on his son's having progeny and consequently wants him to divorce the barren Lubnā. Conversely, in the novel, it is the son who wants to stop his father from marrying for fear he may still beget children (since Zāy's major aim and sine qua non condition is to have a child or two, cf. p. 112),

Consequent to this general inversion, both the roles and the means of pressure are inverted. Instead of the father trying to commit suicide, it is the son who does that. This goes hand in hand with a basic opposition in psychological and physical characteristics as well as social behavior and attitude toward money and wealth.

1. The father is a happy-go-lucky, libertarian, nonchalant, carpe-diem type; the son is anxious; he calculates every step and every penny; he feels responsible for his father, whereas the latter is portrayed as "a child," of whom the son or the daughter has to take care (pp. 15, 37).

2. The father is potent; he could "beget a legion of children" (p. 97) if the son doesn't stop him; the son seems sometimes unable to make love without resorting to the use of Viagra. The word "impotence" is repeated in the text (cf. pp. 120,151).

3. While pretending to be in dire need of company as a way out of his isolation, the father behaves as an overly generous lady's man. This allows him to live as a king or a caliph.

a. He lays his legs on Zāy's lap in order to have her natural warmth as a cure against rheumatism. In this, he claims to be imitating the old Persian kings and Arab caliphs, who did that with boys and girls in their puberty. For him, Zāy's importance in this operation lies in her virginity (p. 82).

b. He is self-confident, free and indifferent to what people say. He allows his daughter to stay out late in the evening and leaves her alone at home with her fiancé. When the narrator worries that this laxity would make the family "the talk of the people" (hadìth an-nās), the father retorts: "I am the people" (ana n-nās). "As if," says the narrator, "he had in his blood some blood of the great 
Arab caliphs, one of whom once said: "We are the Times, for the one we raise will rise, and the one we humble will be humbled" (pp. 22-23). ${ }^{30}$ Against this boastful, royal attitude, the son is a permanent loser. He is constantly worried about life and about his actual and future financial and social situation. He is totally at the mercy of a mercantile society, by which he seems to be as overwhelmed as he is by his father's whims.

\section{A Double Incest?}

In the Qays-Lubnā story, the father refuses to replace Qays in marrying a young woman, so as to beget new children, and thus leave Qays with the barren Lubnā. Here, not only does the father establish a sexual relationship with his son's girlfriend, the son, in turn, deflowers his father's "wife". This is not a clear oedipal relationship, since it is done out of revenge and devilish scheming and not out of attraction to the mother. Still, it is a rather incestuous relationship, since Zāy is virtually his father's wife, without being his own mother: just before the narrator sleeps with her, she clearly refers to the father as "my husband" (zawjī, p. 126). ${ }^{31}$ Here, again, what some critics see as a shocking, "pornographic" act is not unknown in the Abbasid period; similar stories are told in a simple and straightforward way in al-Aghāni, such as that of 'Abdalwahhāb ath-Thaqafi's son, Muhnammad, who was in love with his father's wife, Bāna, from whom he had a son, Ziyād, who looked so much like him. ${ }^{32}$ That this whole episode may have been inspired by such stories is corroborated by a strong marker that relates the love act to an anecdote in al-Aghānī. When the narrator ejaculates in Zay he says: "My father can now detect my traces in his wife's vagina” (p. 127). The same terms (athari fi hiri zawjatih) are found in al-Aghān $\vec{\imath}$ s anecdote about Manẓūr ibn Zabbān who married Malikka, his father's wife, and then was ordered to divorce her by the caliph Omar, who chided him by saying: "How do you marry your father's wife; she is your mother!” Malikka remarried Muhnammad ibn Tāha who was later addressed by Manzūr with these terms "How did you find the traces of my penis in Malikka's vagina?” (athara ayri fì hiri Malīka). ${ }^{33}$ The immediate allusion to this passage in al-Aghānī

30. This is cited from Abū Manșūr 'Abdalmalik b. Muḥammad b. Ismā‘̄il ath-Tha‘ālibī, al-Lutf wal-lațā'if, ed. Maḥmūd 'Abdallah al-Jādir, Beirut, 'Ālam al-kutub, 1997, p. 21.

31. "Why should the recognition of my humanity be against my husband?” p. 126.

32. Al-Aghānī, vol. 18, p. 110

33. See "Akhbār Manzūr Ibn Zabbān", al-Aāghnī, vol. 12, ed. 'Abdassattār Aḥmad Farrāj, Beirut, Dār ath-thaqāfa, 1990, $8^{\text {th }}$ printing, pp. 189-194, here 192. 
is obvious, not only through the term athar (trace, traces), but also through the unusual usage in modern Arabic of the very term hir for vagina.

Moreover, this possible incestuous relationship is corroborated by Laylā's comment: "It is shameful to sleep with your father's wife" (p. 56). This dimension of the son-father relationship may imply a hidden desire by the son to get rid of the father's dominant presence or even existence (symbolized by procreation). This seems all the more probable when we remember the oppressive, almost castrating father's potency and the son's feeling that since he was a child his father has had a tendency to devour him: "In an old picture one sees him kissing me, with his mouth open, as if I were a piece of cake" (p. 87). This deeply repressed feeling towards the father comes out in a burst of anger: "I really wanted to explode him!” (p. 150).

\section{Laylā: Mother Theresa.}

The novel presents two parallel couples: the narrator and Laylā, and the father and Zāy. The narrator's intention to break the father-Zāy couple leads him first to offer Laylā to his father as a "deterrent", and then to rape Zāy. If we consider the father-Zāy couple as an activation of the Qays-Lubnā couple through the sun-stroke marker, it would not be too far-fetched to think of the narrator-Laylā couple as activating the other famous 'udhrī Qays-Laylā couple. One may thus claim that the narrator's girlfriend is called Laylā, both as the eponym of all beloved women in the classical (and modern) tradition and as the particularly "virgin" beloved of the love-mad-poet al-Majnūn. ${ }^{34}$ Here the inversion of all values (Genette's Transvaluation?) resides in the fact that this Layla $\bar{a}$ is "virgin" only through hypocritical appearance, ${ }^{35}$ whereas in reality, she has no scruples about selling herself for money, or simply enjoying sex for her pleasure's sake, so long as this is done in secret and her "honor" is not tarnished. While taking great care not to get pregnant, or to let her parents suspect anything wrong in her "behavior" (sulūk), she has no restraint in her sexual pleasures: "I love "fu..." more than anyone else, as you know and as you've realized yourself," (p. 119) says she to the narrator in one of their discussions.

The climax of sarcasm is reached when the narrator likens Laylā to "Mother Theresa" (he uses the term "Sister Theresa", p. 119), while he

34. One must remember here the many ' $u d h r \bar{t}$ traits common to the stories (anecdotes and poetry) and characters of the two famous love-poets, Qays Laylā and Qays Lubnā. 35. "She is purity itself." p. 45. 
likens his father to Gandhi. "Laylā" being traditionally the incarnation of chaste, 'udhri love, it is rather astonishing that, even without noticing the intertextual allusions, critics have not given this fact enough attention.

\section{The Story of Sallāma az-Zarqā'}

Al-Daif uses the well-known story of the singer Sallāma az-Zarqā' with the jeweller Yazīd ibn 'Awn al-'Ibādi aș-Ṣayrafî, from the chapter that al-Aghāni dedicates to Sallāma. ${ }^{36}$ His use of the story serves also to demonstrate the discrepancy in values between the classical and modern times.

The singer az-Zarqā' was married to Muhammad ibn Sulaymān, who had bought her for the huge sum of 80,000 dirhems. One day he asked her if anyone of those who loved her ever got intimate with her or was able to kiss her. She admitted that no one except Yazīd ibn 'Awn al-'Ibādi aș-Ṣayrafĩ: "He kissed me once and threw in my mouth a pearl which I sold for 30000 dirham." The story is further related in some detail by a certain 'Abdarrahman ibn Muqrin, where he tells how he went with this Yazīd aș-Ṣayrafĩ to Ibn Rāmīn the master of az-Zarqā', where she was singing, and that after she stopped singing, Yazīd aș-Ṣayrafĩ told her he had two pearls that were worth 40,000 dirhems, and that if she wanted them she would have to get them with her lips from his mouth. He crawls on all four with the pearls in his mouth, and when she does the same and tries to get them with her lips, he repeatedly tries to sneak away so she would be obliged to keep trying to stick her lips on his. Finally, her maid holds him from behind, and Sallāma snatches the pearls from his mouth, upon which she blushes for shame and tries to counterattack Yazidd, claiming that she had won over him, but he says that her flavour would remain for ever in his nose and mouth.

Al-Daif uses the same anecdote, integrating it into his general descriptions of the father's extravagant behaviour. The father does the same with Laylā, not with pearls but with a sum of paper money hidden in a small plastic envelop within his mouth. In order to get the money, Laylā was supposed to get that envelop out with her mouth (p. 99). The father greatly enjoyed the game, and Laylā was happy to play it even for a miserable sum of money in comparison with what az-Zarqā' got (the pearls were worth half the price that her master got by selling her).

Another variation on the same anecdote is found in the story of Layla's friend, Dān, who dates an old man, rich enough to afford such

36. Al-Aghānī, vol. 15, pp. 46-58, here p. 52. 
games. He would put in his mouth a precious present and let Dān get it with her mouth. Sometimes, he even puts the present on his genitals, turns off the light, and asks Dān to find it and get it. She enjoyed the game, because "she liked him a lot" (p. 57).

7. Let me see your legs! (Arīnī sāqaykī)

Zynab bint Yūsuf ibn al-Ḥakam ath-Thaqafì, the sister of the famous al-Hajjāj, goes out to a certain garden in the company of some women. She is told that one of them has the nicest legs ever seen. Zaynab turns to that woman and tells her: "Let me see your legs!" The woman says: "No, except in seclusion.” Zaynab says: "As you wish.” Once in seclusion, the lady uncovers her legs, and Zaynab, full of admiration, gives her thirty dinars, and says: "Buy yourself anklets." ${ }^{\text {" }}$

The same story is taken up by al-Daif, but, as usual, with the contrary effect. Being intrigued by Laylā's body that so much attracts the father, Zāy expresses one day the same wish as Zaynab's in al-Aghānī and uses with Layla the same terms, telling her: "Let me see your legs!" But instead of being impressed and giving Laylā a present as a sign of admiration, Zāy goes into a fit of jealousy, keeps frenetically repeating: 'Mabrūk, mabrūk, mabrūk!' (Congratulations!), and then, feeling that life is unfair, she breaks into tears (pp. 100-101).

\section{A Chart of Inversions}

As already mentioned the marker, suicide by sun-stroke, establishes both the fundamental relation between the two texts and the basic inversion. In both stories there is a suicide attempt by exposing the head to the scorching sun, an attempt aimed at exerting moral pressure on another man in order to oblige him to sever his relationship with a certain woman. In the hypotext the attempt succeeds, whereas in the hypertext it fails. The major difference between the two does not lie in the results of the attempt, but in the inversion of roles and of the motives for separating the two lovers.

In the case of Qays ibn Dharîn it is the father who wants his son to divorce because of Lubnā's barrenness, whereas in the case of the narrator it is the son who wants his father to break with Zāy because of her possible fertility. The fact that Dharị finally succeeds in forcing his son to divorce gives the story a different turn of events from that of the modern novel, in which the son's failure to separate his father from Zāy

37. Al-Aghānī, vol. 6, p. 190. 
pushes him into a deeper indulgence in his phantasms and eccentric tricks to reach his goal.

Without necessarily being the generic nucleus of the novel, the Aghānithypotext provides a wide network of motifs and strongly enters in a polemic rather than in a dialogue with the novel's modern social and moral world.

By exposing the inversion of norms and behavioral patterns that is manifest all through the text, the author stresses the strong discrepancy between old, ideal values and present, actual living. This discrepancy generates the double life of external values and hidden intentions and feelings. The polemic with the world of the novel's hypotext helps the author to operate a ruthless deconstruction of the patriarchal discourse and to lay bare the whole web of hypocrisy and lies that dominate modern life. Suffice it here to mention some examples that spread over the different individual, social, and moral levels.

\begin{tabular}{|c|c|c|}
\hline & Al-Aghānī & Insay as-Sayyāra \\
\hline Nature of life & $\begin{array}{l}\text { Life is lived according to } \\
\text { accepted norms and seems to } \\
\text { be affected by human will. }\end{array}$ & $\begin{array}{l}\text { "Life is treacherous" (p. 106). } \\
\text { All norms are inverted. }\end{array}$ \\
\hline Context & Traditional Arab society. & $\begin{array}{l}\text { Inversion of contexts, after } \\
\text { September } 11,2001 \text { (p. 108). }\end{array}$ \\
\hline Feelings & $\begin{array}{l}\text { Strong feelings yet bound by } \\
\text { social and family rules. }\end{array}$ & Inversion of feelings (p. 106). \\
\hline $\begin{array}{l}\text { Social \& moral } \\
\text { system }\end{array}$ & $\begin{array}{l}\text { Very clear patriarchal system. } \\
\text { Social and moral taboos. } \\
\text { - Women are rather subdued } \\
\text { and follow what the males } \\
\text { decide }\end{array}$ & $\begin{array}{l}\text { - The patriarchal system is put } \\
\text { into question. } \\
\text { Taboos are transgressed. } \\
\text { Women, in general, are } \\
\text { stronger and more cunning } \\
\text { than men. }\end{array}$ \\
\hline Family & $\begin{array}{l}\text { The family behaves according } \\
\text { to the social and moral norms } \\
\text { of the times. }\end{array}$ & $\begin{array}{l}\text { The narrator's family is "not } \\
\text { normal”. He even thinks that } \\
\text { no family is normal (p. 108). }\end{array}$ \\
\hline $\begin{array}{l}\text { Traditional } \\
\text { values, } \\
\text { Honor } \\
\text { and honesty }\end{array}$ & $\begin{array}{l}\text { They are highly respected, in } \\
\text { line with the general mores of } \\
\text { the times. }\end{array}$ & $\begin{array}{l}\text { Totally absent among the } \\
\text { protagonists, except as } \\
\text { pretension, for the sake of the } \\
\text { conservative old generation. }\end{array}$ \\
\hline $\begin{array}{l}\text { Appearance and } \\
\text { reality }\end{array}$ & $\begin{array}{l}\text { Respect for appearances, but } \\
\text { in accordance with reality. }\end{array}$ & $\begin{array}{l}\text { Appearance and not reality is } \\
\text { what counts, esp. in matters of } \\
\text { honor and integrity. }\end{array}$ \\
\hline
\end{tabular}




\section{Al-Aghānī}

The Problem

\section{Insay as-Sayyāra}

The instinctive need for survival through selfimplantation, i. e., procreation, is hampered by Lubnā's barrenness.

Love
whole story, love is a passion
that makes the beloved
irreplaceable.
- Qays and Lubnā remain true
even when forced to divorce
and when each of them
remarries.

\begin{tabular}{|c|c|}
\hline $\begin{array}{l}\text { Looks and } \\
\text { Fertility }\end{array}$ & $\begin{array}{l}\text { Lubnā is beautiful and } \\
\text { passionately loved. } \\
\text { She yearns for children, but is } \\
\text { barren. }\end{array}$ \\
\hline Marriage & $\begin{array}{l}\text { Son is married. His family } \\
\text { wants him to divorce. }\end{array}$ \\
\hline Suicide attempt & $\begin{array}{l}\text { Father tries to commit suicide } \\
\text { by exposing his head to the } \\
\text { sun. Son protects him. }\end{array}$ \\
\hline
\end{tabular}

Divorce

Father succeeds in forcing his son to divorce.

There is no real love in any of the relations.

It is replaced by sex and used as a means for material exploitation. It is a mercantile commodity.

- Laylā is not true. Sleeping with the father turns her "upside-down” (p. 118).

Zāy is extremely ugly and not really loved.

She yearns for children and is probably pregnant.

Father wants to marry. Son wants to hinder that marriage.

Son tries to commit suicide by exposing his oiled head to the sun. Father protects him.

Son fails in foiling father's plan to marry.

Father's character Traditional father, serious, and thinking responsible, and ready to die for the sake of his family's interests.

Happy-go-lucky, libertarian, and irresponsible father, with eccentric and even abnormal thinking (pp. 106, 117, 118).

Family relations

The father cares about the son's future and wishes him to have progeny and keep the wealth in the family.

No one really cares about anyone else's future.

The son only worries that the father would squander the family's money.

Value of material Caring only about keeping wealth Lubnā, Qays would rather have his father marry a young woman, beget children and have them inherit his wealth.

Worried about his financial situation, the narrator abhors his father's plans to marry and have children who would become dependent on the narrator himself.

Father's sexuality The father refuses to have The father craves sexual sexual relations or to marry a young woman, for the sake of progeny. relations. He is still potent and can "beget a legion of children. (p. 97) 


\section{Al-Aghānī}

Sex and Lovemaking
Sex is the fulfillment of love and a means for procreation. - Lovemaking is part of the love relationship and reflects perfect harmony. Love being sacred, it is the indispensable condition for having sex. That is why Qays does not even touch the second Lubnā.

\section{Insay as-Sayyāra}

Sex is either an end in itself under the appearance of love (narrator and Laylā) or is prostituted for money (Sīn and Laylā with the father).

- Sex is used to deter the father from marriage and procreation.

- Lovemaking is travestied as violence and war between the narrator and Zāy (p. 132). The act is described in war terms (p. 104). Instead of being knocked out, Zāy turns things upside-down. Says he: "as if she is the one who deflowered me" (p. 132).

\begin{tabular}{lll}
$\begin{array}{l}\text { Human and } \\
\text { political relations }\end{array}$ & $\begin{array}{l}\text { They seem to follow } \\
\text { traditionally } \\
\text { established conventions. }\end{array}$ & $\begin{array}{l}\text { They are "disconnected and } \\
\text { inverted after September 11, } \\
\text { 2001" (pp. 107f). }\end{array}$ \\
\hdashline$y_{\text {Friendship }}$ & $\begin{array}{l}\text { Important: for instance, the } \\
\text { intervention of al-Husayn ibn }\end{array}$ & $\begin{array}{l}\text { Friendship is inverted into } \\
\text { exploitation and cheating. The }\end{array}$ \\
& $\begin{array}{l}\text { 'Alīibn Abī Țālib in favor of } \\
\text { Qays. }\end{array}$ & $\begin{array}{l}\text { narrator is betrayed by his } \\
\text { friend, who bluffs him with } \\
\text { the car (p. 108). }\end{array}$
\end{tabular}

Such examples are abundant in the novel and touch on all three taboos of politics, religion, and especially sex.

1. Socio-politically, the background of the novel is less the actual civil war than its atmosphere, mentality, and social and moral consequences: the broken family and social relations, the economic profiteering and cheating, the explosive relations similar to the usually booby-trapped cars so common during the civil war and in its aftermath. Furthermore, civil war means also civil-war economy: the narrator would have liked the war to go on much longer; his business of pirating CDs, floppies and dictionaries would have continued to flourish (p. 93).

2. Religion is nowadays, even in Lebanon, the most dangerous to challenge. It is not directly attacked, but frequently hinted at in the form of the fake bigotry and hypocrisy that dominate the moral behavior of the characters, who never give up the claim of being religiously correct: the protagonist claims to be a believer, because he normally prays, while accusing his father of unbelief (p. 10). Yet 
our protagonist misses no occasion to manipulate others for his own profit. The best example, however, is a main representative of the patriarchal system, namely, Idrīs's father, who is a practicing believer and a daily prayer leader, ${ }^{38}$ and yet allows himself to fornicate at home, without really hiding, i. e., without any deference to the quasi-religious precept that says: "If you are inflicted with sin, hide yourselves." ${ }^{39}$

3. As for sex, it is the main device for deconstructing family, love and social relations exposed to the socioeconomic pressures of civil war and Westernization.

\section{$* * *$}

Al-Daif uses many devices to keep the suspense and the reader's interest in the story. He makes us believe that his novel's strange events and bizarre characters are not improbable in modern Beirut. Without pretending as usual that the novel is partially autobiographical, he uses many devices to embed the narrative in present Lebanese life. Besides the intertext from Idrīs's Memoirs, one of his devices is to use the initials "Z" and " $\mathrm{S}$ " in order to add a touch of realism, giving the impression that they are the initials of two real women, whose full names the narrator wants to hide. ${ }^{40}$ All this goes into strengthening the impression of this novel being a natural exhibition of inverted values and norms.

Most critics have noted the double standards in the behavior of the characters, but an awareness of its major hypotext, I mean al-Aghān $\vec{\imath}$ story of Qays and Lubnā, helps the reader realize the extent to which the novel exploits the parodic inversion of all values and norms thus sharply contrasting the 'udhri code of love and honor with the pretensions of our modern times.

Finally, al-Daif has risked a lot in betting on the critics'knowledge of classical Arabic literature. If his novel's structure and external meaning are intriguing and enjoyable enough to keep the readers engrossed, the wager is with the critics to uncover the hidden layers of the text. Giving no real clues to its hypotext, the novel conceals the network of themes and motifs that may be activated upon noticing the main marker (suicide by sun-stroke). By pointing to the 'udhrī Story of Qays and Lubnā

38. Suhayl Idrīs, Dhikrayāt al-adab wal-hubb, op. cit, p. 17.

39. "Idhā bulītum bil-ma‘āṣī fa-statirū.” This is not really a Prophetic tradition, but it is often mistaken to be so.

40. He makes clear that he hides Sīn's real name because people would easily recognize her, since she works in a very famous shop (p. 52). 
Rachid El-Daïf-Le roman arabe dans la tourmente de la modernisation

and to the manifold Abbasid background of al-Ahgānī, this marker allows a new reading, replete with interesting perspectives on another one of al-Daif's arresting novels.

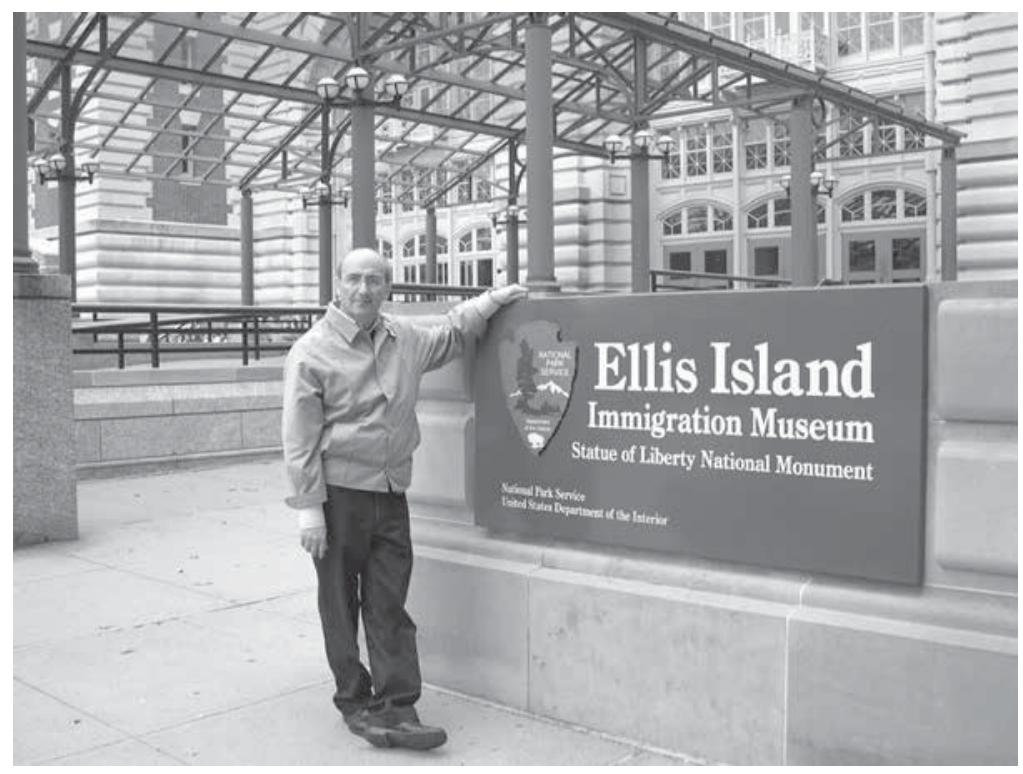

À New York 


\title{
10 \\ Quand l'écrivain interroge son œuvre ${ }^{1}$
}

\author{
Rachid El-Daïf
}

\section{L'Occident vu par l'Orient: tensions et fascination}

Fascination. La première fois que je me suis rendu à l'ambassade de France à Beyrouth pour instruire une demande de visa, je fus fasciné par les vues, accrochées aux murs, de paysages français, naturels ou urbains. Ces images avaient quelque chose de mystérieux et de fascinant. J'eus hâte d'obtenir le visa, afin de pouvoir scruter de mes propres yeux les réalités correspondantes. Cette anecdote ne témoigne d'aucune singularité personnelle: l'Europe en général, et la France en particulier, ont toujours exercé une forte influence sur des catégories entières de la population des pays de l'autre rive de la Méditerranée, spécialement sur les intellectuels.

Érotisme. Lorsque nous étions jeunes, les langues européennes exerçaient sur nous un pouvoir érotique, mieux elles nous le transmettaient: par elles nous pouvions séduire et vaincre... Par langues européennes, j'entends en fait le français, la seule langue étrangère que je pouvais alors imaginer d'apprendre, dans un Liban encore tout récemment sous mandat français. Pour ma génération et pour mon milieu social, la langue de Molière et de bien d'autres était la clef d'un monde plein de joie et de belles aventures. Chaque mot nouveau que

1. Ce chapitre synthétise trois conférences prononcées par Rachid El-Daïf lors de sa venue à Paris, du 6 au 20 décembre 2014, sur la double invitation de l'Institut d'études de l'Islam et des sociétés du monde musulman (IISMM) et du centre de recherches de l'École des hautes études en sciences sociales (EHESS), dans le cadre du séminaire " Orient-Littératures " créé et dirigé par Gilles Ladkany. Ces conférences s’intitulaient "L'Occident vu par l'Orient: tensions et fascination ", EHESS, 18 décembre 2014; " Aspects de l'altérité ", Université Paris, 11 décembre 2014. "L écrivain face à son œuvre ", Inalco, 9 décembre 2014. 
nous apprenions augmentait nos chances de séduire, notre " capital de séduction ». Les obstacles nous séparant de cette joie et de ce plaisir ne pouvaient que disparaître au gré de nos progrès dans l'apprentissage et la maîtrise de cette langue. Nous avions l'idée que la femme européenne, la Française au premier chef, était toute disponibilité, que rien ne l'empêchait d'avoir des relations amoureuses ou même purement sexuelles avec l'homme de son choix. Aucun de ces obstacles que nous rencontrions chez nous dans les relations hommes-femmes (relevant de la famille, de la religion, de la tradition, du culte de la virginité, etc.) n'avait d'importance pour la femme européenne ou française... Dans notre esprit, il suffisait donc de la séduire. La langue étrangère nous donnait la possibilité de nous affranchir de tout obstacle et de conquérir ce monde nouveau, ouvert au plaisir et aux promesses. Je me souviens très bien de ce que représentait pour nous Paris dans les années 1960: une ville lointaine et une source d'inspiration. Paris peuplait notre imagination d'images de belles filles cultivées, intelligentes, délicates et surtout émancipées. En un mot, apprendre le français équivalait à apprendre le discours amoureux. L'amour sous le signe plaisir, mais aussi de la culture, de la justice, de l'égalité...

La séduction, dans notre culture arabe contemporaine, est un signe de modernité. Bien entendu, on n'apprend pas le français ou l'anglais dans le seul but de séduire, mais la séduction demeure une dimension du phénomène d'apprentissage de ces deux langues. Je me réfère particulièrement au français et à l'anglais parce qu'ils sont les plus répandus au Liban et, je pense, dans tout le monde arabe.

Apprendre une langue européenne est indéniablement un moyen d'ascension sociale. Connaître le français (l'anglais surtout, maintenant) revient à accroître sa chance d'être promu.

Les mœurs. La question des mœurs est nodale dans l'histoire des relations entre l'Occident (c'est-à-dire les États-Unis d'Amérique et l'Europe) et le monde arabe. Les sociétés orientales sont sensibles aux acquis occidentaux dans tous les domaines, mais le sont de manière exacerbée sitôt qu'il s'agit des mœurs, des régimes relationnels. S'est induit un métissage culturel, aussi entraînant que résistible, et très lourd de conséquences sur la famille et sur les relations entre les hommes et les femmes: les modèles traditionnels se sont retrouvés secoués comme sous l'effet d'un séisme, provoquant angoisse et remises en question profondes. Et l'angoisse est un sentiment ambigu, où se mêlent désir d'émulation et rejet. Toutefois, ce conflit des mœurs ne se 
joue pas seulement entre " Nous » et l'« Occident » tel que la littérature arabe le laisse parfois entendre. Il est d'abord intérieur, entre nous et nous-mêmes; c'est une " guerre civile " et fratricide, si j'ose dire.

Rester soi-même. Il existe, au sein de toutes les couches sociales, une tendance à voir dans l'Europe un rival historique (pour ne pas dire un ennemi). Vouloir connaître l'Europe ne se fait pas dès lors dans le but du rapprochement, ou plutôt on ne se rapproche que pour apprendre à se déprendre: pour mieux se préserver et conserver, voire (re) trouver son authenticité. Je crains d'ailleurs que cette approche ne finisse, dans les périodes de crise, par être dominante. Au plus poussé, elle cristallisera son ambiguïté quelque peu agressive dans la formule: "l'Andalousie est à reconquérir ".

L'Europe est en nous. Contrairement à ce que l'on peut penser, l'Europe n'est ni l'Autre, ni l'Ailleurs; elle est en "nous " (nous, les Orientaux). Elle est présente dans notre façon de nous habiller, de manger, et d'aimer, présente aussi dans la construction de l'État, des institutions, de l'Université, dans l'architecture de nos villes et de nos maisons privées et dans notre littérature. Le roman arabe moderne est une rencontre entre la tradition narrative arabe et le roman moderne européen. La langue arabe, celle pratiquée aujourd'hui, est très " européanisée ». Le narrateur de mon roman Learning English disait à juste titre que nous parlons anglais en arabe. Nombre de vocables et locutions sont introduits par le contact quotidien qui dure depuis deux siècles d'abord avec le français, ensuite avec l'anglais. Ces apports sont déterminants, tant ils véhiculent une certaine représentation du monde et une façon de voir et de concevoir.

Fi l-haqqīqa . Je voudrais risquer une analyse de la locution fi l-ḥaqīqa (" en vérité ") et expliquer sa genèse: cette locution n'existait pas en arabe, dans ce sens précis, avant la nahḍa (" renaissance arabe "). Son apparition remonte à la " modernisation ", à la période où les États se construisirent en référence aux schémas illustrés par la Révolution française. Celui qui se met alors à dire: $f$ l-haqiqah se pose en personne croyant en l'existence objective de la vérité, une vérité régie par des lois propres qu'il est capable de découvrir en homme libre. Bref, il n'est plus soumis à l'arbitraire d'un khalife, d'un sultan, d'un roi ou d'un seigneur féodal, mais se considère désormais comme le citoyen d'un État régi par des lois et des institutions.

Dans le Coran, le mot ḥaqq (حقّ) employé presque trois cents fois dans le sens de "vérité " ou "bien ", n’est jamais un élément 
constituant d'une locution. La locution "en vérité " est, en quelque sorte, une "laïcisation" du mot "حق " (haqq) née du contact avec l'Europe moderne.

Les temps changent. La fascination qu'exerce l'Europe sur les peuples de l'autre rive de la Méditerranée s'est quelque peu brouillée et n'est plus ce qu'elle était. De modèle à suivre, l'Europe suscite aujourd'hui la suspicion. L'Occident ne mesure pas à quel point — alors même que le colonialisme est derrière nous et que la mondialisation à l'américaine semble aller de soi, sauf du côté des terroristes et autres récalcitrants - il a cessé de subjuguer les esprits. L’Occident n'est plus désormais qu'un commerçant armé jusqu'aux dents, et le monde arabe, autre image reçue, une vache à traire...

\section{Aspects de l'altérité}

Le sol natal n'est pas seulement le lieu géographique de naissance. Il est aussi un espace culturel qui peut exister ailleurs et à n'importe quelle époque. Je raconte souvent ce que j'ai ressenti lors de ma première visite aux États-Unis en 1989, d'abord à New York, puis sur la route reliant Los Angeles à Las Vegas. Le lendemain de mon arrivée à New York, en me promenant à Broadway, j'eus la certitude que j'allais rencontrer mon père dans cette rue grouillante de monde. Je m'attendais à ce qu'il surgisse d'un instant à l'autre. Pourtant mon père est mort au Liban en 1966, il y a vingt-trois ans. Mon oncle paternel a lui, vécu quelques années à Porto Rico avant de s'installer définitivement à New York Mon père a appelé son cinquième fils du nom de ce frère. Moi-même je porte le prénom d'un autre oncle émigré et mort à PortoRico...

L'émigration est " une petite mort ", dit-on chez nous; elle est vécue ainsi non seulement par ceux qui partent, mais aussi par ceux qui restent. Le départ de mes camarades avec leurs familles, pour l'Australie, pour l'Amérique latine ou l'Amérique du Nord, dans les années 1950 et 1960, provoquait en moi une tristesse insurmontable, durable, sans larmes, souvent accompagnée de cauchemars. J'espérais leur retour. Entre-temps, leurs maisons changeaient d'occupants ou se détérioraient par manque d'entretien. Parfois même, avec le temps, elles se transformaient en de véritables ruines. Englouties par l'herbe sauvage, elles offraient un paysage de désolation. C'était, effectivement, "une petite mort ". Abandonnant leurs maisons et les leurs, les absents sont, pour ceux qui demeurent, des quasi-défunts. 
Lorsque j'étais enfant, j'imaginais l'émigration comme le voyage qu'entreprendraient les personnes décédées au Liban pour aller s'installer dans des contrées lointaines, pour l'éternité. Mon père était donc vivant à New York et j'allais le rencontrer. Il allait surgir probablement sous la forme d'une ombre sombre et pressée.

La même année 1989, mon frère m’a emmené visiter Las Vegas en voiture. Sillonnant les plaines entre Los Angeles et Las Vegas, j'ai reconnu les lieux. J'en ai eu le vertige. Ces lieux m'étaient aussi familiers que si j’y avais passé mon enfance! C'est la grâce du cinéma américain: j'avais souvent fait l'école buissonnière pour aller voir tel ou tel western dont l'action se déroulait sur ces mêmes plateaux.

Lorsque Fāris, le personnage principal de mon roman Tablīt al-baḥr (" Paver la mer »), arrive en 1883 à New York, les rues et les immeubles lui semblent familiers. Pourtant, New York était alors à trois mois de voyage de la côte libanaise, trois mois pavés de risques et d'incertitudes. Avant de partir, Fāris avait accompli deux années d'études à la faculté de médecine (devenue plus tard l'Université américaine de Beyrouth) nouvellement fondée (1866). Il connaissait l'anglais-américain et avait comme professeurs des missionnaires protestants. Il avait appris aussi bien la géographie des États-Unis que certains aspects de la vie à l'occidentale. Il savait manger avec un couteau et une fourchette. Il s'était débarrassé du sarouel et du tarbouche et les avait remplacés par un pantalon et un chapeau. Il s'était même rasé la moustache, chose extraordinaire au sens littéral du mot! Naguère encore, être un homme adulte était inconcevable sans moustaches.

Les missionnaires américains (protestants et catholiques) venus sauver nos âmes - puisque la fin du monde était, à leurs yeux, imminente - s'étaient aussi préoccupés des " corps " et de questions plus prosaïques encore, et s'étaient focalisés sur l'éducation et la santé. Ils cherchaient à produire l'homme parfait! Et l'homme parfait était, bien entendu, "occidental». L'image idyllique qu'ils renvoyaient de leurs pays fascinait les "locaux ». Ces derniers, imprégnés par cette image fantasmée et encouragés par l'idée de trouver du travail dans un marché en expansion, rêvaient de partir. Bref, Fāris avait en arrivant l'impression d'être revenu à New York et non de s'y trouver pour la première fois.

Ce phénomène de l'émigration, telle qu'elle s'est configurée et développée dans la seconde moitié du XIXe siècle, est une des principales clefs de compréhension du contact avec la modernité occidentale et des représentations induites. 
L’altérité se manifeste également, dans mes romans, au niveau des valeurs. Conflictuelle et menaçante, elle se décompose et se recompose en permanence. Dans Qu'elle aille au diable, Meryl Streep!, le mari se persuade que le comportement de sa femme est influencé par les films qu'elle passe son temps à regarder à la télévision. Il s'agit surtout de films américains qu'elle comprend facilement, grâce à une bonne connaissance de la langue (en plus de l'anglais, elle médite d'ailleurs d'apprendre le français, langue de la culture et de la finesse,...). Son mari, de son diminutif Rashshūd, doute de plus en plus de la fidélité de sa jeune épouse. Il apprécie fort la comédienne américaine Meryl Streep, mais ne veut pas que les femmes de son pays la prennent comme un exemple à suivre. Dans le film Kramer contre Kramer, Meryl Streep quitte son mari, sans raison valable et, quelques mois plus tard, revendique la garde de leur enfant! Rashshūd, lui, ne peut pas accepter un tel comportement. Les femmes libanaises ne peuvent pas se permettre d'agir aussi librement. Elles se doivent d'être responsables et de rester dignes de traditions vénérables.

Les problèmes engendrés par les confrontations culturelles ne sont pas de moindre importance que les crises économiques. La violence à laquelle on assiste depuis quelques décennies a probablement pris cette ampleur en raison du développement inouï des moyens de communication et d'information, surtout l'internet. Il n'est pas exclu qu'elle soit assez directement liée, comme un contre-effet, à ce que beaucoup d'intellectuels, islamistes ou autres, qualifient d'invasion culturelle et morale.

Dans Learning English, Rashīd, un professeur d'université, a obtenu son doctorat en France et connaît bien la langue française. Il a été marxiste avant d'assister, impuissant, à l'effondrement de l'Union soviétique. Son désir d'être un homme contemporain, " moderne ", le pousse à apprendre l'anglais, la langue de communication mondiale aujourd'hui. Le français ne lui est plus de grande utilité. Mais le voilà soudainement confronté à un problème qui remet en question cette image d'homme moderne qu'il s'est efforçé de (se) donner: son père a été tué par vendetta; selon la tradition, il doit venger ce père. S'il décide de se dérober à son devoir, il sera dénigré par les siens. Les circonstances du meurtre, en même temps qu'ils ébranlent sa certitude d'être un fils légitime, mettent en tension fidélité aux traditions et volonté de rupture.

Cher Monsieur Kawabata décrit les petits soucis du narrateur avec le petit-déjeuner. À l'école, l'enseignant leur apprend que le petit-déjeuner 
se compose de pain, de beurre, de la confiture, du lait et du café pour les plus grands. Ce pauvre enfant, qui préférait manger les restes des plats préparés la veille par sa mère, souffrait de devoir renoncer à son bon petit-déjeuner traditionnel pour de la confiture et du café-crème.

Les personnages de mes romans ne sont pas représentatifs de l'ensemble des Libanais ni des Arabes. Ils ne renvoient pas non plus à une catégorie sociale ou communautaire. Leurs préoccupations dépassent les «frontières " de leur propre culture. D'ailleurs, les frontières culturelles ont-elles jamais existé? Vouloir expliquer, par exemple, l'histoire de la littérature d'un pays uniquement par des facteurs endogènes est une posture erronée et politiquement suspecte. Ce qui a changé aujourd'hui c'est le rythme du changement et des échanges, accru à une vitesse vertigineuse.

Des personnes "étrangères " peuvent éprouver des affinités avec certains de mes personnages. Lors d'une rencontre, une dame anglaise et aristocratique ayant lu Qu'elle aille au diable, Meryl Streep! me dit: " ne croyez pas que les hommes " chez nous " différent beaucoup de " vos " compatriotes. Et un journaliste allemand me confie: " en lisant votre roman, je me suis couvert le visage de honte ».

\section{L'écrivain face à son œuvre}

C'est seulement après avoir terminé un roman que je me mets à réfléchir sur son "sens ». Pendant que j'écris, je fais face à des questions d'un autre ordre, à des problèmes "techniques »: comment passer, par exemple, d'un événement à un autre, quel niveau de langue tel personnage devrait adopter, comment alterner narration et dialogues, quelle fonction particulière attribuer au dialogue (en arabe s'entend, pour autant que les différences entre le dialectal et l'arabe littéral sont très profondes), comment surprendre, intéresser, soutenir l'attention du lecteur ou comment concilier la simplicité avec la profondeur, etc.

Mon roman Learning English, par exemple, commence par l'assassinat du père du narrateur pour cause de vendetta. J'ignore moi-même comment la situation pourrait évoluer et voudrais savoir pourquoi personne n'a averti le narrateur du meurtre de son père, lui son fils unique. Pour y répondre, je suis poussé à poursuivre l'investigation. J'ai réalisé que ce roman soulève la question de l'identité lorsque j'eus terminé de l'écrire: le narrateur pourrait être un fils illégitime, le fruit de la relation de sa mère avec son amant. Comme il pourrait évoquer la présence des chrétiens du Liban au sein d'une majorité musulmane; le père du narrateur s'appelle " Hamad (حَ). D 》. Les racines de ce mot 
(h/m/d) forment hamada, le verbe arabe et musulman par excellence qui signifie "louer ", "louange " dont dérive le nom de Muhammad, le prophète de l'islam. Rien n'est moins sûr, mais la question se pose. Je doute d'ailleurs que le romancier puisse se constituer en éclaireur ou interprète du « sens " de son œuvre.

Le lit, dans Qu'elle aille au diable, Meryl Streep!, est un champ de bataille entre la tradition et la modernité. C'est l'explication que j'en donne. Mais pendant que j'écrivais, la question n'était pas présente à mon esprit de cette façon. J'imaginais un conflit entre deux nouveaux mariés de caractères et de tempéraments différents, mais, surtout, ayant des conceptions différentes du monde. Je tâchais de trouver le niveau de style adéquat pour exprimer la vision "ouverte " de la mariée et celle, "traditionaliste", de son époux. Mon intention " consciente " était de porter la différence et le conflit qui les oppose à leur point culminant. Je ne voulais aucunement donner une illustration des conflits entre l'Orient et l'Occident. Que le narrateur puisse me ressembler ou pas n'est pas la question; il m'a permis d'extérioriser des sentiments intimes qu'un homme "bien " devrait garder pour lui. En ce sens, l'écriture peut être parfois une auto-humiliation ou une autoflagellation; elle m’a dévoilé, à mon insu. Le roman que je crée, me crée en retour. Il me dévoile à moi-même et, ce faisant, me façonne profondément.

Je raconte souvent l'anecdote suivante: en 1979, une voiture piégée a explosé juste à l'entrée de l'immeuble que j'habitais; l'attentat a fait une dizaine de morts et nombre de blessés. Une petite heure avant l'explosion, je tournais autour de cette voiture, car je projetais d'en acheter une de la même marque. Après cet accident traumatisant à travers lequel j'ai vécu ma propre mort, j'ai décidé de publier les pensées poétiques que j'écrivais de temps à autre, avant et pendant la guerre civile libanaise (1975-1990). J'ai montré le manuscrit à mon professeur et ami J.- E. Bencheikh. Il l'a lu et proposé de le traduire. Ma joie, comme vous pouvez le deviner, a été immense. Dans sa préface, il a écrit que mon texte est plein d'humour. Cette remarque m'a énormément surpris. Je m'attendais à ce que mon texte exprime mes sentiments au moment où je les écrivais, c'est-à-dire la tristesse, le désespoir, la fatigue, la colère, en un mot, tout sauf l'humour!

Pareil au militant qui n'est jamais certain des suites de son engagement, tout en y croyant fermement, le romancier ignore ce que sera son œuvre. Je me rappelle avoir lu dans un livre datant de l'ère soviétique — je ne me souviens plus lequel — qu’un ouvrier bénévole, tombé du 
haut d'un barrage en construction, avait demandé qu'on le ramène sur le chantier de travail, avant de succomber à ses blessures. Des centaines de milliers d'ouvriers offraient des journées de travail pour la construction du socialisme. Cet ouvrier ne pouvait imaginer que son dévouement préparait le stalinisme. L'histoire est imprévisible; elle n'est pas la somme des bonnes volontés individuelles. Mon expérience de la guerre du Liban me rappelle cet ouvrier. Je fais partie d'une génération qui a réalisé que son engagement et sa lutte n'ont contribué en rien à éviter la destruction du pays.

L'écrivain n'est pas le seul "créateur " de son texte. Il en est l'un des multiples contributeurs. Dès qu'il se met à écrire, il se soumet à un genre littéraire avec des règles préétablies. Les refuser n'est pas donné à tout le monde; seuls des génies sont capables d'inventer de nouvelles règles. Les autres se contentent d'être de bons joueurs. Le style lui-même n'est pas la marque spécifique de l'écrivain, quand bien même il est le miroir de son individualité. La syntaxe, le vocabulaire, les phrases, les thèmes abordés ne sont pas aussi originaux que l'on pourrait le croire; ils sont le produit d'un contexte sociopolitique, géographique, temporel déterminé. Ceci dit, l'écrivain reste, bien sûr, le créateur de l'œuvre. Il est la goutte de colorant qui, diluée dans l'eau, en arrive à modifier la couleur et la teneur. Ce quelque chose d'insaisissable fait qu'une œuvre est, ou non, originale. 



\section{Bibliographie}

\section{OUVRAGES DE RACHID EL-DAÏF}

\section{Poésie}

Hiina ḥalla al-sayfu 'alā al-ṣayf, Beyrouth, Dār al-Fārābī, 1979. Trad. par J.E. Bencheikh, L'Été au tranchant de l'épée, Paris, Le Sycomore, édition bilingue, 1979.

Lä shay'a yafūqu al-wașf (" Rien n'est indescriptible »), Beyrouth, Manshūrāt Lubnān al-jadīd, 1980.

Ayyu thaljin yahbuțu bi-salām ("Qu'elle neige tombe en paix "), Beyrouth, Mukhtārāt, 1993.

\section{Romans}

Al-Mustabidd (“ Le Tyran »), Beyrouth, Dār Abād, 1983. Réédition Riāḍ al-Rayyis, 2001.

Unsī yalhū ma'a Ritta- kitāb al-bālighīn ("Ounsi s'amuse avec Ritta, le livre des adultes »), Beyrouth, Al-Mu'assasa al-jāmi'iyya li-l-dirāsāt wa-l-nashr, 1983.

Fusḥa mustahdafa bayna al-nu'ās wa-al-nawm, Beyrouth, Mukhtārāt, 1986. Réédition Riāḍ al-Rayyīs, 2001. Trad. par Luc Barbulesco et Philippe Cardinal, Passage au crépuscule, Arles, Actes Sud, 1992. Trad. en anglais par Nirvana Tanoukhi, Passage to Dusk, Austin, Center for middle Eastern Studies: University of Texas, 2001.

Ahl al-ẓill, Beyrouth, Mukhtārāt, 1987. Réédition Riāḍ al-Rayyīs, 2000. Trad. et présentation par Edgard Weber, L'Insolence du serpent ou Les Créatures de l'ombre, Toulouse, AMAM, 1997.

Taqaniyyāt al-bu’s ( Les Techniques de la misère »), Beyrouth, Mukhtārāt, 1989. Réédition Riād al-Rayyis, 2001. Seuls des extraits ont été publiés en français : "Techniques de la misère ", trad. Par Leila Guermouche et Brigitte Marino, Méditerranéennes 5, 1993, pp. 96-101. 
Ghaflat al-turāb ("Terre étourdie »), Mukhtārāt, 1991. Réédition Riāọ al-Rayyis, 2001.

'Azīzī al-sayyid Kawabata, Beyrouth, Mukhtārāt, 1995. Réédition Riāḍ al-Rayyis, 2001. Trad. par Yves Gonzales- Quijano, Cher Monsieur Kawabata, Arles, Sindbad-Actes Sud, 1998. Trad. en anglais par Paul Starkey, London, Quartet Books, 1999, et Massachusetts-USA, Interlik Books, 2000.

Nāḥiyat al-barā'a (" Du côté de l'innocence »), Beyrouth, Al-Masār, 1997. Trad. en anglais par Paula Haydar, This Side of innocence, Massachusetts-USA, Interlink Books, 2001.

Līrning İnglish, Beyrouth, Dār al-Nahār, 1998. Réédition Riāḍ al-Rayyis, 2005. Trad. par Yves Gonzales-Quijano, Learning English, Arles, Actes Sud, 2002. Trad. en anglais par Paula Haydar, MassachusettsUSA, Interlink Books, 2007.

Tișțifil Meryl Streep, Beyrouth, Riyāọ al-Rayyis, 2001. Trad. Par Edgard Weber, Qu'elle aille au diable Meryl Streep!, Arles, Actes Sud, 2004. Trad. en anglais par Paula Haydar et Nadine Sinno, Austin, Center for Middle Eastern Studies: University of Texas, 2014.

Insay al-sayyāra (" Oublie la voiture »), Beyrouth, Riāọ al-Rayyis, 2002. Trad. par Yves Gonzales-Quijano, Fais voir tes jambes Leila!, Arles, Actes Sud, 2006.

Ma'bad yanjah fi Baghdād, Beyrouth, Riyāọ al-Rayyis, 2005.Trad. par Xavier Luffin, Le Musicien et le calife de Bagdad, Arles, Actes Sud, 2010.

'Awdat al-almānì ilā rushdihi (" Le Retour de l'Allemand à la raison "), Beyrouth, Riāọ al-Rayyis, 2006. Trad. en anglais par Ken Seigneurie et Gary Schmidt : Rashid Al-Daif \& Joachim Helfer, What Makes a Man? Sex Talk in Beirut and Berlin, Austin, Center of Middle Eastern Studies: The University of Texas, 2015.

Ok, måa al-salāma ( Ok. Au revoir »), Beyrouth, Riāọ al-Rayyis, 2008.

Tablīt al-baḥr ( Paver la mer »), Beyrouth, Riāḍ al-Rayyis, 2011.

Hirrat Sīkīrīdā (« La Chatte de Sikirida »), Beyrouth, Dār al-Sāqī, 2014. Alwāḥ (" Tableaux »), Beyrouth, Dār al-Sāqī, 2015. 


\section{Filmographie}

Passage au crepuscule, d'après le roman Fusḥa mustahdafa bayna al-nu'ās wa-al-nawm, par le réalisateur Simon Edelstein, Genève, télévision Suisse romande, 2001.

Zinnār al-nār ("Ceinture de feu »), d'après le roman Al-Mustabidd, par le réalisateur libanais Bahij Hojeij, 2002.

\section{Théâtre}

Qu'elle aille au diable, Meryl Streep!, Adaptation par Mohamed Kacimi, Qu'elle aille au diable Meryl Streep, Adaptation par Mohamed Kacimi, mise en scène par Nidal al-Achkar, théâtre du Rond-Point, Paris, 2008, et Masrah al-Madīna (" Théâtre de la ville »), Beyrouth, 2008.

Fais voir tes jambes Leila!, pièce écrite et mise en scène par Rahim Elasri, Bruxelles, La Bellone-Maison du spectacle, janvier 2009; Liège, Grand Manège de la caserne Fonck, avril 2009; Paris, Centre Wallonie-Bruxelles, novembre 2009.

Oublie la voiture, d'après trois romans : Ok. Goodbye, Qu'elle aille au diable Meryl Streep! et Fais voir tes jambes Leila!, pièce écrite et mise en scène par Rahim Elasri (Pilot Group 17), Masrah al- Madīna, Beyrouth, avril 2010.

\section{OUVRAgES CITÉS}

Abi-Rached, Naoum, "Violence et innocence ", Mélanges, Toulouse, AMAM, 1998.

Abū Nuwwās (Dīwān), Beyrouth, Dār al-Kitāb, s.d.

Aghacy, Samira, "The Use of Autobiography in Rashid al-Daif's Dear

M. Kawabata", in Writing the Self: Autobiographical Writing in Modern Arabic Literature, Robin Ostle, Ed de Moor and Stefan Wild (eds.), London, Saqi, 1998.

Aubrit, Jean-Pierre, Le Conte et la nouvelle, Paris, Armand Colin, 1997.

Auerbach, Erich, "Philologie de la littérature mondiale" (texte de 1952), in Où est la littérature mondiale?, Saint-Denis, PUV, 2005.

'Awda, Sulaymān, " al-Mukhayyila al-Hūlyūdiyya », al-Nuqqād, N 138, Beyrouth, $1^{\mathrm{er}}$ janvier, 2002. 
'Awīṭ al-, 'Aql, « Insay al-sayyāra li-Rashīd al-Ḍa'īf: Pornographia l-ḥayāt al-sirrīyya riwāyatan ", Mulḥaq al-Nahār, Beyrouth, 8 décembre, 2002.

Ayad, Christophe, "Liban gueule de bois ", Libération, jeudi 29 octobre 1998.

Bakhtine, Mikhaïl, Esthétique et théorie du roman, Paris, Gallimard, 1991.

Baudrillard, Jean, La Transparence du Mal: Essai sur les phénomènes extrêmes, Paris, Galilée, 1990.

Bīṭār, Hayfā', « Indamā yataḥawwal al-adab ilā film porno », Akhbār al$a d a b$, Le Caire, 4 mai, 2003.

Blachère, Régis, Grammaire de l'arabe classique, Paris, Maisonneuve et Larose, 1952.

- Le Coran, Traduction selon un essai de reclassement des sourates, Paris, Maisonneuve et $\mathrm{C}^{\mathrm{ie}}$., 1951.

Bourneuf, Roland, et Ouellet, Réal, L'Univers du Roman, Paris, PUF, 1981.

Caiani, Fabio, Contemporary Arab Fiction. Innovation from Rama to Yalo, London and New York, Routledge, 2007.

Camus, Albert, L’Étranger, Paris, Gallimard, 1942.

Chatman, Seymour, Story and Discourse, New York, Cornell UP, 1978.

Casanova, Pascale, La République mondiale des Lettres, Paris, Seuil, 1999.

Coetzee, John Maxwell, Waiting for the Barbarians, London, Penguin, 1982.

Colonna, Vincent, L'Autofiction: Essai sur la fictionalisation de soi en littérature, in http://tel.archives-ouvertes.fr/docs/00/04/70/04/PDF/ tel-00006609.pdf et sur Academia. edu.

- Autofictions \& autres mythomanies littéraires, Auch, Tristram, 2004.

- L’Art des séries télé, 2: l'adieu à la morale, Paris, Payot, 2015.

- «Autofinzioni, affabulazioni e istinti » (Autofiction, Affabulation et instincts), revue Algama, Rome, $n^{\circ} 29$, avril, 2015. Version française sur la page Academia. edu.

Daif al-, Rashid, Dear M. Kawabata, Trans. Paul Starkey, Foreword by Margaret Drabble, London, Quartet, 1999.

Davies, Tony, Humanism, London, Routledge, 1997. 
Den Heijer, Johannes, "Middle and Mixed Arabic. A New Trend in the Arabic Studies ", Liesbeth Zack and Arie Schippers (eds.), in Middle Arabic and Mixed Arabic: Diachrony and Synchrony, Leiden, Brill, 2012.

Druon, Maurice, Les Rois maudits. Le Roi de fer, Paris, Le livre de poche, 1970.

Dubois, Jean (dir.), Dictionnaire de linguistique et des sciences du langage, Paris, Larousse, 1994.

Ego, Renaud, « Le Tour du propriétaire », La Pensée de Midi, n 14, 2005.

Encyclopédie de l'islam, Leyde, Brill, et Paris, G.-P. Maisonneuve et Larose, 1990.

Fortin, Damien, "Les "fictions biographiques" contemporaines, un nouveau "sacre de l'écrivain"? ", Acta fabula, vol. 12, n 4, Essais critiques, avril 2011, URL: http://www.fabula.org/revue/document6259. php.

Genette, Gérard, Figure III, Paris, Seuil, 1972.

Gharnāṭ, Muhammad, "Qalaq al-fāris », in Al-șāba wa-l-jarrād, Casablanca, Dār Qurțuba, 1988.

Ghosn, Katia, "Recherche identitaire et quête de territoire dans Learning English de Rašīd al-Ḍa'īf ", Arabica 62, Leiden, Brill, novembre 2015.

Ginsberg, Allen, Paris Review, les Entretiens, Anthologie, Vol. 1 (trad. de l'anglais par Anne Wicke), Paris, Christian Bourgois, 2010.

Gonzalez-Quijano, Yves, "Un choc dans la bataille: le clash des programmes culturels ", Culture et politique arabes, 12 novembre, 2006.

Graham, Allen, Intertextuality, London and New York, Routledge, 2000.

Hāfiz, Sabrī, « "Insay al-Sayyāra” wa-tajalliyāt al-kharāb al-māddī walma‘nawī fī Lubnān », al-‘Arab, Londres, 23 avril, 2003.

Hamarneh, Walid, "Some Narrators and Narrative Modes in the Contemporary Arabic Novel ", in The Arabic Novel Since 1950: Critical Essays, Interviews, and Bibliography, Issa Boullata (ed.), Cambridge, Dar Mahjar Publishing and Distribution, 1994.

Hamon, Philippe, "Statut sémiotique du personnage ", in Poétique du récit, Paris, Seuil, 1977.

Hardt, Michael et Negri, Antonio, Empire, Paris, Exils, 2000. 
Rachid El-Daïf - Le roman arabe dans la tourmente de la modernisation

Hassan, Kadhim Jihad, Le Roman arabe (1834-2004), Arles, SindbadActes Sud, 2006.

Helfer, Joachim, Die Verschwulung der Welt, Rede gegen Rede, BeirutBerlin, Frankfurt am Main, Suhrkamp Verlag, 2006. Trad. en arabe par Yūsuf Ḥijāzī, Khițāb muqābil khițāb, Bayrūt- Birlīn, Beyrouth, Manshūrāt al-Jamal, 2009.

Ḥimmīsh, Bin Sālim, Majnūn al-ḥukm, Le Caire, Al-Afāq, 1998.

Hocquard, Emmanuel, Conditions de lumière, Paris, P.O.L., 2007.

Hubier, Sébastien, Littératures intimes, Les expressions du moi, de l'autobiographie à l'autofiction, Paris, Armand Colin, 2003.

Hutcheon, Linda, A Poetics of Postmodernism: History, Theory, Fiction, New York, Routledge, 1988.

Idrīs, Suhayl, Dhikrayāt al-adab wa l-ḥubb, vol.1, Beyrouth, Dār al-Ādāb, 2002.

Iṣfahān̄̄ al-, Abū al-Faraj, al-Aghānī, vol. 1, 'Abd A. 'Alī Muhannā and Samīr Jābir (eds.), Beyrouth, Dār al-Kutub al-‘ilmīya, 1992.

Jacquemond, Richard, "L'internationalisation de la littérature arabe moderne, du prix Nobel de Naguib Mahfuz (1988) à L'Immeuble Yacoubian (2006) ", en ligne sur www2.univ-paris8.fr, 7 décembre 2007.

Jāḥiz al-, « Mufākharāt al-jawārī wa l-ghilmān », in Rasā’il al-Jāḥiż, vol. 2, 'Abdassalām Hārūn (ed.), Le Caire, Maktabat al-Khānjī, 1965.

Jeanroy, Alfred, Les Chansons de Guillaume IX Duc d'Aquitaine (10711127), Paris, Champion, 1927.

Khūrī, Ilyās, « Al-riwāya, al-riwāēi wa-l-ḥarb, wa kayfa tașīr al-ḥikāyāt riwāya ", Al-Ṭarīq, n 1, janvier-février 2001.

Kilpatrick, Hilary, Making the Great Book of Songs, Londres, Routledge Curzon, 2010.

Meyer, Stefan G., The Experimental Arabic Novel: Postcolonial Literary Modernism in the Levant, Albany, State of New York, 2001.

Morier, Henri, Dictionnaire de poétique et de rhétorique, Paris, PUF, 1975.

Phelan, James, Narrative as Rhetoric: Technique, Audiences, Ethics, Ideology, Columbus, Ohio State UP, 1996.

Prince, Gerald, "Introduction to the Study of the Narratee ", in Reader Response Criticism: From Formalism to Post-Structuralism, Jane P. Tompkins (ed.), Baltimore: Johns Hopkins UP, 1980. 
Qa'īd al-, Muhammad Yūsuf, Laban al-’uṣfūr, Le Caire, Dār al-Hilāl, 1994. Rabinowitz, Peter, Before Reading: Narrative Conventions and the Politics of Interpretation, Columbus, Ohio State UP, 1987.

Raimond, Michel, Le Roman, Paris, Armand Colin, 1989.

Reuter, Yves, Introduction à l'analyse du roman, Paris, Dunod, 1996.

Riffaterre, Michael, "Interpretation and Undecidability ", in New Literary History, Vol. 12, No.2, Johns Hopkins University Press, Winter 1981.

Rimmon-Kenan, Shlomith, Narrative Fiction: Contemporary Poetics, London, Routledge, 1992.

Rosset, Clément, Le Démon de la tautologie suivi de Cinq petites pièces morales, Paris, Minuit, 1997.

Seigneurie, Ken, "Chiasmus on Masculinity in Rashid al-Daif's How the German Came to His senses ", Paper presented at the Modern Language Association Annual Convention: Philadelphia, December 2006. URL: http://www.navidkermani.de/media/raw/Rezensionen_ Diwan_Engl.pdf.

- " A Survival Aesthetic for Ongoing War », in Crisis and Memory: The Representation of Space in Modern Levantine Narrative, Ken Seigneurie (ed.), Wiesbaden: Reichert Verlag, 2003.

- " Ongoing War and Arab Humanism ", in Geomodernisms: " Race ", Modernism, Modernity, Laura Doyle and Laura Winkiel (eds.), 2016.

Shaykh al-, Ḥanān, Inna-hā Lundun ya 'azīzī, Beyrouth, Dār al-ādāb, 2001.

Ṣ̣̂ụāwī, Rafîf Riḍā, Al-naẓra al-riwā’iyya ilā al-ḥarb al-lubnāniyya (19751995), Beyrouth, Dār al-Fārābī, 2003.

Simon, Claude, Quatre Conférences, Paris, Minuit, 2012.

- "L'inattendu attendu ", in Les Tryptiques de Claude Simon ou l'art du montage, Mireille Calle-Grüber (dir.), Paris, Presses de la Sorbonne nouvelle, 2009.

Tha‘ālibī al-, Abū Manșūr 'Abdalmalik b. Muhammad b. Ismā‘īl, al-Lutff wa l-Lațā'if, Maḥmūd 'Abdallah al-Jādir (ed.), Beyrouth, 'Ālam alkutub, 1997.

Walter, Benjamen, " La tâche du traducteur ", in Mythe et violence (trad. de l'allemand par Maurice de Gandillac), Paris, Denoël, 1971. 
Warhol, Robyn R, « « Reader, Can You Imagine? No, You Cannot »: The Narratee as Other. Harriet Jacobs's Text », Narrative. 3. 1, 1995.

- « Toward a Theory of the Engaging Narrator: Earnest Interventions in Gaskell, Stowe, and Eliot », PMLA. 101. 5, 1986.

Wāzin, 'Abdū, Riwāyat al-ḥarb al-lubnāniyya, Dubaï, Dār al-Ṣadā, 2009.

Zaydān, Jirjī, Al-Amīn wa-l-Ma’mūn, Le Caire, Dār al-Hilāl, 1900.

- Shārl wa-'Abd al-Raḥman, Le Caire, Dār al-Hilāl, 1904. 


\section{TABLE DES MATIÈRES}

Translittération .................................................... 5

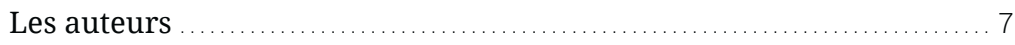

Avant-propos ......................................................... 11

Introduction

Le roman de Rachid El-Daïf à l'ère de la globalisation (Katia Ghosn) .. 15

1. Quatre motifs de l'aliénation dans l'œuvre romanesque

de Rachid El-Daïf (Renaud Ego) ................................... 25

L'occupation .................................................... 26

La filiation ..................................................... 27

La confession .................................................. 29

La possession .............................................. 30

2. Le Phénix fabule
L'autofiction chez Rachid El-Daïf (Vincent Colonna) ................. 35

Fabulation de soi .................................................. 36

Typologie ...................................................... 37

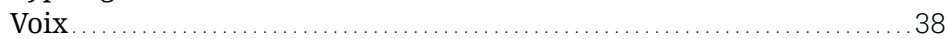

Japoneries...................................................... 39

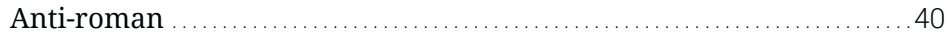

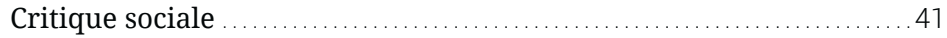

Langue ....................................................... 42

Excentricité ................................................... 43

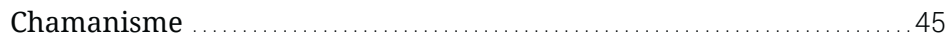

Exploration .................................................. 46

3. 'Awdat al-almānì ilā rushdi-hi-Retour sur une fiction d'un mauvais genre (Yves Gonzalez-Quijano) ....................... 49

Les nombreux noms d'une fiction .................................. 50

Les conséquences d'un " protocole de lecture " ...................... 52

Le « non » à la fiction ............................................. 53

Un choc dans la bataille: le clash des programmes culturels ......... 55

Rachid El-Daïf, Le retour de l'Allemand à la raison, p. 90-92........... 58

Appendice............................................................. 59

4. De l'autodistanciation - Oppression, dérision et autodérision

(Sobhi Boustani et Fatemeh Parchekani) …...............................61

Oppression et évasion illusoire .............................62 
Nāhiyat al-barā'a: oppression et naïveté dérisoire ................66 66

Personnages et dérision ...........................................69 69

Tișțifil Meryl Streep: obsession et ridicule........................... 76

L'illusion d'une autobiographie................................... 76

L'intimité du héros: le « Je » du narrateur est sujet et objet ........... 77

Le héros et sa femme.............................................. 79

5. À propos de Hirrat Sīkīrīdā - La religion au service du

meilleur et du pire (Heidi Toelle] ...................................... 85

Adība et Umm Amal: quand les croyants se montrent tolérants ..... 86

La valorisation des plaisirs de la chair ........................... 92

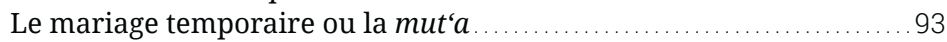

Quand les croyants se montrent intolérants et cèdent à l'appât du

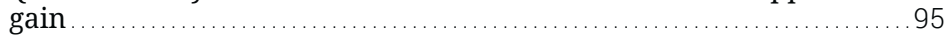

Le sens du titre $d u$ roman...................................... 97

6. Le Musicien et le Calife de Bagdad - Traduire les niveaux de langue d'un roman historique arabe (Xavier Luffin) ................. 99

Littérature arabe contemporaine et niveaux de langues ............ 99

Le cas particulier du roman historique ........................... 101

Le Musicien et le Calife de Bagdad................................... 104

7. La nécessité du récit (Jean-Charles Depaule) ....................... 111

8. The Importance of Being Kawabata - The Narratee in Today's

Literature of Commitment (Ken Seigneurie]..................... 121

Kawabata, the Narratee ........................................... 127

Rashid, the Narrator ............................................ 128

We, the Reader .............................................. 130

Language and Commitment ...................................... 132

9. The Hidden Hypotext: Transtextual Strategies in Rashid al-Daif's Forget about the Car (Insay as-sayyāra) (As‘ad E. Khairallah)....... 139

The Story ...................................................... 142

Other Critics ..................................................... 149

The Story of Qays and Lubnā ................................... 153

Al-Aghānī as Background...................................... 154

Transtextuality and Inversions ................................... 155

The Structural Inversion and its Consequences ................... 157

A Chart of Inversions ............................................... 161

10. Quand l'écrivain interroge son œuvre (Rachid El-Daïf) ........... 167

L'Occident vu par l'Orient: tensions et fascination .................. 167

Aspects de l'altérité .............................................. 170

L'écrivain face à son œuvre ..................................... 173

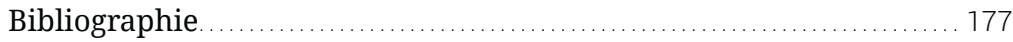

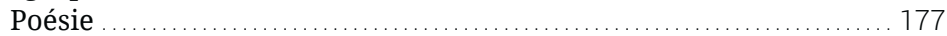

Romans ...................................................... 177

Filmographie ....................................................... 179

Théâtre ....................................................... 179 



\section{Déjà parus aux éditions DEMOPOLIS}

Brossat, Alain

Abécédaire Foucault

Boltanski, Luc

Rendre la réalité inacceptable

Bourdieu, Pierre - Boltanski, Luc

La Production de l'idéologie dominante

Césaire, Aimé - Malcolm X

Black revolution

Clover, Charles

Surpêche

Da Lage, Olivier (sous la dir. de)

Qatar: les nouveaux maîtres du jeu

Denord, François

Néo-libéralisme, version française

Duclert, Vincent

Occupy Gezi

Durpaire, François -

Richomme, Olivier

L'Amérique de Barack Obama

Obama face à la crise

Gaulard, Mylène

Karl Max à Pékin - Les racines de la crise en Chine capitaliste

Garo, Isabelle

Foucault, Deleuze, Althusser et Marx

Hobsbawm, éric

Marx et l'histoire

Hroub, Khaled

Le Hamas

Jaurès, Jean

Le socialisme et la Révolution française

Jennar, Raoul Marc Khieu Samphan \& les Khmers rouges

Khaldi, Eddy

$A B C$ de la Laïcité

Khaldi, Eddy - Fitoussi, Muriel

Main basse sur l'École publique

La République contre son école

Kalfon, Pierre

Chroniques chiliennes

Kamata, Satoshi,

Toyota: I'usine du désespoir

Mamdani, Mahmoud

La ClA et la fabrique

du terrorisme islamique
Labat, Séverine

Les islamistes tunisiens - entre l'état et

la mosquée

Latour, Bruno - Lippman, Walter

Le public fantôme

Lénine

Petit manuel pour rompre avec le capitalisme

1914, repenser le nationalisme et la guerre

Marx, Karl

Qu'est-ce que le capitalisme?

Les Crises du capitalisme

Le Capital financier

Mordillat, Gérard -

Prieur, Jérôme

De la crucifixion considérée

comme un accident du travail

Nsar, Vali

Le renouveau chiite

Pivert, Marceau

L'Église et l'École

Prochasson, Christophe

L'Empire des émotions :

les historiens dans la mêlée

Rebérioux, Madeleine

Vive la République

Rodinson, Maxime

Islam et capitalisme

Sassen, Saskia

Critique de l'État

Saurin, Patrick

Les prêts toxiques : une affaire d'état

Shah, Sonia

Cobayes humains : le grand secret

des essais pharmaceutiques

Uchitelle, Louis

Le salarié jetable

Wallerstein, Immanuel

L'Universalisme européen :

de la colonisation au droit d'ingérence

Wilkinson, Richard

L'égalité, c'est la santé 


\section{Collection « Quaero »}

Cassin, Barbara et Wosny, Danièle (dir.) Les intraduisibles du patrimoine en Afrique subsaharienne

Dawod, Hosham (dir.) La constante "Tribu ", variations arabomusulmanes

Ehrenfreund, Christian et Schreiber, Jean-Philippe (dir.)

Les marranismes. De la religiosité cachée à la société ouverte

Emmanuel Ethis, Le cinéma près de la vie. Prises de vue sociologique sur le spectateur du $X X I^{e}$ siècle

Fontaine, Alexandre Aux heures suisses de l'école républicaine

Ghasarian, Christian

Rapa. île du bout du monde, île dans le monde

Hoai Juong Aubert-Nguyen et Michel Magne (dir.)

Le Vietnam, une histoire de transferts culturels

Niveleau, Charles-édouard (dir.) Vers une philosophie scientifique Le programme de Brentano

Émilie Oléron Evans, Nikolaus Pevsner, arpenteur des arts

Rabault-Feuerhahn, Pascale (dir.) Théories intercontinentales - Voyages du comparatisme postcolonial

Docteur Michèle-H. Salamagne et Patrick Thominet (dir.)

Accompagner - trente ans de soins palliatifs en France

Alicia Fernández García et Mathieu Petithomme (dir.)

Contester en Espagne - Crise

démocratique et mouvements sociaux 
Achevé d'imprimer en France en 2015 dans les ateliers de Dupli-print à Domont (95) $\mathrm{N}^{\circ}$ d'impression:

Dépôt légal: février 2016 
Figure marquante de la littérature arabe contemporaine, le Libanais Rachid ElDaif a construit un univers littéraire d'une authentique singularité. Ses romans, marqués par la guerre civile (1975-1990), opèrent la douloureuse rupture avec les grandes idéologies et se heurtent à l'effondrement du projet initial de modernité arabe à double référence, au modèle européen et à l'expérience endogène. Faire la part entre ce qui est à prendre à l'Occident et ce qui est à rejeter relève en effet de l'aporie et ne fait qu'attiser la crise des valeurs. Pour décrire cette réalité embourbée dans ses contradictions, El-Daif emprunte les voies de l'intime, de la sexualité, du sujet diffracté, du récit hallucinatoire, jouant des choix narratifs avec un art consommé. Cet ouvrage collectif explore les aspects distinctifs de cette œuvre importante et largement traduite : il en interroge les fondements esthétiques, les héritages assumés comme la dimension transculturelle novatrice. Ce faisant, il illustre les tensions, mais aussi les riches potentialités qui travaillent aujourd'hui les cultures arabes.

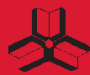

Ouvrage collectif sous la direcion de Katia Ghosn, regroupant des études de plusieurs spécialistes: théoriciens, professeurs d'universités, traducteurs des romans de Rachid el-Daïf.

$27 €$

www.demopolis.fr 